\title{
Recolyed sting
}

ANL-91/36

FEB 051992

Chemical Technology Division Chemical Technology Division Chemical Technology Division

\section{Parametric Effects on Glass Reaction in the Unsaturated Test Method}

by Alan B. Woodland, John K. Bates, and Thomas J. Gerding

Argonne National Laboratory, Argonne. Illinois 60439 operated by The University of Chicago

for the United States Department of Energy under Contract W-31-109-Eng-38 
Argonne National Laboratory, with facilities in the states of Illinois and ldaho, is owned by the United States government, and operated by The University of Chicago under the provisions of a contract with the Department of Energy.

\section{DISCLAIMER}

This report wats prepared as an accounl of work sponsored by an agency of the United States Government. Neither the United States Government nor any agency thereof, nor any of their employees, makes any warranty, express or implied, or assumes an, legal liability or responsibility for the accuracy, completeness, or usefulness of any information, apparatus, product, or process disclosed, or represents that its use would not infringe privately owned rights. Reference herein 10 any specific commercial product, process, or service by trade name, trademark, manufacturer. or otherwise. does not necessarily constitute or imply its endorsement, recommendation, or favoring by the United States Government or any agency thereof. The views and opinions of authors expressed herein do non necessarily state or reflect those of the United States (iovernment or any agency therest.

Reproduced from the best available copy.

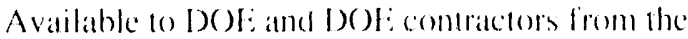

()ffice of Scientific and Technical Information

P.O. Bux 6?

()ak Ridge, TN $37 \times 31$

Prices available from (61.5) 576-8401) . FTS 626-840)

Avatiathe of the public from the

Nattonal fechnical Infermation Service:

U.S. Department of C'ommeres:

528.5 Port Royal Roald

Springliceld. VA 22161 
Distribution Category:

High-Level Radioartive Waste

Disposal in Tuff

(UC-814)

ANL-91/36

ANL- $-91 / 36$

DE92 007578

\section{ARGONNE NATIONAL LABORATORY \\ 9700 South Cass Avenue \\ Argonne, IL 60439}

\section{PARAMETRIC EFFECTS ON GLASS REAC'TION IN THE UNSATURATED TEST METHOD}

by

Alan B. Woodland, John K. Bates, and Thomas J. Gerding

Chemical Technology Division

December 1991 


\section{TABLE OF CONTENTS}

Page

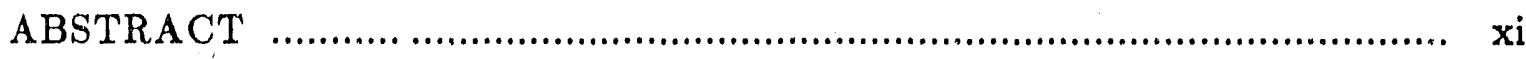

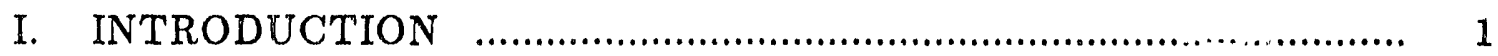

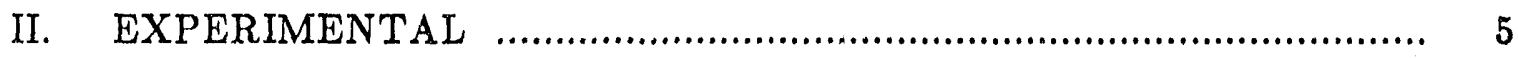

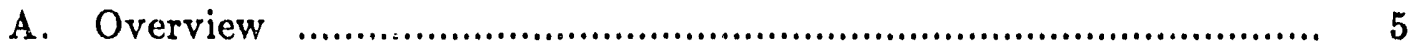

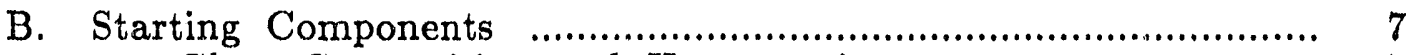

1. Glass Composition and Homogeneity ........................... 7

2. Water .................................................................. 8

3. $304 \mathrm{~L}$ Stainless Steel Waste Form Holders ........................ 8

III. RESULTS AND DISCUSSION ............................................. 8

A. P-II Experiments ......................................................... 10

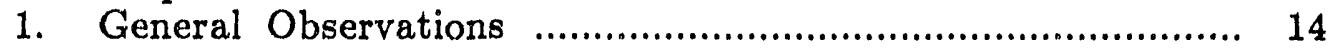

2. Component Analyses .................................................. 14

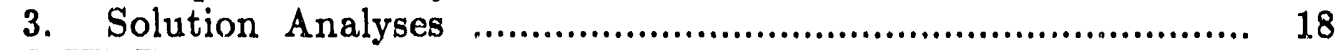

B. P-III Experiments ........................................................... 22

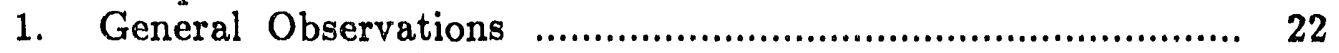

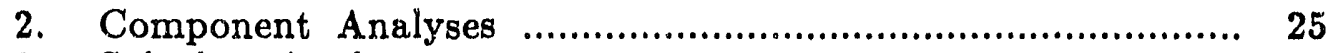

3. Solution Analyses ........................................................ 41

4. Discussion ................................................................ 45

C. P-IV Experiments ............................................................... 46

1. General Observations ................................................. 46

2. Component Analyses .................................................. 46

3. Solution Analyses ..................................................... 51

4. Discussion ............................................................. 51

D. P-V Experiments .......................................................... 55

1. General Observations .................................................. 55

2. Component Analyses ..................................................... 55

3. Solution Analyses .................................................... 66

4. Discussion ......................................................... 68

E. P.VIII Experiments ........................................................ 69

1. General Observations ............................................. 69

2. Component Analyses .................................................. 70

3. Solution Analyses .................................................... 83

4. Discussion ........................................................ 86

IV. DISCUSSION AND CONCLUSIONS .................................... 86

A. Parametric Effects ........................................................ 86

B. The Surface Layer and Secondary Phases .......................... 89 


\section{TABLE 'OF CONTENTS - Cont'd}

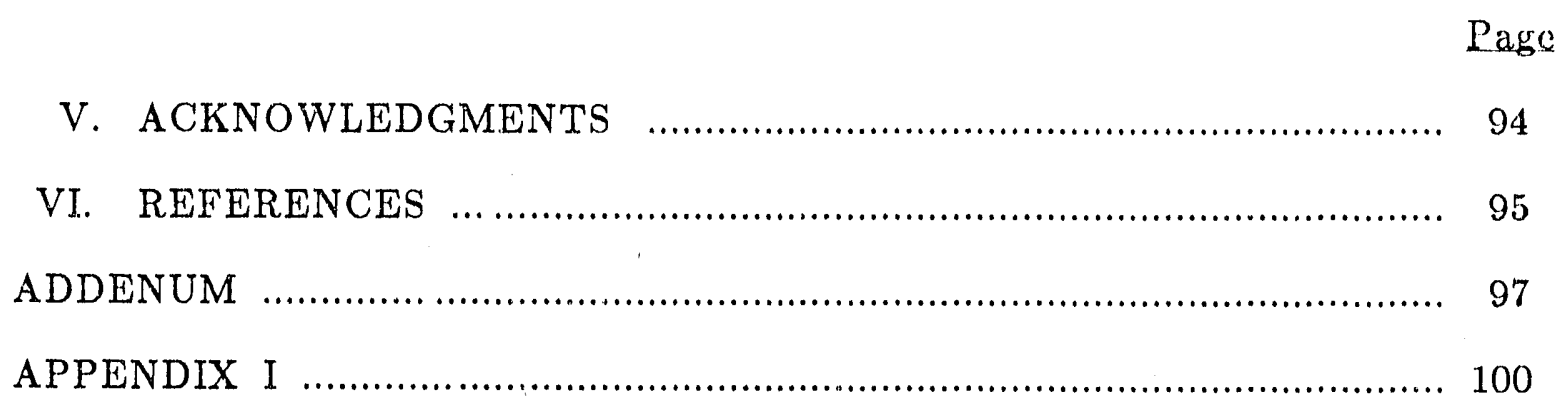




\section{LIST OF TABLES}

No.

Title

Page

1. Test Matrix for Unsaturated Tests

2. Description, Purpose, and Status of Parametric

Experiments and N2 Unsaturated Test

3. Composition of Glasses Used in the Parametric Experiments

4. Composition of J-13 and EJ-13 Water Used

in the Parametric Experiments

5. Composition of 304L Stainless Steel Used in the

Parametric Experiments and N2 Unsaturated Test

6. Experimental Matrix and Weight Change Results

from the P-II Series

7. Normalized Release in the P-II Series

8. Experimental Matrix and Weight Change Results

for the P-III Series

9. Normalized Release in P-IJI Series

10. Experimental Matrix and Weight Change Results

for the P-IV Series

11. Normalized Elemental Release for the P-IV Series

12. Experimental Matrix and Weight Change Results

for the P-V Series

13. Normalized Elemental Release for the P-V Series

14. Experimental Matrix and Weight Change Results

for the P-VIII Series

15. Normalized Elemental Release for the P-VIII Series

16. Summary of Phases Tentative Identified in the

Parametric Tests

17. Comparison of Normalized Release of B, Li, and $U$ between the Leaching Experiments of Ebert and the Parametric Experiments 


\section{LIST OF FIGURES}

No.

Title

Page

1. Schematic Drawing of the Unsaturated Test

Apparatus and Side and Top Views of the

Waste Package Assemblage

2

2. EDS Spectra of Unreacted Glass and 304L

Stainless Steel

3. SEM Micrographs and EDS Spectra of Reaction

Products Formed on the Top Surface of

Experiment P-II-5

4. SEM Micrographs and EDS Spectra of Reaction

Products Formed on the Bottom Surface of

Experiment P-II-5

5. SEM Micrographs of Reaction Products Formed

on the Top Surface of Experiment P-II-7

6. SEM Micrographs and EDS Spectra of Reaction

Products Formed on the Bottorn Surface of

Experiment P-II-7

7. Cumulative Release for Selected Elements from

the P-II-1 and P-II-2 Continuous Experiments

8. SEM Micrograph and EDS Spectrum of the Metal

Surface in Contact with Glass from the Top

Section of the Waste Form Holder in

Experiment P-III-4; Clumps of the Mat

Materials that Formed on the Top and Bottom

Metal Sections from Experiment P-III-4;

Reaction Products Observed on the Bottom

Metal Section from Experiment P-III-4

9. SEM Micrographs and EDS Spectra of Reaction

Products on the Bottom Surface of the Glass

from Experiment P-III-4

10. SIMS Spectra Showing the Profiles of $\mathrm{Li}, \mathrm{Mg}$,

and $\mathrm{B}$ Relative to $\mathrm{Si}$ for Sample P-III-3

11. SEM Micrographs and EDS Spectra of Reaction

Products on the Metal Components of P-III-6

12. SEM Micrographs and Associated EDS Spectra

from the Bottom Glass Section from

Experiment P-III-6 


\section{LIST OF FIGURES - Cont'd}

No.

Title

13. SEM Micrographs and EDS Spectra of Features

from the Top Metal Component of

Experiment P-III-8

14. SEM Micrographs and EDS Spectra of the

Side Glass of P-III-8

15. SEM Micrographs and EDS Spectrum from

the Top Glass Surface of P-III-9

16. Optical Photographs of the Bottom Glass

Surface of P-III-9

17. SIMS Profiles of the Bottom Glass Section

from Experiment P-III-9 in a Region of

Glass-Metal Contact

18. SEM Micrographs Showing the Coarse-Grained

Appearance of the Surface Layer, Exposed

Etched Glass, and a Cross Section of the

Botiom Glass Surface from P-III-10

19. SIMS Profiles of the Reacted Bottom and

Side Surfaces of the Glass from

Experiment P-III-10

20. Cumulative Release of Selected Elements from

the P-III-1 and P-III-2 Continuous Experiments

21. SEM Photomicrographs of the Bottom Glass

Surface from Experiment P-IV-3

22. SEM Photomicrographs of the Top Glass

Surface from Experiment P-IV-3

23. SEM Micrographs of the Bottom Glass

from P-IV -5

24. SEM Micrographs and EDS Spectra of Reaction

Products on the Top Surface of P-IV-5

25. Cumulative Release of Selected Elements from the P-IV-1 and P.IV-2 Continuous Experiments

26. SEM Micrographs of the Surface Layer and

Reaction Products on the T'op Surface of P-V-3 


\section{LIST OF FIGURES - Cont'd}

No.

Title

Page

27. SEM Micrographs and EDS Spectrum of

Reaction Products on the Top Glass

Surface of P.V-4

28. SEM Micrographs of the Bottom Surface

of $\mathrm{P}-\mathrm{V}-4$

29. SEM Micrographs Showing the General Surface

Features on the Top of P-V-6

30. SEM Micrographs of the Surface Layer and

Other Reaction Products on the Top of P-V-7

31. SEM Micrographs of Surface Layer Features

on the Bottom of P-V -7

32. Cumulative Releases of Selected Elements

from the P.V-1 Continuous Experiment

33. SEM Micrographs and EDS Spectra from the

Top of P-VIII-4

34. SEM Micrographs and EDS Spectra from the

Top of P-VIII-6

35. SEM Micrographs and EDS Spectrum of Surface Layer Features from the Bottom of P-VIII-6

36. SEM Micrograph and EDS Spectrum of Fe- and

Cr-Rich Deposit on the Bottom Surface of

the Metal Component on P-VIII-6

37. SEM Micrograph and EDS Spectra of Reaction

Products on the Top Glass of P-VIII-7

38. SEM Micrographs of Surface Layer Features

on the Bottom of P-VIII-7

39. EDS Spectra of Precipitates on the Top

Metal Component of P-VIII-7 


\section{LIST OF FIGURES - Cont'd}

No.

Title

Page

40. Cumulative Release of Selected Elements from the P-VIII-1 and P-VIII-2

Continuous Experiments

41. Normalized Releases of $\mathrm{B}, \mathrm{Li}$, and $\mathrm{U}$ for the Parametric and "Standardized" N2

Unsaturated Experiments

42. TEM Micrograph of the Layer from the Bottorn of P-VIII-7

43. TEM Micrograph of the Side of P-III-10 


\title{
PARAMETRIC EFFECTS ON GLASS REACTION IN THE UNSATURATED TEST METHOD
}

\author{
by
}

\author{
Alan B. Woodland, John K. Bates, and Thomas J. Gerding
}

\begin{abstract}
The Unsaturated Test Method has been applied to study glass reaction under conditions that may be present at the potential Yucca Mountain site, currently under evaluation for storage of reprocessed high-level nuclear waste. The results from five separate sets of parametric experiments are presented wherein test parameters ranging from water contact volume to serisitization of metal in contact with the glass were examined. The most significant effect was observed when the volume of water, as controlled by the water inject volume and interval period, was such to allow exfoliation of reacted glass to occur. The extent of reaction was also influenced to a lesser extent by the degree of sensitization of the 304L stainless steel. For each experiment, the release of cations from the glass and alteration of the glass were examined. The major alteration product is a smectite clay that forms both from precipitation from solution and from in-situ alteration of the glass itself. It is this clay that undergoes exfoliation as water drips from the glass. A comparison is made between the results of the parametric experiments with those of static leach tests. In the static tests the rates of release become progressively reduced through 39 weeks while, in contrast, they remain relatively constant in the parametric experiments for at least 300 weeks. This differing behavior may be attributable to the dripping water environment where fresh water is periodically added and where evaporation can occur.
\end{abstract}




\section{PARAMETRIC EFFECTS ON GLASS REACTION IN THE UNSATURATED TEST METHOD}

\section{INTRODUCTION}

The Unsaturated Test method has been developed ${ }^{1,2}$ as a procedure to monitor the reaction of glass with water under conditions that are relevant to the potential repository at Yucca Mountain, Nevada. The Yucca Mountain site is located in the unsaturated zone and the repository horizon is composed of beds of welded and devitrified tuff. During the waste containment period (300/1000 years), heat generated by the radioactive waste is expected to maintain the temperature of the near-field environment above $100^{\circ} \mathrm{C} .^{3}$ In addition, the metal containers which surround the waste are anticipated to retain their integrity during this period. Thus, for the initial 300/1000-year period, the glass waste form is unlikely to contact liquid water. However, once the temperature has cooled to below $96^{\circ} \mathrm{C}$, the local boiling point of groundwater at the Yuccai Mountain Site, and the container is breach 1 , liquid water will have access to the waste form.

Water contact is likely to occur in several modes: (1) continuous contact between the waste form and water vapor, (2) slow ingress and accumulation of water in the container, and (3) intermittent contact between water and glass as water periodically flows into and passes through the container. The Unsaturated Test method was developed to study glass-water reaction where a number of glass/water contact modes exist so that site-relevant data can be generated to assess the importance of interactive effects between waste package components. The data provide a release rate or glass reaction progress for a specific set of conditions and, if the physical parameters incorporated into the test are chosen judiciously, may be able to provide information to bound releases expected to occur in the repository. The release data can also be used in the validation of geochemical modeling methods that are being developed to project glass reaction. 4,5

To facilitate performance of the Unsaturated Test, a rigorous procedure and set of test parameters have been employed. The test is designed to study the three types of interactions that affect the reaction of the glass and that are anticipated to occur under unsaturated conditions. These include (1) contact between the glass and moist air, followed by periodic rinsing of the glass surface with flowing water; (2) contact between the glass and standing water; and (3) contact between the glass and standing water in close contact with partially sensitized 304L stainless steel. The Unsaturated 'I'est provides for the possibility that these interactions will occur and specifies analyses to be performed that are designed to judge the importance of each one.

The apparatus used in the Unsaturated Test has been described previously ${ }^{1,2}$ and a schematic diagram of the system is shown in Fig. 1 . The components of the test apparatus are the test vessel, which provides for collection and containment of liquid and support of the waste package; the waste package assemblage (WPA), which consists of the waste form and presensitized metallic components representing the canister (Fig. 1b); and a solution feed system to inject water. 
(a)

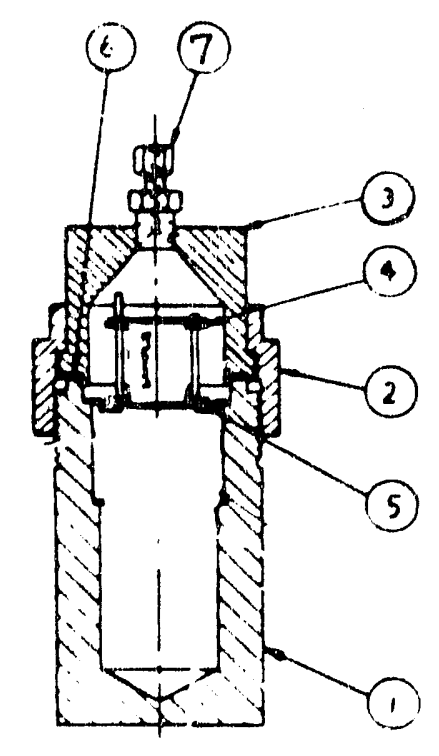

1. Body

2. Nut

3. Cap

4. Retainer Top

5. Retainer Bottom

6. Ethylene Propylene Gasket

7. Swagelok Fitting

(b)
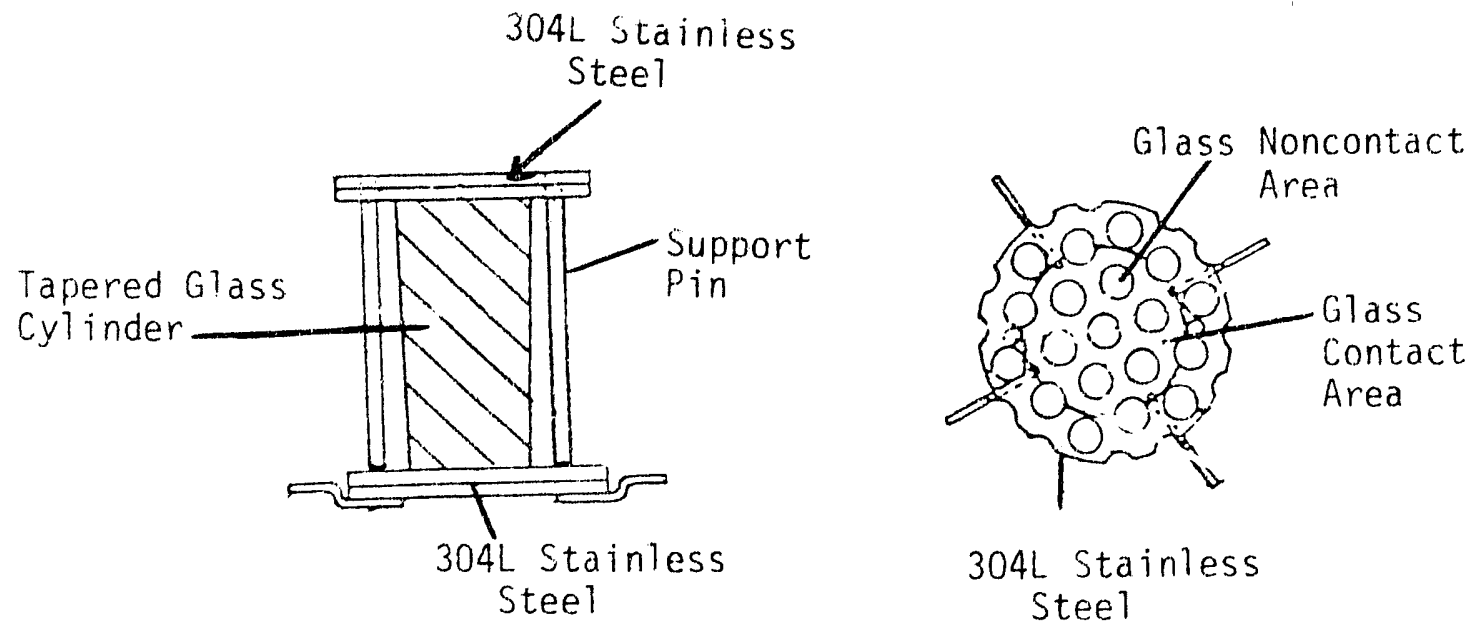

304L Stainless Steel

Fig. 1. (a) Schematic Drawing of Unsaturated Test Apparatus. (b) Schematic Drawing of the Side and Top Views of the Waste Package Assemblage 
The WPA is contacted every 3.5 days by $0.075 \mathrm{~mL}$ (drops) of water from the J-13 well that was preequilibrated with Topopah Spring tuff at $90^{\circ} \mathrm{C}$. The tests are conducted at $90^{\circ} \mathrm{C}$ and the fluid injection system is configured so that the water attains a temperature of $\sim 90^{\circ} \mathrm{C}$ before contacting the glass. Elemental release is determined by chemical analysis of the water thit contacted the WPA and by surface analysis of the assemblage components. Solution samples are collected immediately upon termination of the experiment and after the vessel ras been acid stripped to remove any material that may have precipitated or adsorbed onto the vessel walls. Although the solution is sampled at ambient temperature, it dripped from the WPA and collected in the vessel bottom at $90^{\prime \prime} \mathrm{C}$. Material interactions are noted and secondary phases, which may influence clemental release, are identified.

The test procedure incorporates batch and continuous tests (Table 1). In the batch mode, tests are terminated at 13-week intervals through 52 weeks. In the batch mode, the apparatus is disassembled, and analyses of both the solution and components are performed. In the continuous mode, the WPA (including liquid associated with tin WPA) is transferred to a new vessel, and the test is continued. For the first 52 weeks the continuous tests are sampled at 6.5-week intervals. After 52 weeks, 13- or 26-week intervals are used. Analyses are done on the solution in the old vessel. In addition, visual investigation of the components is possible at the termination points, and yet the test can continue for an unspecified period or until information most useful to repository evaluation is obtained.

One key to the applicability of the data generated by the Unsaturated Test is the relationship between the set conditions used in the test, e.g., tcmiperature, water contact interval, water composition, drop volume, condition of the stainless steel in contact with the glass, and surface area of the glass, and the eventual conditions encountered in the repository. Since it is likely that many of the conditions listed above may vary between individua! waste packages, and will certainly vary with time, the conditions were set using reasonable values at the time the test procedure was developed (1984). At that time, it was recognized that the set conditions chosen may not have been the best possible, based on refinement of the description of the waste package environment and on parametric effects not yet identified. Thus, a series of pr.rametric experiments were initiated to determine to what degree each parameter affected the glass reaction.

The parameters chosen to study were:

(1) exclusion of stainless steel contact with the glass;

(2) the surface area of the glass;

(3) the volume of water contacting the glass;

(4) the interval of water injection; and

(5) the effect of stainless steel composition and extent of sensitization. 


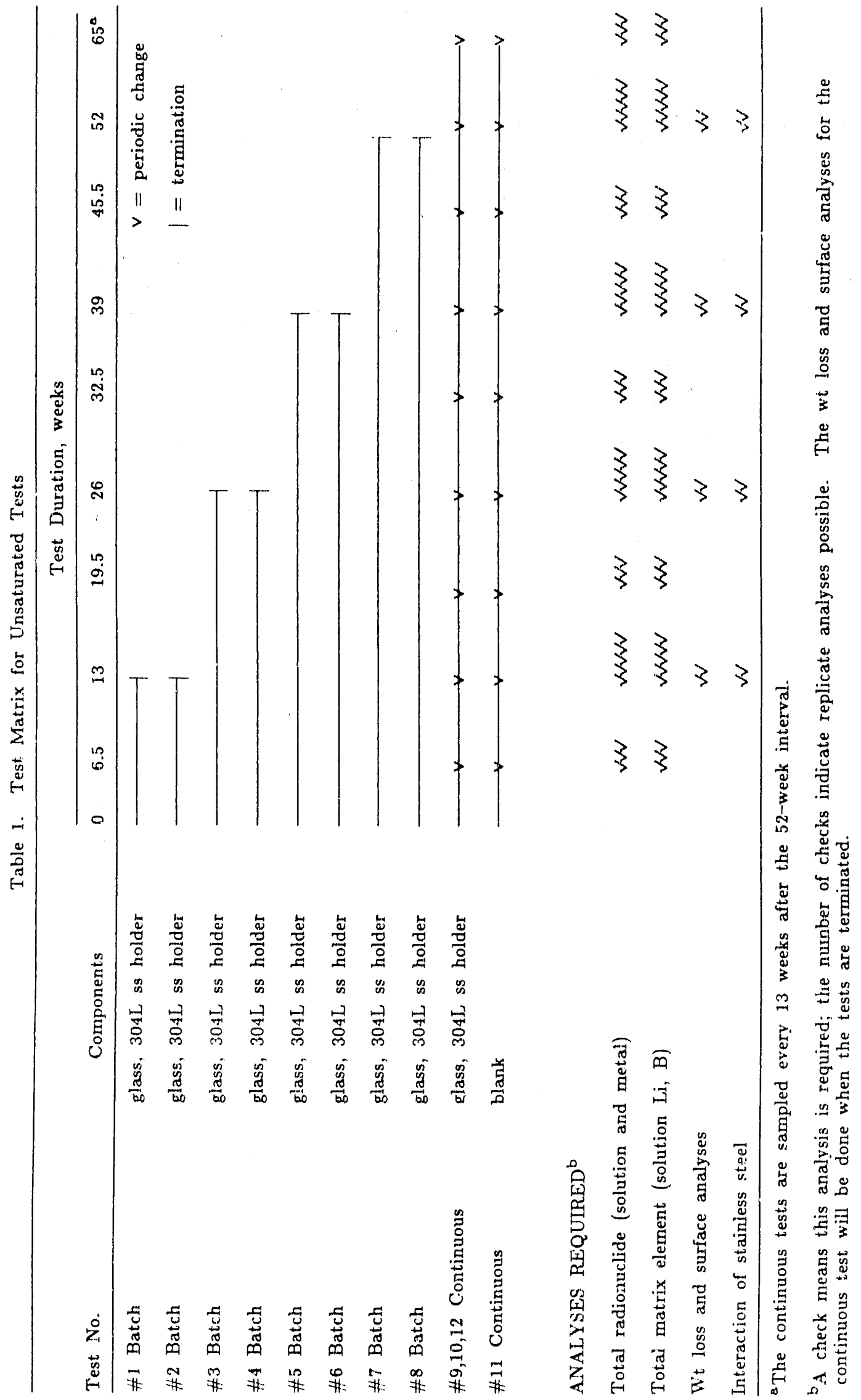


These parametric experiments have now been in progress for up to four years. In this report the details of each experiment are described, the results are presented, and a comparison is made between the results from the various parametric experiments and the N2 Unsaturated Test series ${ }^{6}$ to determine the relative importance of each parameter in affecting glass reaction.

\section{EXPERIMENTAL PROCEDURE}

\section{A. Qverview}

The apparatus used in the parametric experiments is the same as used in the Unsaturated Test except for the containment vessel and gasket (items 1, 2, 3, and 6 in Fig. 1). In the parametric experiments a $22 \mathrm{~mL}$ Parr vessel \#4703 modified by reducing the wall thickness 1/32" to a depth 1 " from the top of the vessel is used as the vessel body (item 1). This modification creates a ledge on which the retainer bottom (item 5, Fig. 1) is positioned. The cap for the vessel (item 3) was machined to provide the umbrella effect shown in Fig. 1 which directs condensation on the vessel lid to the walls of the vessel body instead of to the glass. All the material used in construction of the vessel is $304 \mathrm{~L}$ stainless steel. The gasket material used in the parametric experiments is Teflon $^{\text {TM }}$. The above changes were made to reduce the cost of the apparatus and to aid in ease of performing the experiments. None of the changes should appreciably affect the extent of glass reaction except that the vessel used in the parametric experiments is ten times less massive than the one used in the Unsaturated Tests. This reduced mass may increase the effect of the small temperature fluctuations caused by the ovens. As temperature gradients between the vessel and WPA will cause vapor transport, this is an important process that must be considered when comparing results from different experiments.

The conditions used in each parametric experiment plus the rationale for performing the experiment are given in Table 2 . The experimental matrix used for each series is detailed in Section III, but in most cases both batch and continuous experiments were run. All of the batch experiments have been terminated, while the continuous experiments are still in progress.

The solutions from the vessel bottom are analyzed for $\mathrm{Al}, \mathrm{B}, \mathrm{Ca}, \mathrm{Fe}$, $\mathrm{K}, \mathrm{Li}, \mathrm{Mg}, \mathrm{Mn}, \mathrm{Na}, \mathrm{Ni}, \mathrm{Si}$, and $\mathrm{S}$ using Inductively Coupled Plasma/Atomic Emission Spectroscopy (ICP/AES). The analytical uncertainty is 3-1.0\% depending on the element and its concentration. Uranium is determined by the Sintrex method which is based on laser-induced fluorescence ( $\pm 10 \%$ uncertainty). When enough solution is available, the $\mathrm{pH}$ (glass electrode, Orion model 501 Digital Ionanalyzer), total and organic carbon (Dohrmann Total Organic Carbon Analyzer Model DC-80), and the anions $\mathrm{F}^{-}, \mathrm{Cl}^{-}, \mathrm{NO}_{2}^{-}, \mathrm{NO}_{3}{ }^{-}, \mathrm{SO}_{4}{ }^{-}, \mathrm{HPO}_{4}=$ $\mathrm{CHO}_{2}$, and $\mathrm{C}_{2} \mathrm{O}_{4}=$ (ion chromatography) are measured with uncertainties all in the range of $5-10 \%$. 


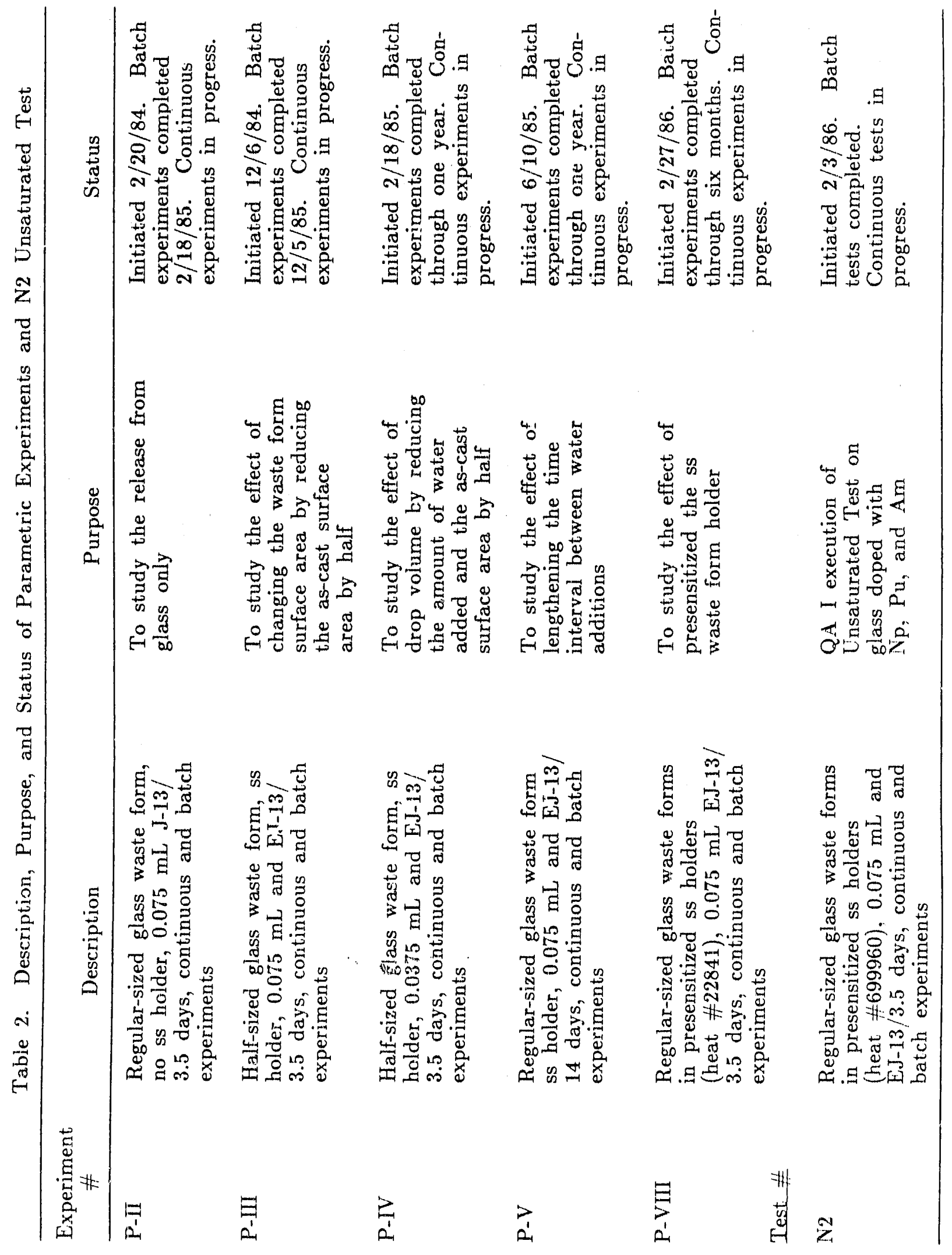


Raw and "corrected" solution analyses are presented in the appendices. The "corrected" data account for the elemental contribution from the injected water. This is done by subtracting from the total solution analysis the amount of each element contained in the water that was injected during the experiment period and added at the beginning of an experiment period. Such a correction assumes that all the water injected actually goes into the vessel. This concern exists because after several years, the injection lines may become partially plugged which makes complete water injection uncertain. The correction also assumes that any leakage from the vessel is only water (presumably as vapor) and that all cations are retained in the vessel. It should be noted that, when analyzed concentrations were reported to be below the detection limit, the detection limit value was used. Thus, the results for elements frequently at very low concentration represent maximum values. These elements include $\mathrm{Al}, \mathrm{Mg}$, $\mathrm{Ni}$, and $\mathrm{Sr}$.

Interpretation of the solution data requires consideration of processes that may occur intermittently during the experiment. For example, if curing a certain period there has been considerable evaporation from the WPA surface, it is possible that none of the water that contacts the top surface actually drips off of the glass to be collected in the test solution. If this happens, then all elements will show a negative deviation. However, if during the next period effective water transfer from the glass to the test vessel occurs, then a sharp positive deviation in elemental release may be observed. Consequently, elemental relcase should be viewed as a trend over the entire experiment duration with little weight given to individual deviations from this trend.

In the batch experiments analysis is also performed on the metal and glass components of the systems. The components are observed first using a low-power optical microscope where color photographs are taken and the surfaces mapped for scanning electron microscopy (SEM) and secondary ion mass spectroscopy (SIMS) analysis. If appropriate, samples are taken for $\mathrm{x}$-ray diffraction (XRD) analysis. The samples are then examined by SEM with associated energy dispersive spectrosccpy (EDS) and wavelength dispersive spectroscopy (WDS) to characterize the alteration products that formed during the reaction.

\section{B. Starting Components}

The procedures used in setting up, performing, and analyzing the experiments are essentially the same as used in the Unsaturated Test. ${ }^{1,6}$ Throughout the entire series of experiments a consistency in methods was maintained.

\section{Glass Composition and Homogeneity}

The basis for the glass compusition is SRL 165 black frit doped with $\mathrm{Cs}, \mathrm{Sr}$, and $\mathrm{U}^{7}$ In this report this glass is referred to as SRL $U$ glass. This composition was chosen because of the data available as part of the SRL testing program ${ }^{7}$ and because at the time the experiments were initiated, 165 type black frit was the reference glass composition for processing in the 
Defense Waste Processing Facility (DWPF). Subsequently, the glass processing procedure has been altered and glasses based on frit 200 with both sludge and precipitate hydrolysis components added have been designated as DWPF candidate glasses. ${ }^{8}$ Based on hydration theory, ${ }^{9}$ SRL 165 black frit type glasses should have the best durability of glasses that fit into the potential range of glasses to be produced by the DWPF.

A single quantity of SRL black frit has formed the basis of all the parametric experimentation described in this report. The glass composition is given in Table 3 together with analyses of the starting material as obtained by different laboratories. EDS spectra of the glass at 10 and $20 \mathrm{keV}$ are presented in Figs. 2a and $2 \mathrm{~b}$ for reference.

\section{Water}

A 5-gal batch of J-13 water from the J-13 well located near the potential repository horizon was used as the source of water for these experiments. In some experiments the water was used as received and in other experiments the J-13 water was equilibrated with tuff at $90^{\circ} \mathrm{C}$ following established procedures ${ }^{1}$ to produce EJ-13 water, which is taken to be more representative of water that will be present in the waste package environment. Several equilibrations have been done over the course of these experiments and the water compositions used in the parametric experiments are given in Table 4.

\section{304L Stainless Steel Waste Form Holders}

The waste form holders that enclose the glass during the experiments consist of perforated pieces of $304 \mathrm{~L}$ stainless steel. The perforations are present to permit direct contact between the dripping water and the glass. Steel from two different heats was used during the course of the experiments (Table 5). In addition, different heat treatments were imposed on the steel to simulate heating that may occur during glass processing and long-term storage in the repository at elevated temperatures. Such heat treatment may cause the steel to lose its resistance to corrosion and become sensitized. In some of the experiments the starting metal was purposely sensitized to measure its influence on glass reaction. Details of the sensitization treatments are presented in the sections describing each indi-idual series of experiments. For reference, an EDS spectrum of $304 \mathrm{~L}$ stainless steel is presented in Fig. 2c.

\section{RESULTS AND DISCUSSION}

The results from each series of parametric experiments are presented below as individual subsections. Thereafter a comparison is made between the different, series to assess the importance of each physical parameter on glass reaction. 
Table 3. Composition of Glasses Used in the Parametric Experiments

\begin{tabular}{|c|c|c|c|c|}
\hline \multirow[b]{2}{*}{ Formula } & \multicolumn{2}{|c|}{ SRL U Glass } & \multicolumn{2}{|c|}{$\begin{array}{c}\text { Black Frit Oxide } \\
\text { wt } \%\end{array}$} \\
\hline & $\begin{array}{l}\text { Oxide } \\
\text { wt } \%\end{array}$ & $\begin{array}{l}\text { Element } \\
\text { wt } \%\end{array}$ & Eerro & $\mathrm{MCC}^{\mathrm{b}}$ \\
\hline $\mathrm{Al}_{2} \mathrm{O}_{3}$ & 4.08 & 2.16 & 4.1 & 4.3 \\
\hline $\mathrm{B}_{2} \mathrm{O}_{3}$ & 6.76 & 2.09 & 6.8 & 6.8 \\
\hline $\mathrm{BaO}$ & 0.06 & 0.05 & & -0.1 \\
\hline $\mathrm{CaO}$ & 1.62 & 1.16 & 1.5 & 1.6 \\
\hline $\mathrm{CeO}_{2}$ & $<0.05$ & $<0.04$ & & \\
\hline $\mathrm{Cr}_{2} \mathrm{O}_{3}$ & $<0.01$ & $<0.007$ & & \\
\hline $\mathrm{C}_{\mathrm{s}_{2}} \mathrm{O}$ & 0.072 & 0.07 & & \\
\hline $\mathrm{Fe}_{2} \mathrm{O}_{3}$ & 11.74 & 8.20 & 12.3 & 11.7 \\
\hline $\mathrm{K}$ & $N A^{c}$ & & & \\
\hline $\mathrm{La}_{2} \mathrm{O}_{3}$ & $<0.05$ & $<0.004$ & & 0.2 \\
\hline $\mathrm{Li}_{2} \mathrm{O}$ & 4.18 & 1.94 & 4.7 & 4.8 \\
\hline $\mathrm{MgO}$ & 0.70 & 0.42 & 0.8 & 0.6 \\
\hline $\mathrm{MnO}_{2}$ & 2.79 & 1.76 & 2.9 & 2.8 \\
\hline $\mathrm{MoO}_{3}$ & $<0.01$ & $<0.007$ & & \\
\hline $\mathrm{Na}_{2} \mathrm{O}$ & 10.85 & 8.05 & 10.3 & 10.8 \\
\hline $\mathrm{Nd}_{2} \mathrm{O}_{3}$ & $<0.05$ & $<0.005$ & & \\
\hline $\mathrm{NiO}$ & 0.85 & 0.67 & 0.9 & 0.8 \\
\hline $\mathrm{P}_{2} \mathrm{O}_{5}$ & 0.29 & 0.13 & & 0.3 \\
\hline $\mathrm{SiO}_{2}$ & 52.86 & 24.71 & 54.1 & 51.6 \\
\hline $\mathrm{SrO}_{2}$ & 0.11 & 0.10 & & 0.2 \\
\hline $\mathrm{TiO}_{2}$ & 0.14 & 0.08 & & $<0.1$ \\
\hline $\mathrm{UO}_{2}$ & 0.92 & 0.81 & & \\
\hline $\mathrm{ZnO}$ & 0.04 & 0.03 & & \\
\hline $\mathrm{ZrO}_{2}$ & 0.66 & 0.48 & 1.2 & 0.7 \\
\hline $\mathrm{F}$ & & & 0.06 & \\
\hline $\mathrm{Cl}$ & & & 0.05 & \\
\hline $\mathrm{Pb}$ & & & 0.05 & \\
\hline
\end{tabular}

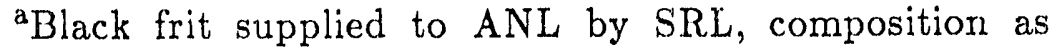
determined by Ferro Corp.

bBlack frit supplied by SRL to the Materials Characterization Center (MCC), composition as determined by MCC.

${ }^{\mathrm{c}} \mathrm{NA}=$ not analyzed. 
(a)

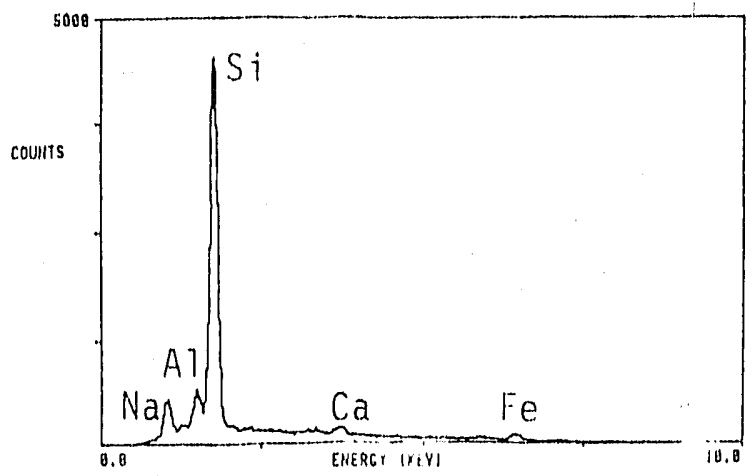

(b)

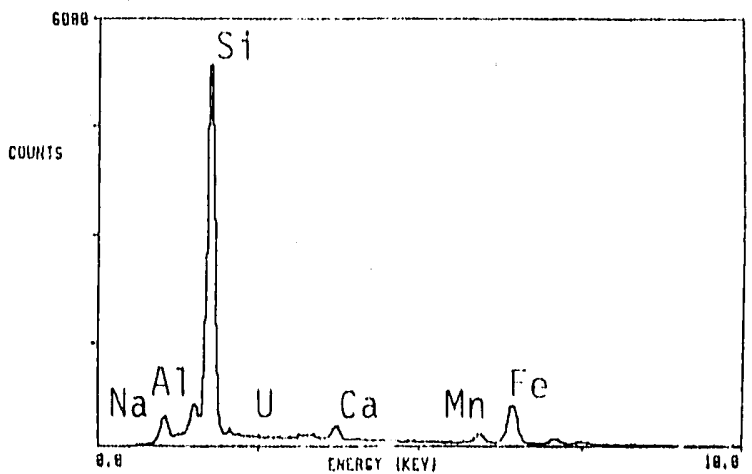

(c)

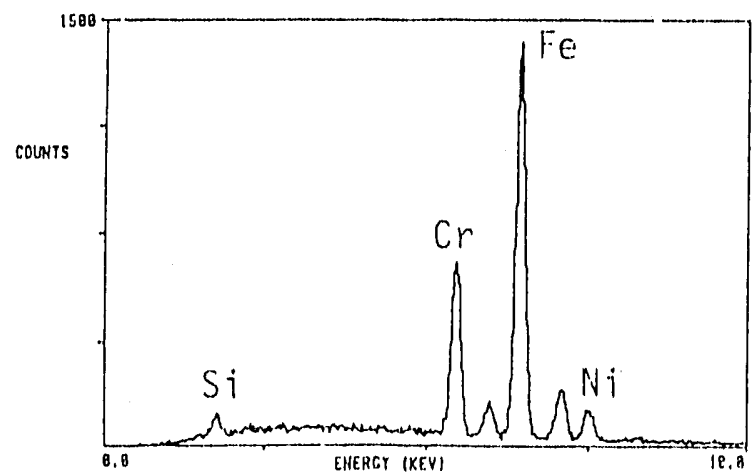

Fig. 2. EDS Spectra of (a) Unreacted Glass at $10 \mathrm{keV}$, (b) Unreacted Glass at $20 \mathrm{keV}$, and (c) $304 \mathrm{~L}$ Stainless Steel at $20 \mathrm{keV}$

\section{A. P-II Experiments}

This set of experiments is being performed following the Unsaturated Test protocol, ${ }^{2}$ except that there is no metal retainer and all vessel components are made of Teflon ${ }^{2 M}$. All measured release should be solely due to glass/water interaction. This provides a baseline for comparison with the results of other experiments where metal components are present. In addition, the results are directly applicable to those areas of the glass where there is no direct metal contact (i.e., the top portions of the glass in the pour canisters).

The detailed experimental matrix and weight change measurements are presented in Table 6.

The experiments were initiated $2 / 20 / 84$ and have been completed through 301 weeks. For the first year, batch experiments were terminated at the 6.5-, 13-, 26-, 39-, and 52-week periods, while the continuous experiments were sampled every 6.5 weeks. For the second yaar, the continuous experiments were sampled every 6.5 weeks and thereafter at irregular intervals of approximately 13 weeks. 


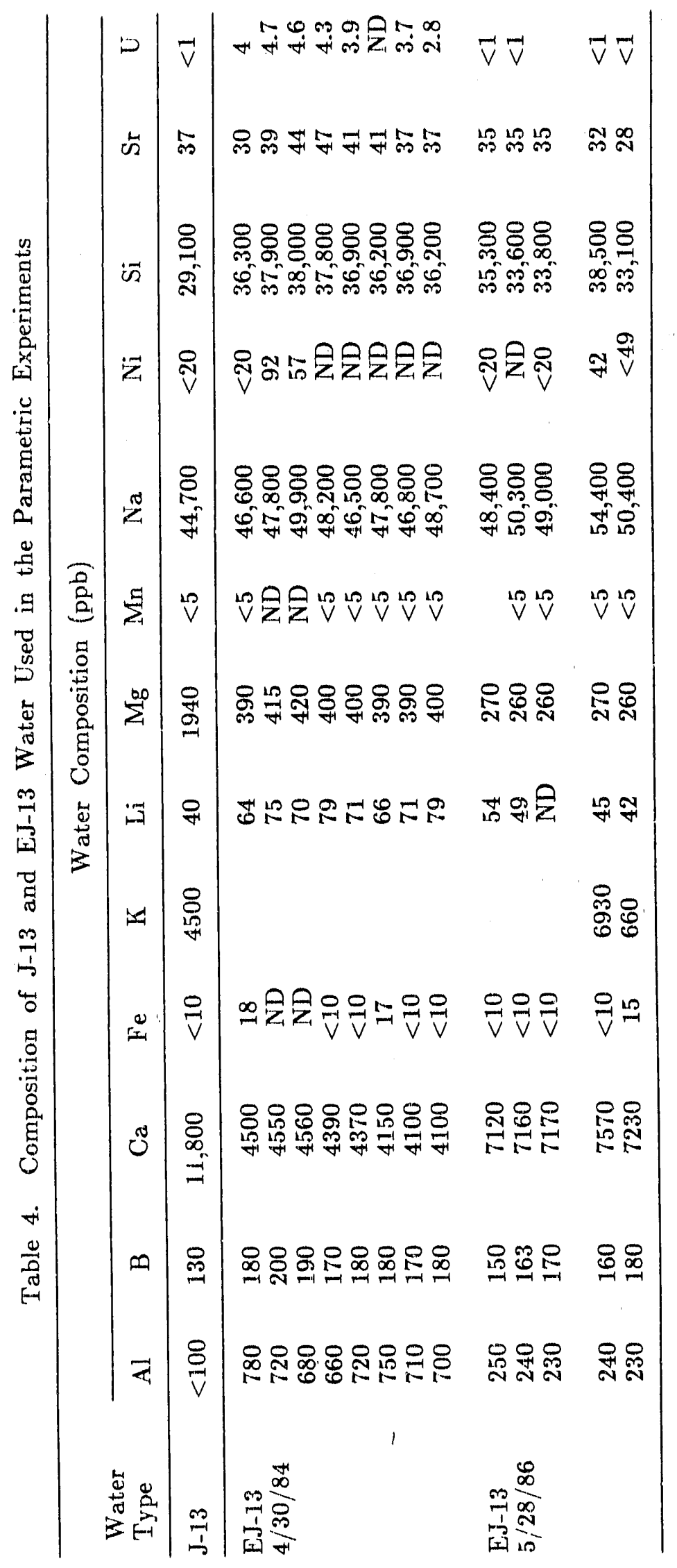




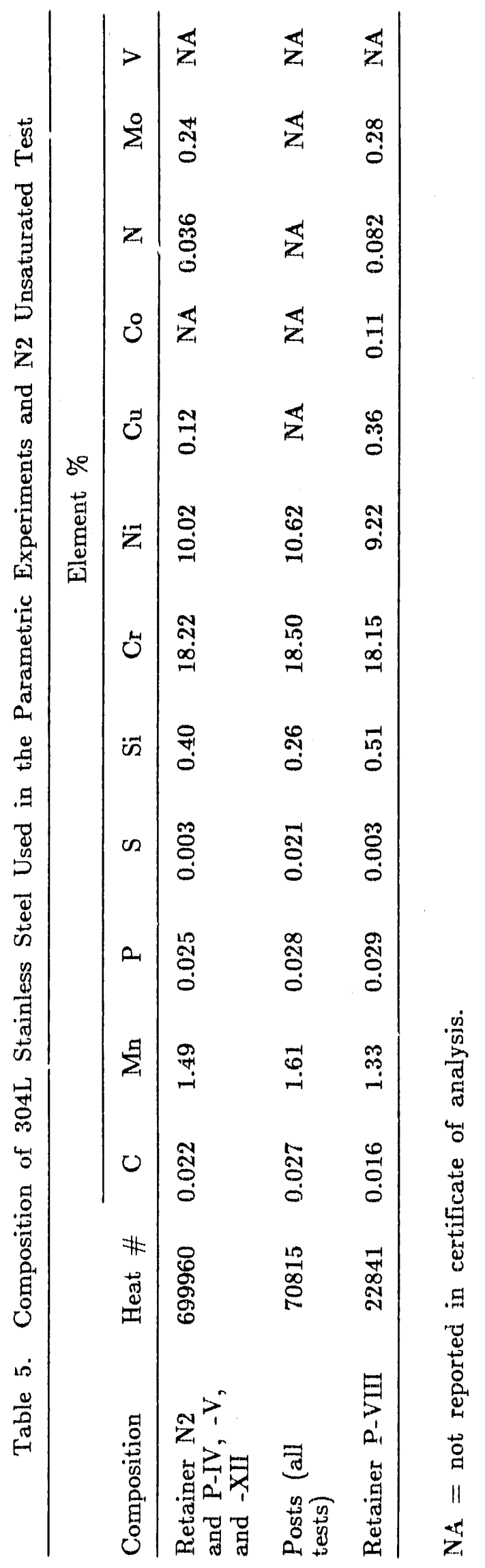




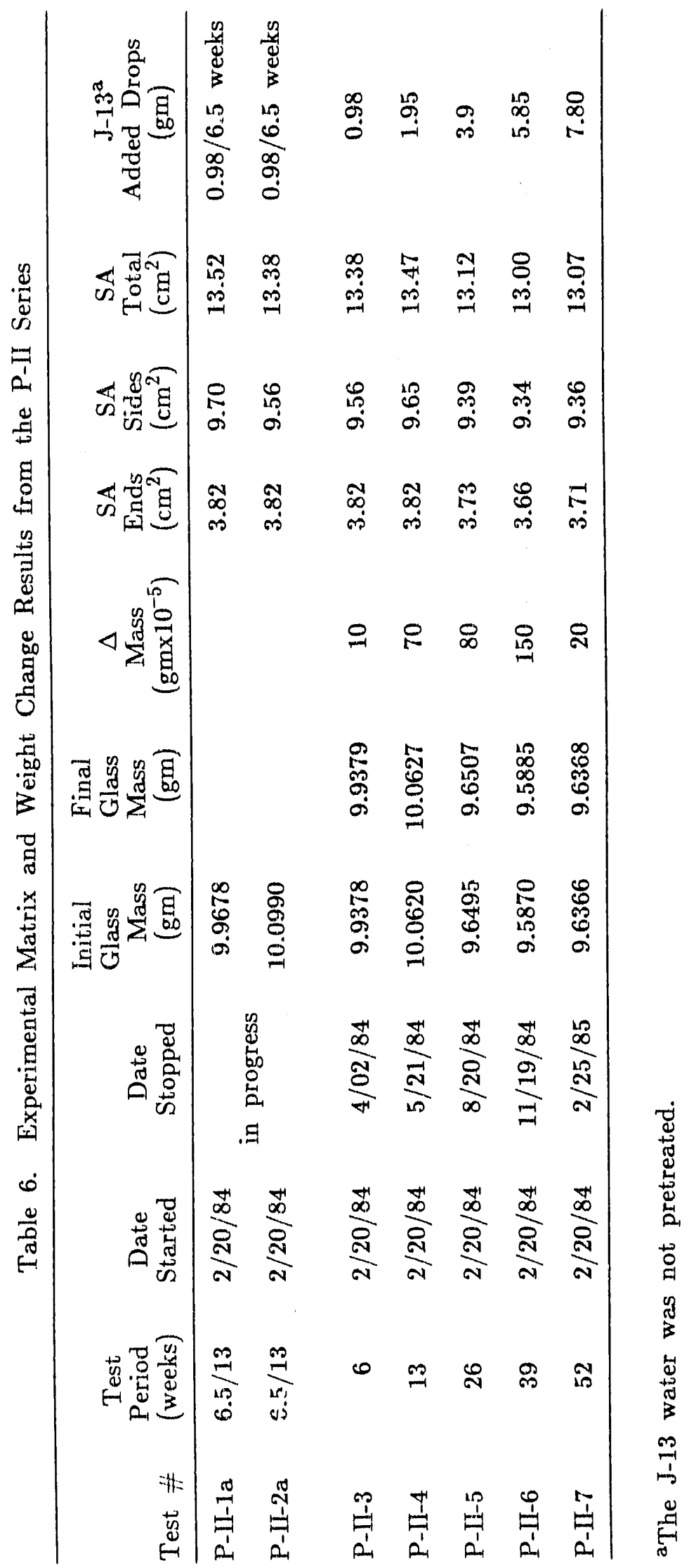


The experiments have been. conducted using J-13 water of composition given in Table 4. The water was received from Lawrence Livermore National Laboratory (LLNL) and has been stored in its original shipping container. The. source water has been analyzed periodically and its composition remains relativoly stable (Table 4).

The results of these experiments will be discussed by describing the general appearance of the glass as observed throughout the test period, by examining the glass surfaces from the batch experiments, and by correlating the solution results with these observations.

\section{General Observations}

(a) The waste form steadily gained weight during successive sampling periods through 39 weeks. Thi, is the result of precipitation on the glass surface. The precipitates were clearly visible after 6.5 weeks. They initially formed on the top surface and coverage began to extend onto the sides after 224.5 weeks in the continuous experiments. The accumulation of precipitates does not occur on the bottom surface. Based upon detailed investigation of the batch experiments, the precipitates are primarily aluminosilicates (see below).

(b) On the top surface, no accumulation of standing water appears to have occurred. Upon opening the vessels (after cooling), the top surface dries within 10-20 seconds and the surface changes from a dark gray to a dirty white color when drying.

(c) The bottom surface of the glass was usually in contact with standing water throughout the sampling interval and remained wet during sampling.

(d) There was some water loss during the sampling intervals due to vapor escaping from the vessels. However, some fluid was always present in the bottom of the vessels upon sampling or experiment termination, indicating that vapcr-saturated conditions were maintained throughout the experiment. A new vessel design was introduced at the 210 -week sampling in an attempt to reduce vapor loss and to provide a more secure positioning of the glass in the center of the vessel.

\section{Component Analyses}

Selected samples from the batch experiments were examined by SEM/EDS/WDS. To do this, the top and bottom faces were carefully cut from the waste form and mounted on aluminum stubs. The reaction products observed on all samples are generally similar with greater coverage evident on the longer duration samples. The following is a description of the 26- and 52-week samples. 


\section{a. P-II-5,26-Week Sample}

A Si-rich surface layer is well developed on the glass with two types of reacted areas present. In some areas, the surface is covered by a smooth ueposit which is similar in composition to that of the unreacted glass, except that it is somewhat depleted in $\mathrm{Na}$ and enriched in $\mathrm{Mg}, \mathrm{S}$, and $\mathrm{K}$ (Figs. 3a and 3b/EDS, compare with Fig. 2a/EDS). This deposit cover - $25 \%$ of the surface and appears io have formed by precipitation. The remainder of the surface has a rougher textured appearance, which at high magnification reveals many small platelets (Fig. 3d). This material is similar in composition io the smooth regions (compare Figs. $3 e / E D S$ and $3 b / E D S$ ). There are many small areas which are somewhat enriched in $S$ and $C$ a relative to the typical surface layer suggesting the presence of gypsum or anhydrite.

Many small grains are distributed over the surface (Fig. 3f). The two most common have been identified by XRD as calcite and gypsum. Calcite takes the form of vertical protrusions from the surface. Gypsum grains are typically very irregular in form (Fig. 3a) and have easily distinguishable EDS spectra (Fig. 3c/EDS). Both phases occur up to $100 \mu \mathrm{m}$ across. Since gypsim is not stable above $42 \mathrm{C}$, at 1 atm, it must have formed either by lowtemperature hydration of preexisting anhydrite or by direct precipitation during cooling of the WPA when the experiment was terminated. ${ }^{10}$ There are a number of other phases present; lowever, they were too fine grained to permit identification by XRD. These other grains are rich in $\mathrm{Na}, \mathrm{K}$, or $\mathrm{Mg}$.

The bottom surface has far fewer grains on it compared to the top surface. The points of contact between the Teflon ${ }^{T M}$ grid and the glass are evident to the eye and in the SEM (Fig. 4a). The contours of the as-cut surface are still visible but some places anpear to be highly eroded. Sorne of the surface is covered by a smooth deposit; however, the majority has a rougher tertured appearance (Fig. 4b). The roughness is more pronounced in the area of the Teflon thi contact. This reacted surface layer has a similar composition in the contact and noncontact areas (Fig. 4c/EDS). A reaction product, not observed on the top surface, occurs as dark splotches (Fig. 4d) and smooth rounded grains (Fig. 4e) on the SEM and is composed predominantly of $\mathrm{Na}$ (Fig. 4f/EDS). While it has not been possible to collect a sample for XRD analysis, the EDS spectra and the fact that the grains are beam sensitive suggests it is $\mathrm{Na}_{2} \mathrm{CO}_{3}$. The possibility of this being a borate may be excluded based inon WDS analysis of similar grains on the top surface which revealed no boron. The Si and $A I$ in the EDS spectra probably result from excitation of the surface layer as the beam penetrated the grains.

\section{b. P-II-Z, ¿2-lWeek Sample}

A reacted layer is well developed on the top sirface. It has a rongh textured appearance and is composed of staked irregular shaped platelet: (Fig. $5 a)$. There is heavier coverage of precipitated grains compared with P-II-j (Fig. 5b). These grains are predominantly calcite and gypsum. However, ther: are also many very irregular shaped grains rich in $\mathrm{Na}$ and $\mathrm{Cl}$ and are presumably $\mathrm{NaCl}$ (Fig. $5 \mathrm{c}$ ). 
(a)

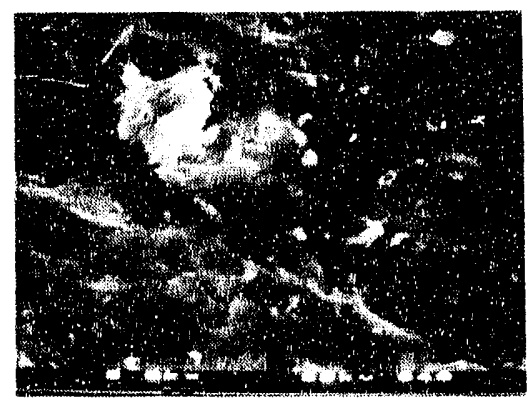

(c)

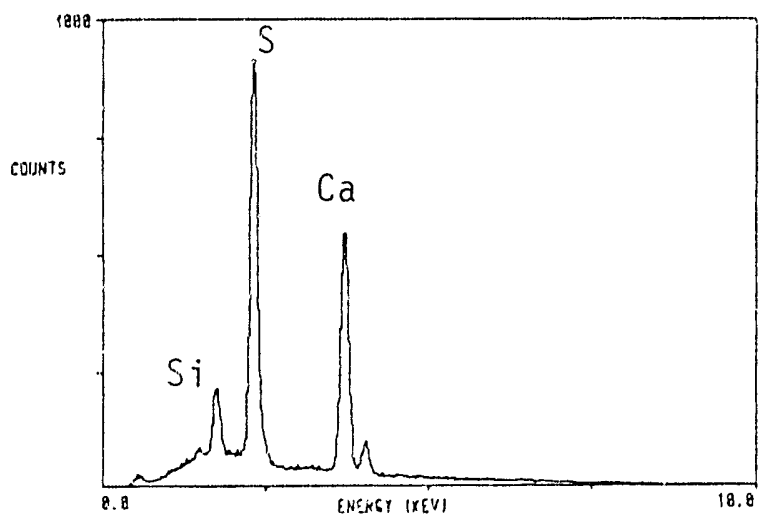

(e)

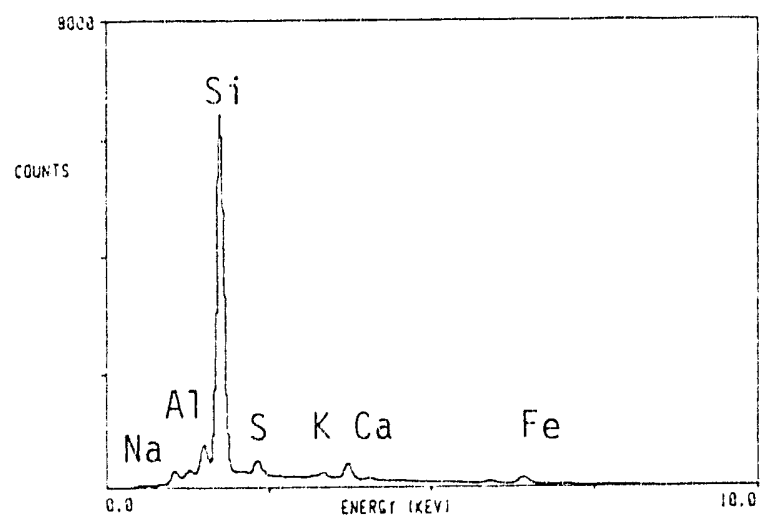

(b)

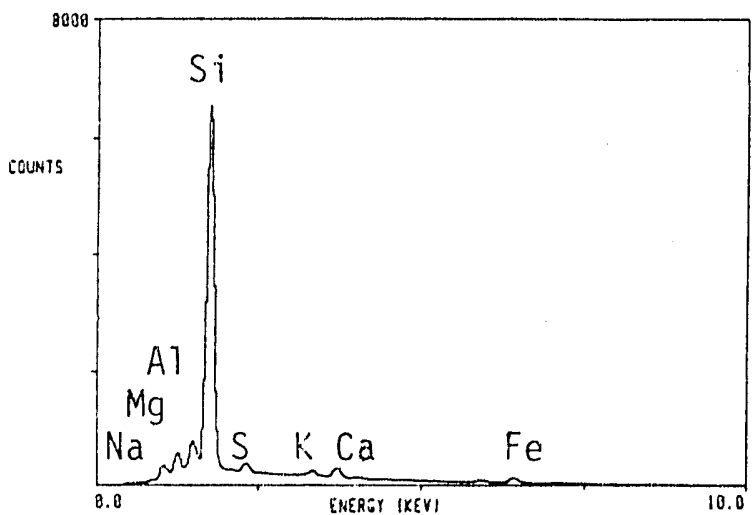

(d)

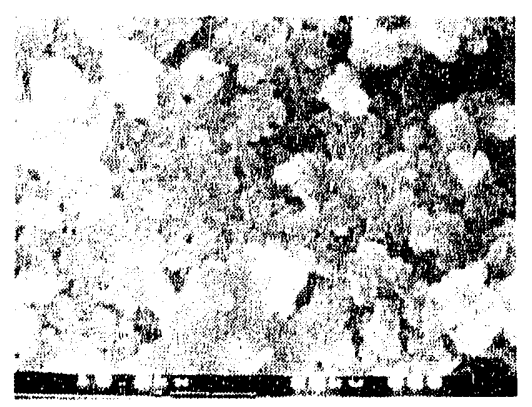

(f)

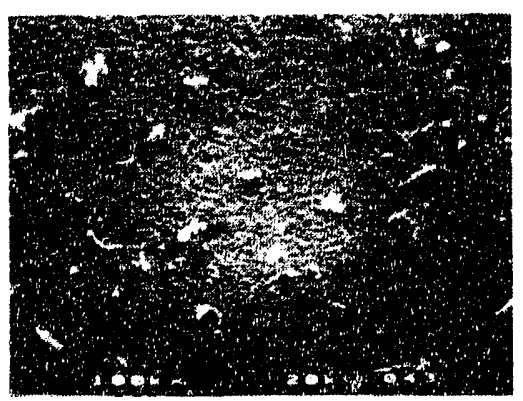

Fig. 3. SEM Micrographs and EDS Spectra of Reaction Products Formed on the Top Suriace of Experiment P-II-5 (26-Week Sample) (a) 2000X, (d) $15,000 \mathrm{X}$, and (f) $100 \mathrm{X}$ 
(a)

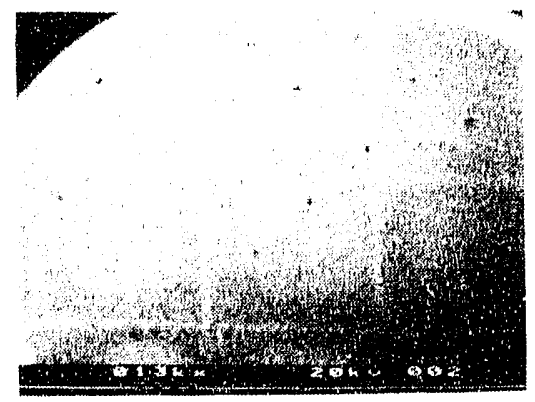

(c)

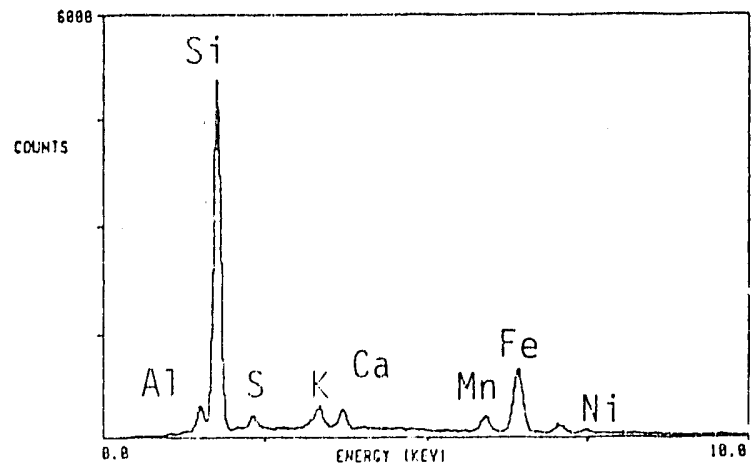

(e)

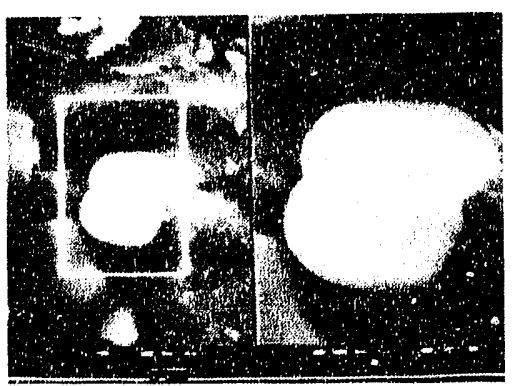

(b)

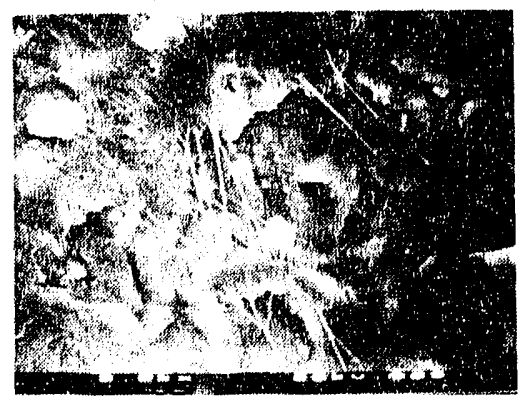

(d)

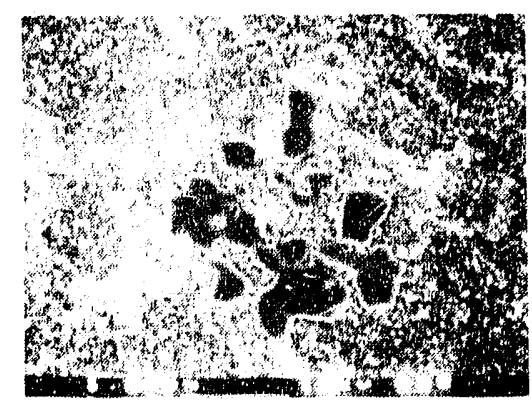

(f)

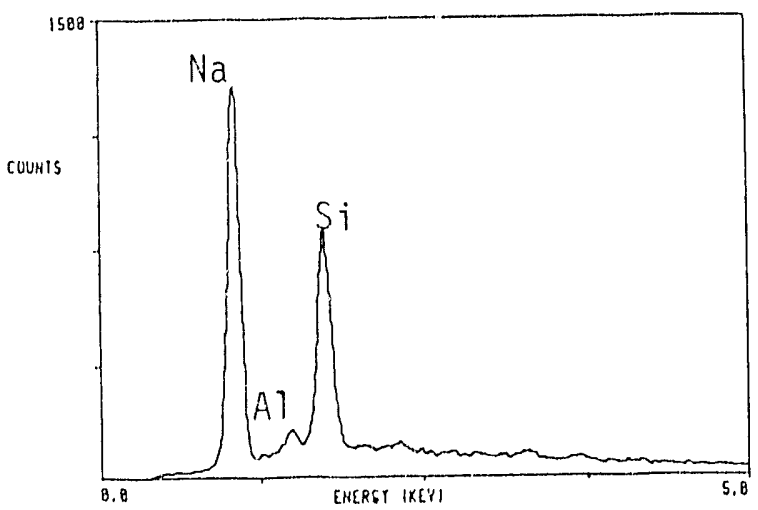

Fig. 4. SEM Micrographs and EDS Spectra of Reaction Products Formed on the Bottorn Surface of Experiment P-II-5 (26-Week Sample) (a) 13X, (b) $2000 \mathrm{X}$, (d) $1930 \mathrm{X}$, and (e) $4200 \mathrm{X} / 8400 \mathrm{X}$ 
(a)

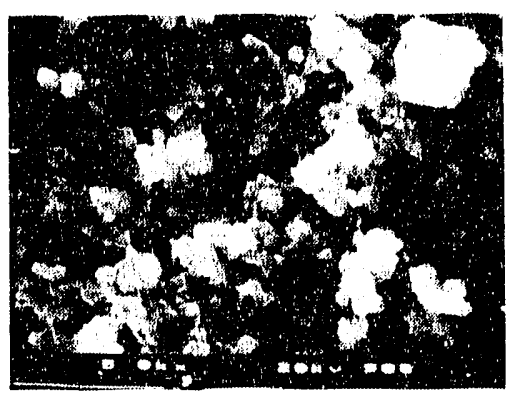

(b)

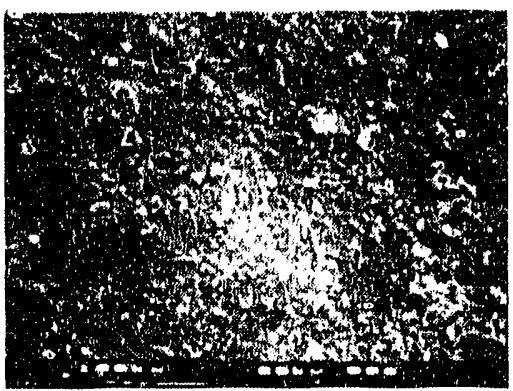

(c)

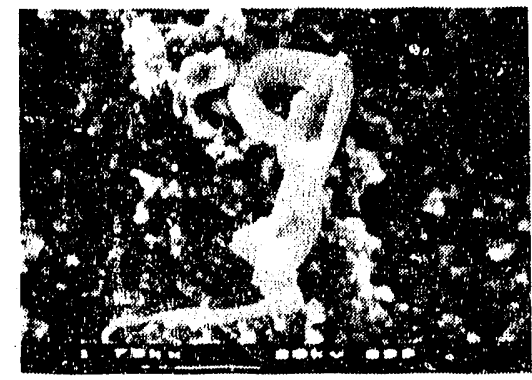

Fig. 5. SEM Micrographs of Reaction Products Formed on the Top Surface of Experiment P-II-7 (52-Week Sample) (a) 5000X, (b) 100X, and (c) $1750 \mathrm{X}$

The bottom surface has a coarse texture similar to that observed on the top surface. A fine-grained precipitated deposit covers much of the coarse reacted layer (Figs. 6a and 6b/EDS). It is not a continuous deposit and it has a porous structure visible at high magnification. Its composition is essentially the same as the coarse reacted layer (compare Figs. 6b/EDS and 6c/EDS). In places, both the precipitated deposit and the reacted layer have exfoliated, exposing etched glass from below (Fig. 6d). The presence of precipitates on the exposed glass indicates that exfoliation occurred during the experiment rather than after termination. Many small grains of $\mathrm{NaCl}$ are present (Figs. 6e and 6f/EDS).

\section{Solution Analyses}

The elemental releases from the two continuous experiments are presented in Fig. 7. Selected element releases normalized for glass composition and sample surface area are given in Table 7. All raw and corrected solution data are presented in Appendix I for both the continuous and batch experiments.

The release of $\mathrm{Li}, \mathrm{B}$, and $\mathrm{U}$ can be used to monitor glass reaction because they occur in low concentration in the J-13 water. In addition, they are not generally observed to be incorporated in secondary phases. ${ }^{11}$ However, some caution must be exercised since tincalconite (hydrated Na-borate) has been detected on the surface of steam-reacted West Valley glass. ${ }^{11}$ The $\mathrm{Li}$ release in both continuous experiments is similar being released at a slowly declining rate over the course of the experiments, reaching a cumulative value of $\sim 67 \mu \mathrm{g}$ after 301 weeks. The release observed in the batch experiments, which includes a final rinse component not present in the continuous experiments, is only slightly greater than observed in the continuous experiments. The release of $\mathrm{Li}$ normalized to the total surface area of the sample and its concentration in the glass is $-2.5 \mathrm{~g} / \mathrm{m}^{2}$ after the 301 -week sampling. Boron release is distinctly different from that of $\mathrm{Li}$. Up through the 210-week period in the two 
(a)

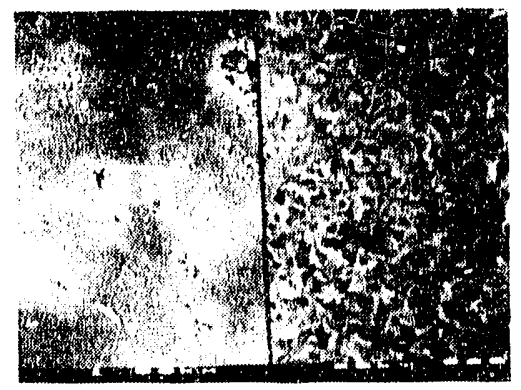

(c)

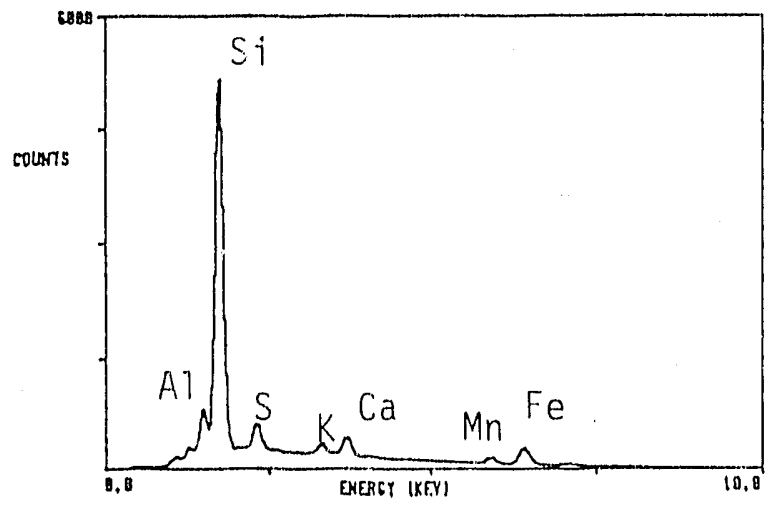

(e)

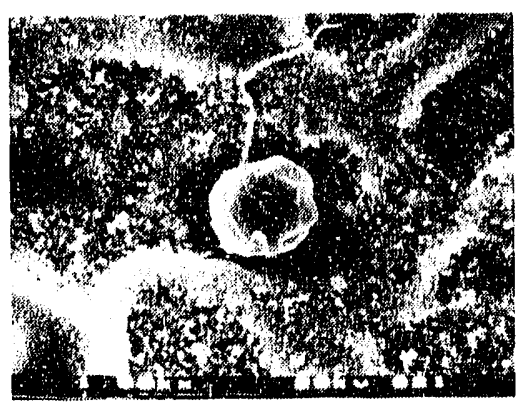

(b)

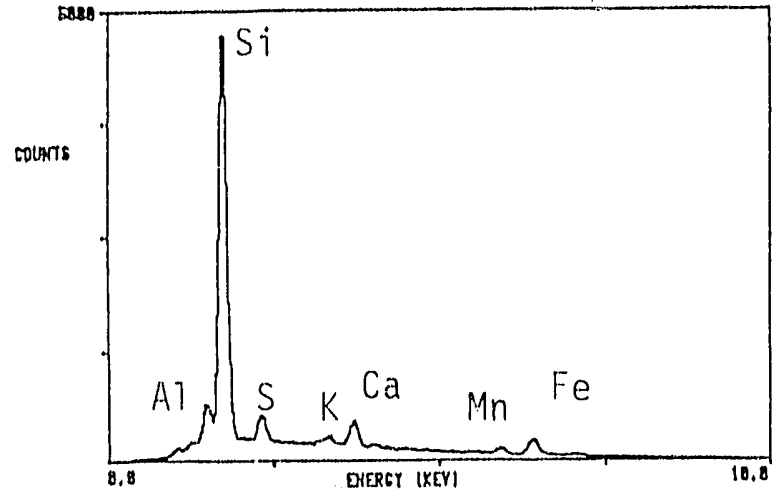

(d)

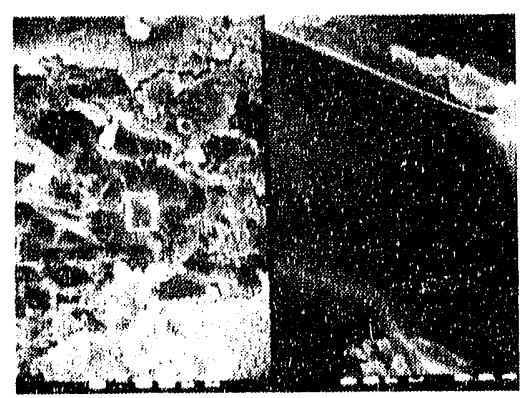

(f)

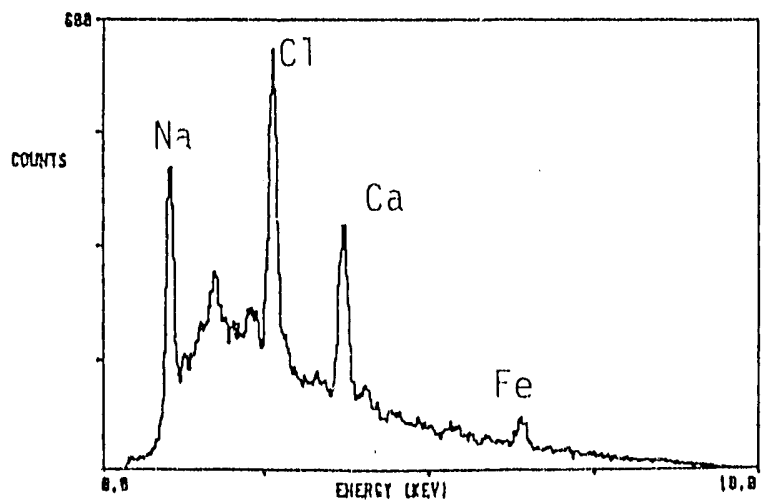

Fig. 6. SEM Micrographs and EDS Spectra of Reaction Products Formed on the Bottom Surface of Experiment P-II-7 (52-Week Sample)

(a) $1000 \mathrm{X} / 10,000 \mathrm{X}$, (d) $500 \mathrm{X} / 5000 \mathrm{X}$, and (e) $1500 \mathrm{X}$ 
(a)

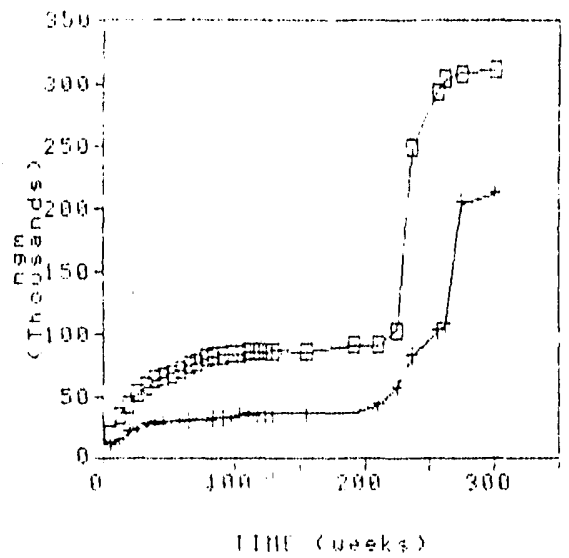

(c)

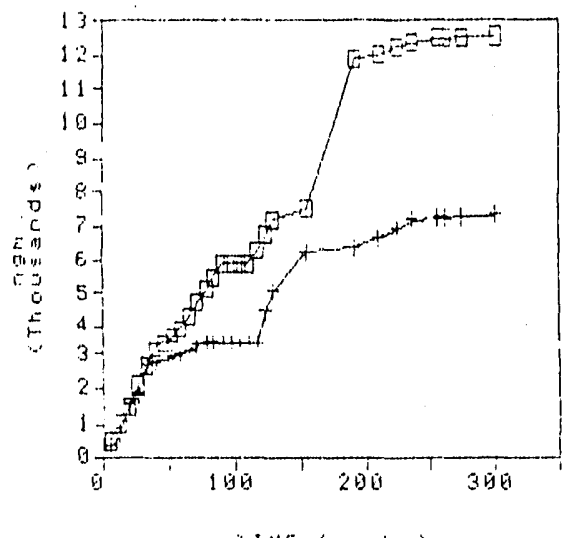

(e)

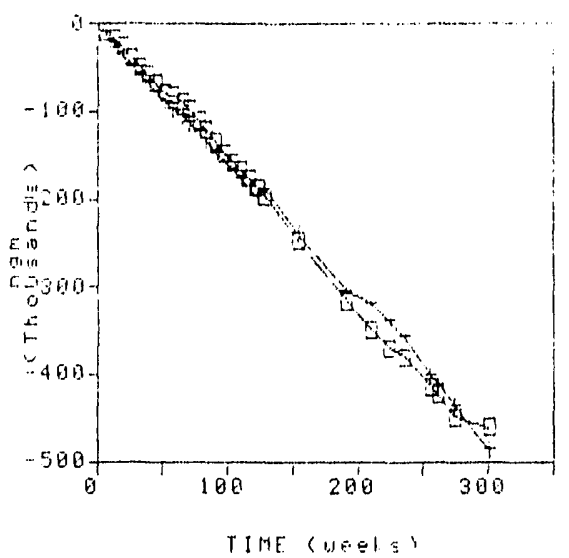

$(\mathrm{g})$

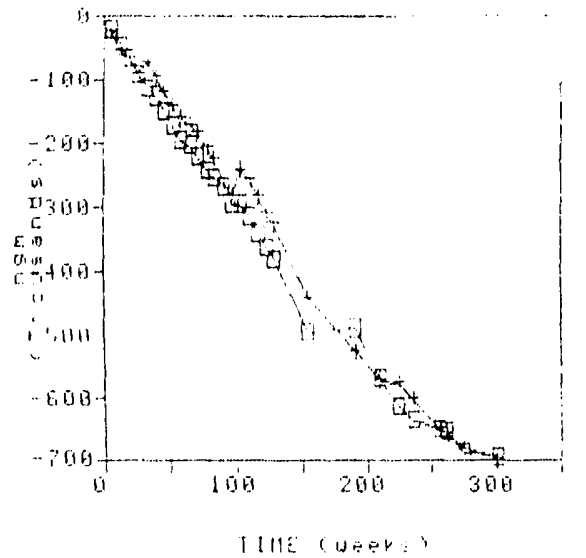

(b)

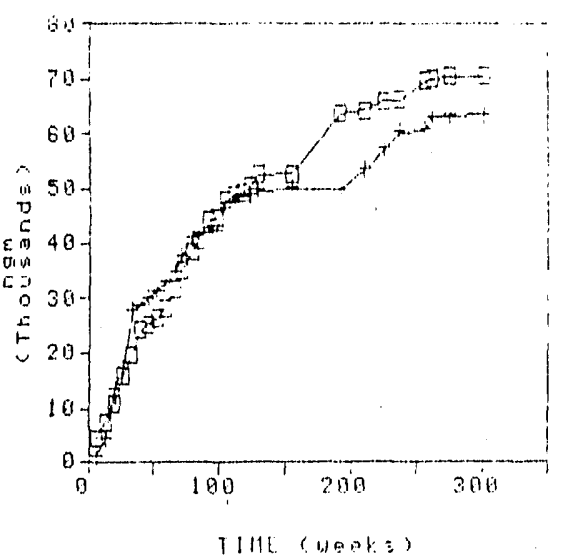

(d)

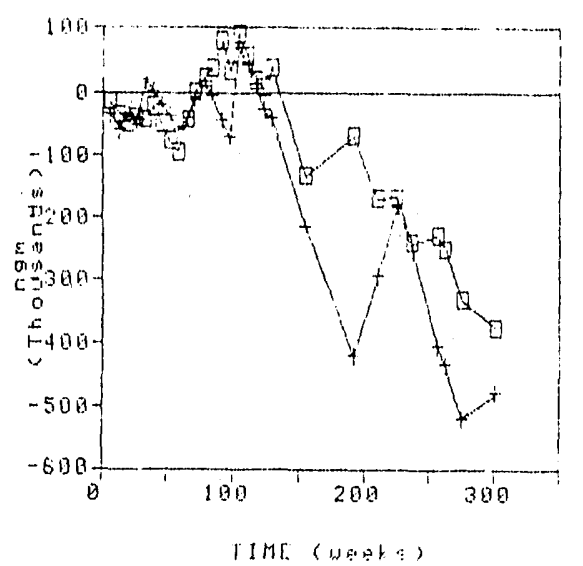

(f)

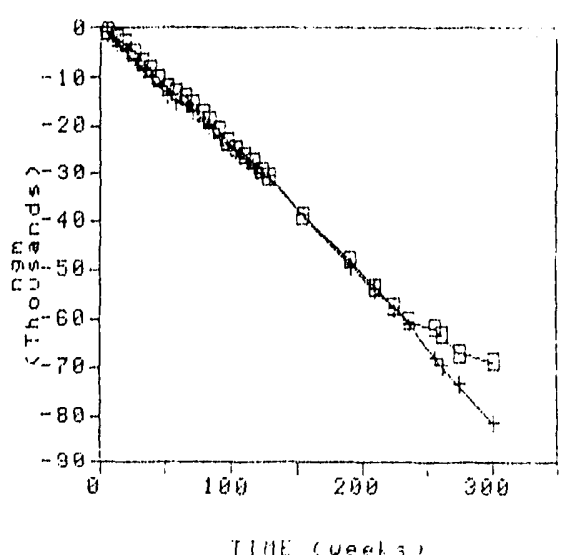

Fig. 7.

Cumulative Release for Selected Elements from the P-II-1 and P-II-2 Continuous Experiments. (a) Boron, (b) lithium, (c) uranium, (d) sodium, (e) calcium, (f) magnesium, and (g) silicon 
Table 7. Normalized Release in the P-II Series

\begin{tabular}{lcccc}
\hline & & \multicolumn{3}{c}{ Normalized Releas: $\left(\mathrm{g} / \mathrm{m}^{2}\right)$} \\
\cline { 3 - 5 } Test \# & $\begin{array}{c}\text { Period } \\
\text { (weeks) }\end{array}$ & $\mathrm{B}$ & $\mathrm{Li}$ & $\mathrm{U}$ \\
\hline P-II-3 & 6 & 0.3 & 0.4 & 0.07 \\
P-II-4 & 13 & 0.9 & 0.9 & 0.16 \\
P-II-5 & 26 & 0.4 & 0.8 & 0.14 \\
P-II-6 & 39 & 0.8 & 1.1 & 0.27 \\
P-II-7 & 52 & 0.9 & 1.6 & 0.77 \\
& & & & \\
P-II-1 & 52 & 2.4 & 1.0 & 0.32 \\
& 104 & 3.0 & 1.8 & 0.53 \\
& 155 & 3.0 & 2.0 & 0.68 \\
& 210 & 3.2 & 2.5 & 1.10 \\
& 262 & 10.8 & 2.7 & 1.14 \\
& 301 & 11.0 & 2.7 & 1.14 \\
P-II-2 & 52 & 1.0 & 1.2 & 0.26 \\
& 104 & 1.2 & 1.8 & 0.31 \\
& 155 & 1.3 & 1.9 & 0.57 \\
& 210 & 1.5 & 2.1 & 0.61 \\
& 262 & 3.8 & 2.4 & 0.65 \\
& 301 & 7.6 & 2.4 & 0.66 \\
\hline
\end{tabular}

continuous experiments, B release leveled off. This was followed by a sharp incrcase in rclease. This increase coincides with the time when the vessels were morlified to reduce fluid loss. After 301 weeks, release in the P-II-1 experiment is about $50 \%$ greater than in P-II-2. There are two possible explanations for this behavior. The first is that little or no reaction took place between 80 and 200 weeks due to vapor loss. Reaction then resumed once the vessel design was modified to retain more water. This is unlikely since the release of $\mathrm{Li}$ indicates that reaction continued throughout the entire duration of experiments. An alternative is that a B-bearing phase precipitated and then dissolved once more water was retained. As the continuous experiments are still ongoing, it is not yet possible to verify this contention.

There is a slow, steady release of $U$ throughout the 301-week duration of the experiments. Like $\mathrm{B}$, the release of $\mathrm{U}$ is about $50 \%$ greater in the P-II-1 experiment. It is not clear why this difference exists, although it is probably attributable to differing degrees of water retention in the two experiments. 
There is a distinct and regular net negative release of $\mathrm{Ca}, \mathrm{Mg}$, and $\mathrm{Si}$. This indicates that these elements were removed from solution during the experiment. This is consistent with the observed occurrence of calcite and gypsum on a Si-rich surface layer on samples from the batch experiments. This behavior suggests that some of the surface layer has formed by precipitation rather than transformation of the glass. Sodium also has a net negative release but its behavior is erratic. This may be the result of periodic precipitation and subsequent redissolution of $\mathrm{NaCl}$ and $\mathrm{Na}_{2} \mathrm{CO}_{3}$. The behavior of these elements demonstrates that the J-13 water plays a role in the formation of the secondary phases.

\section{B. P-III Lixperiments}

The glass surface area is the modified parameter in these experiments. The surface area is reduced by $\sim 50 \%$ by shortening the glass cylinders. The area ratio of the "as cut" top and bottom surfaces to the side is reduced from $\sim 2.6$ to 0.8 . The stainless steel components are from heat \#22841. The metal was not heat ti- ated except for the two TIG welds that join the supporting pins to tha bottom pinit of the holder.

This set of experiments was initiated on $12 / 6 / 84$ and the continuous experiments are still in progress, having completed the 260-week sampling. The experiments were performed at $90^{\circ} \mathrm{C}$ with an injection volume of $0.075 \mathrm{~mL}$ of EJ-13 water everv 3.5 days. The batch experiments were terminated in duplicate after 13, 26, 39, nd 52 weeks. The continuous experiments were sampled every 6.5 weeks through the 78 th week and then about every 13 weeks thereafter. Two different batches of EJ-13 water were used, the compositions of which are given in Table 4. The change in EJ-13 water was on 10/1/86. The experimental matrix, along with selected weight change data, are presented in Table 8.

\section{General Observations}

(a) The WPA generally lost weight during the experiments. In most cases, the metal components gained a small amount of weight, presumably from precipitating phases; however, this gain was much less than the amount lost from the glass (Table: 8). The one exception to this behavior is P-III-9 which. showed a small net increase in weight.

(b) The top glass was always damp during sampling of the continuous experiments and termination of the batch experiments. The amount of water varied from being only at the rims of the metal perforations in the metal to almost filling the noncontact areas.

(c) Standing water was present on the bottom surface of the WPA. In some cases, water bridged the gap between the metal support posts and the side of the glass.

(d) Both the top and bottom metal components showed no local discoloration after the experiments. This suggests that reaction of the metal was minimal. 


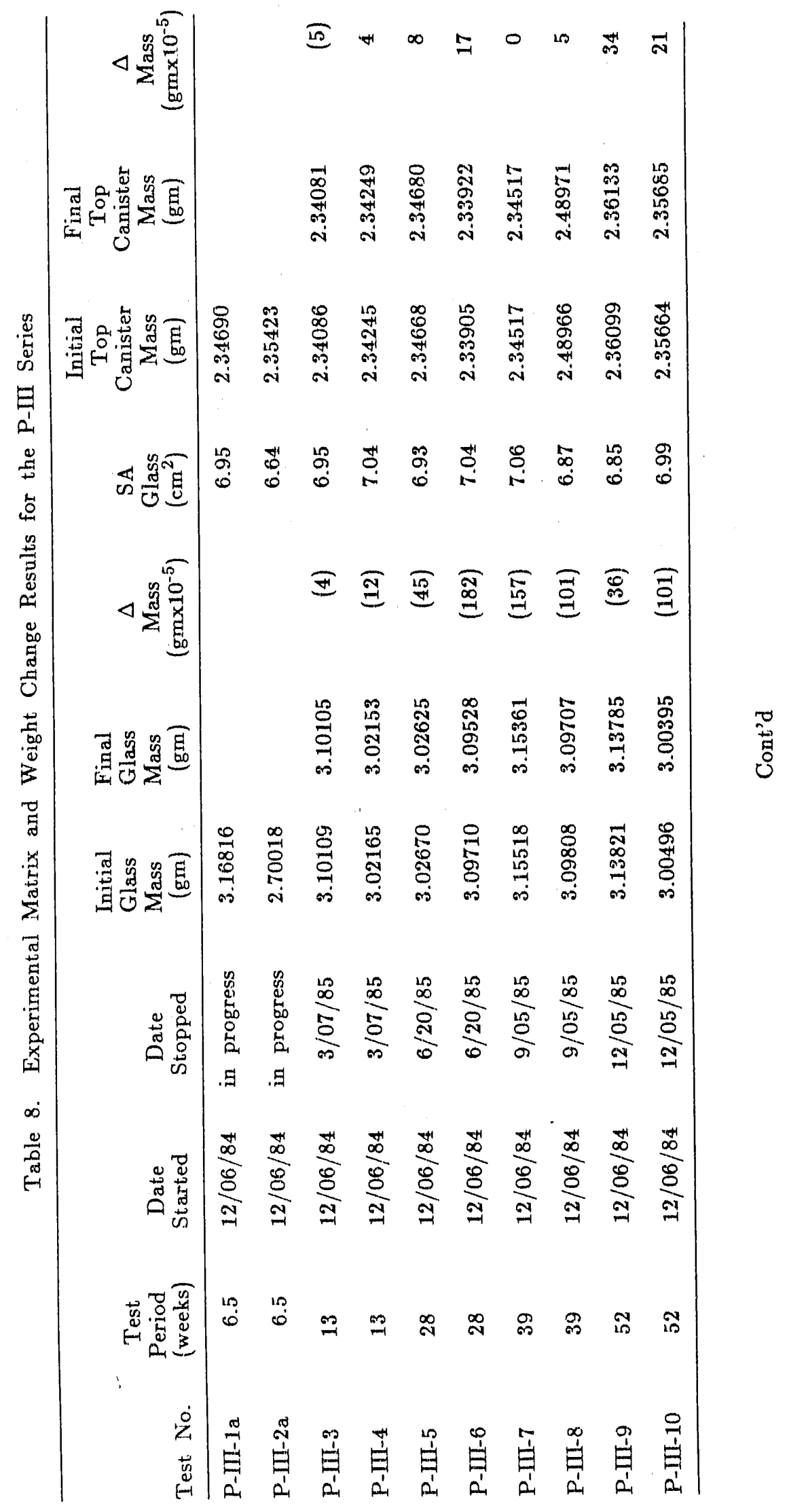




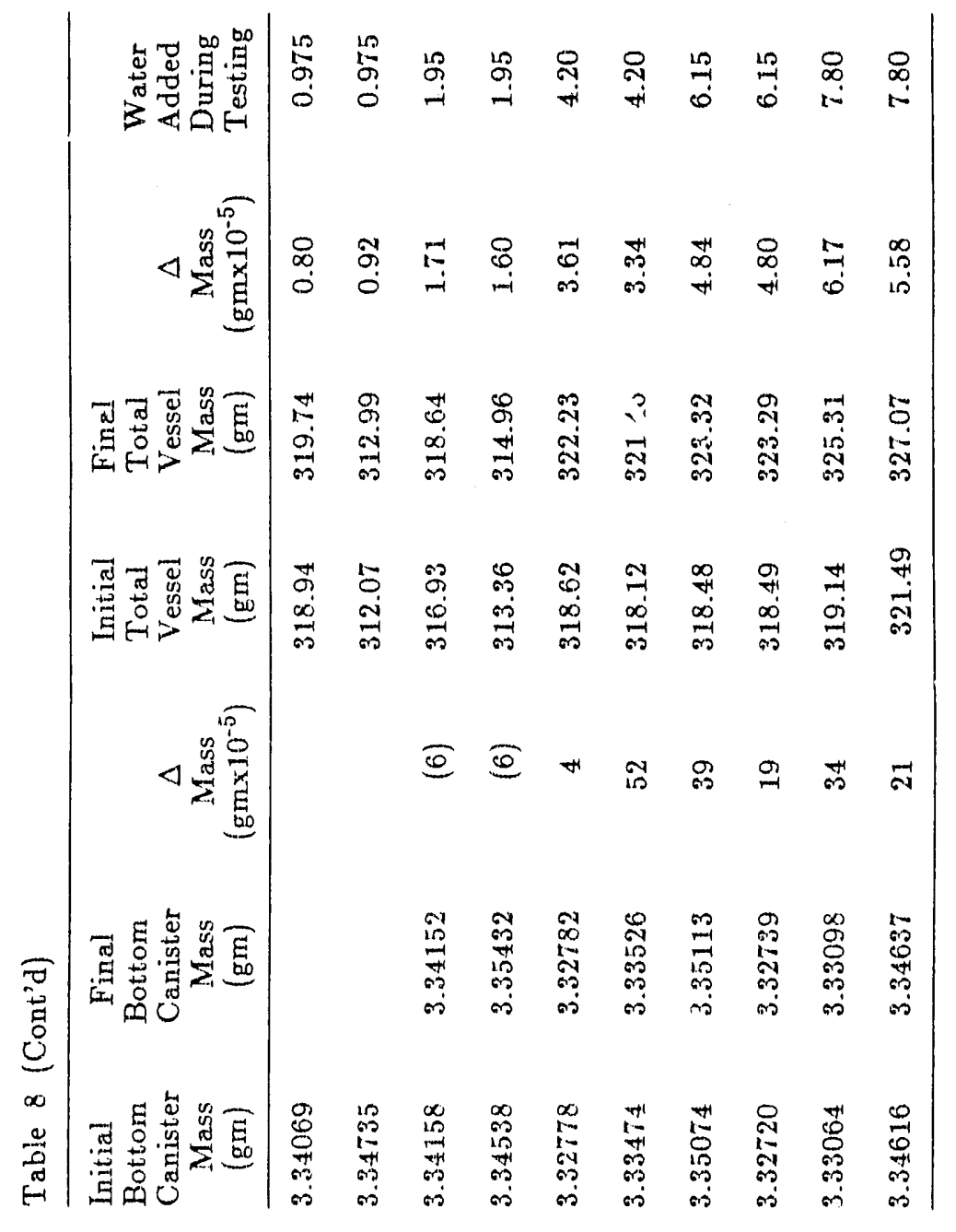




\section{Component Analysols}

The glass and metal components were first examined optically up) to a magnification of 140X. At this time, surface features were mapped and areas for further investigation were identified. Some samples were examined by SEM/EDS/WDS and/or SIMS. At least one sample from each experiment was examined.

\section{a. P-III-3 and P-III-4, 13-Week Samples}

The metal components of the P-III-3 and P-III-4 samples aro very similar in appearance. The parts of the components not in direct contact with the glass have no evidence of accelerated reaction. In the areas where glass contact occurred, there is a thin Si-rich mat developed (Tig. 8a, 8b/EDS). Its texture is essentially the same as that observed on the glass (see below). In a few places this mat forms thicker clumps (Figs. 8c, 8d/EDS, 8e, and 8f/EDS). Overall, precipitate coverage is heavier on the bottom component. Aside from the Si-rich deposit, other precipitated phases include chloride ( $\mathrm{NaCl}$ ?) and sulfates $\left(\mathrm{CaSO}_{4}\right.$ ?) as shown in Figs, 8e, 8f/EDS, 8g, and 8h/EDS. Note the small Ca and $S$ peaks in the EDS spectrum in Fig. 8f/EDS. This suggests the

intermingling of phases at a very fine scale. There are also some small irregularshaped masses rich in $\mathrm{Na}$ (Figs, $8 \mathrm{i}$ and $8 \mathrm{j} / \mathrm{EDS}$ ). These are electron beam sensitive and are similar to that observed on the P-II samples which were tentatively identified as $\mathrm{Na}_{2} \mathrm{CO}_{3}$ (compare Fig. \&i with Figs, 4d and 4e).

The bottom glass surface has partially defined regions of metal and nonmetal contact. This duality in appearance suggests that there was not close metal-glass contact over the entire surface. The contact and noncontact regions have the same appearance where the "as cut" contours of the glass are still clearly defined but the surface appearance has been transformed from a smooth fractured surface to one covered with an interwoven phase with a "cardhouse" texture (Fig. 9a). Its texture and composition are consistenit with a. smectite clay (Figs. 9b/EDS and 9c/EDS). Small precipitates are present in crevices and fractures on the glass surface (Fig. 9d). From EDS analysis, these range in composition from only containing $\mathrm{Si}$ to having $\mathrm{Si}$ and $\mathrm{Al}$ to having $\mathrm{Si}$, Al, Cr, and Mn. (Figs. 9e/EDS, 9f/EDS, and 9g/EDS). This apparent compositional range may be attributable to the presence of multiple phases at a fine scale.

On the top glass surface, the noncontact areas are clearly defined as light gray to tan circular regions set on a dark brown-black background. The contact areas (with the metal component) have the same textured appearance as observed on the bottom glass (Fig. 9a), but the noncontact areas either retain an unreacted appearance or show incipient development of a textured layer (Fig. 9d). EDS spectra taken from all regions of the top surface are similar to unreacted glass. 
(a)

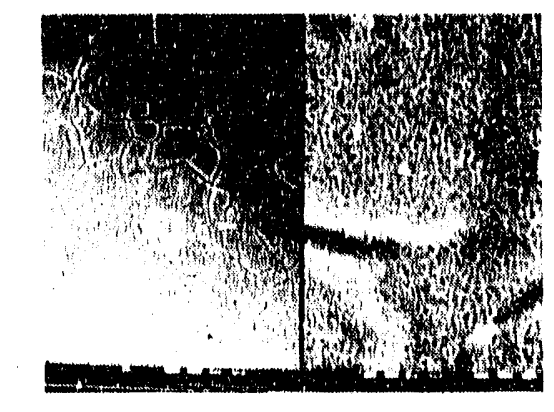

$1000 \mathrm{X} \quad 10,000 \mathrm{X}$

(c)

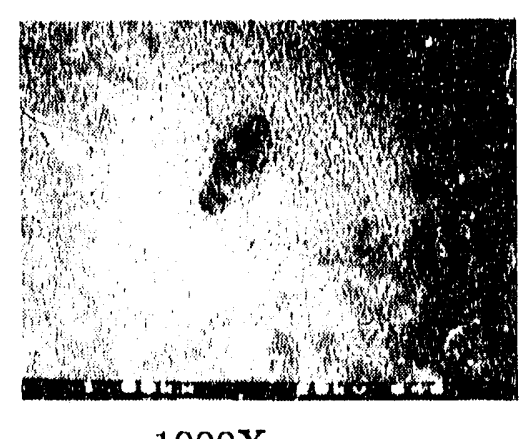

$1000 \mathrm{X}$ (b)

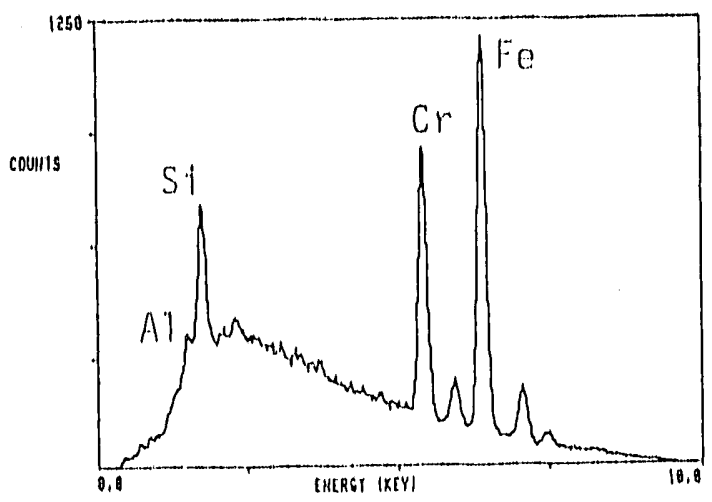

(d)

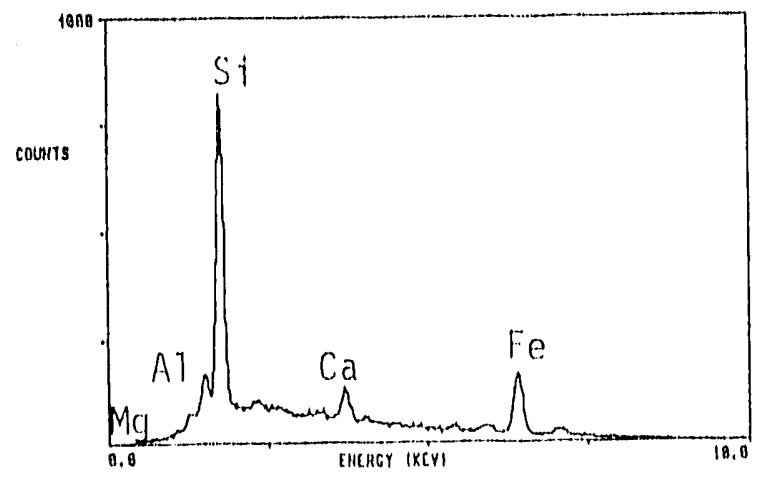

Fig. 8. SEM Micrograph and EDS Spectrum of ( $a$ and b) the Metal Surface in Contact with Glass from the Top Section of the Waste Form Holder in Experiment P-III-4; (c and d) Clumps of the Mat Matierials that Formed on the Top and Bottom Metal Sections from Experiment P-III-4; (e-j) Reaction Products Observed on the Bottom Metal Section from Experiment P-III-4. 
(e)

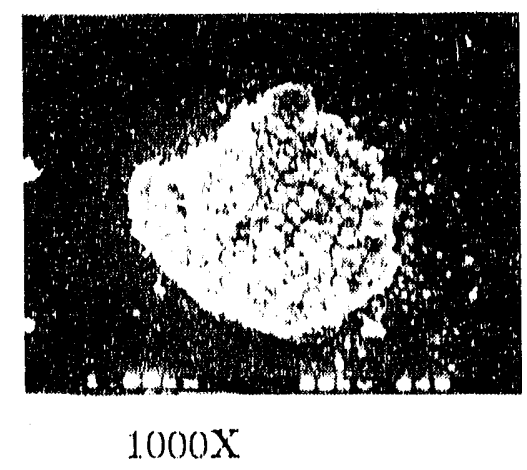

(g)

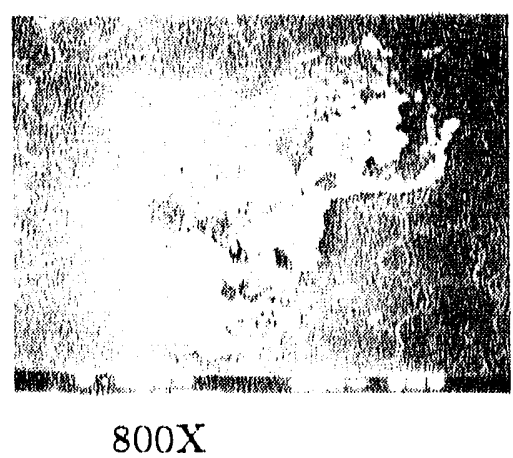

(i)

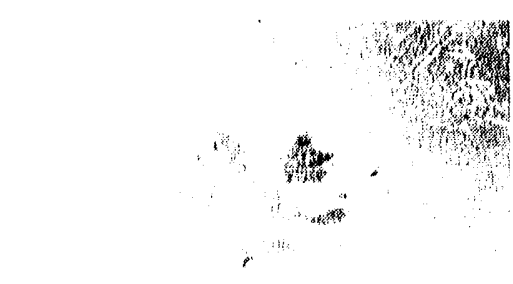

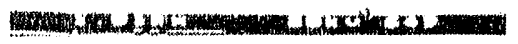

$1010 \mathrm{X}$ (f)

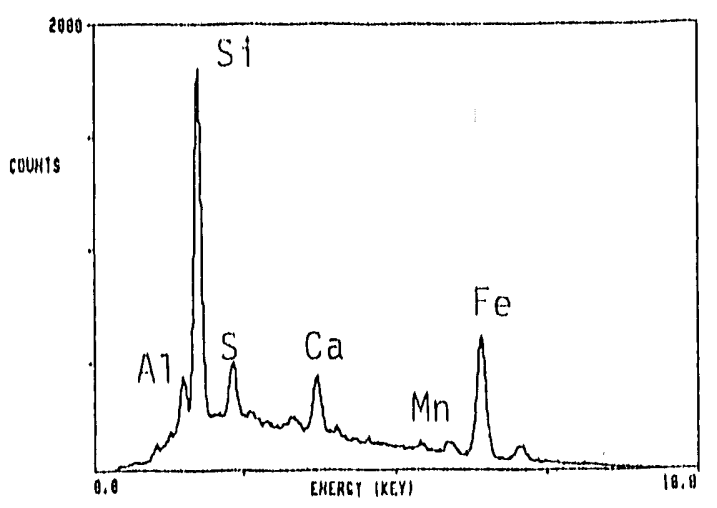

(h)

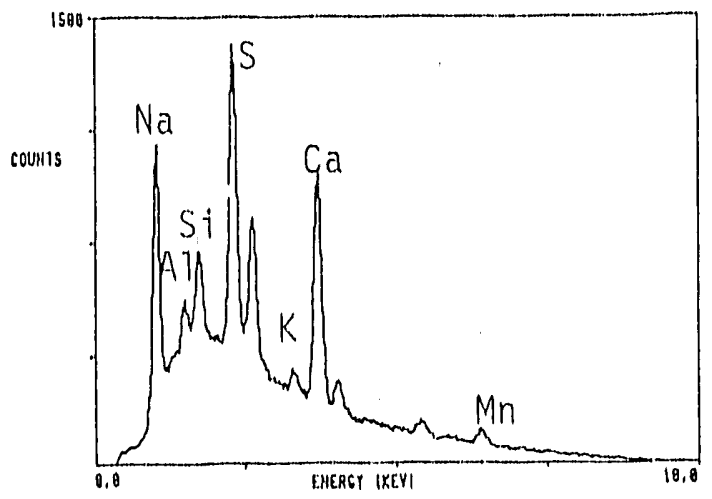

(j)

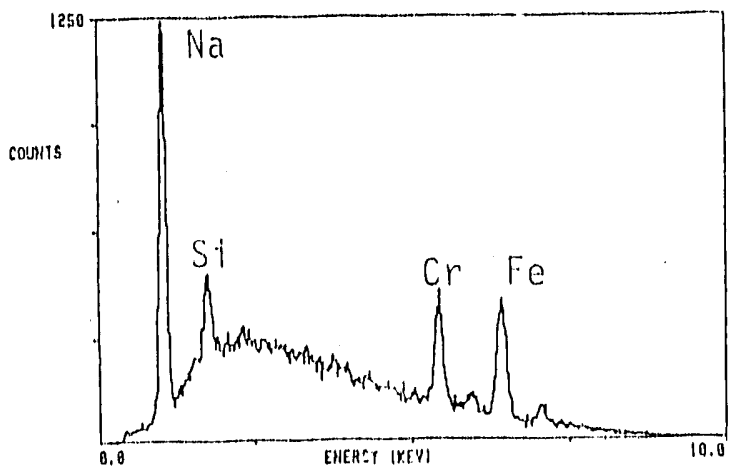

Fig. 8. Cont'd 
(a)

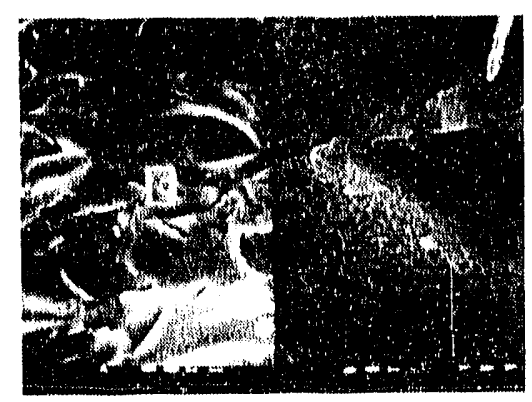

(c)

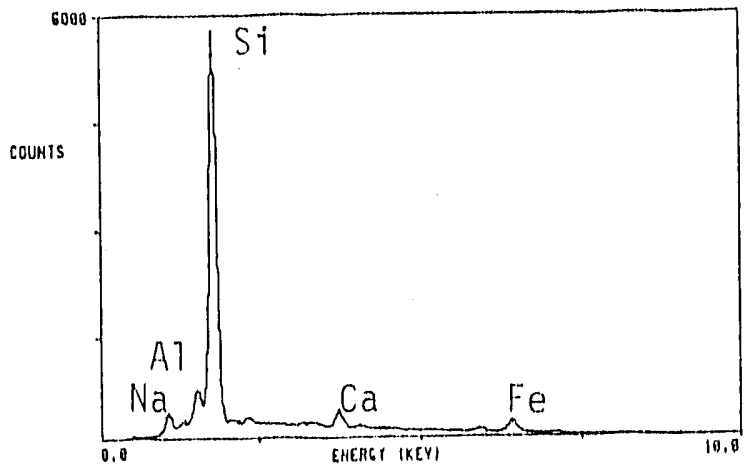

(b)

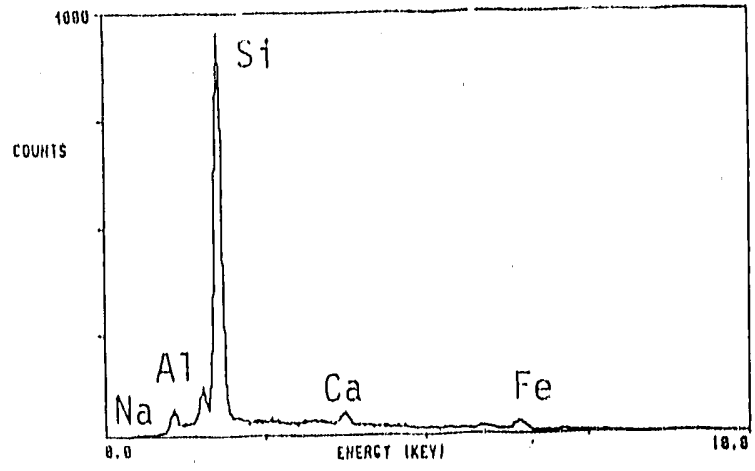

(d)

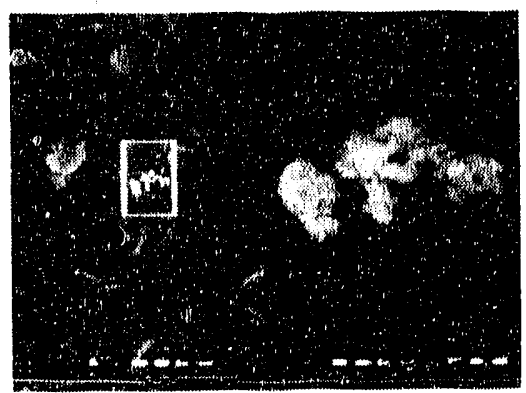

Fig. 9. SEM Micrographs and EDS Spectra of Reaction Products on the Bottom Surface of the Glass from Fxperiment P-III-4. This is typical of both metal contact and noncontact regions. (a) $1000 \mathrm{X} / 10,000 \mathrm{X}$. EDS spectra of the contact and noncontact regions are shown in (b) and (c), respectively, (d) $1000 \mathrm{X} / 10,000 \mathrm{X}$ (see text) 
(e)

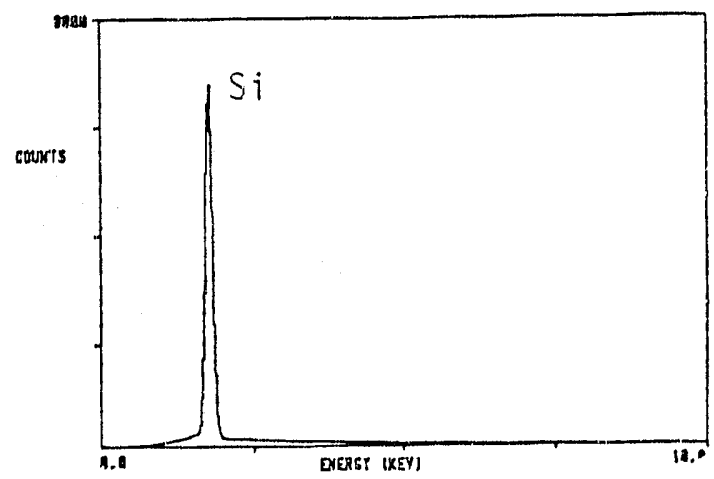

(g)

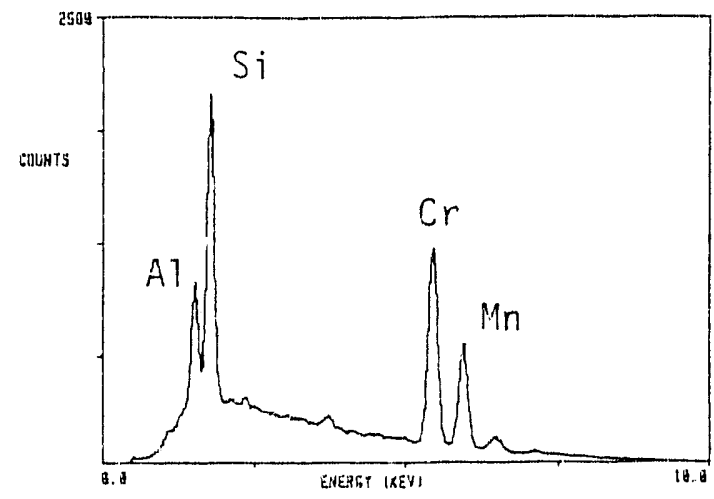

(f)

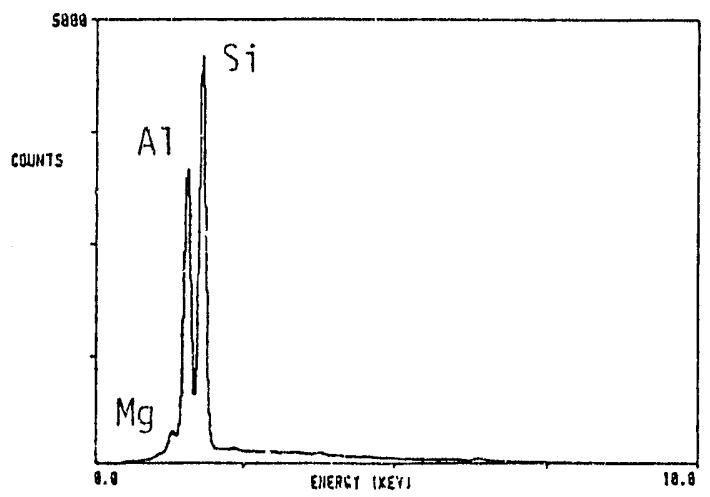

(h)

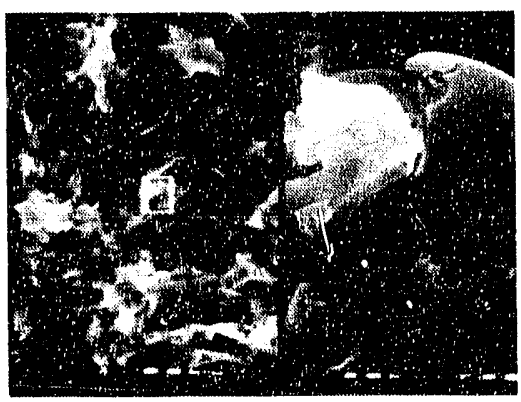

Fig. 9. Cont'd

SEM Micrograph and EDS Spectra of Reaction Products on the Bottom Surface of the Glass from Experiment P-III-4. (h) $1000 \mathrm{X} / 10,000 \mathrm{X}$ view of noncontact area 
SIMS depth profiling was performed on the P-III-3 glass. The profiles are normalized to ${ }^{28} \mathrm{Si}$ intensity. The normalization is a standard technique used to account for variations in the sputtering conditions. As a result, the profiles only show preferential depletion or enrichment relative to $\mathrm{Si}$ which is the most abundant component in the glass. Depth profiles of $\mathrm{Li}, \mathrm{B}$, and $\mathrm{Mg}$ from the contact and noncontact areas of the bottom glass and from the side glass are presented in Fig. 10. In all cases, $\mathrm{Li}$ is depleted to a depth of at least $1 \mu \mathrm{m}$. The depletion is not sharp, but instead is of a gradual nature. Boron is also depleted on the bottom surface but it appears to be restricted to the outer $0.3 \mu \mathrm{m}$ (see mark on Fig. $3 \mathrm{~b}$ profile). No B depletion is apparent on the side glass surface, however. Relative to $\mathrm{Si}$, the distribution of $\mathrm{Mg}$ is constant.

In summary, the extent of reaction is greatest on the bottom surface and least on the sides. Depletion of $\mathrm{Li}$ appears to occur to a greater depth than B. Precipitation of Si-rich "clay" and other phases occurs on both the metal and glass components. This masks the original concoidally fractured appearance of the glass surfaces.

\section{b. P-III-5 and P-III-6, 26-Week Samples}

The metal components have the same general appearance as that described for sample P-III-4. The noncontact-contact boundaries are well defined. A Si-rich deposit covers the metal especially where it was in contact with the glass and is much thicker on the P-III-6 components. Development of this deposit is greatest on the bottom component in the contact areas and in the noncontact areas where standing water was present during the experiment

(Fig. 11a). This Si-rich material also occurs in clumps. Some of these clumps contain a mixture of phases which may be rich in Ti, Cl, and/or S (Figs. 11b, $11 \mathrm{c} / \mathrm{EDS}, 11 \mathrm{~d}$, and $11 \mathrm{e} / \mathrm{EDS})$. The presence of anhydrite or gypsum is suggested by the $\mathrm{Ca}$ and $\mathrm{S}$ peaks in the EDS spectrum shown in Fig. 11e/EDS. A U-bearing phase occurs on the noncontact area (Figs. 11f and $11 \mathrm{~g} / \mathrm{EDS}$ ). It contains $\mathrm{Si}$ and $\mathrm{Ca}$ and has an acicular form, suggestive of uranophane. There was not enough material available for XRD analysis.

The top glass surface has no clearly marked circular noncontact regions and the original surface contours are still apparent. The surface is covered by a Si-rich layer similar in composition to that observed on other samples. Clumps of this same material are also present.

The bottom glass surface is megascopically different in appearance from the outer samples. It has a uniform gold-colored haze and the contact and noncontact areas are only partially visible. At higher magnification, the surface has a thick textured surface layer which is somewhat coarser than observed elsewhere (Fig. 12a). Its composition is consistent with a Ca-smectite (Fig. 12b/EDS). The original surface contours are only barely visible and are considerably rounded. In one region, the surface layer is discontinuous, exposing the glass from below (Fig. 12c). Here, it appears that the thick surface layer exfoliated during the experiment and the glass is now partially overgrown by precipitation of Si-rich "clay." A small cluster of yellow grains is also present on the exfoliated surface (Figs. 12d and 12e/EDS). These grains contain $\mathrm{Na}, \mathrm{Ca}$, $S$, and $C$ ! but have not been positively identified. 
(a)

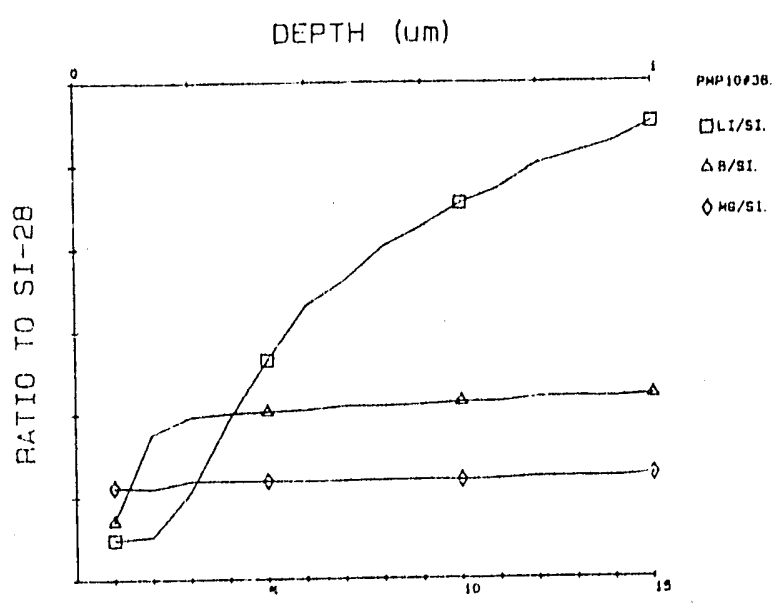

(b)

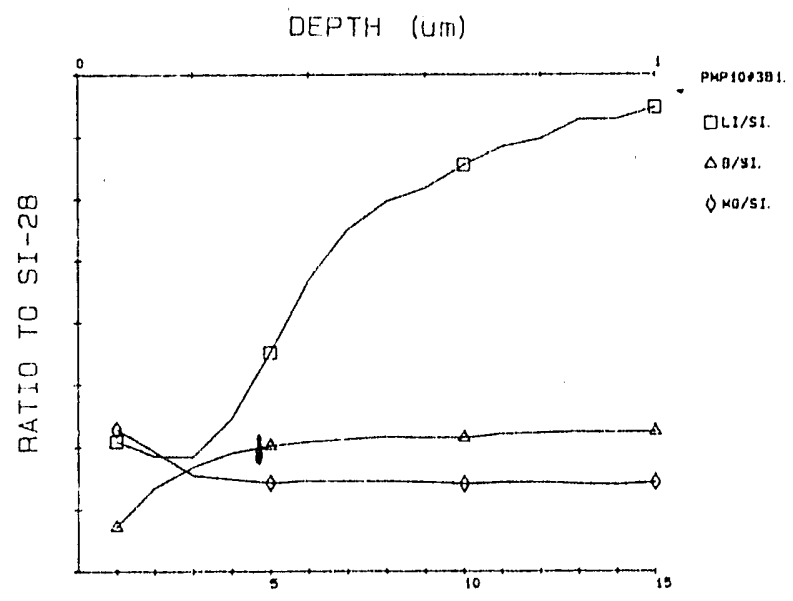

(c)

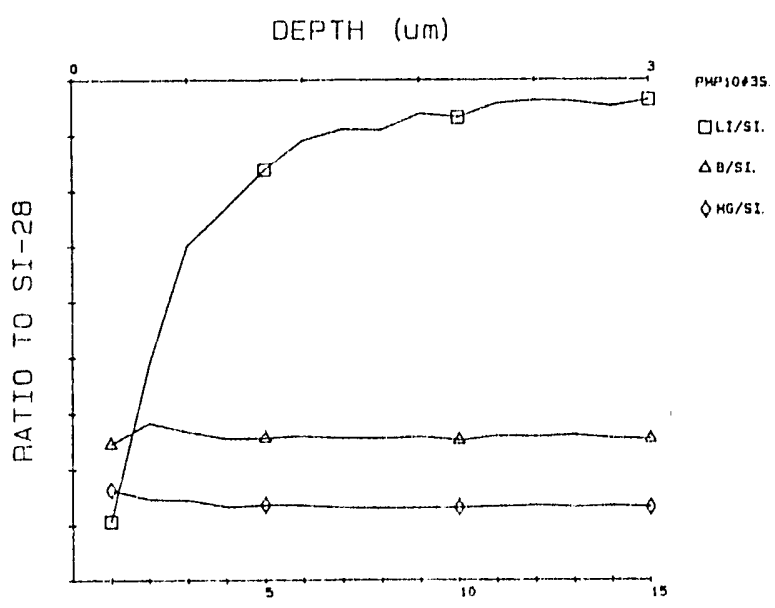

Fig. 10. SIMS Spectra Showing the Profiles of $\mathrm{Li}, \mathrm{Mg}$, and $\mathrm{B}$ Relative to $\mathrm{Si}$ for Sample P-III-3 (a) Bottom Section Non-Metal Contact, (b) Bottom Section Metal Contact, and (c) Side Surface. Note the different depth scale in $(c)$ 
(a)

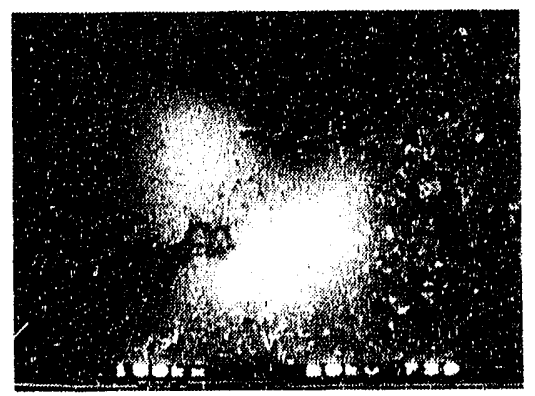

(c)

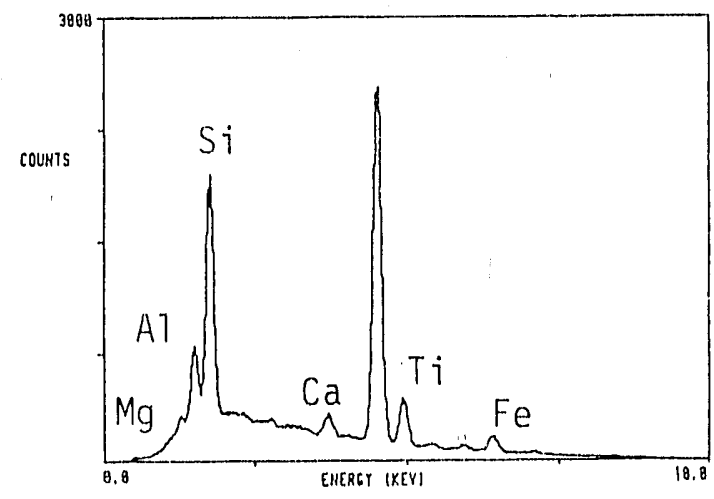

(e)

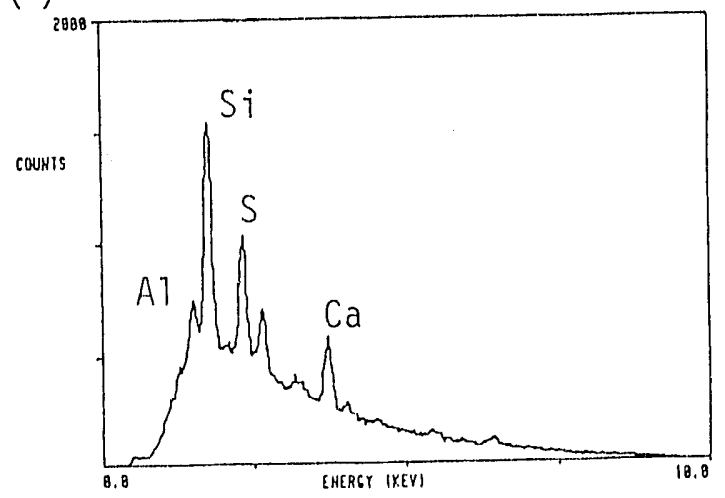

(g)

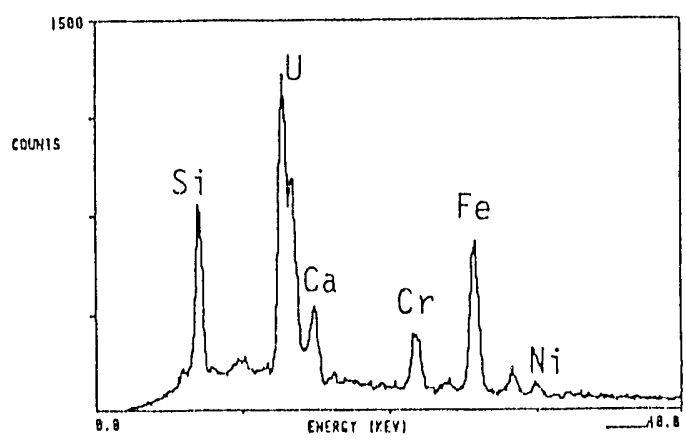

(b)

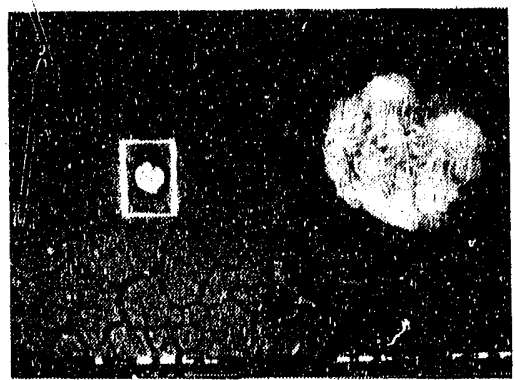

(d)

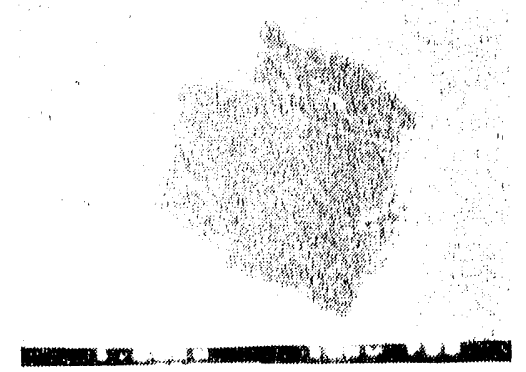

(f)

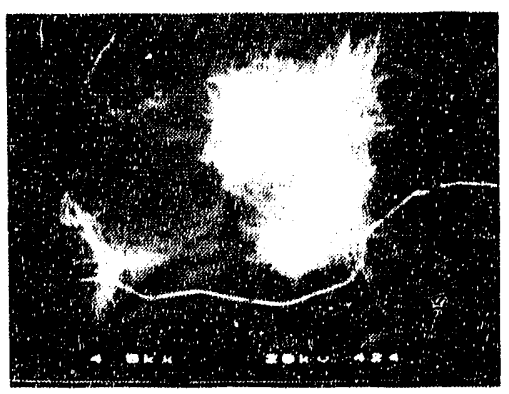

Fig. 11.

SEM Micrographs and EDS Spectra of Reaction Products on the Metal Components of P-III-6. (a) 150X, contact area, (b and c) SEM micrograph (3500X) and EDS spectrum of a Ti-rich alteration product. Note the thick matted appearance of the metal surface. (d) SEM micrograph 1250X of Si-rich alteration product. (e) EDS spectrum of Deposit shown in (d), (f) SEM micrograph of U-ricn phase at $4500 \mathrm{X}$, and (g) EDS spectrum of phase shown in (f). 
(a)

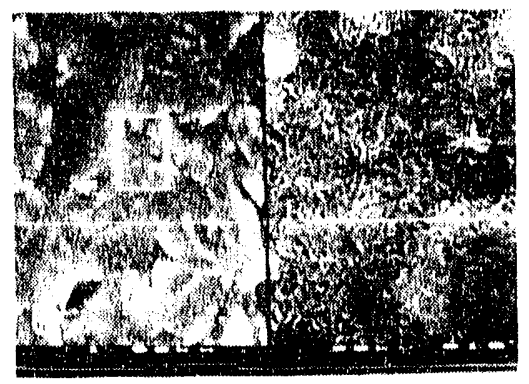

(c)

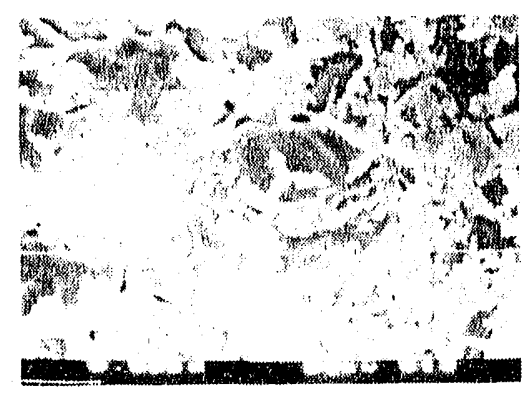

(e)

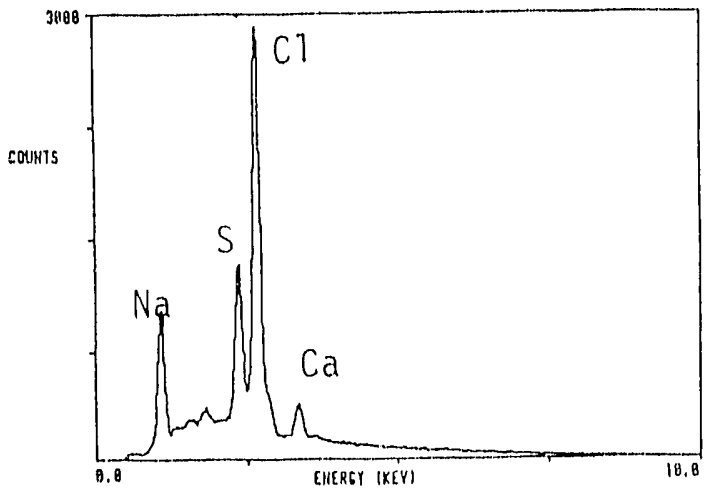

(b)

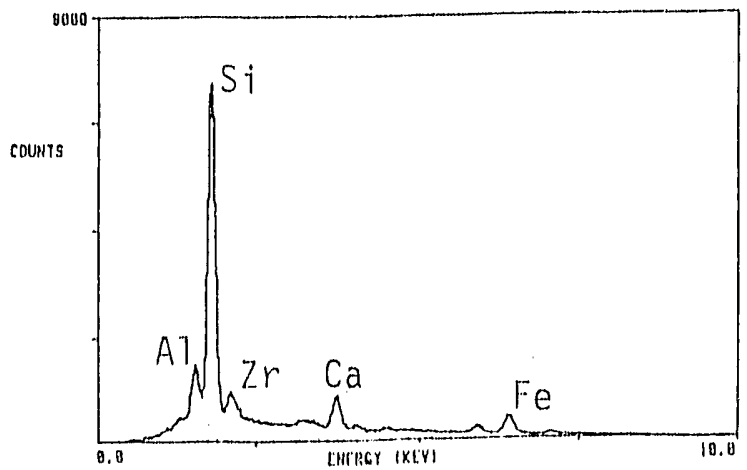

(d)

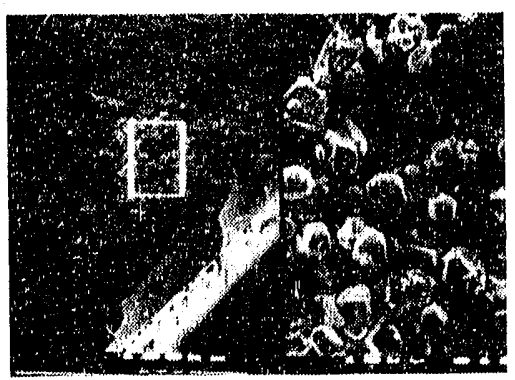

Fig. 12.

SEM Micrographs and Associated EDS Spectra from the Bottom Glass Section from Experiment P-III-6. (a) Reacted contact area $(1000 \mathrm{X} / 10,000 \mathrm{X})$; (b) EDS spectrum of surface in (a); (c) exfoliated, precipitated area $(990 \mathrm{X})$; (d) yellow crystals $(100 \mathrm{X} / 1000 \mathrm{X})$ from near the exfoliated region; and (e) EDS spectrum of yellow crystals. Note the high $\mathrm{Na}$ and $\mathrm{Cl}$ content 


\section{c. P-III-7 and P-III-8, 39-Week Samples}

Sample P-III-8 visually appears to be somewhat more altered so it was investigated further by SEM/EDS. A Si-rich deposit, probably smectite, occurs on both the contact and noncontact regions of the top metal component. The noncontact-contact boundary is well marked (Fig. 13a). The Si-rich deposit also occurs in clumps, some of which contain $\mathrm{Mn}, \mathrm{Cr}$, or $\mathrm{Fe}$ (Figs. $13 \mathrm{~b}$ and $13 \mathrm{c} / \mathrm{EDS})$. Based upon numerous EDS spectra, the Al content appears to be somewhat variable. A Ti-rich phase occurs rarely and seems to be intimately associated with clumps of Si-rich "clay" (Fig. 13d/EDS). It may be anatase $\left(\mathrm{TiO}_{2}\right)$, but XRD analysis was not possible to confirm this.

The bottom metal component is discolored in areas around the support pin welds, but there is no indication of glass-metal reaction. The noncontact-contact boundary is well defined. Like the top component, a Si-rich deposit also covers the bottom metal piece. Clumps of precipitates are extensively developed, many of which have the same composition as the deposit (Fig. 13e). Some thin disc-shaped masses are present which are rich in $\mathrm{Ca}$ and $S$ suggesting they are either gypsum or anhydrite (Figo. $13 f$ and $13 \mathrm{~g} / \mathrm{EDS}$ ).

Other, thicker disc-shaped grains occur which appear to be pieces of the suriace layer that stuck to the metal when the sample was disassembled after termination of the experiment (Fig, 13h).

The circular noncontact areas are well marked on the top glass surface. However, there is no significant difference in composition between the noncontact and contact areas. The "as-cut" contours are partially obscured by growth of che reacted layer. Exfoliation of this layer has occurred in places, exposing the glass from below. In these areas, precipitates now partially cover the glass surface. These precipitates, like numerous clumps elsewhere, have a similar composition and appearance to that of the surface layer.

The bottom glass surface also appears highly reacted with the identity of the "as-cut" contours being almost obscured by the presence of a surface layer. The layer, as well as many clumps on the surface, have the same texture and composition as found on the top glass. However, in one area, a smooth overgrowth is present that is somewhat enriched in $\mathrm{Ca}$. The surface layer has exfoliated in some places and a discontinuous cover of precipitates is present on the newly exposed surface.

The side glass near the bottom surface was also investigated by SEM/EDS. The surface has a textured appearance with a "cardhouse" type structure and composition consistent with smectite. There are two layers closest to the bottom surface with a precipitation front visible several millimeters up the side (Fig. 14a). Many chloride-bearing grains are present at this front (Fig. 14c/EDS). Some mottled regions of the upper layer are rich in Fe and $\mathrm{Mn}$ suggesting the presence of Fe-Mn oxides or hydroxides intermingled with smectite (Figs. 14d and 14b/EDS). The lower layer has a similar morphology and composition to the upper layer. In places where the lower layer has broken away. during sample preparation, a view in the third dimension is possible (Fig. 14d). The layer appears to only be a coating on an otherwise smooth glass surface which suggests the layer developed solely by precipitation rather than by direct glass reaction. This is supported by the presence of small regions 
(a)

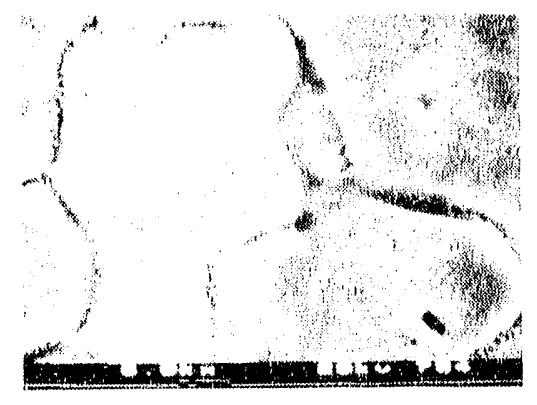

(c)

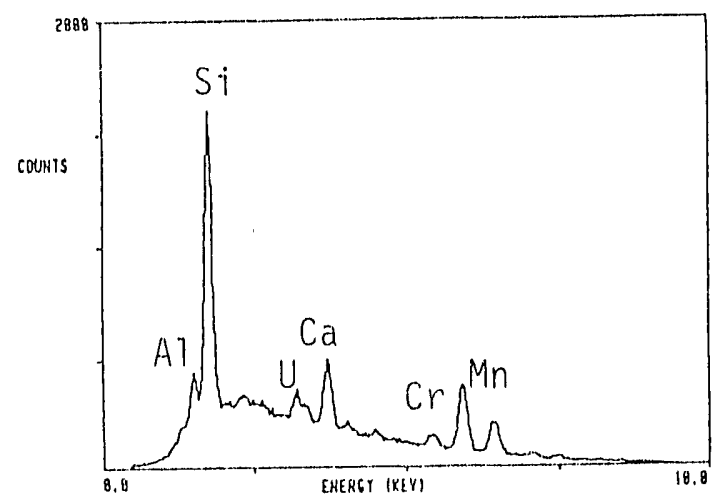

(b)

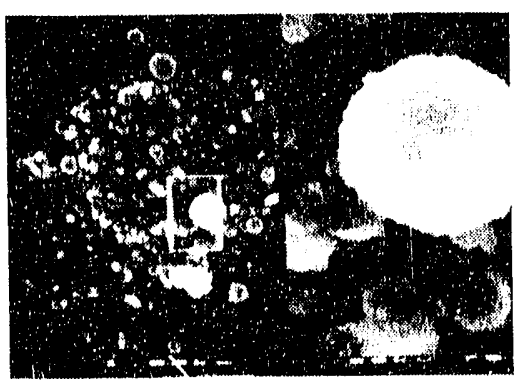

(d)

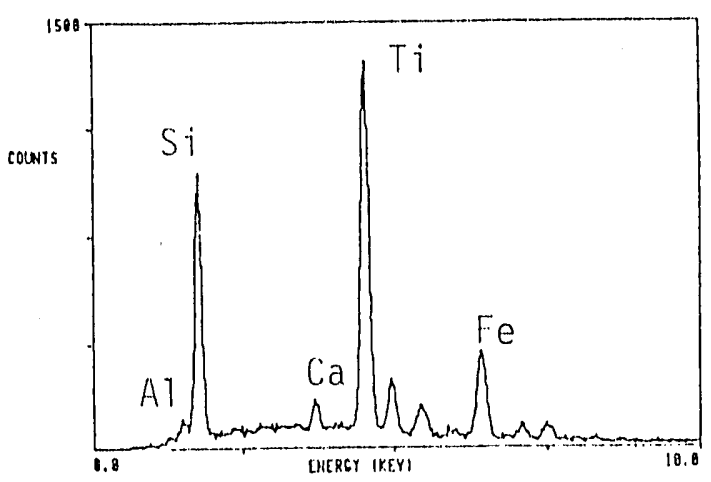

Fig. 13. SEM Micrographs and EDS Spectra of Features from the Top Metal Component of Experiment P-III-8. (a) Glass contact/noncontact interface $(6000 \mathrm{X})$; (b) Mn-enriched cluster of alteration products $(1000 \mathrm{X} / 10,000 \mathrm{X}) ;$ (c) EDS spectrum of material shown in (b); (d) EDS spectrum of Ti-rich grain 
(e)

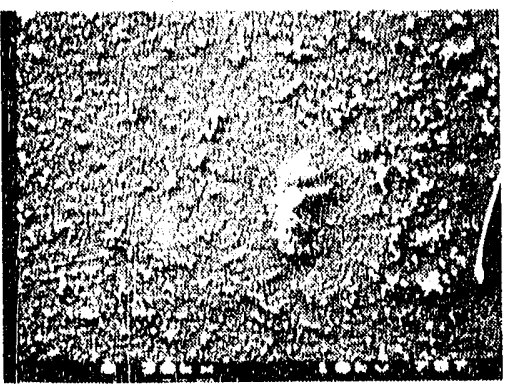

(f)

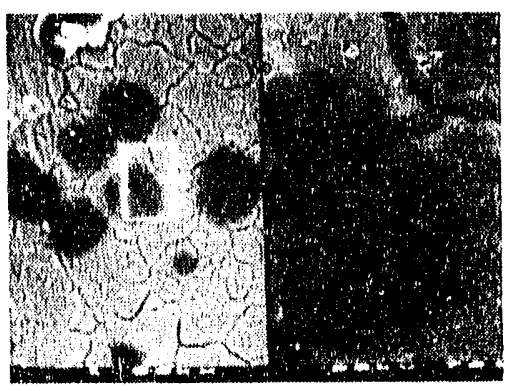

(g)

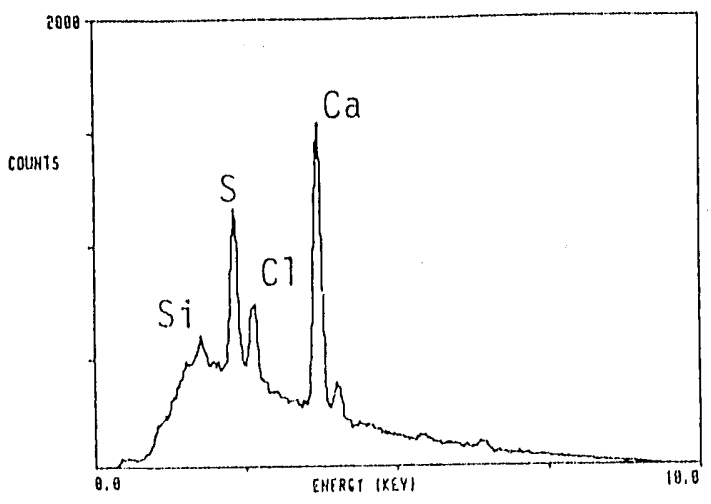

(h)

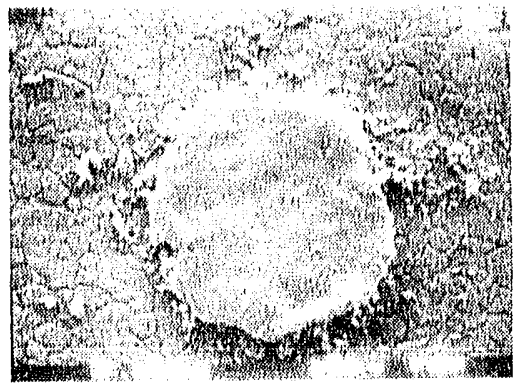

Fig. 13. Cont'd

SEM Micrographs and EDS Spectra of Features from the Top Metal Component of Experiment P-III-8. (e) micrograph (300X) showing general view of precipitate coverage; (f) micrograph $(1000 \mathrm{X} / 5000 \mathrm{X})$ of dark splotches. (g) EDS spectrum of splotches shown in (f); and (h) micrograph $(600 \mathrm{X})$ of a piece of the altered layer from the glass that stuck to the metal component on separation 
(a)

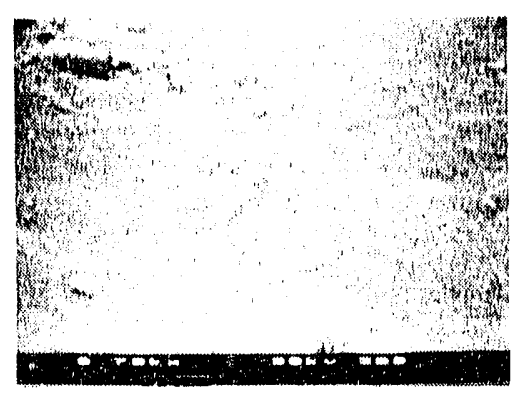

(c)

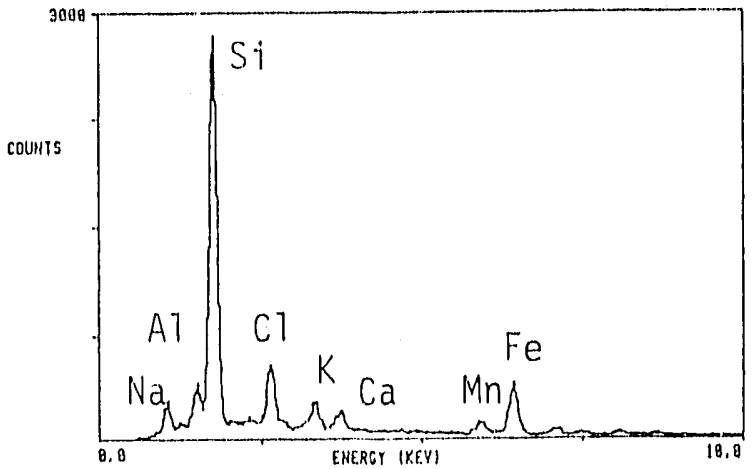

(e)

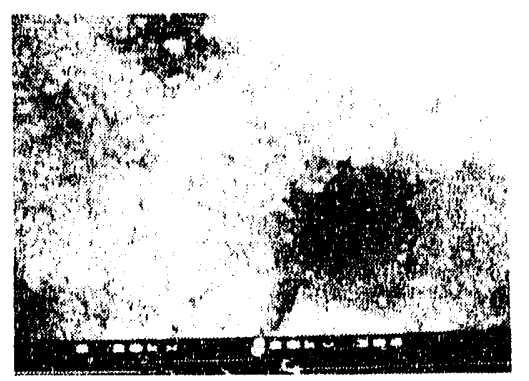

(b)

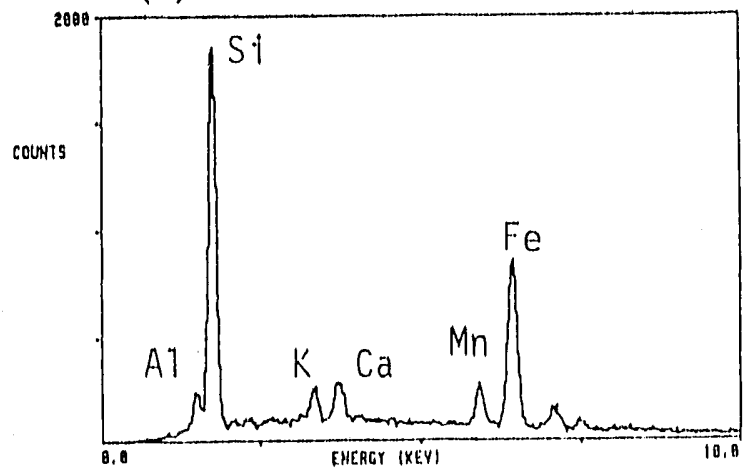

(d)

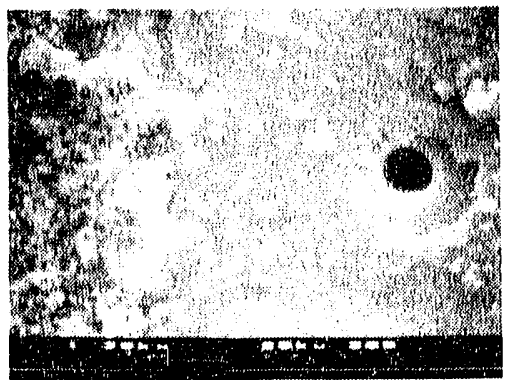

Fig. 14. SEM Micrographs and EDS Spectra of the Side Glass of P-III-8. (a) View $(700 \mathrm{X})$ of the precipitation front (see text); (b) EDS spectrum of precipitated surface layer; (c) EDS spectrum from the precipitation front where chlorides are intergrown with the Si-rich "clay" 
whare the lower layer is incomplete. Here, loosely connected precipitates encroach on small open areas where apparently etched glass is exposed (Fig. 14f). However, investigation of the layer formed on the side surfuce using analytical electron microscopy provides a more detailed description of the structure of the reacted glass, and should help identify the process by which the glass reacts (see addendum).

\section{d. P-III-9 and P-III-10, 52-Week Samples}

The glass surfaces of both samples were unalyzed by $S E M / E D S$ and SIMS, but the metal components were not examined.

\section{(1) P-III-9}

This sample appears to be more reacted than P-III-10. The top glass surface looks highly reacted and cracked and is covered with precipitates (Fig. 15a). However, the noncontact areas are not distinct from the contact areas. The light-colored streaks in Fig. 15a are due to charging along cracks in the surface layer. The layer is Si-rich and is essentially the same composition as observed for other samples (Fig. 15b/EDS). Exfoliation of portions of the surface layer is common (Fig. 15a). Other areas are in the processes of exfoliating as shown in Fig. 15c. The newly exposed glass has the appearance of having been etched (Figs. 15a and 15c). There are numerous precipitates on the surface, often associated with the exfoliated areas. Many are $\mathrm{Ca}$ - and S-rich and are probably gypsum or anhydrite (Figs. 15d and 15e/EDS). Round grains and thin threads of $\mathrm{NaCl}$ occur over the entire surface (Fig. 15f). Other chlorides, possibly $\mathrm{CaCl}_{2}$, are also indicated from the EDS spectrum shown in Fig. $15 \mathrm{~g} /$ EDS. Small grains of Fe-Mn oxide or hydroxide are often intimately associated with the Si-rich "clay" surface layer.

The bottom glass surface has distinctly iighter color noncontact areas (Fig, 16a). Like the top surface, a thick surface layer has developed which is extensively cracked and is exfoliating, especially in the noncontact areas (Figs. 16a, 16b, ind 16c). The "as-cut" appearance is completely masked and there are numerous precipitates on the surface. Most of the precipitates, like those in Fig. 16c, are probably either gypsum or anhydrite.

SIMS profiles were obtained from the top and bottom surfaces. Silicon normalized profiles for several elements from the bottom surface are presented in Fig. 17. Lithium is depleted relative to $\mathrm{Si}$ to a depth of $2.5 \mu \mathrm{m}$, while $\mathrm{Mg}, \mathrm{Mn}$, and $\mathrm{K}$ (not shown) are relatively enriched close to the surface. Boron shows some depletion in the near-surface region.

\section{(2) P-III-10}

Only the bottom surface of P-III-10 was investigated. The noncontact areas are partially visible and the "as cut" contours are obscured by the growth of a Si-rich surface layer. This layer is generally coarser grained than observed on P-III-9 (Fig. 18a). Exfoliation of the surface layer has occurred in places, although to a lesser extent than on P.III-9. The newly exposed glass is etched and appears to be somewhat altered (Tig. 18b). Small round precipitates dot the surface which contain $\mathrm{Ca}$ and $\mathrm{S}$ and are probably either gypsum or anhydrite. 
(a)

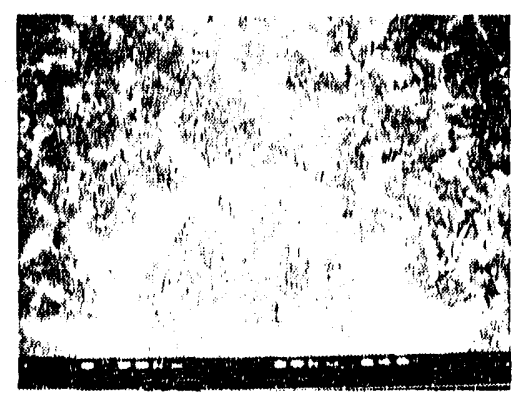

(c)

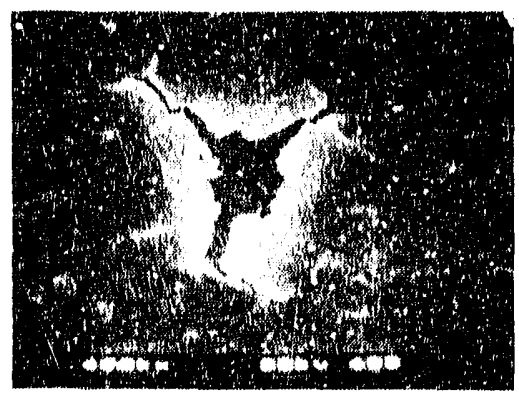

(b)

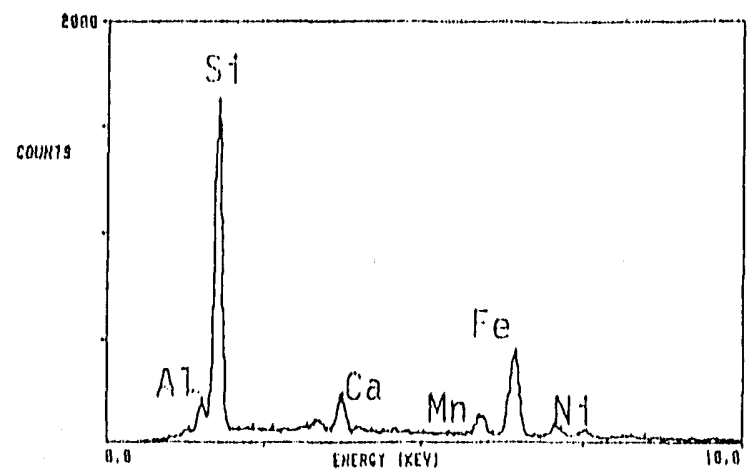

(d)

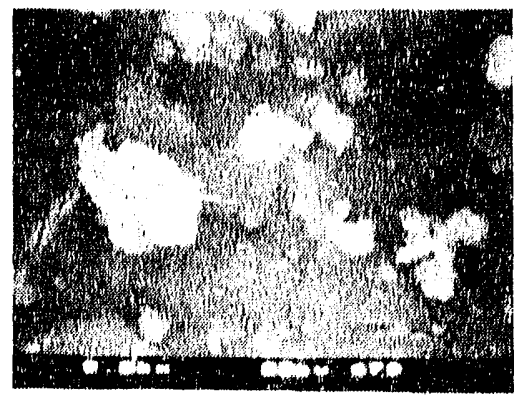

Fig. 15. SEM Micrographs and EDS Spectrum from the Top Glass Surface of P-III-9. (a) General surface with Ca/S-rich precipitates and exfoliated region $(500 \mathrm{X})$, (b) EDS spectrum of surface layer, (c) initial phase of exfoliation (400X), and (d) Ca-S precipitates on surface (5000X) 
(a)

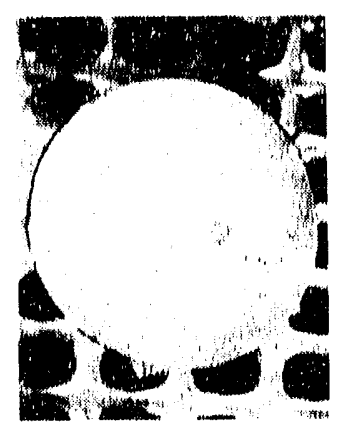

(c)

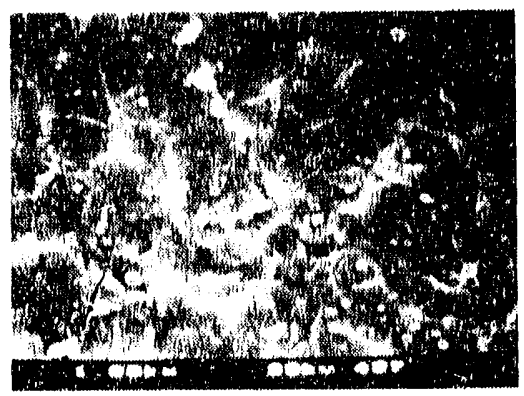

(b)

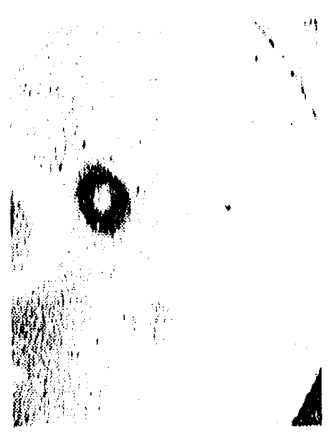

(d)

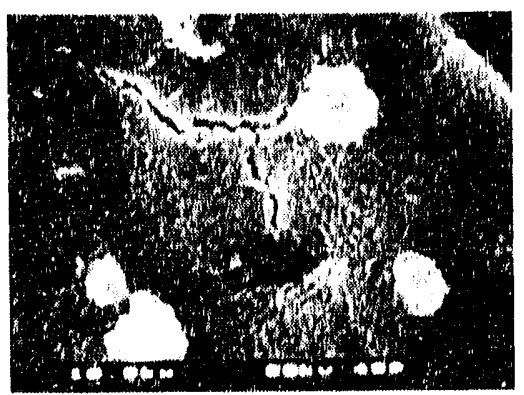

Tig. 16. Optical Photographs of the Bottom Glass Surface of P-III-9. (a) 6X; (b) $12 \mathrm{X}$, the spot with the dark halo is the result of a SIMS analysis. SEM micrographs of features from the bottom glass surface of P-III-9. (c) General surface appearance (1000X) and (d) higher magnification of surface $(10,000 \mathrm{X})$ showing a cracked region plus small $\mathrm{Ca} / \mathrm{S}$-rich grains

(a)

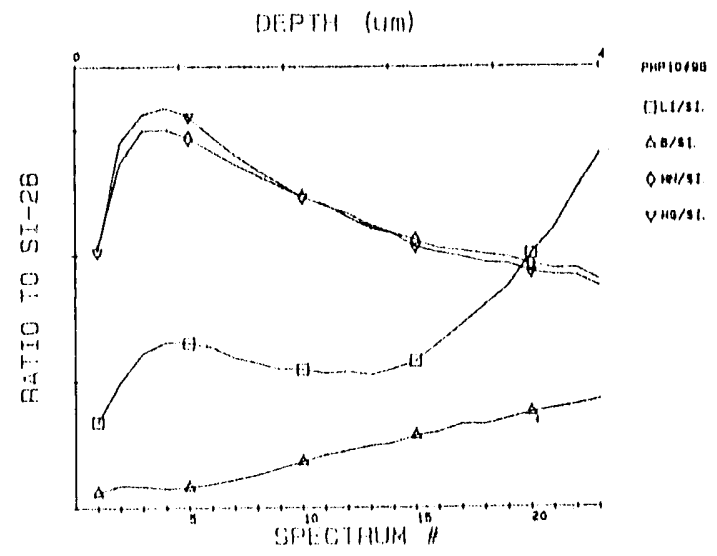

(b)

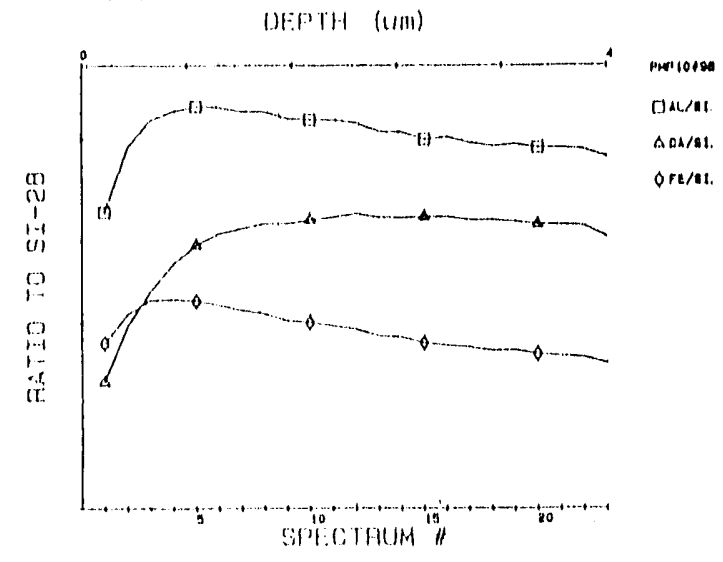

Fig. 17. SIMS Profiles of the Bottom Glass Section from Experiment P-III-9 in a Region of Glass-Metal Contact 
(a)

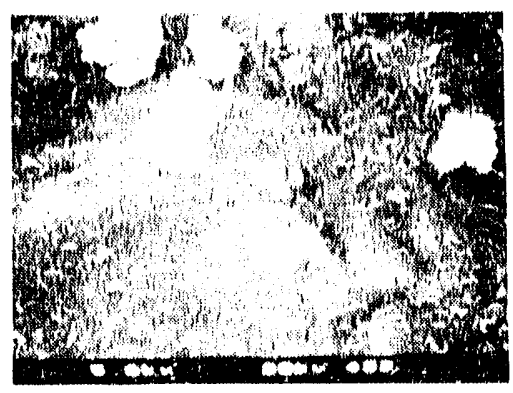

(b)

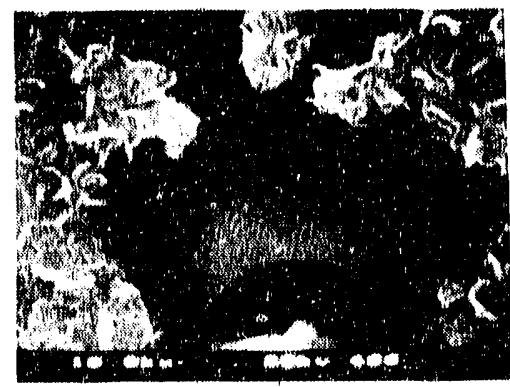

(c)

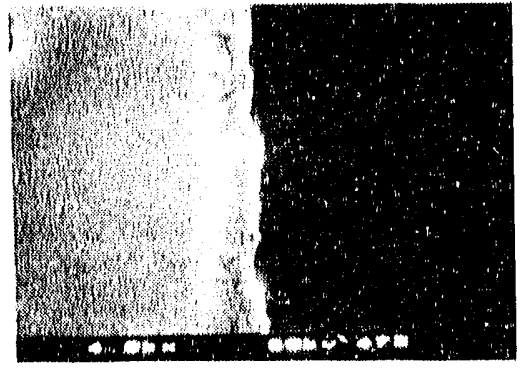

Fig. 18. (a) SEM Micrograph (5000X) Showing the Coarse-Grained Appearance of the Surface Layer; (b) Micrograph (10,000X) Showing Exposed Etched Glass; and (c) SEM Micrograph of a Cross Section of the Bottom Glass Surface from P-III-10

A polished cross section of the bottom glass was also prepared and studied by SEM (Fig. 18c). A band $\sim 1.5 \mu \mathrm{m}$ thick is visible at the edge of the glass. The band is comprised of regions of varying electron density contrast with the bright streaks due to charging ut the sample-epoxy interface. A survey of the unreacted glass was performed to check for inhomogeneities in the glass. Overall, the composition is quite uniform except that traces of $\mathrm{S}$ and $\mathrm{Cl}$ are intermittently detectable.

SIMS profiles were obt ined from the bottom surface and the side of the glass (Figs. 19a and 19b). The profiles, normalized to $\mathrm{Si}$, are broadly similar to those from P-III-9. Lithium is depleted to a depth of $\sim 1.5 \mu \mathrm{m}$ on the bottom surfane, which is consistent with the thickness of the altered layer observed by the SEM (Fig. 18c). Boron is also depleted in the near surface. The depletion is more gradual on the bottom than it is on the side.

\section{Solution Analyses}

Elemental releases from the continuous experiments are shown in Fig. 20, and normalized releases for selected elements are given in Table 9. The raw data and the background subtracted cumulative releases are included in Appendix I for both the continuous and batch experiments.

Partial blockage of the inlet lines occurred in P-III-2 after the second year of the experiment and has continued intermittently to date despite efforts to clear the line without disassembly of the system. However, at no time was the line completely blocked. As a result, less water was injected during these periods than was required. 
(a)
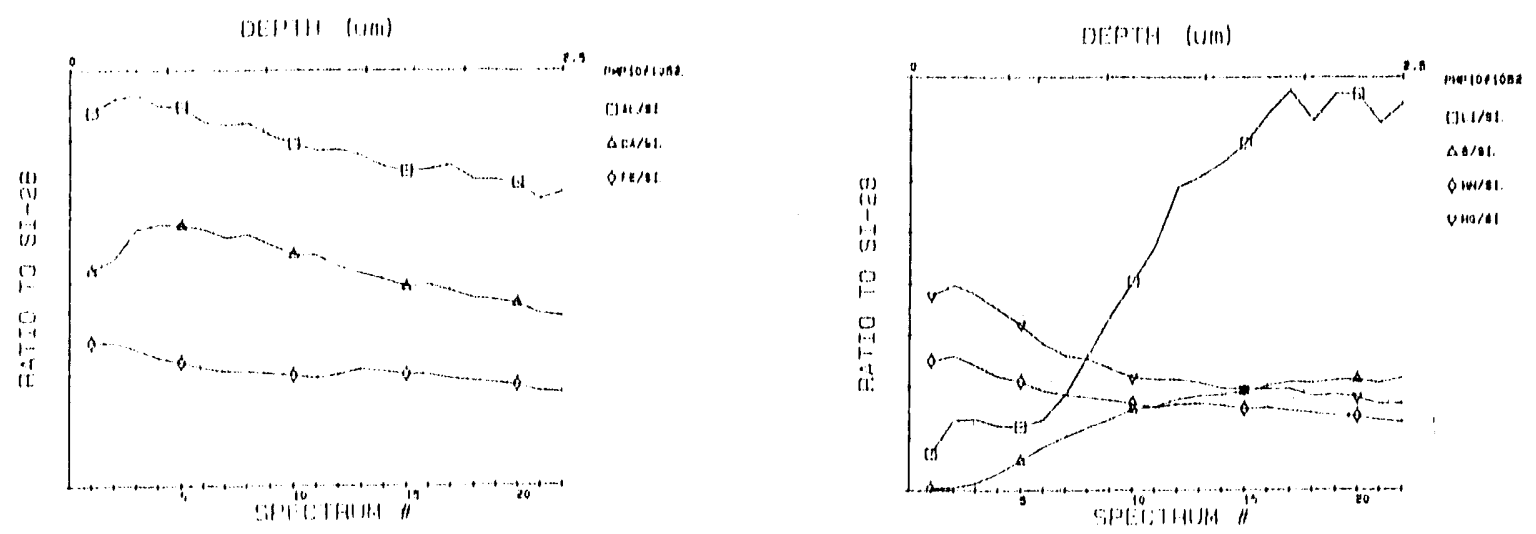

(b)
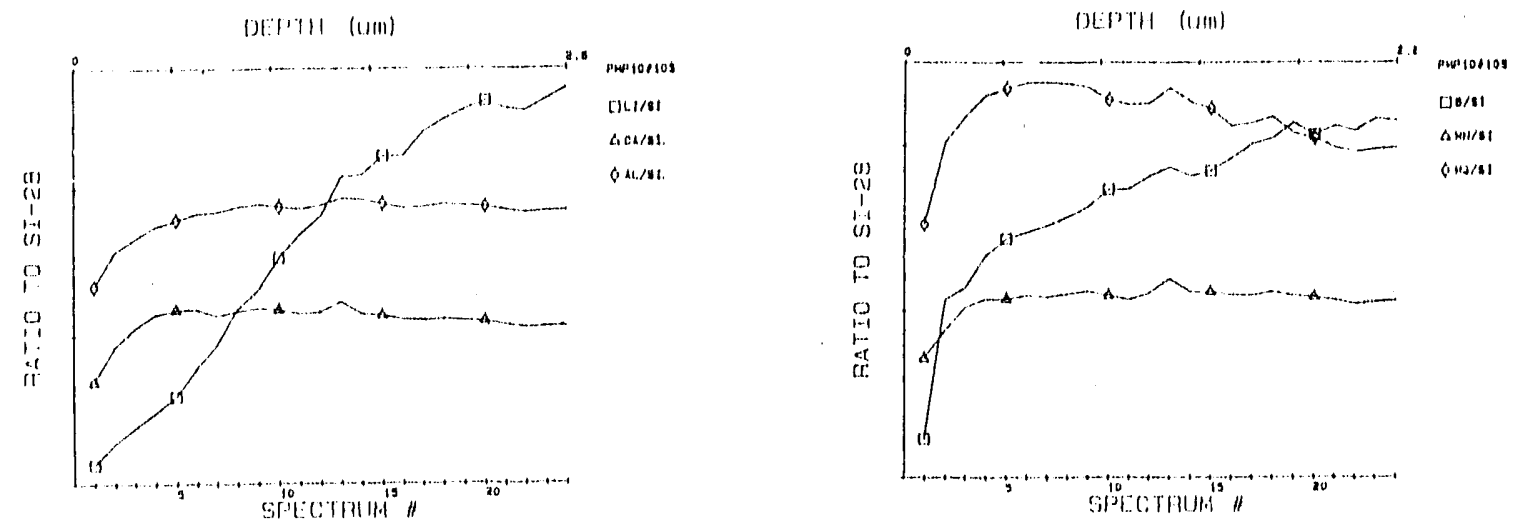

Fig. 19. SIMS Profiles of the Reacted Bottorn and Side Surfaces of the Glass from Experiment P-III-10.

(b) side surface

(a) Bottom surface metal contact and

There is good agreement in the element release trends between the P-III-1 and P-III-2 experiments. There is some divergence apparent in the most recent analysis, which correlates with the smaller amount of fluid recovered from the P-III-2 vessel. Normalized release of $\mathrm{Li}$ is the greatest of all elements, reaching a value of $\sim 6.5 \mathrm{~g} / \mathrm{m}^{2}$ after 260 weeks. The rate of Li release in both experiments decreased steadily for the first two years after which the rate became relatively constant. However, since about 170 weeks, the rate has increased fairly sharply, especially in the P-III-1 experiment (Fig. 20). The normalized release of $\mathrm{B}$ at 260 weeks is $\sim 3.1 \mathrm{~g} / \mathrm{m}^{2}$ or about half that of $\mathrm{Li}$. The trend of release closely follows that of $\mathrm{Li}$ over the entire duration of the experiments. The rate of $U$ release has been fairly constant, although a slight increase seems to have occurred after about 170 weeks. The normalized release reached $\sim 3.3 \mathrm{~g} / \mathrm{m}^{2}$ after 260 weeks which is about the same as for $B$. 
Egran

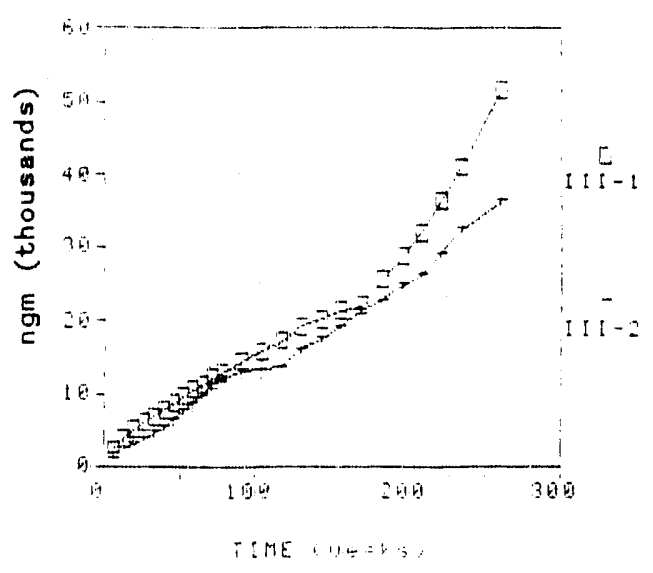

Uranium

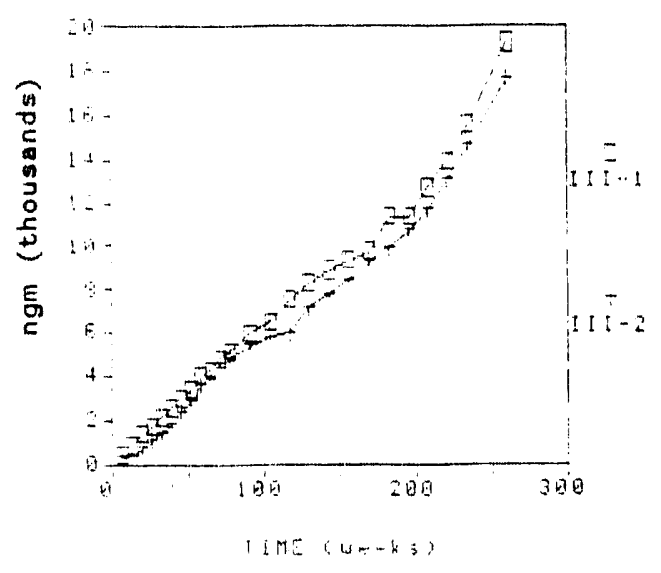

Caloilu

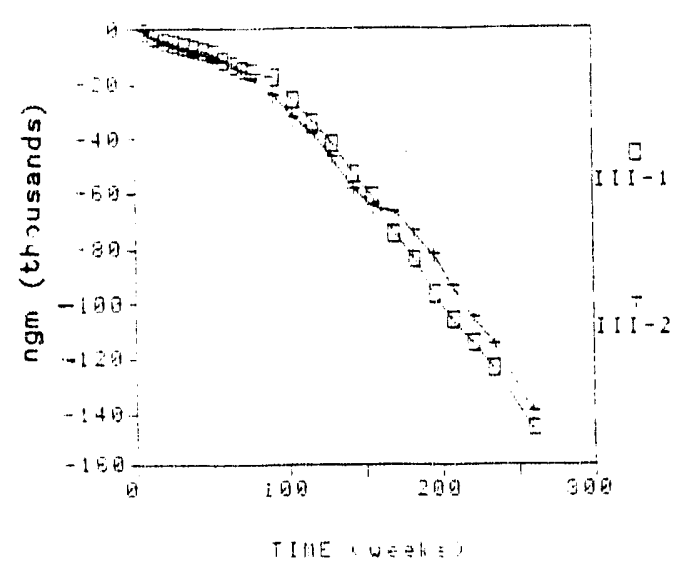

Lithium

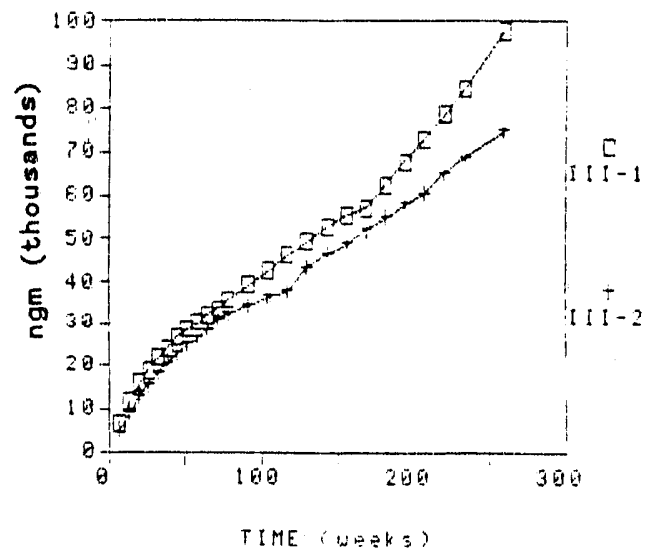

Sogiul

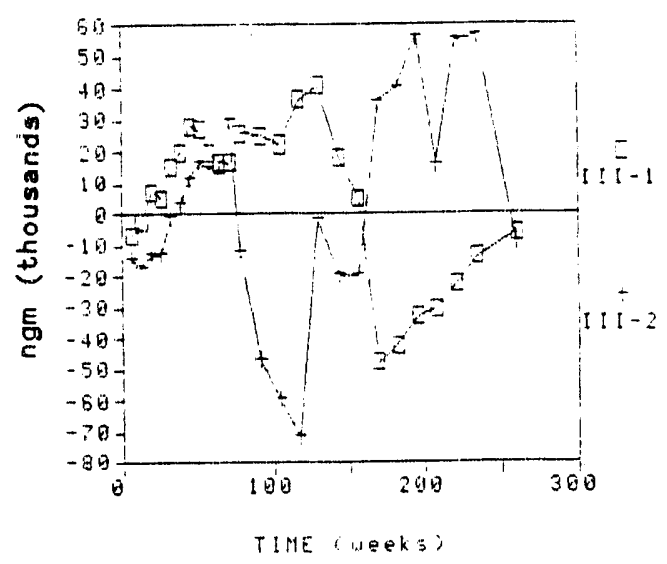

Siliogr

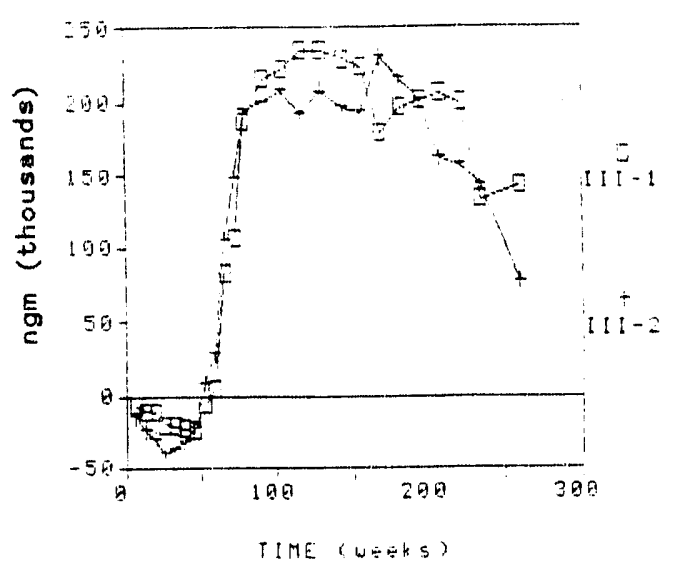

Fig. 20. Cumulative Release of Selected Elements from the P-III-1 and P-III-2 Continuous Experiments 
Table 9. Norralized Release in P-III Series

\begin{tabular}{crrrr}
\hline & & \multicolumn{3}{c}{ Normalized Release $\left(\mathrm{g} / \mathrm{m}^{2}\right)$} \\
\cline { 4 - 5 } Test \# & $\begin{array}{c}\text { Period } \\
\text { (weeks) }\end{array}$ & $\mathrm{B}$ & $\mathrm{Li}$ & $\mathrm{U}$ \\
\hline P-III-3 & 13 & 0.2 & 1.0 & 0.1 \\
-4 & 13 & 0.3 & 1.1 & 0.2 \\
-5 & 28 & 0.7 & 1.8 & 0.6 \\
-6 & 28 & 3.2 & 4.3 & 2.3 \\
-7 & 39 & 3.1 & 4.2 & 2.1 \\
-8 & 39 & 2.0 & 3.3 & 1.5 \\
-9 & 52 & 3.7 & 5.6 & 2.6 \\
-10 & 52 & 2.3 & 4.0 & 1.7 \\
& & & & \\
P-III-1 & 52 & 0.7 & 2.1 & 0.6 \\
& 104 & 1.1 & 3.2 & 0.8 \\
& 156 & 1.5 & 4.1 & 1.2 \\
& 208 & 2.2 & 5.4 & 2.3 \\
& 234 & 2.8 & 6.3 & 2.8 \\
& 260 & 3.6 & 7.3 & 3.4 \\
P-III-2 & & & & \\
& 52 & 0.5 & 1.9 & 0.4 \\
& 104 & 0.9 & 2.8 & 0.8 \\
& 156 & 1.4 & 3.8 & 1.1 \\
& 208 & 1.9 & 4.7 & 2.2 \\
& 234 & 2.3 & 5.3 & 2.7 \\
& 260 & 2.6 & 5.8 & 3.3 \\
\hline
\end{tabular}

There is a consistent net negative release of $\mathrm{Ca}$ and $\mathrm{Mg}$, indicating that these elements have been removed from the injected EJ-13 water and incorporated into the secondary phases. This is consistent with the ubiquitous occurrence of gypsum or anhydrite on the batch samples. The $\mathrm{Mg}$ may be accommodated in the Si-rich "clay" layer.

Both $\mathrm{Na}$ and $\mathrm{Si}$ have erratic release patterns which are similar in the P-III-1 and P-III-2 experiments. This variable behavior may be attributable to periodic precipitation and redissolution of $\mathrm{NaCl}$ (or $\mathrm{Na}_{2} \mathrm{CO}_{3}$ ?) which is observable on the batch samples. There was a net negative release of $\mathrm{Si}$ through the first year followed by a sharp positive release. Then, at the 104-week period for P-III-1 and the 91-week period for P-III-2, the Si release rate diminished. The reason for this behavior is unclear; however, it rnay be caused by secondary phase formation such as smectite. The sharp increase in release may indicate the initiation of surface layer exfoliation. Since the surface layer is composed predominantly of $\mathrm{Si}$, if pieces of the layer were to fall into the solution, the subsequent acidification of the solution during sampling would preferentially enhance the $\mathrm{Si}$ concentration relative to the other elements. 
Except for the 13-week samples, elemental release is usually much greater in the batch experiments compared to the continuous experiments (Table 9). At the 13-week period, releases are about the same in both types of experiments. While the WPA wash that is incorporated into the termination procedure of the batch experiments adds about $10 \%$ to the total release, this cannot account for the up to five-fold difference that is observed for some elements (Appendix I). The extent of element releasis is markedly different between the duplicate batch experiments terminated afier 28 and 52 weeks. The reason for this discrepancy is unknown, although there is a correlation between larger release and a greater volume of solution recovered from the vessel upon termination of the experiments.

\section{Discussion}

The observation that normalized release of $\mathrm{Li}$ is twice that of $\mathrm{B}$ suggests these elements behave differently during glass reaction and that nonstoichiometric dissolution has occurred. SIMS profiles are consistent with the solution release trends in that $B$ is retained to greater degree than $\mathrm{Li}$ in the residual altered layer (Figs. 10, 17, and 19). Another possibility is that $B$ is incorporated in secondary phases. No B-bearing phases have been detected using the WDS system. While both $\mathrm{Li}$ and $\mathrm{B}$ are removed from the glass during reaction, $\mathrm{Li}$ is depleted to a greater depth than $\mathrm{B}$ (Figs. 10, 17, and 19). This suggests that $\mathrm{Li}$ is more mobile than $\mathrm{B}$ and, therefore, a greater volume of glass is leached of $\mathrm{Li}$ per unit time. Correlation of the SIMS data with AEM data will hopefully more clearly define the leaching process.

Depletion of $\mathrm{Ca}, \mathrm{Mg}$, and $\mathrm{Na}$ in solution is associated with the formation of secondary phases on the WPA. The erratic nature of $\mathrm{Na}$ release may be due to periodic precipitation of $\mathrm{NaCl}$ or $\mathrm{Na}_{2} \mathrm{CO}_{3}$ ? followed by dissolution.

The most abundant secondary phase is the Si-rich layer that is present on both the glass and metal components. Its composition and "cardhouse" type texture suggests it is composed of smectite (e.g., Figs. 12a and $12 \mathrm{~b} / \mathrm{EDS}$ ). The deposit on the metal and at least some of the layer on the glass formed by precipitation. Other parts of the layer on the glass may have transformed in situ from the altered glass, although this has not been demonstrated definitively. Release of $\mathrm{Si}$ into solution does not follow a. systematic trend (Figs. 20a and 20b). This may in part be due to exfoliation of the surface layer.

Fxfoliation of the surface layer is observed in all samples that reacted for at least 26 weeks (i.e., P-III-6, P-III-8, P-III-9, P-III-10). Precipitation of Si-rich "clay" on the newly exposed glass indicates that exfoliation must have occurred during the experiment. This process has important implications for the rate of glass reaction and for interpretation of solution chemistry data. 


\section{P-IV Experiments}

The purpose of these experiments is to examine the effect of reducing the water volume during each injection period. While maintaining the normal injection interval of 3.5 days, the drop volume is reduced by $50 \%$ to $0.038 \mathrm{~mL}$. The surface area of the glass is also reduced by $\sim 50 \%$, which is the same as for the P-III experiments.

The experiments were initiated on $2 / 18 / 85$ and have been completed through 247 weeks. The batch experiments were terminated in duplicate at 25.5 and 52 weeks. The continuous experiments are ongoing and have been sampled every 13 weeks up to 221 weeks and for longer intervals since. Two batches of EJ-13 water have been used (Table 4). The switch in batches occurred after 91 weeks. The experimental matrix is given in Table 10.

\section{General Observations}

The appearance of the WPA during the sampling periods and at termination was very similar to that noted for the P-III experiments. The top surface of glass was damp in the areas not in contact with the stainless steel and there was standing water around the circumference of each hole in the metal. There were small droplets of water present on the top surface of the stainless steel. However, there was no evidence of localized reaction between the metal and glass. The bottom surface had standing water around the circumference of the glass and between the glass and the metal rim. The regions of nonmetal contact were also wet. In some experiments water bridged the gap between the glass and the metal support pin(s).

The weight change measurements (Table 10) indicate that the glass lost weight during all experiments. There is good reproducibility between duplicate samples, and the 52-week samples show slightly more than twice the weight loss of the 25.5-week samples. The metal sections gained weight in most. cases with the weight gain being greater for the shorter tests than the longer.

\section{Component Analyses}

The glass from all the terminated batch experiments was examined optically, and the top and bottom surfaces of P-IV-3 and P.-IV-5 were investigated by SEM/EDS.

\section{a. P-IV-3 and P-IV-4, 25.5-Week Samples}

The general appearance of the two samples is similar. The noncontact areas on the bottom surfaces are clearly visible, appearing as light gray circles on a dark background. There is no suck demarkation on the top surface of P-IV-3. However, small irregular whitish patches occur in the central portions of the noncontact areas. Dark circular regions are discernible on the top surface of P-IV-4. The side surfaces are generally shiny brown-black with irregular-shaped areas that correspond to regions of standing water during the experiments. This includes the lower third of the sides where a cracked and peeled bronze-colored scale is present. Near the top surface is an irregularly distributed whitish deposit. 


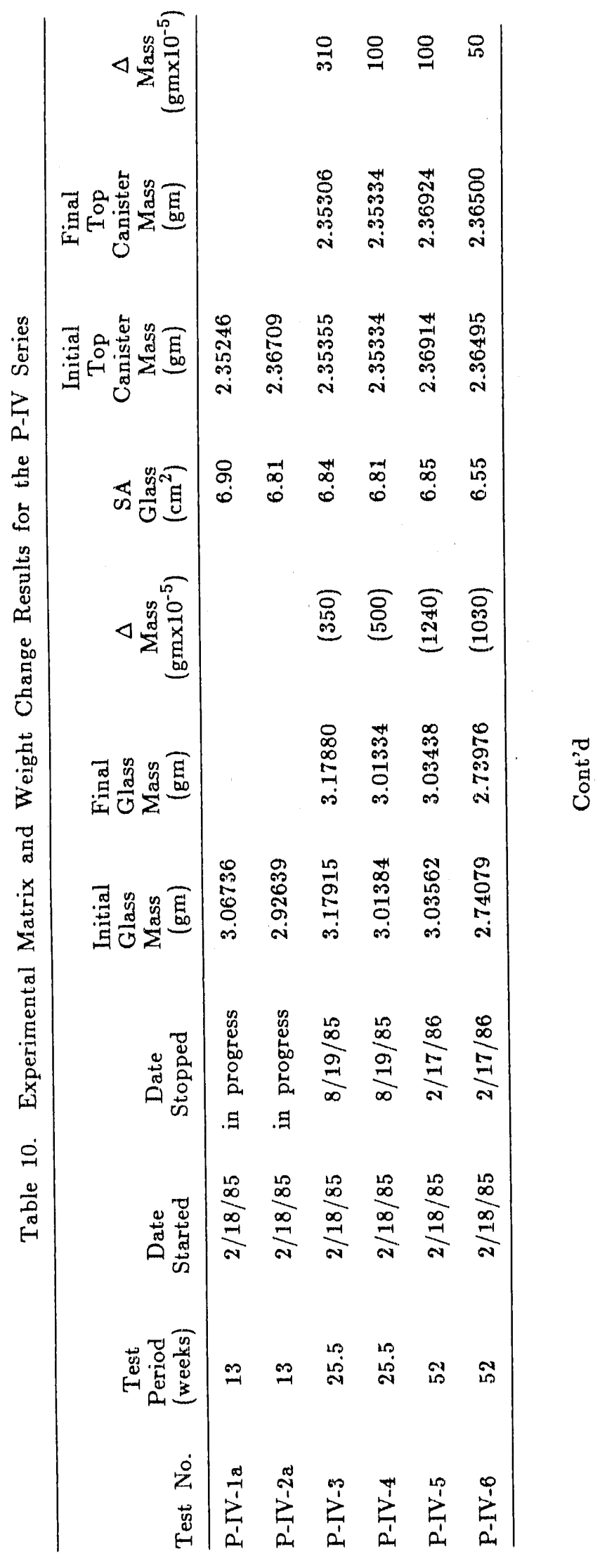




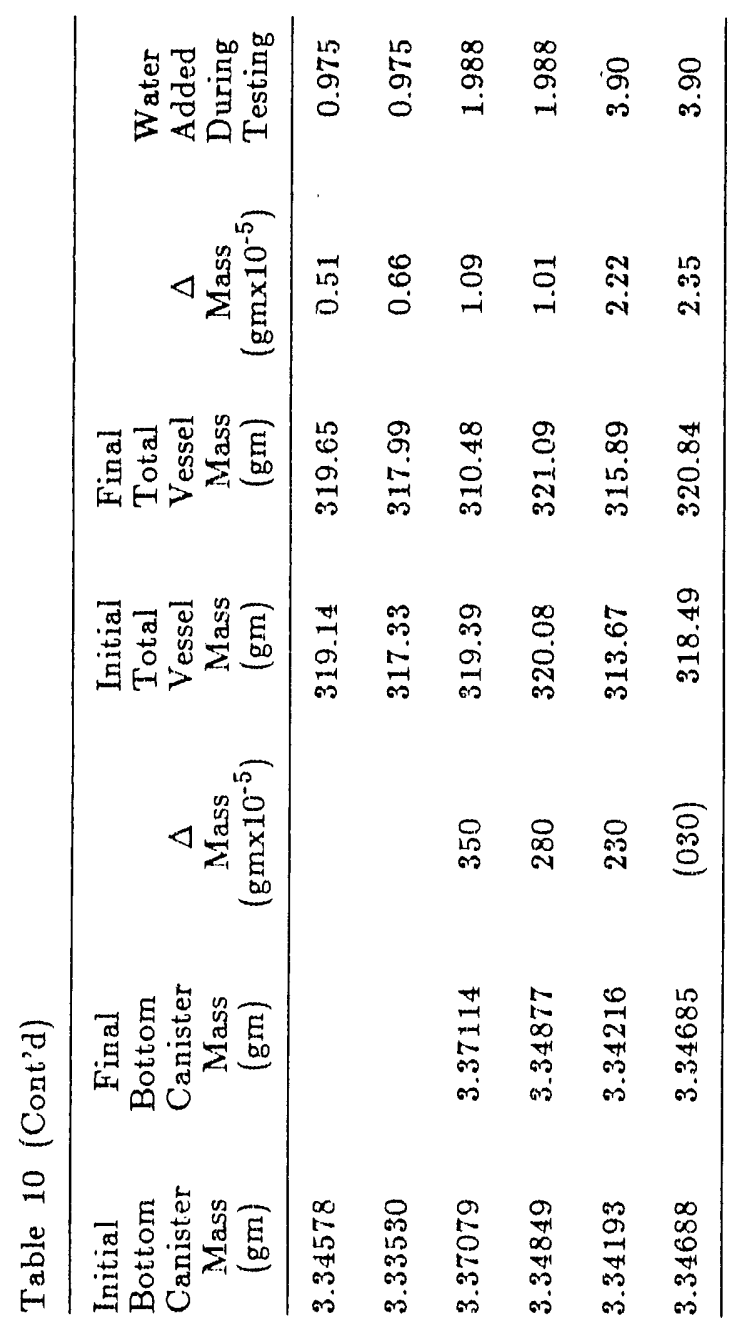


Examination of the bottom glass surface of P-IV-3 by SEM reveals a surface layer has developed similar to that observed on the P-III samples (compare Figs. 21a and Fig. 12a). The layer is Si-rich and is depleted in $\mathrm{Na}$ and enriched in $\mathrm{Fe}$ and $\mathrm{Mn}$ relative to the glass. The development of this layer in the noncontact areas is incomplete (Fig. 21b). Here, glass is still exposed over approximately $10 \%$ of the area. It appears that most of the surface layer has formed by precipitation (Figs. $21 \mathrm{~b}$ and $21 \mathrm{c}$ ). The glass is quite smooth, even at $10,000 \mathrm{X}$ magnification, although there is some fine-scale structure indicating reaction has occurred (Fig. 21c).

The top glass surface has retained most of its original "as cut" appearance; however, clear evidence of reaction is revealed at higher magnification (Figs. 22a, 22b, and 22c). A Si-rich layer has developed across the entire surface.

The contact and noncontact areas are texturally indistinguishable at the scale of the SEM. There are numerous isolated precipitates present which are too small for XRD analysis, but EDS spectra indicate several different compositions. Some have essentially the same composition as the surface layer, while others are composed only of silica and are possibly quartz or opal. Some calcite is present. There are also clusters of precipitates rich in $\mathrm{Cr}, \mathrm{Fe}$, and $\mathrm{Mn}$ and are probably an oxide or hydroxide phase.

\section{b. P-IV-5 and P-IV-6, 52-Week Samples}

The bottom surfaces of these two samples have clearly marked noncontact areas that are light gray in color. These areas are intact on P-IV-6, but on P-IV-5, a surface layer is observable which is cracked and has separated from the glass in many places. This is similar to the appearance of several samples from the P-III experiments.

The top surfaces are very different in appearance. The noncontact areas on P-IV-5 are fairly well marked, being darker than the light blue-green to brown contact areas. Small whitish patches of precipitates are present in the center of a few of the noncontact areas. The noncontact areas on P-IV-6 are barely discernible. An extensive array of saw marks is the most prominent feature which form whitish streaks on a relatively uniform dark background.

The bottom surface of P-IV-5 has a similar appearance to that of P-IV-3 under the SEM, except that there are many small Ca- and S-bearing grains which are probably gypsum or anhydrite (Fig. 23a). A Si-rich layer is present but it is incomplete, exposing glass from below. In some places, the layer is cracked and pieces have exfoliated (Fig. 23a). The process of cracking and exfoliation has begun even before the surface layer has completely developed. The exposed glass surface shows only slight evidence of etching but, otherwise, it looks unreacted (Figs. 23a and 23b). However, the early stages of alteration, where a gel layer forms, may not be readily discernible by SEM. ${ }^{12}$ Precipitation of a Si-rich layer appears to be quite rapid in the freshly exposed areas. 
(a)

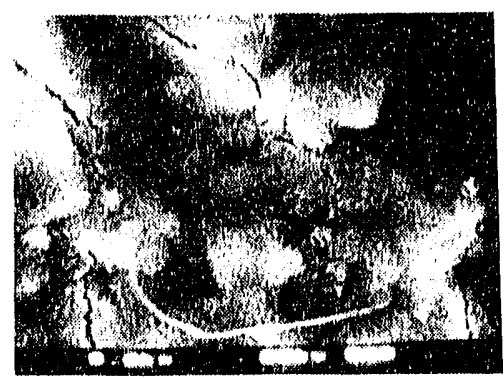

(b)

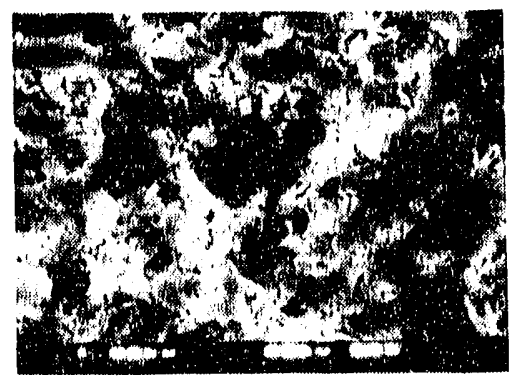

(c)

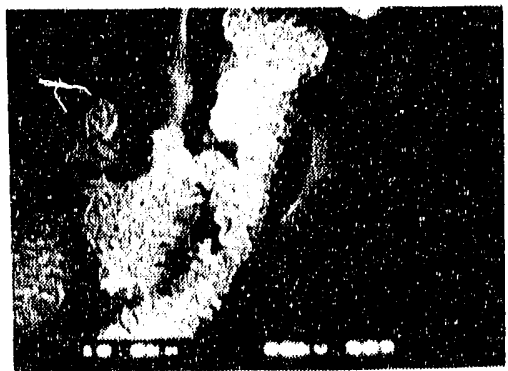

Fig. 21. SEM Photomicrographs of the Bottom Glass Surface from Experiment P-IV-3. (a) General surface, ss contact (5000X); (b) general surface, noncontact $(1000 \mathrm{X})$; and $(\mathrm{c})$ localized precipitation in the noncontact area $(10,000 \mathrm{X})$

(a)

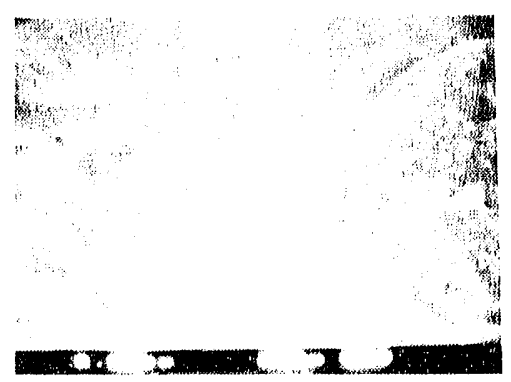

(b)

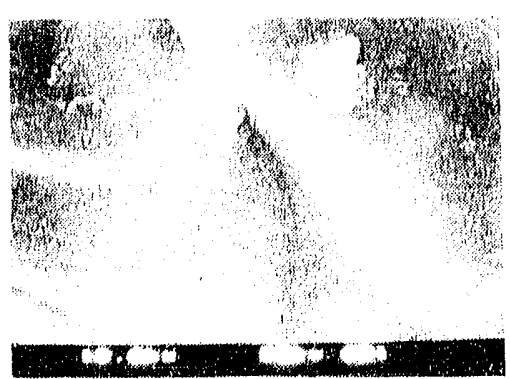

(c)

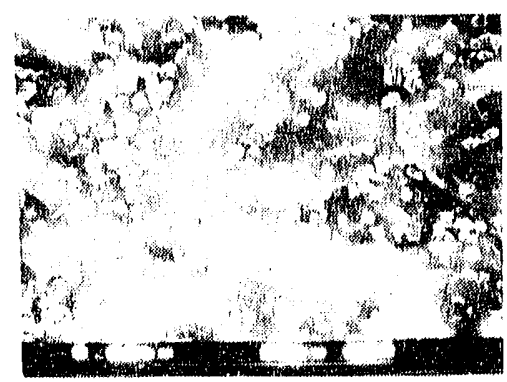

Fig. 22. SEM Photomicrographs of the Top Glass Surface from Experiment P-IV-3. (a) General surface $(2000 \mathrm{X})$; (b) general surface texture $(10,000 \mathrm{X}) ;$ and $(\mathrm{c})$ general surface $(5000 \mathrm{X})$

(a)

- $x$

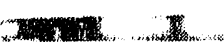

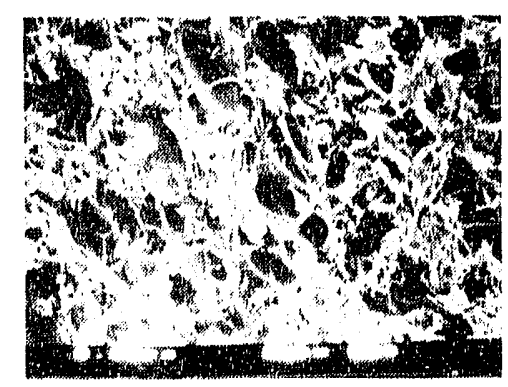

Fig. 23. SEM Micrographs of the Bottom Glass Surface from Experiment P-IV-5.

(a) Exfoliation of surface layer and numerous Cs-S grains (600X) and

(b) glass surface with only partial coverage of precipitates (300X) 
The top surface of P-IV-5 is also similar to the top of P-IV-3. Although the "as cut" contours are still readily visible, a uniform continuous fine-grained surface layer has developed (Fig. 24a). Its Si-rich composition is typical of the layers developed on other samples. No exfoliated areas are present. However, there are numerous places where the layer is cracked and small pieces are raised up from the glass (Fig. 24a). This suggests an incipient stage in the exfoliation process. The surface is dusted with small $(\leq 2 \mu \mathrm{m})$ round grains of gypsum or anhydrite (i.e., $\mathrm{Ca}+\mathrm{S}$ bearing). Other precipitates include clusters of $\mathrm{Cr}-, \mathrm{Mn}-, \mathrm{Fe}-$, and Ni-bearing grains (Fig. 24b) which are probably oxide or hydroxide phases. Their composition is variable from containing mostly $\mathrm{Fe}$ and $\mathrm{Ni}$, to containing $\mathrm{Ni}$ only, to containing predominantly $\mathrm{Cr}$ and $\mathrm{Mn}$ (Figs. 24c/EDS, 24d/EDS, and 24e/EDS). Others have compositions similar to stainless steel (compare Fig. 24f/EDS with Fig. 2c/EDS).

\section{Solution Analyses}

Elemental releases from the continuous experiments are presented in Fig. 25 and normalized release of $\mathrm{Li}, \mathrm{B}, \mathrm{U}, \mathrm{Na}$, and $\mathrm{Si}$ are given in Table 11. The raw data and the background subtracted cumulative releases are included in Appendix I for the batch and continuous experiments.

The trends in element release are similar between experiments P-IV-1 and P-IV-2 (Fig. 25). However, the magnitude of release from P-IV-2 is on the order of two times that of P-IV-1. It is not clear why these two experiments, which show the same release pattern, should have such different ovcrall release. In both experiments $\mathrm{Li}, \mathrm{B}, \mathrm{Na}, \mathrm{Si}$, and $\mathrm{U}$ all have positive releases. After 182 weeks, however, a sharp reduction in the rate of release is apparent for all these elements suggesting a slowing of glass reaction and/or release from the WPA.

Lithium has the greatest normalized release, although it is not much greater than $\mathrm{B}$ or $\mathrm{Na}$ (Table 11). Release of $\mathrm{U}$ is only slightly less than $\mathrm{B}$ and $\mathrm{Na}$. Silicon release is much less than these elements. This is attributable to the formation of the Si-rich surface layer on the glass and metal which acts as a sink for $\mathrm{Si}$. The only element with a negative release is Ca. This indicates significant precipitation of a Ca-bearing phase or phases which depletes $\mathrm{Ca}$ in the EJ-13 water. This correlates with the observation of tiny grains of gypsum or anhydrite distributed over the surfaces of the batch samples.

\section{Discussion}

The top and bottom surfaces in the P-IV batch experiments have a different appearance visually as well as under the SEM. The surface layer on the bottom surfaces has a textured appearance and coverage is incomplete. In some places, it is evident that pieces of the surface layer have exfoliated, exposing patches of glass from below. Elsewhere, it appears that the surface layer never developed completely across the glass. Based upon the generally unreacted appearance of the exposed glass, and the distribution of new deposits in the partially covered areas, it seems that the surface layer has formed mostly by precipitation. Other precipitated phases are conspicuous by their absence. 
(a)

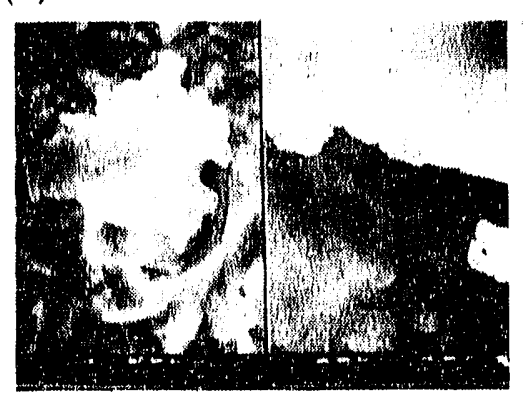

(c)

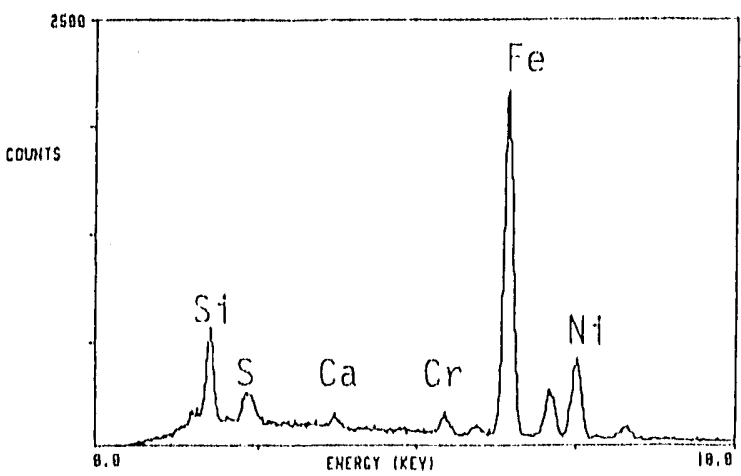

(e)

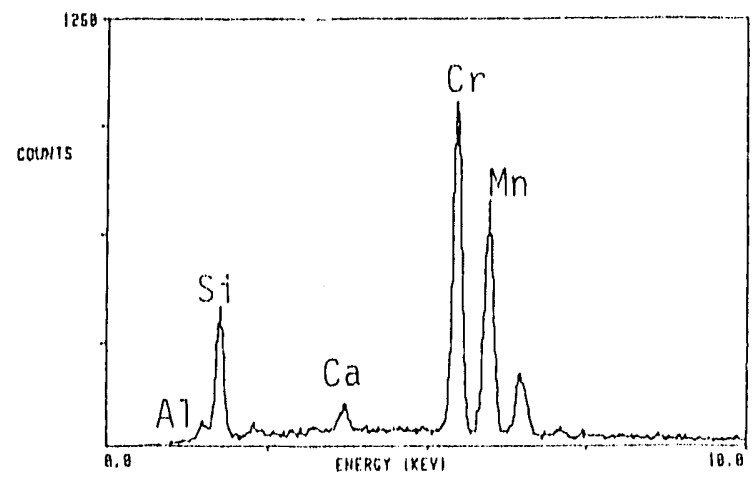

(b)

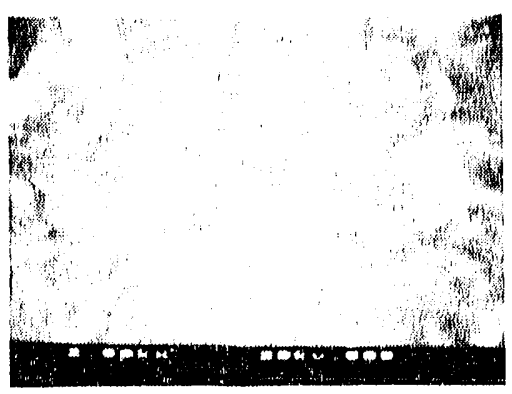

(d)

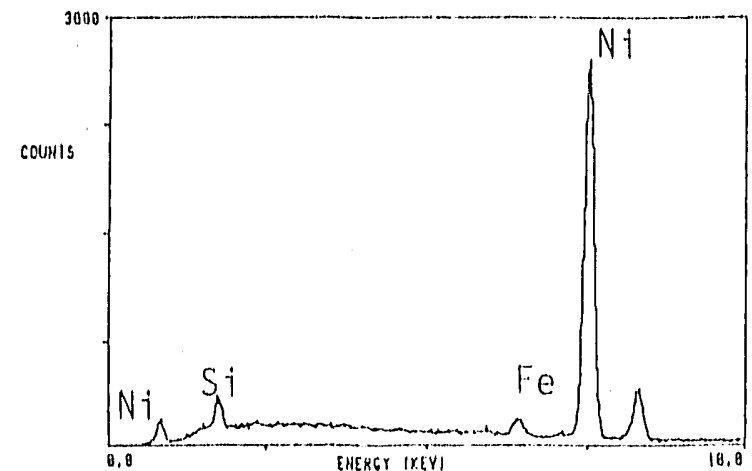

(f)

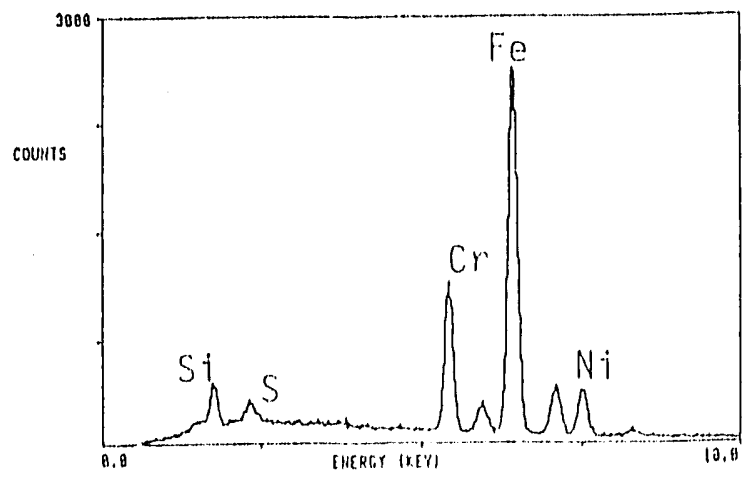

Fig. 24. SEM Micrographs and EDS Spectra of Reaction Products on the Top Surface of P-IV-5. (a) Micrograph (2000X/10,000X) of surface layer); (b) micrograph (2000X) of surface layer and $\mathrm{Cr}-$, Mn-, Fe-, and Ni-bearing grains; (c-f) EDS spectra of grains shown in (b) 
Egror

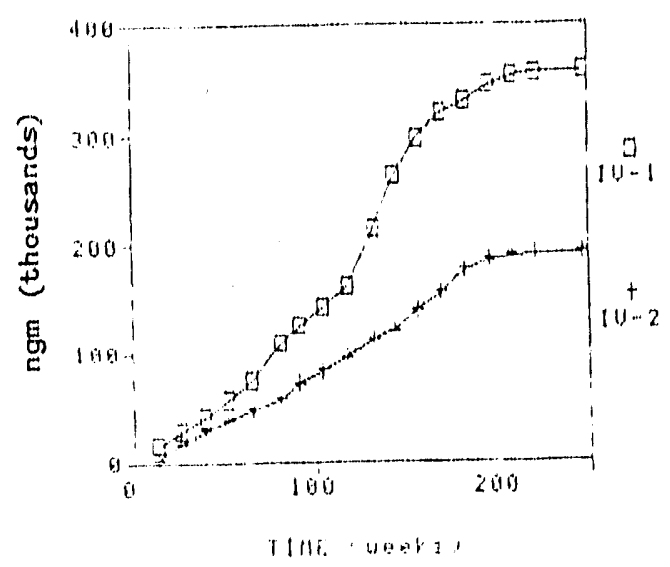

Lithilli

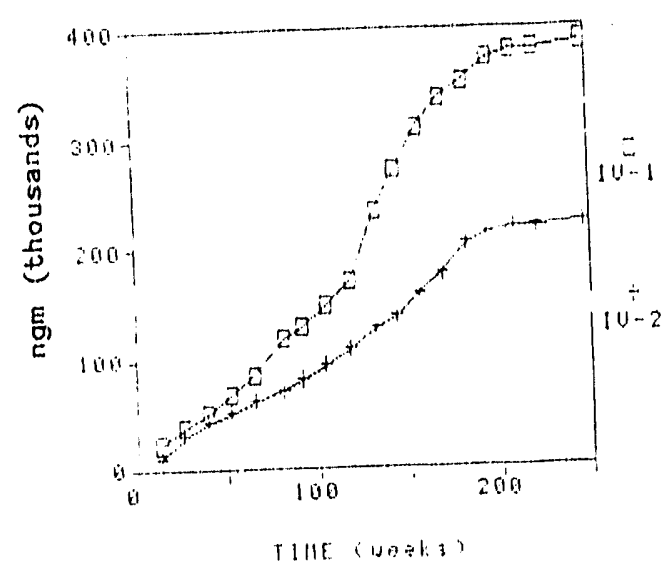

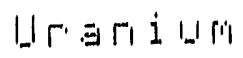

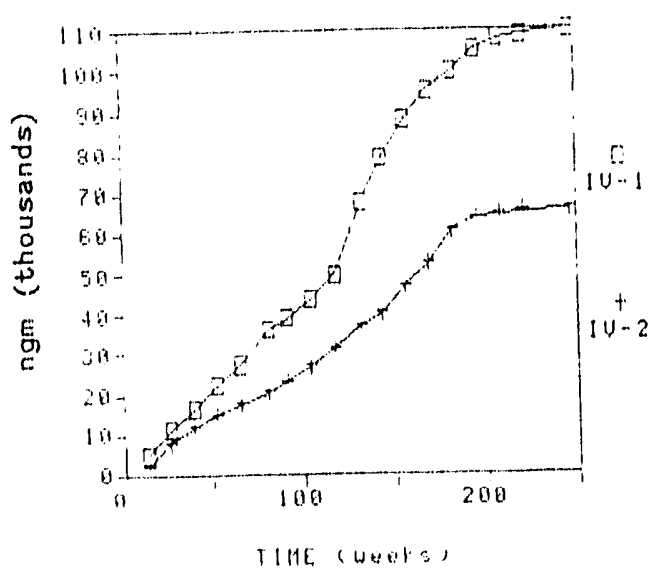

Sodium

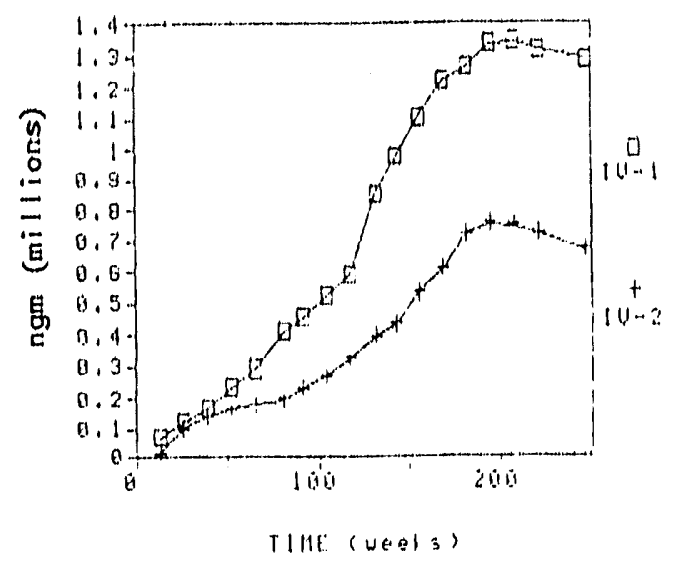

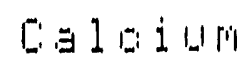

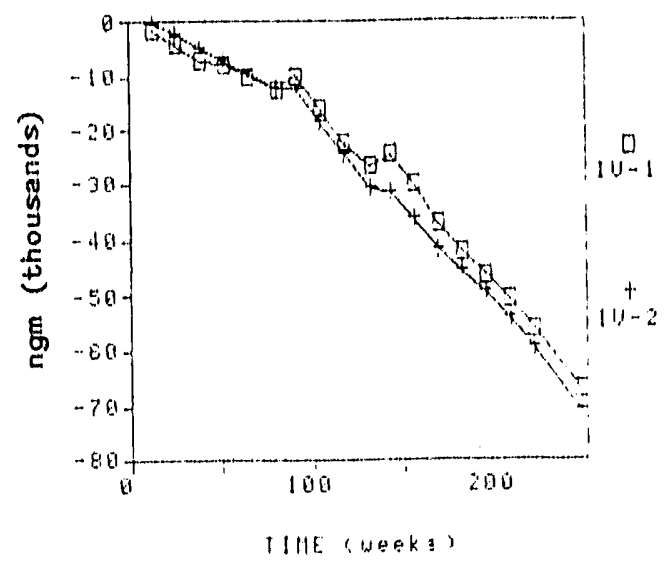

Eiliogr

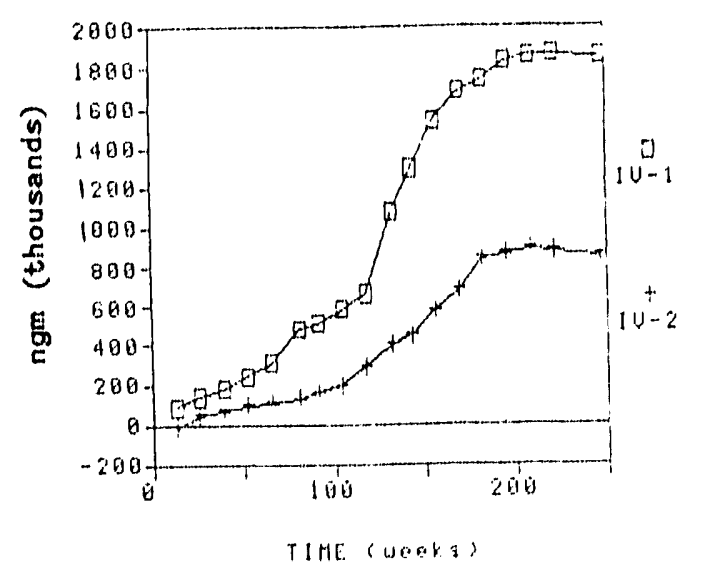

Fig. 25. Cumulative Release of Selected Elements from the P-IV-1 and P-IV-2 Continous Experiments 
Table 11. Normalized Elenented Release for the P-IV Sorles

\begin{tabular}{|c|c|c|c|c|c|c|}
\hline \multirow[b]{2}{*}{ Test \# } & \multirow{2}{*}{$\begin{array}{l}\text { Poriod } \\
\text { (woeks) }\end{array}$} & \multicolumn{5}{|c|}{ Normallzed Release $\left(\mathrm{g} / \mathrm{m}^{2}\right)$} \\
\hline & & $\mathrm{Na}$ & Si & $\mathrm{B}$ & $\mathrm{Ll}$ & $\mathrm{U}$ \\
\hline P-IV-3 & 25.5 & 2.4 & 0.6 & 1.4 & 2.3 & $1 .()$ \\
\hline$P-I V-4$ & 25.5 & 2.1 & 0,0 & 1.2 & 2.0 & 1.0 \\
\hline P-IV-5 & 52 & 4.4 & 1.5 & 2.9 & 3.8 & 2.0 \\
\hline P-IV-6 & 52 & 4.5 & 1,0 & 1.7 & 3.1 & 1.0 \\
\hline P-IV 1 & $\begin{array}{r}52 \\
104 \\
156 \\
208 \\
247\end{array}$ & $\begin{array}{r}4.1 \\
9.3 \\
1.9 .8 \\
24.2 \\
23.2\end{array}$ & $\begin{array}{r}1.4 \\
3.4 \\
9.0 \\
10.8 \\
10.8\end{array}$ & $\begin{array}{r}3.8 \\
9.8 \\
20.6 \\
24.6 \\
24.8\end{array}$ & $\begin{array}{r}5.0 \\
11.0 \\
23.2 \\
28.4 \\
29.0\end{array}$ & $\begin{array}{r}3.8 \\
7.8 \\
15.8 \\
18.8 \\
19.7\end{array}$ \\
\hline P-IV-2 & $\begin{array}{r}52 \\
104 \\
156 \\
208 \\
247\end{array}$ & $\begin{array}{r}2.9 \\
4.8 \\
9.7 \\
13.5 \\
12.2\end{array}$ & $\begin{array}{l}0.6 \\
1.2 \\
3.4 \\
5.3 \\
5.1\end{array}$ & $\begin{array}{r}2.7 \\
5.8 \\
9.7 \\
13.2 \\
13.4\end{array}$ & $\begin{array}{r}3.8 \\
7.1 \\
11.9 \\
16.4 \\
16.7\end{array}$ & $\begin{array}{r}2.7 \\
4.8 \\
8.5 \\
11.7 \\
12 .(0\end{array}$ \\
\hline
\end{tabular}

In contrast, the top surfaces are completely covered with a rather uniform fine-grained material whose morphology is only apparent at very high magnification. The "as-cut" contours of the original glass surface are still casily discernible. Cracking and puckering of the layer are visible but this has not progressed to the point of exfoliation. The uniformity of this deposit, and the preservation of the original surface topography, suggest this layer formed mostly through alteration of the glass rather than by precipitation. A precipitated layer tends to have irregular coverage and masks surface features. However, numerous small precipitated grains rich in $\mathrm{Ca}$ and $\mathrm{S}$ or $\mathrm{Cr}, \mathrm{Mn}, \mathrm{Fe}$, and $\mathrm{Ni}$ occur on the surface.

The P-IV experinents have the greatest normalizod elemental release of any of the parametric experiments. This is a curious result consiclering that the volume of injected water is less than for the other experiments. It is possible that the smaller fluid volume saturates more rapidly, thereby causing precipitation of secondary phases. This could in turn enhance glass reaction by maintaining solute concentrations significantly below the apparent saturation lovel for the glass. However, the amount of precipitates on the P-IV samples is certainly no more and probably less than that observed on samples from other experiments. Furthermore, observation of the WPA's during sampling of the continuous experiments indicates that the surfuces were always wet or damp which is not the case for most other experiments. This suggestos greuter 
water-glass contact despite the fact that loss water is injected. An explanation for the high release in the P-IV experiments may be that glass reaction is continuous due to the perpetual avallability of water. In other experiments, where WPA surfaces are occasionally observed to be damp or dry, glass reaction would only be periodic in nature.

\section{P-V Experiments}

In this set of experiments, the injection rate is reduced from one drop avery 3.5 days to one drop every 14 days. All other paraneters follow the stindard configuration and procedure. The experimental matrix is given in Table 12. The P-V series was initiated on $6 / 10 / 85$ and the batch experiments werc terminated after $26,52,110$, and 254 weeks. One continuous experiment has been in progress for 234 weeks while the other was terminated after 39.5 weeks because of problems that arose with the WPA during sampling. At the onset, the experiments were conducted using silicone gaskets in an attempt to minimize water loss. This sort of gasket has been used in MCC..1 type leaching experiments with no observed loss of solution. ${ }^{13}$ However, in the P.V oxperiments, the silicone rubber extruded inside the vessel during closure, providing the opportunity for Si contamination of the solution that collected at the bottom of the vessel. The gasket material in the continuous experiments was changed to Teflon TM after the 26-week sampling.

\section{General Observations}

Upon termination of the batch experiments, the bottom of the WPA was always wet with some standing water present. The top of the WPA ranged from wet with standing water rimming the inside of the circular holes in the metal, to damp with no stunding water, to completely dry in the exposed surface areas. For the continuous experiment, the bottom was usually wet with standing water, however, sometimes it was damp or dry. The top ranged from wet to dry, with dry being the most common state.

All the metal components have a shiny appearance with no local discoloration occurring in any of the experiments. No particulates were ever observed in the solutions during sampling. The glass gained a small amount of woight in all the experiments (Table 12). Some of the metal components gained a very small amount of weight while others showed a slight weight loss.

\section{Component Analyses}

The glass from all the terminated batch experiments was examined optically. The top and bottom surfaces of P-V-3, P-V-4, and P-V-7 were studied by SEM/EDS, but only the top of P-V-6 was investigated. None of the metal components were examined in detail. 


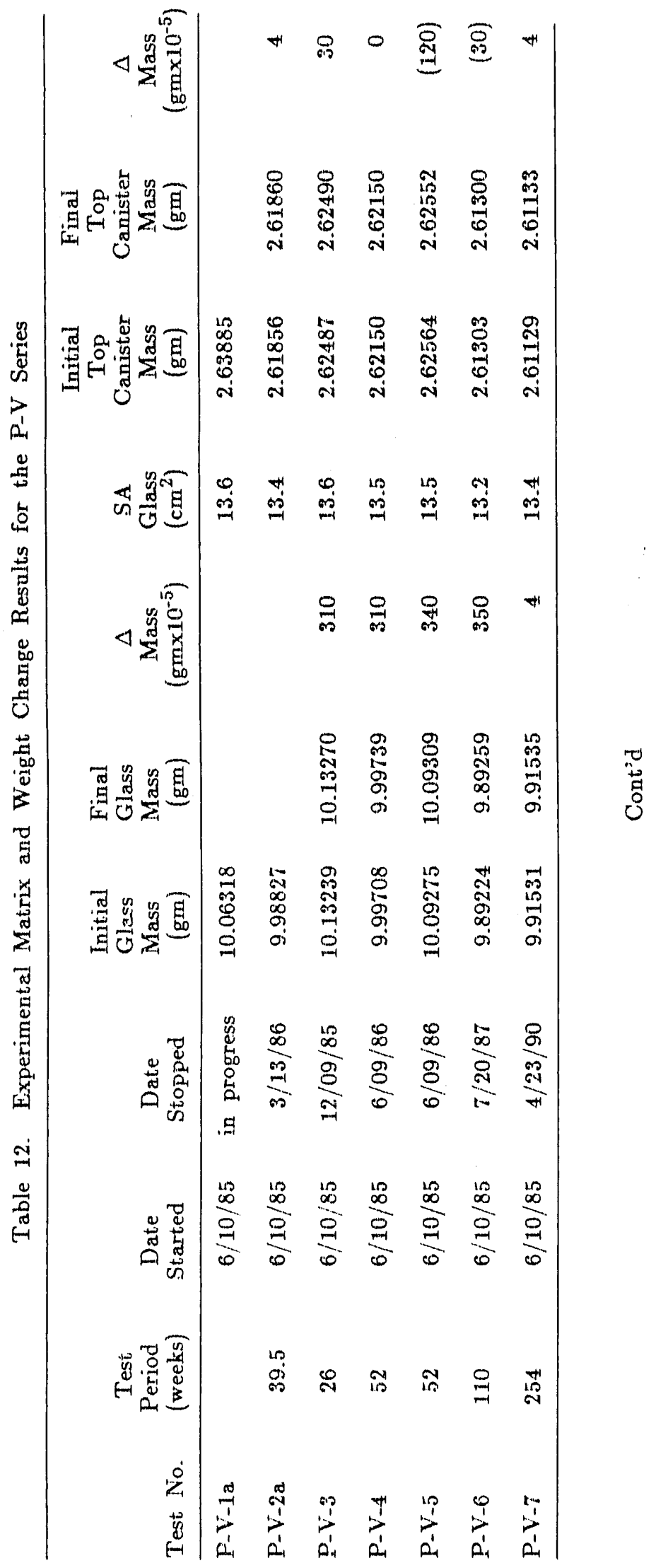




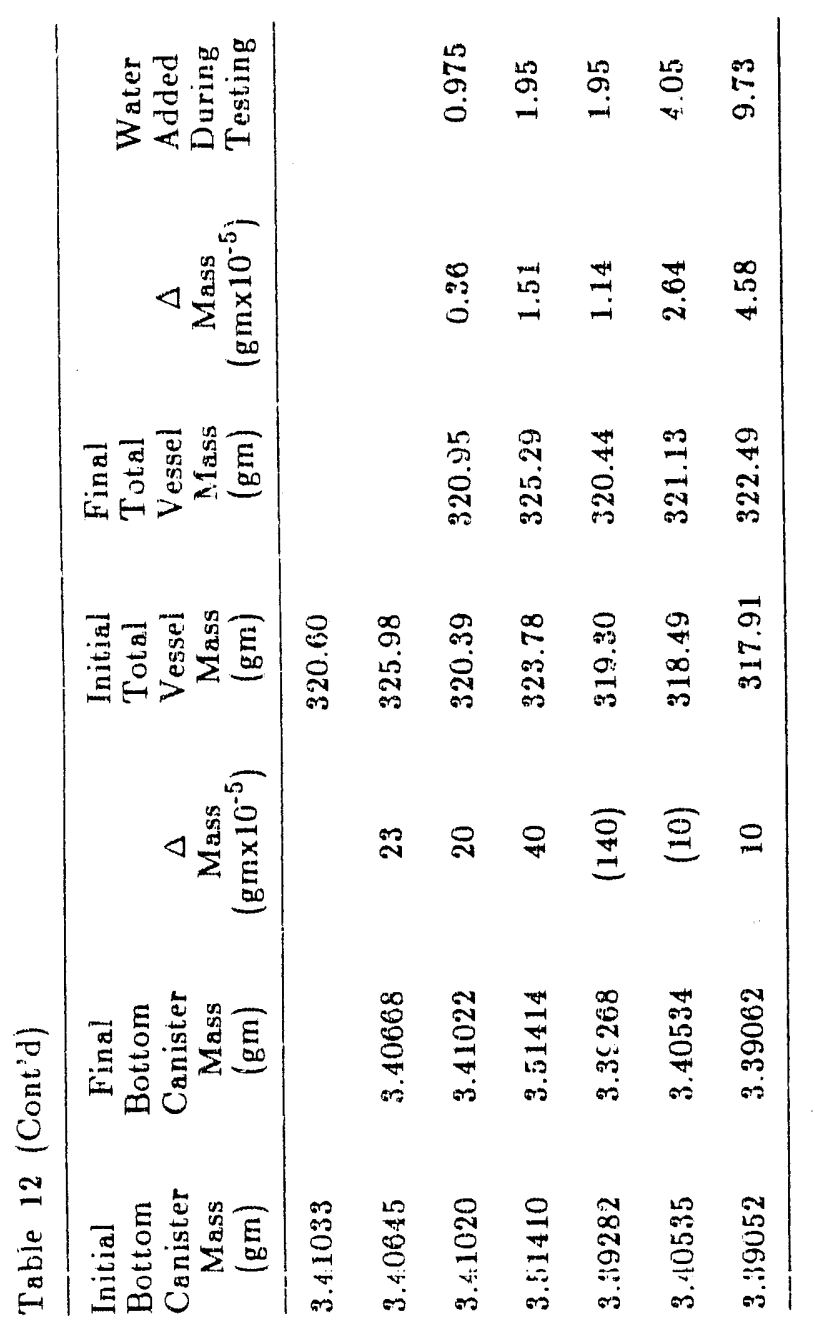




\section{a. P-V-3, 26-Week Sample}

The top surface has clearly marked circular regions corresponding to the noncontact areas. Five of the circular regions are a light gray in contrast to the brown/black background of the glass. The remaining two circular regions have a splotchy light blue-gray appearance, as though the reaction has not progressed to the extent observed in the other noncontact areas. The general appearance of the top surface is not much different than the bottom surfaces from the P-III and P-IV experiments. Several string-like deposits occur at the noncontact-contact boundary. Approximately one half of the contact area has a bluish cast. Superimposed upon this color scheme is a coarser area caused by saw marks. There is a mottled appearance in this region. This appears to be the result of puckering of the surface layer away from the glass. Within some of the saw marks there is a deep blue iridescent appearance, possibly from exposed glass.

For the most part, the top surface preserves the original "as-cut" appearance. A surface layer is developing, although it is not complete and glass is still exposed (Fig. 26a). The distinction between the original glass and the surface layer is not always clear. In general, the sharp edges and ridges become more rounded and stress and chattermarks begin to disappear (Fig. 26a). In some areas, a textured surface is beginning to develop, visible only at high magnification. A Si-rich deposit, essentially the same composition as the surface layer has locally precipitated (Fig. 26b). This is the origin of the string-like marks observed optically at the noncontact-contact boundary. In the rougher regions (caused by saw marks), the surface layer is beginning to pucker and pull away from the glass (Fig. 26c). No complete exfoliation has occurred.

There are a number of phases that have precipitated on the top glass surface. In addition to the $\mathrm{Si}$-rich deposit, small isolated ciumps of Sirich "clay" are present on the surface. These often have $\mathrm{CaSO}_{4}$ intermingled with the "clay". Small "flowers" of $\mathrm{CaSO}_{4}$ (whether this is gypsum or anhydrite has not been determined) occur randomly on the surface (see Figs. 26a and 26c). The next most abundant phase is $\mathrm{Cr}-\mathrm{Mn}$ rich and occurs mostly in small $(<5 \mu \mathrm{m})$ spheres, although some grains are tabular. Some grains have $\mathrm{Mn}>\mathrm{Cr}$ and contain $\mathrm{Fe}$, but the dominant composition is $\mathrm{Cr}$ and $\mathrm{Mn}$ only with $\mathrm{Cr}>\mathrm{Mn}$ (Fig. 26d/EDS). These are probably oxides or hydroxides. One portion of the surface has colonies of small Cr-Mn grains (Fig. 26e). The abundance of $\mathrm{Cr}$ is unusual and this phase has only rarely been observed on the stainless steel components of other experiments (e.g., on P-VIII-7). Several other precipitated phases include silica, $\mathrm{Al}$-rich grains, $\mathrm{NaCl}, \mathrm{KCl}$, calcite, and a $\mathrm{Ca}-\mathrm{P}$ phase, possibly apatite.

The noncontact areas on the bottom surface are poorly defined, being only a little lighter in color than the brown-black contact areas. Like the top, there is a rougher region which has a coarse speckled appearance.

The surface layer is less well developed than the top. The criteria described for the top glass were used to distinguish altered and unaltered surfaces. The layer consists of dispersed altered areas which have an irregular distribution and appear to be a function of the original surface roughness. No puckering of the altered surface was observed. Unlike most other experiments, the top surface appears to be more reacted than the bottom surface. 
(a)

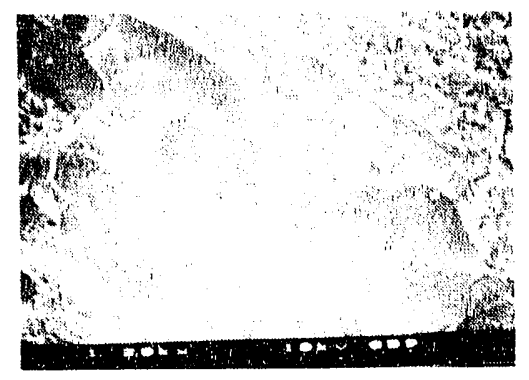

(c)

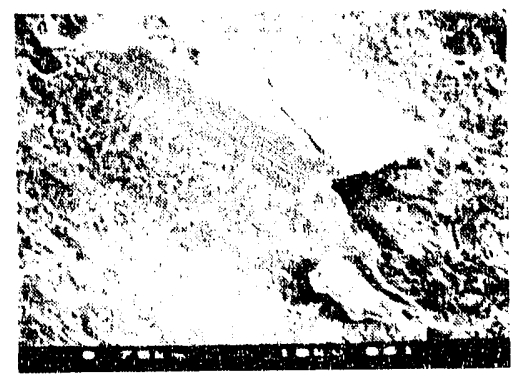

(e)

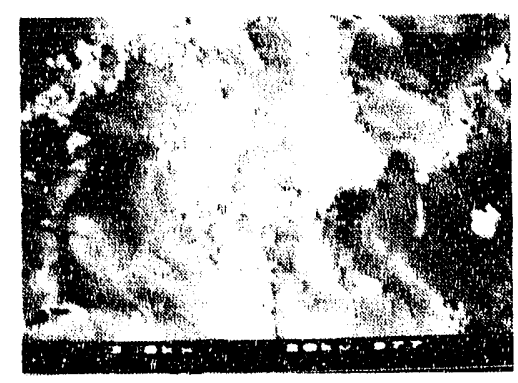

(b)

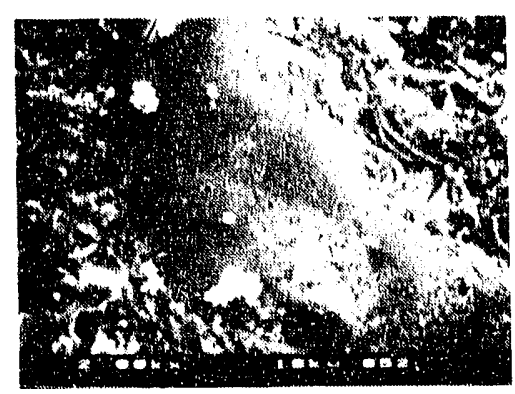

(d)

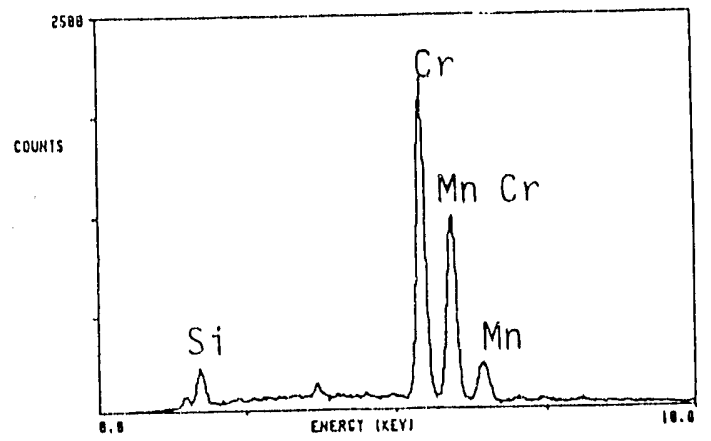

Fig. 26. SEM Micrographs of the Surface Layer and Reaction Products on the Top Surface of P-V-3. (see text).

(a) $1200 \mathrm{X}$, (b) $2000 \mathrm{X}$, (c) $750 \mathrm{X}$, and (e) $3000 \mathrm{X}$

Small patches of precipitates occur on both the altered and unaltered surfaces. The amount of precipitates is small compared to the top glass. The most common phases are Si-rich "clay" and $\mathrm{CaSO}_{4}$ (gypsum or anhydrite). In addition to occurring as small "flowers," there is a large round mat $(\sim 130 \mathrm{~mm})$ of $\mathrm{CaSO}_{4}$ near the edge of the glass. There are a number of beam sensitive grains distributed on the surface that appear to only contain $\mathrm{Na}$ like those observed on the P-II experiments. These may very will be $\mathrm{Na}_{2} \mathrm{CO}_{3}$. Other phases include calcite, dolomite, Al-rich grains, mixed grains with $\mathrm{Na}, \mathrm{K}$, $\mathrm{Ca}, \mathrm{Cl}$, and $\mathrm{S}$, and a Ti-bearing mixed grain. 


\section{b. P-V-2, 39.5-Week Sample}

Although this sample was intended as a continuous experiment, it was abruptly terminated during the 39.5-week sampling due to problems with the WPA. The top surface has a similar appearance to the top of P-V-3. Most of the surface has a brown-black color. Several areas in the contact and noncontact areas have a light blue cast. The noncontact areas are partially covered by light-colored precipitates. String-shaped deposits occur at the noncontact-contact area boundaries. There is also a small coarse-grained area that has a speckled appearance.

The bottom is generally coarser grained with speckles like that of P-V-3. The noncontact areas are gray with bluish haloes extending into the contact areas. Very few precipitates are observable.

\section{c. P-V-4 and P-Y-5, 52-Week Samples}

Sample P-V-4 was investigated optically and by SEM/EDS, but P-V-5 was only examined optically. The top glass surfaces are somewhat different in appearance. The contact areas on P-V-4 are either brown-black or have a milky blue hue, similar to the tops of $\mathrm{P}-\mathrm{V}-3$ and $\mathrm{P}-\mathrm{V}-2$. The majority of the P-V-5 contact area has a shiny honey-brown color. On both samples the noncontact areas have a deposit of precipitates in the middle, surrounded by a grayish region. Discontinuous string-shaped deposits are developed at several of the noncontact area boundaries.

From SEM/EDS observation, the top glass of P-V-4 has reacted much more than the top of the P-V-3 experiment. The surface has a fuzzy appearance at low magnification indicating that an altered layer has developed. At high magnification, the surface has a variable texture. In some places it is quite smooth with only a hint of fine scale structure. Elsewhere, a coarser texture is developed, reminiscent of the "cardhouse" texture observed on the P-VIII samples (Fig. 27a). There is a range in the coarseness which may correspond to progressive recrystallization of an initially amorphous hydrated layer, although this is only a hypothesis. Alternatively, the coarser areas may have formed by precipitation.

In a number of places the surface layer is cracked and exfoliation has begun. This is best developed in the noncontact areas although it also occurs in the contact areas, especially where the "as-cut" surface is rough. A more complex layer structure is revealed in these areas. The altered layer is actually composed of three or four discrete layers (Fig. 27b). The bottom layer has a coarse texture. Above this are one or two smoother layers. The outermost layer is coarse, having an appearance similar to the bottom layer. The outermost layer is discontinuous, suggesting it formed by precipitation. This patchy distribution results in the observed variation in surface texture described above. The compositions of all the layers are similar and are consistent with the coarse layers being Fe-rich smectite. Small clumps of precipitates are present on all exposed surfaces and have the same composition as the altered layer (see Figs. $27 \mathrm{a}$ and $27 \mathrm{~b}$ ). In some places the smooth layer has a mottled appearance (Fig. 27c). EDS analysis indicates that this is due to the incorporation of $\mathrm{Cr}-\mathrm{Mn} \pm \mathrm{Fe}$ oxide or hydroxide grains within this layer (Fig. 27d/EDS). 
(a)

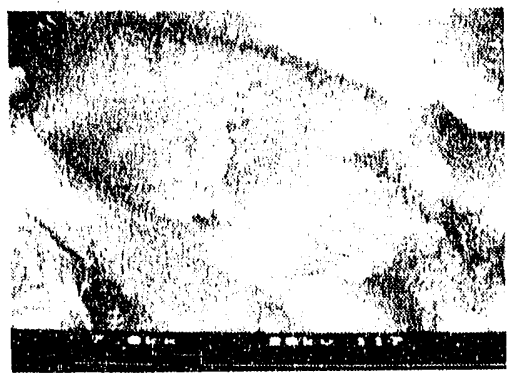

(c)

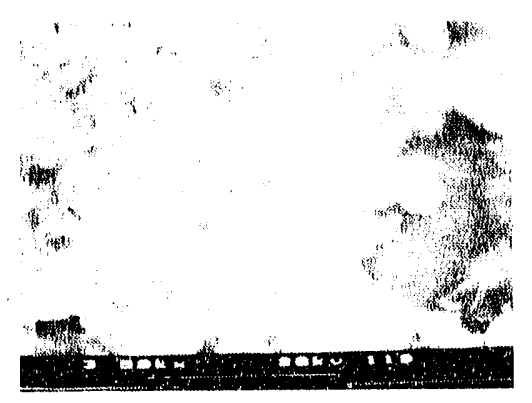

(b)

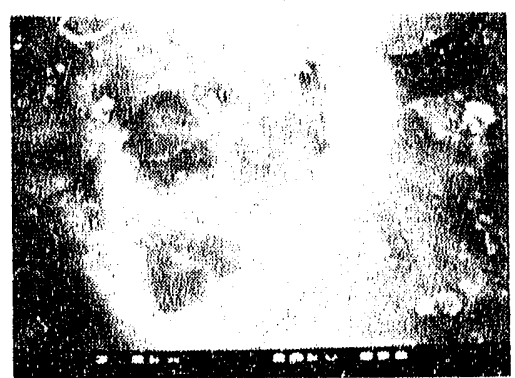

(d)

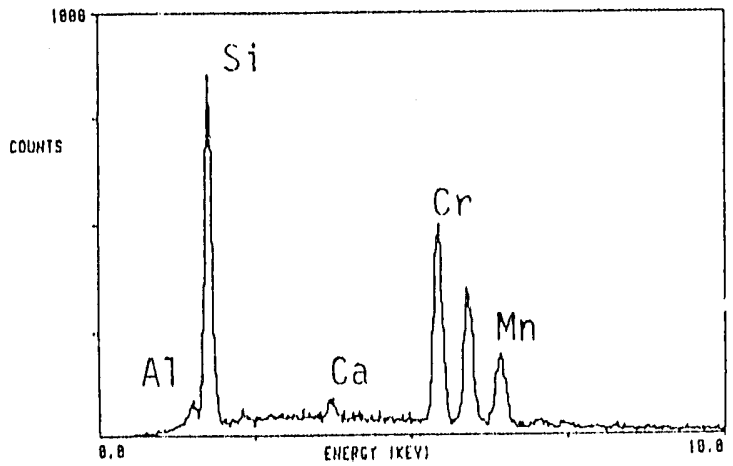

Fig. 27. SEM Micrographs and SEM Spectrum of Reaction Products on the Top Glass Surface of P-V-4. (a) 7000X, (b) $3200 \mathrm{X}$, (c) $3500 \mathrm{X}$ (see text).

Aside from the Si-rich "clay" (smectite?) and the Cr-Mn*Fe oxide/hydroxide grains, $\mathrm{CaSO}_{4}$ (gypsum or anhydrite) is the predominant secondary wineral. There are also some Al-rich grains present that may be gibbsite.

The bottom surfaces of $\mathrm{P}-\mathrm{V}-4$ and $\mathrm{P}-\mathrm{V}-5$ are coarser than the tops and are similar to $\mathrm{P}-\mathrm{V}-3$. The contact area of $\mathrm{P}-\mathrm{V}-5$ is generally brownblack while that of $\mathrm{P}-\mathrm{V}-4$ is a lighter shiny tan color. The noncontact areas are grayish on both samples and the circular marks extend into the contact area. There are very few precipitates optically visible.

The bottom surface of P-V-4 has a general fuzzy appearance but this is not as well developed as on the top surface. The altered surface is fairly smooth with only a little fine scale texture. In places the texture is somewhat coarser although this material may have formed by precipitation. This is suggested by the areas where the coarser material is restricted to high points and ridges and appears to spread into surface depressions (Fig. 28a). Etching of the surface is suggested by the presence of cuspate depressions on the surface. Preferential etching of stress marks is also apparent and, in some cases, tinese etched marks provide nucleation sites for Si-rich "clay" precipitates (Fig. 28b). In the rougher areas cracking and exfoliation have begun, but this is much less advanced compared to the top surface. The only other precipitated phase besides the Si-rich "clay" is $\mathrm{CaSO}_{4}$ (either gypsum or anhydrite). 
(a)

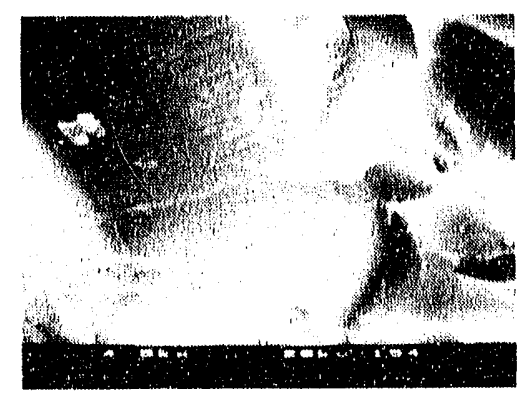

(b)

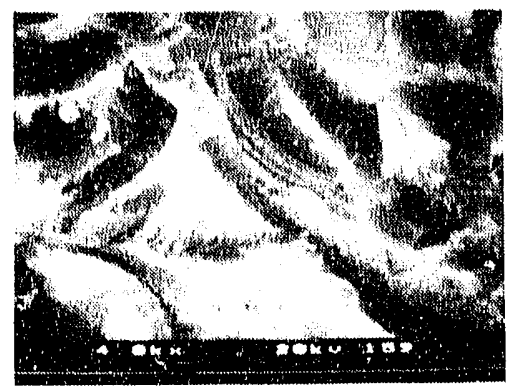

Fig. 28. SEM Micrographs of the Bottom Surface of P-V-4. (a) $4500 \mathrm{X}$ and (b) 4000X (see text)

\section{d. P-V-6, 110-Week Sample}

The top and bottom surfaces were examined optically but only the top surface was investigated by SEM/EDS. The bottom surface has an appearance like the other P.V samples (see above). The noncontact areas have complex variations in color, creating bull's eye type features. The central portions are gray and are surrounded by successive rings which are brown-black, then blue, followed by gray at the outer margins.

The top surface of P-V-6 is megascopically smoother than any other sample surface (Fig. 29a). It appears that the "as-cut" surface was ground down somewhat prior to the experiment. There are, however, numerous shallow striations with different orientations distributed across the surface, which occur as white streaks on a brown-black background. The noncontact areas have a variably developed milky white hue. Some light-colored precipitates occur in the noncontact areas.

From observation using the SEM/EDS, there is a fine-scale texture which varies from smooth to coarse, although it is never as coarse as observed on the top of P-V-4. The surface has more of a flaky texture rather than a "cardhouse" texture (Fig. 29b, compare with Fig. 27a). In some areas, mostly in proximity to the contact-noncontact boundaries there is a thicker buildup of the surface layer. This may be due to a thickening of the surface layer or from precipitation. There is no evidence for the presence of a complex layer structure. Some minor cracking and puckering of the surface layer is observable (Fig. 29c). The location of the puckered areas seems to be controlled by the shallow striations and the few remaining saw marks on the surface. Overall, the surface layer appears to be less well developed compared to P-V-4, even though the duration of P-V-6 was twice as long. This suggests that initial surface roughness may play a role in accelerating surface layer development and the initiation of exfoliation. 
(a)

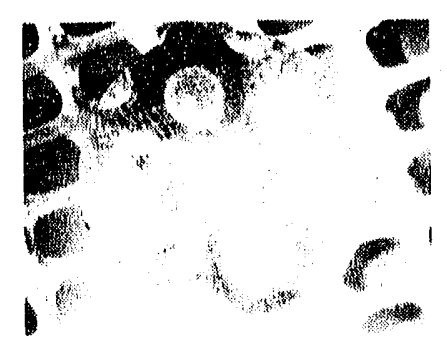

(c)

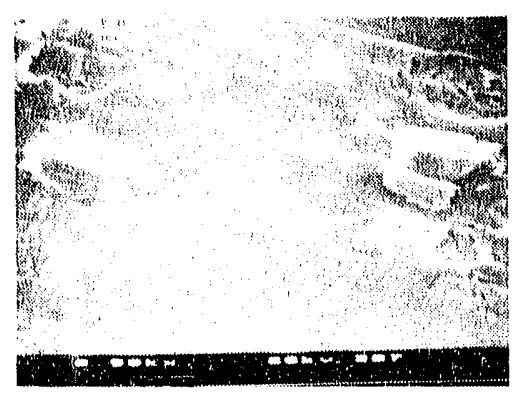

(b)

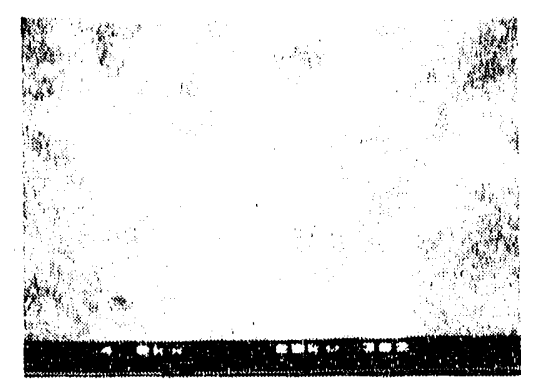

(d)

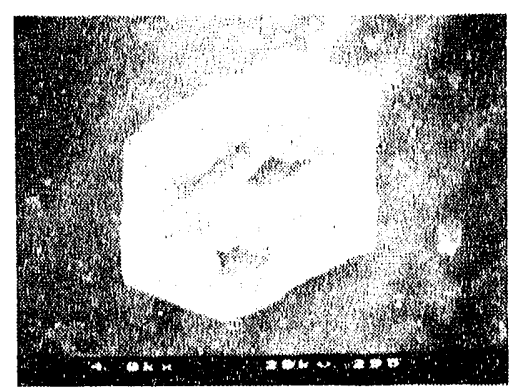

Fig. 29. SEM Micrographs Showing the General Surface Features on the Top of P-V-6. (a) $6 \mathrm{X}$, (b) $4000 \mathrm{X}$, (c) $500 \mathrm{X}$, and (d) $4000 \mathrm{X}$ (see text)

In contrast with all the other samples in the P.V series, no $\mathrm{CaSO}_{4}$ is present. Instead, $\mathrm{CaCO}_{3}$ occurs in fine fluffy masses and as fairly large (up to $20 \mu$ ) euhedral grains (Fig. 29d). The large euhedral grains show evidence of having undergone an episode of dissolution. As $\mathrm{CaCO}_{3}$ has retrograde solubility, this may have occurred when the sample was cooled during termination of the experiment. The only other secondary phase is $\mathrm{Cr}-\mathrm{Mn} \pm \mathrm{Fe}$ oxide or hydroxide. These occur as fine grains distributed across the surface and sometimes in small colonies similar to P-V-7 (see Fig. 30d). In some places, small clusters of grains occur within the layer which imparts a mottled appearance, similar to that observed on the top of $\mathrm{P}-\mathrm{V}-4$.

\section{e. P-V-7, 254-Weak Sample}

This sample is from the longest duration batch experiment. The top surface is similar to the other $\mathrm{P}-\mathrm{V}$ experiments except that no saw marks are present. There are two well-defined regions, one which is brown-black and another which has a light blue-gray cast. The noncontact areas are poorly discernible. In two of these areas, there are small masses of milky-blue precipitates. There are a number of string-shaped deposits in the contact area (see below). In two noncontact areas and near the edge of the glass, there are patches of large prismatic grains, which EDS analyses suggest are calcite (see below). 
(a)

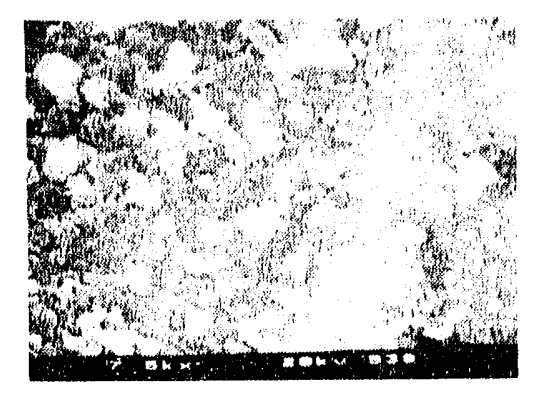

(c)

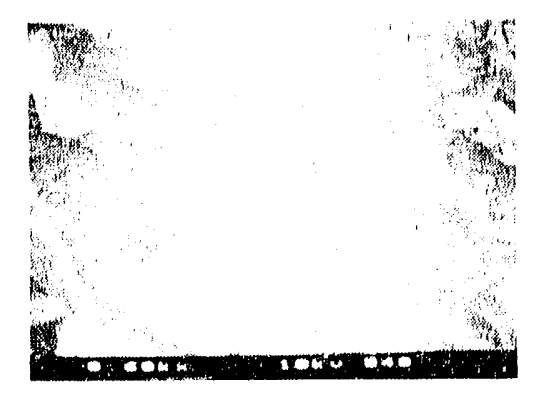

(e)

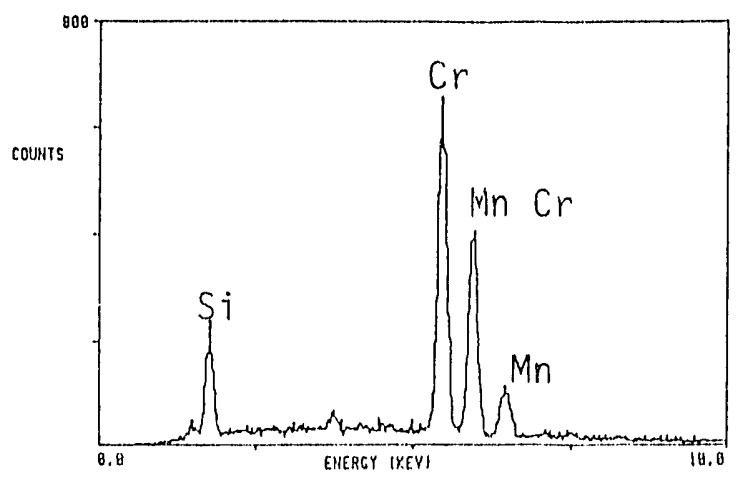

(g)

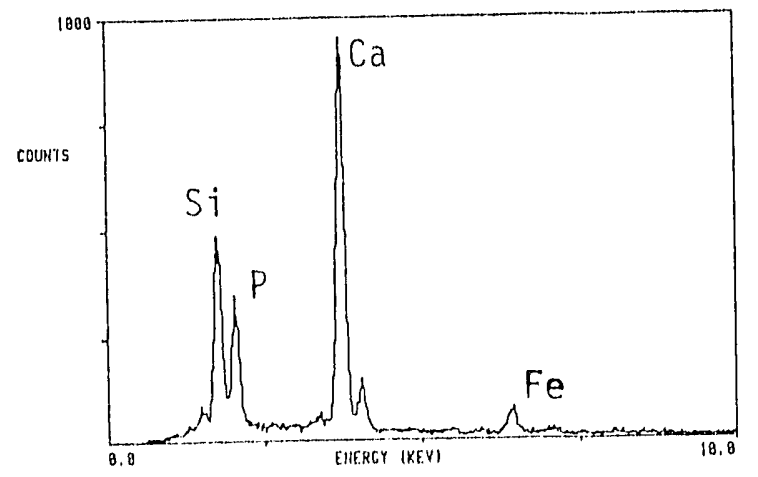

(b)

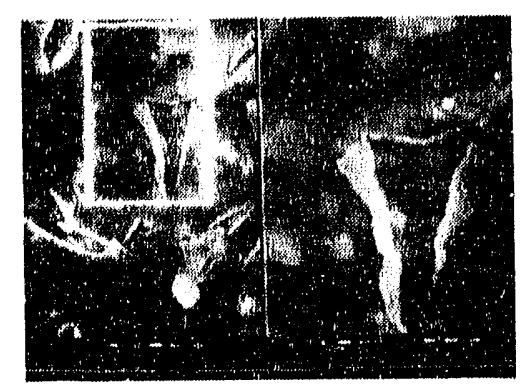

(d)

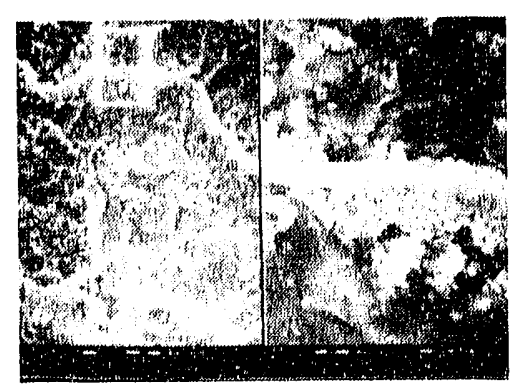

(f)

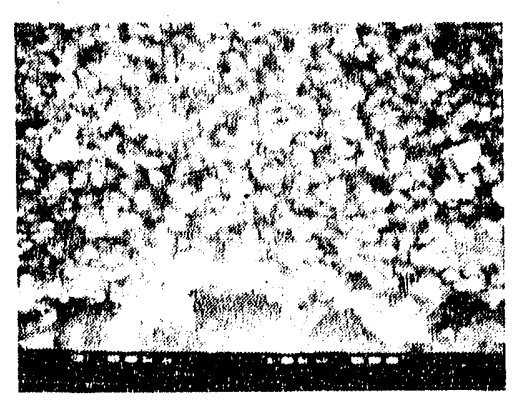

Fig. 30 .

SEM Micrographs of the Surface Layer and Other Reaction Products on the Top of P-V-7. (a) 7500X, (b) 4000X, (c) $600 \mathrm{X}$, and (d) $500 \mathrm{X}$ (see text) 
A reacted layer has developed on the top surface, giving a fuzzy appearance at low magnification. The "as-cut" surface is generally preserved although the contours are noticeably rounded. At higher magnification the surface has a variably developed flaky texture similar to that observed on P-V-4 (Fig. 30a). The flaky texture is generally coarser in the noncontact areas. A hummocky appearance has developed, indicating local variations in layer thickness. The flaky texture and composition suggest the layer is composed of Fe-smectite.

A complex layer structure has locally developed in both the contact and noncontact areas. A thin, smooth layer is draped over the flaky textured material. This deposit is frequently cracked and split, revealing the coarser material from below (Fig. 30b). The smooth areas are somewhat enriched in $\mathrm{Si}$ relative to Al. Discontinuous sheets of precipitates have formed on top of the smooth layer, although to a lesser extent than that observed on P-V-4. It would seem, based on examination of the surfaces only, that the top of P-V-4 has evolved to a greater extent even though it was terminated after only 52 weeks. There is no evidence of large-scale exfoliation; however, there are many places where the layer has cracked and pieces have raised up from the surface. The lack of considerable exfoliation may be attributable to the absence of rough saw-marked regions on the surface.

Calcite is abundant, especially in the noncontact areas. Several colonies of large $(\sim 60 \mu \mathrm{m})$ etched prismatic grains are present (Fig. 30c). Small isolated grains of calcite are also present, often associated with other secondary phases. Fine $\mathrm{Cr}$ - and Mn-rich grains, presumably oxide or hydroxide, occur as small clusters and as large colonies (Figs. 30d and 30e/EDS). This phase is responsible for the string-shaped deposits observed under the optical microscope. Both calcite and the Crm-Mn-rich phase were observed on P-V-6. Other colonies on the top glass are composed of $\mathrm{Ca}$ - and P-bearing grains (Figs. 30f and $30 \mathrm{~g} / \mathrm{EDS}$ ). These may very well be apatite. Rare Timrich grains are present which may be anatase $\left(\mathrm{TiO}_{2}\right)$.

The bottom giass surface is similar to the other P-V samples. The noncontact areas are well marked and the light gray coloration extends into the adjacent contact area. The contact area is brown-black with some lightcolored speckles. The surface layer appears to be pulling away from the glass but no exfoliation is apparent.

The bottom surface has a fuzzy surface at low magnification under the SEM. The "as-cut" contours are partially obscured. In detail, the surface layer is quite different compared to the top. Two distinct layers are apparent, although the upper layer is discontinuous (Fig. 31a). The upper layer has a "cardhouse" texture indicative of precipitated smectite. Its composition is consistent with this interpretation. In some places, it seems as though the upper layer has only partially formed (Fig. 31b), while elsewhere it appears to have formed and exfoliated (Fig. 31a). The lower layer has a bumpy texture with the individual bumps $\sim 0.5 \mu \mathrm{m}$ across (Figs. $31 \mathrm{~b}$ and $31 \mathrm{c}$ ). Locally there is a preferred orientation to the bumps, possibly related to the presence of stress marks on the original glass surface. The alignment is apparent particularly in 
(a)

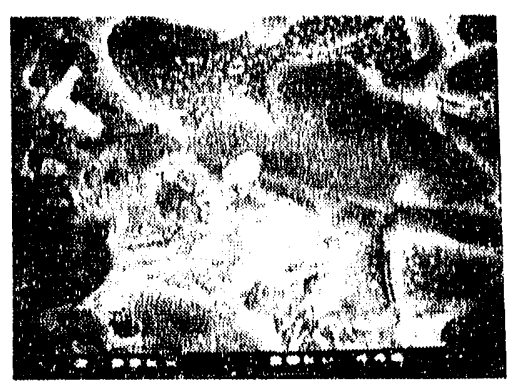

(b)

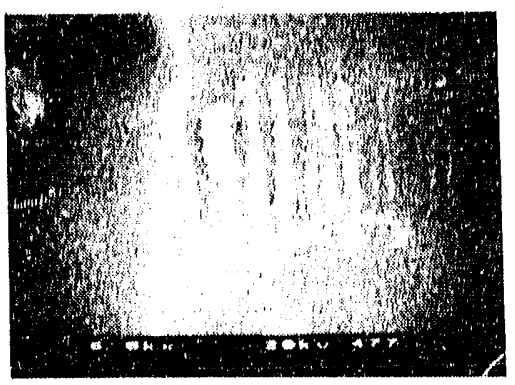

(c)

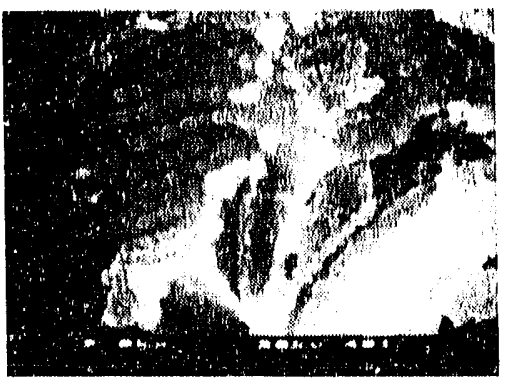

Fig. 31. SEM Micrographs of Surface Layer Features on the Bottom of P-V-7. (a) $2900 \mathrm{X}$, (b) $6000 \mathrm{X}$, and (c) $9000 \mathrm{X}$ (see text)

Fig. 31c but is also visible in Fig. 31b. Preferential precipitation of the Si-rich "clay" occurs on these aligned bumps. The lower layer shows extensive cracking and puckering from the surface; however, no complete exfoliation has occurred. There are very few precipitated grains on the surface aside from the Si-rich "clay". Traces of $\mathrm{S}$ and $\mathrm{Cl}$ are occasionally detectable in EDS analyses of the surface layer.

\section{Solution Analyses}

Elemental releases from the P-V-1 continuous experiment are shown in Fig. 32 and normalized releases for $\mathrm{Li}, \mathrm{B}$, and $\mathrm{U}$ are given in Table 13. The raw data and background subtracted cumulative releases are included in Appendix I for both the continuous and batch experiments.

The P-V experiments have the smallest element release of any of the parametric experiments. There are, however, several factors that hamper interpretation of the solution data. The most significant problem results from the lack of recovered solution during sampling. When the solution was diluted to obtain enough for chemical analysis (usually 20 times the original volume), many elements including $\mathrm{Li}, \mathrm{B}$, and $\mathrm{U}$ were sometimes below the level of detection. For the P-V-1 experiment B was below the detection limit on nine occasions (out of a total of 17), while $\mathrm{Li}$ and $\mathrm{U}$ were below the limit three times. Since the detection limit value is used when computing cumulative release, the magnitude of release must be viewed as a maximum. Similarly, trends also represent maximum rates of release. Another problem involves the observed extrusion of the silicone rubber gaskets into the vessels. It is unknown what contribution, if any, the gaskets made to the amount of Si in solution, but the reported Si values must be suspect for the first 26 weeks.

The concentrations of $\mathrm{Ca}$ and $\mathrm{Na}$ were always above the detection limit even though both have a net negative cumulative release. This corresponds to the precipitation of $\mathrm{Ca}$ - and $\mathrm{Na}$-bearing phases on the WPA. The erratic behavior of $\mathrm{Na}$ suggests that precipitation of an Na-bearing phase occurs when little water is available and it is subject to dissolution when more water is present. 
Earor

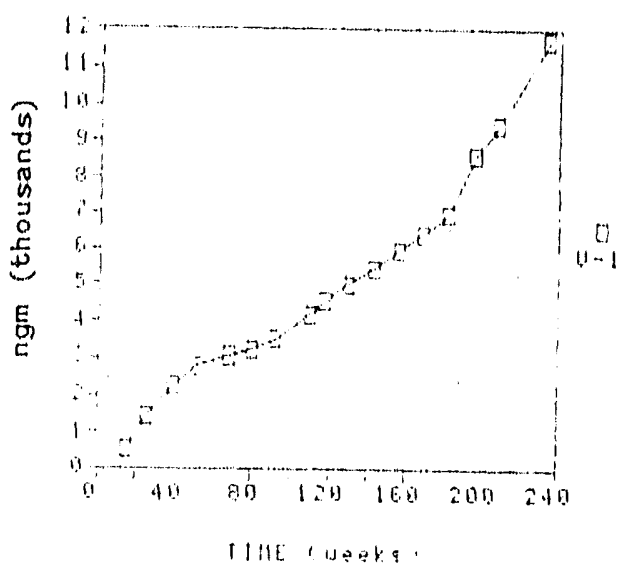

1.

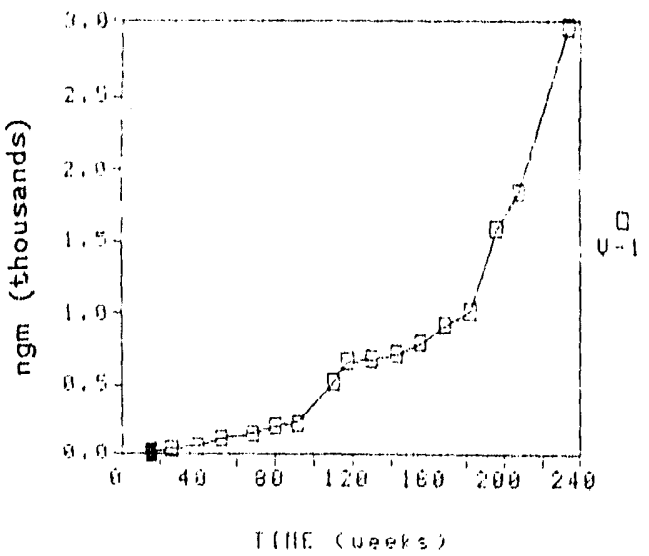

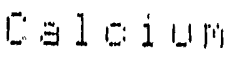

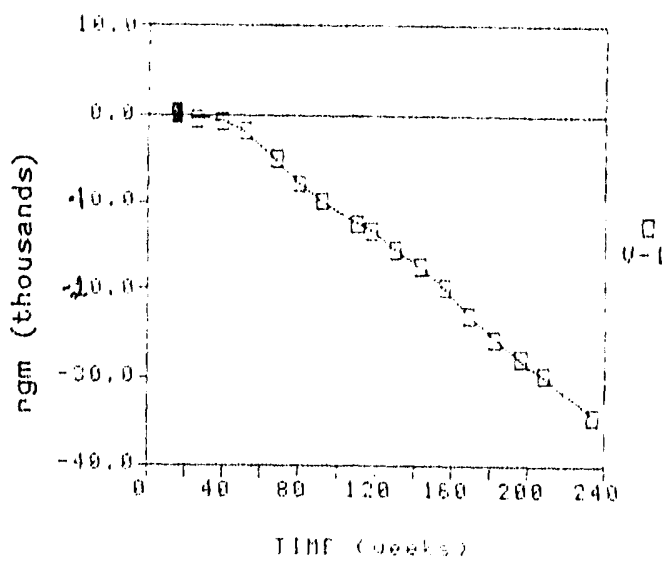

Lith 1 um

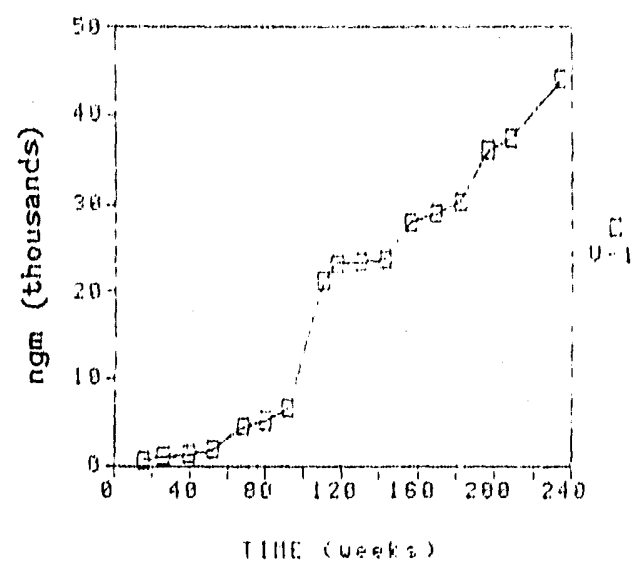

Sodiu

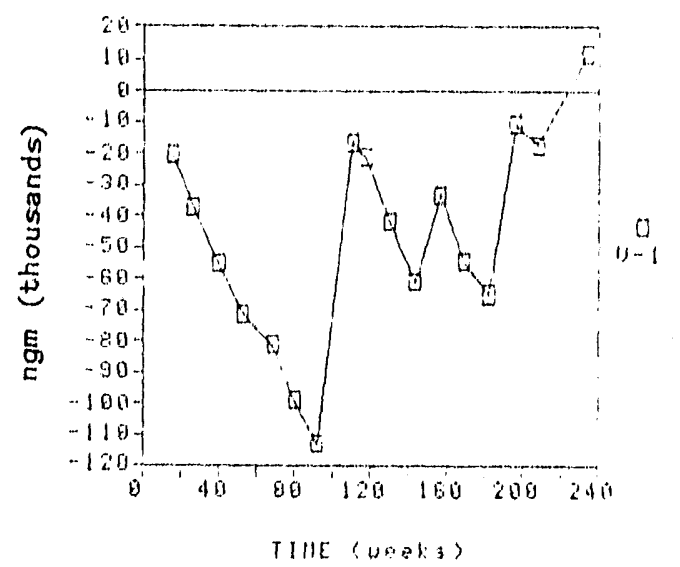

Eilioon

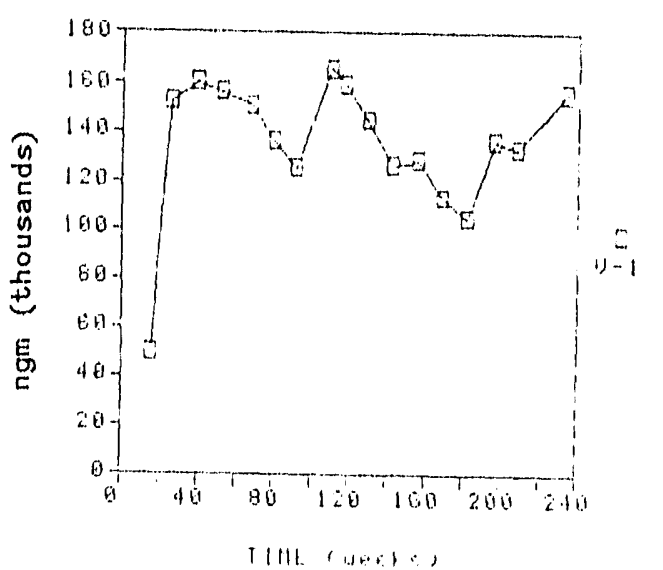

Fig. 32. Cumulative Releases of Selected Elements from the P-V-1 Continuous Experiment 
Table 13. Normalized Elomental Relouse for the P-V Series

\begin{tabular}{lcccc}
\hline & & \multicolumn{3}{c}{ Normalized Releaso $\left(\mathrm{g} / \mathrm{m}^{2}\right)$} \\
\cline { 5 - 6 } Test \# & $\begin{array}{c}\text { Period } \\
\text { (weeks) }\end{array}$ & $\mathrm{B}$ & $\mathrm{Li}$ & $\mathrm{U}$ \\
\hline P-V-3 & 26 & 0.2 & 0.0 & 0.1 \\
P-V-4 & 52 & 0.4 & 1.1 & 0.3 \\
P-V-5 & 52 & 0.3 & 1.0 & 0.2 \\
& & & & \\
P-V-6 & 110 & 0.2 & 0.0 & 0.1 \\
& & & & \\
P-V-1 & 26 & 0.1 & 0.0 & 0.0 \\
& 52 & 0.1 & 0.1 & 0.0 \\
& 110 & 0.2 & 0.8 & 0.1 \\
& 156 & 0.2 & 1.1 & 0.1 \\
& 182 & 0.2 & 1.1 & 0.1 \\
& 208 & 0.3 & 1.4 & 0.2 \\
& 234 & 0.4 & 1.7 & 0.3 \\
P-V-2 & & & & \\
& 26 & 0.1 & 0.1 & 0.0 \\
& 39.5 & 0.1 & 0.5 & 0.1 \\
\hline
\end{tabular}

"Values are affected by the Si contributed by the silicone rubber gasket.

\section{Discussion}

The P-V samples appear to have undergone less alteration compared with the other experiments. This conclusion. is based on the smaller quantity of precipitates on the surfaces and the low measured eloment releases. These samples provide insight into the initial stages of surface layer formation. Initial alteration (hydration and leaching) of the glass surface is nonuniform and may be influenced by the surface roughness. Like the glass, there is no finescale texture in altered areas; however, the surface does appear somewhat furay and stress marks are absent. Precipitation of a Si-rich "clay" mat begins at an early stage, even before a continuous hydrated glass layer is completed. This signals the beginning of what will become a composite surface layer. Sample P-V-3 is at this early stage, while P-V-4 already has a partially developed composite layer. The altered layer begins to crack and pull away from the glass. This marks the onset of the process that leads to exfoliation. It is important to note that this process can commence even before the altered layer has completely developed across the surface. Precipitation of the Si-rich "clay" layer uppears to be independent of this process. The original surface roughness may be an important factor in the pace and location of exfoliation. Cracks secm to develop first in the rough regions associated with the suw marks. For example, 
on the top of P-V-O, where the surface is generally quite smooth, cracking and packering of the surface layer is restricted to the striations and shallow saw mark traces. As the surface layer ages, coarsening of its texture is apparent. This is particularly noticeable for P-V -7 , the 254-weok duration experiment. This coarsening may correspond to progressive crystallization of an amorphous layer, but, this is not revealed at the resolution of the SEM.

The top of P-V-6 appears much less reacted than the top of P-V-4 cven though its duration was twice as long. This may be the result of the smoother surface on P-V-6 impeding reaction but this is only a hypothesis. The lack of reaction might also result from less water-glass contact during the experiment, perhaps due to evaporation during the experiment.

In all the P-V experiments, $C a$ is removed from the EJ-13 water, This is consistent with the presence of Ca-bearing phases on the batch samples. On samples P-V-3 and P-V-4 $\mathrm{CaSO}_{4}$ (either gypsum or anhydrite) is ubiquitous. On samples P-V-6 and P-V-7 calcite is abundant and $\mathrm{CaSO}_{4}$ is absent. While the availability of sulfate is not well understood, it is unknown why such a difference in mineral occurrence shou!d happen between these samples.

\section{E. P-VIJI Experiments}

The purpose of these experiments is to examine the effect of sensitization of the stainless steel components on metal-glass-fluid interactions. As the stainless steel pour canisters are anticipated to be exposed to elevated tcmperatures during filling, the behavior of heat-sensitized steel has direct relevance to waste form performance in the proposed geologic repository. ${ }^{3}$ The stainless steel used in the experiments is from heat \#22841 which contains 0.016 wt\% carbon. The components were held at $550 \neq 20^{\circ} \mathrm{C}$ for 24 hours and were then slowly cooled to room temperature by turning off the furnace. This steel proved very difficult to sensitize, owing to its low carbon content. ${ }^{13}$ The degree of sensitization to the actual samples, while believed to be low based on testing of heat-treated but unreacted steel, has not been measured.

The experiments were initiated on $2 / 27 / 86$ and have been completed through 195 weeks. Batch experiments were terminated after 13, 26, 39, 52, and 104 weeks. Continuous experiment P-VIII-2 was terminated after 170 weeks because the WPA tipped and would no longer remain upright. The batch sample P-VIII-8, which was first sampled after 104 weeks, is presently being treated as a continuous experiment.

\section{General Observations}

The WPA had a similar appearance in all the experiments during sampling. The top surface was always dry with some light-colored precipitates aften present on the glass in the noncontact areas. Some precipitation of secondary phases occurred on the metal. The bottom surface was always wet with some standing water around the circumference of the glass (sample P-VIII-4 was dry upon termination, however). The extent of standing water was variable. 
At termination of P-VIII-7 (1.04 woeks), the water was about at the level of the bottom of the glass. When P-VIII-8 was first sampled after 104 weeks, the water level was halfway up the side of the WPA indicating that the bottom lind been inundated for a significant period of time. These observations must be: considered when interpreting the solution composition data from these experiments.

The metal components from all the terminated experinents experienced approximately the same amount of weight gain (Table 14). This is conststent with the observation of secondary phases on the metal. The glass in the short-term experiments ( $\$ 20$ weeks) gained a small anount of weight, while there was a net decrease in the longer experiments proportional to the experiment duration.

\section{Component Analyses}

The glass from all the terminated batch experiments was examined optically. The top surface of P-VIII-4 and the top and bottom surfaces of P.VIII-6 and P-VIII-7 were investigated by SEM/EDS. The metal componerts from P-VIII-6 and P-VIII-7 were also examined by SEM/LDS.

\section{a. P-VIII-3, 13-Week Sample}

The noncontact areas on the top surface are rather discrete. They have a light gray tint which is in contrast with the brownish background of the contact areas. The central noncontact area, however, has a bluish cast. There are three small light-colored areas, in the contact area, suggesting localized precipitation has occurred.

The bottom surface has a uniform gray color and the noncontact areas are not discernible. There is one light-colored area at the edge of the glass which is similar to the patches on the top surface. Saw marks are readily visible as light-colored streaks on both the bottom and top surfaces. Rougher regions are associated with the saw marks which have a coarse speckled appearance. Finer speckling is visible in the smooth regions at higher magnification.

\section{b. P-VIII-4,_26-Week Sample}

Several features stand out on the top surface. Part of the surface has a light gray-blue tint which is mostly associated with the central noncontact area. White precipitates are present in the bluish regions. The other noncontact areas are poorly marked. These are somewhat lighter in color with sune white precipitates at their margins. The contact area is generally brownish but light gray tinting occurs around the edge of the glass. Saw marks, visible. as white streaks, are present over much of the surface, imparting a coarsespeckled appearance. 


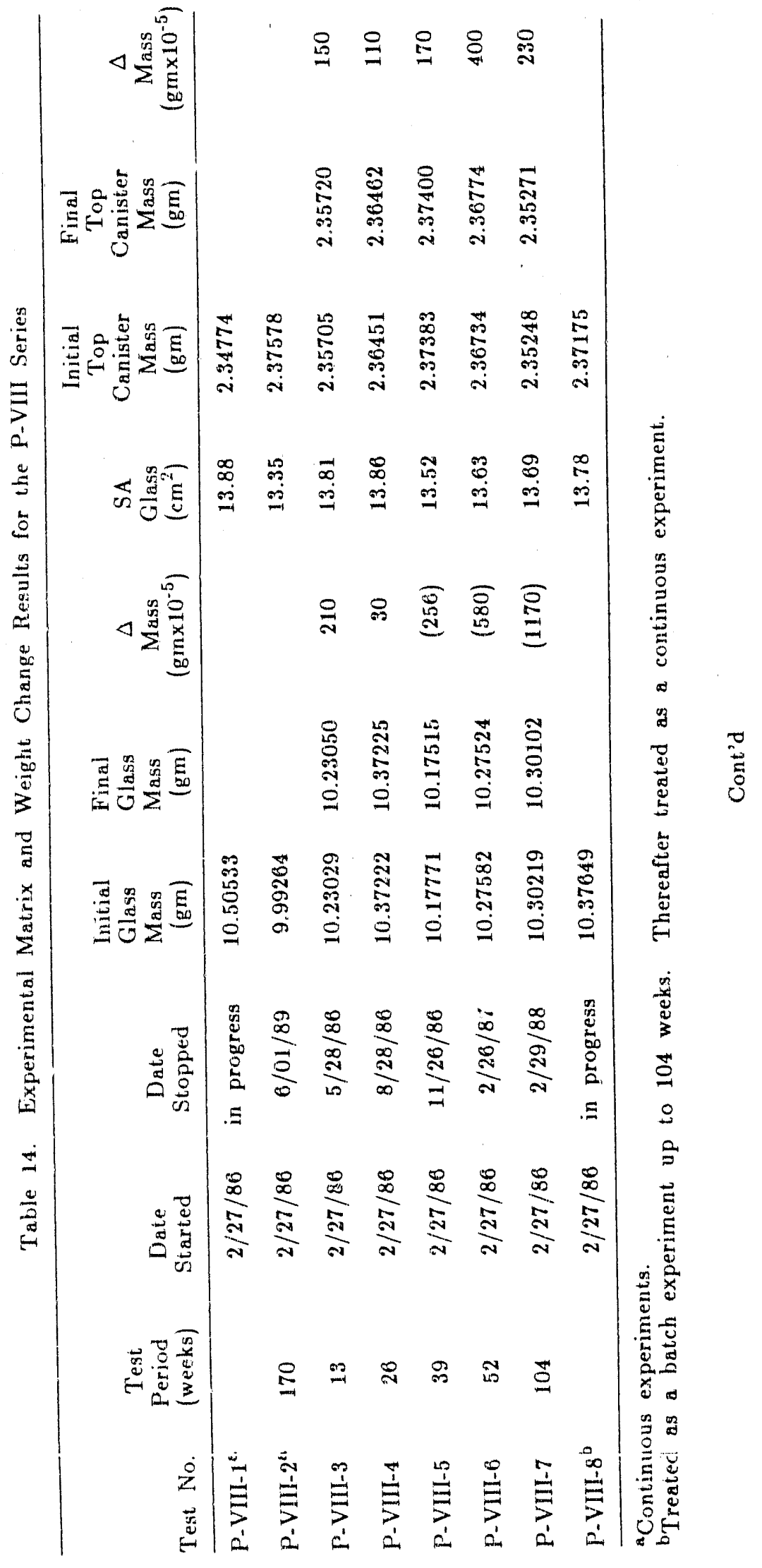




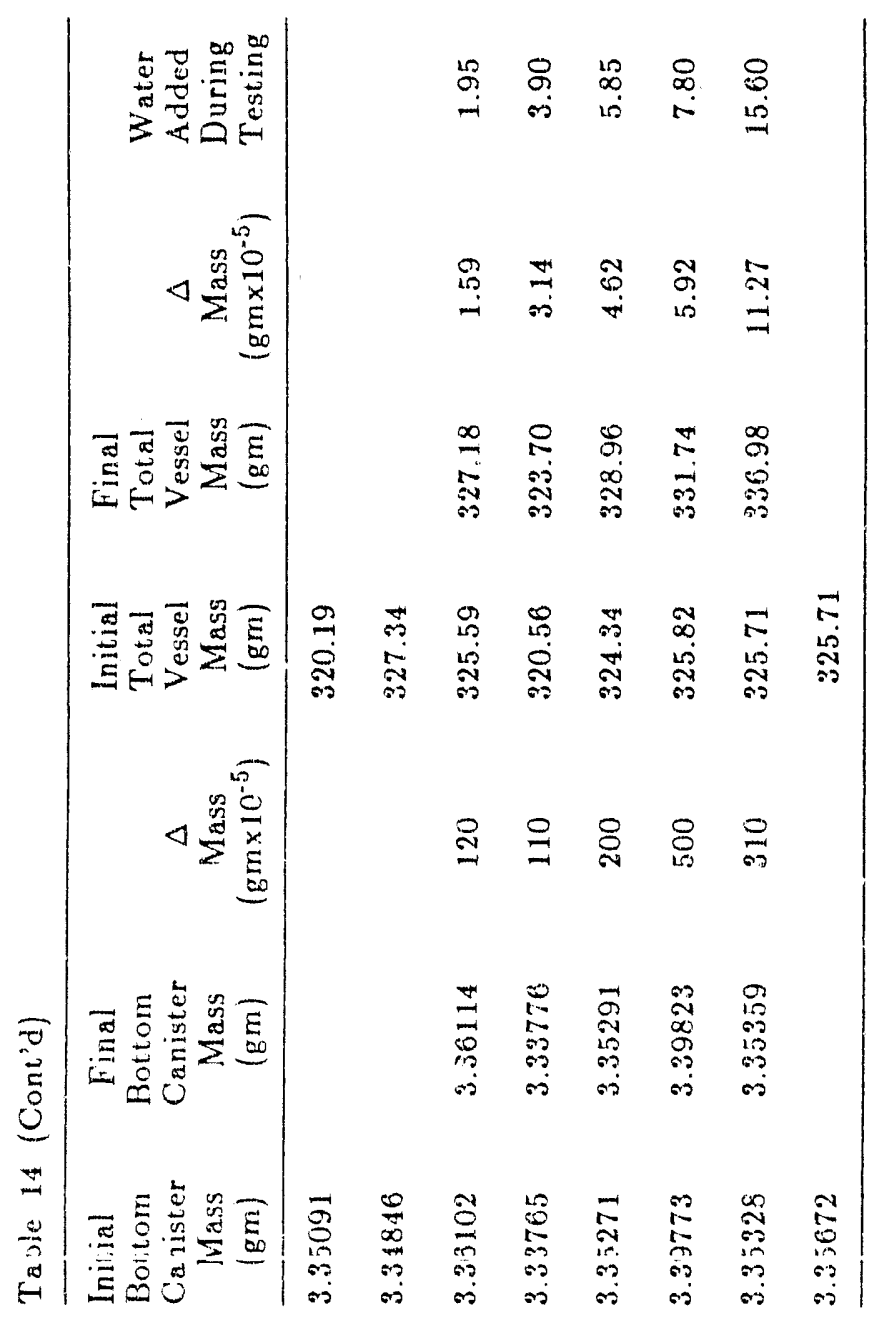


The bottom surface has a rather uniform dark gray color. The noncontact areas are marked by somewhat lighter colored rings around a central region that looks much like the contact area. There is a patch of whitish precipitates, similar to that observed on P-VIII-3. Saw marks give a coarse-speckled appearance to approximately one quarter of the surface.

Only the top surface was investigated by SEM/EDS. The general appearance is similar to the P-IV experiments. The "as-cut" contours are clearly visible, however, the surface has a fine-scale texture at high magnification indicating that reaction has occurred (Fig. 33a). A Si-rich alteration layer has developed across the glass surface. Its composition is essentially the same as observed for the other experiments. Small precipitates of similar composition occur on the surface (Fig. 33a). In some parts, coverage is extensive, forming a discontinuous upper layer upon the altered surface. That the glass has reacted is also indicated by the preferential etcling of stress marks. Short cracks have locally developed in the layer and small portions have raised up from the glass. This phenomenon occurs in both the contact and noncontact areas.

Aside from the Si-rich layer, there are several other secondary phases that have precipitated on the surface. There are colonies of small $1<0.5 \mu \mathrm{m})$ spherical grains distributed over the entire surface (Fig. 33b). These areas are enriched in $F e$ relative to the surface layer and EDS analyses suggest a very fine-grained mixture of Si-rich "clay" and $\mathrm{Fe} \pm \mathrm{Mn} \neq \mathrm{Ni}$ oxide or hydroxide (Fig. 33c/EDS). This is based on the observation that the $\mathrm{Si}, \mathrm{Al}$, and Ca peaks have relative intensities approximately equal to precipitated Si-rich "clay" (compare Fig. 33c with Fig. 34c). The Fe peak intensity varies from spot to spot, suggesting its signal is independent of $\mathrm{Si}, \mathrm{Al}$, and $\mathrm{Ca}$ and that this results from variable proportions of two phases being detected. The phenomenon of coprecipitation is well known. ${ }^{14,15}$

Other irregular-shaped grains contain $\mathrm{Ca}$ and $\mathrm{S}$ and are probably either gypsum or anhydrite (see above). A number of large (up to $180 \mu \mathrm{m}$ ) prismatic grains are present whose EDS spectrum consists of only a $\mathrm{Ca}$ peak suggesting it is calcite. Several irregular fluffy masses occur with only $\mathrm{Si}, \mathrm{Al}$, and $\mathrm{K}$ detectable by EDS (Figs. 33d and 33e/EDS). Their approximate stoichiometry is consistent with K feldspar, but they have not been analyzed by XRD.

\section{c. P-VIII-5, 39-Week Sample}

The noncontact areas on the top surface are easily visible owing to a rather heavy coverage of whitish-gray precipitates. The central noncontact area is gray, and extends into the adjacent contact area. Exfoliation of the altered layer is apparent in the middle of several noncontact areas. The contact areas are brown except in the saw marked regions which have lightcolored speckles as observed on most other P-VIII samples. The bottom surface is similar to the top of P-VIII-3. Most of the noncontact areas are only faintly visible with a slight grayish tone. Saw marks and a corresponding roughspeckled appearance covers approximately half the surface. 
(a)

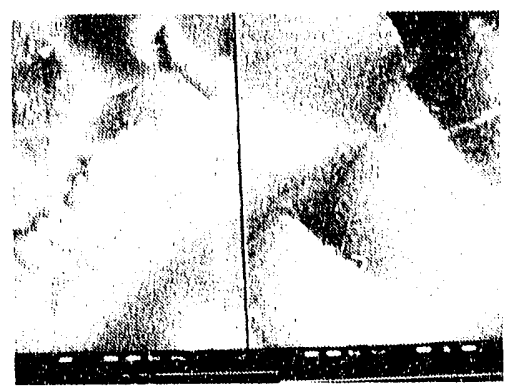

(c)

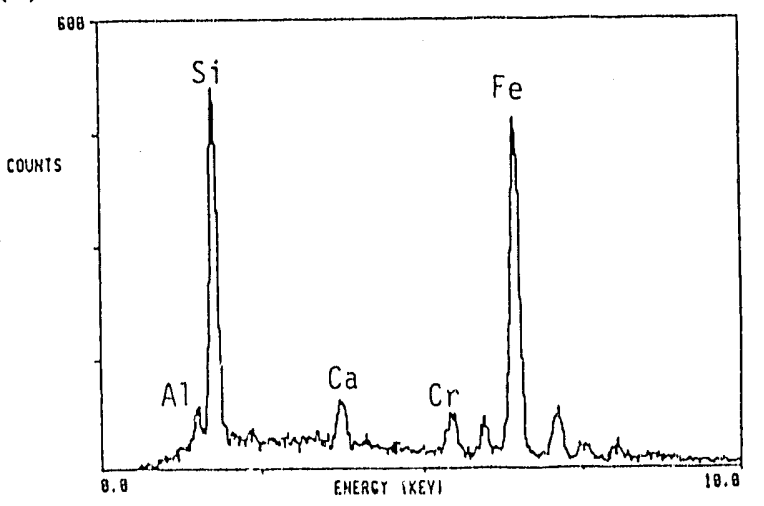

(b)

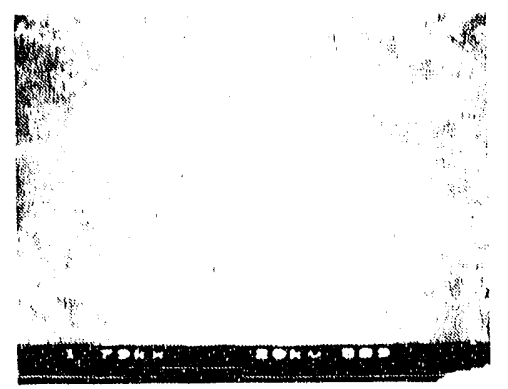

(d)

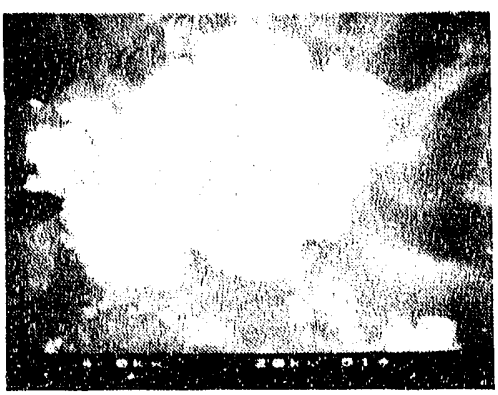

(e)

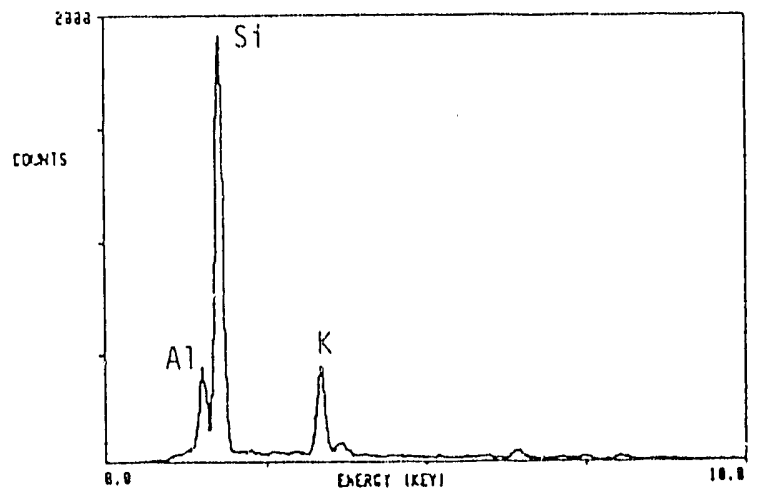

Fig. 33. S.M Micrographs and EDS Spectra from the Top of P-VIII-4.

(a) $2500 \mathrm{X}$, (b) $1790 \mathrm{X}$, (c) EDS spectrum of material shown in (b), (d) 4000X, and (e) EDS spectrum of grain shown in (d) 
(a)

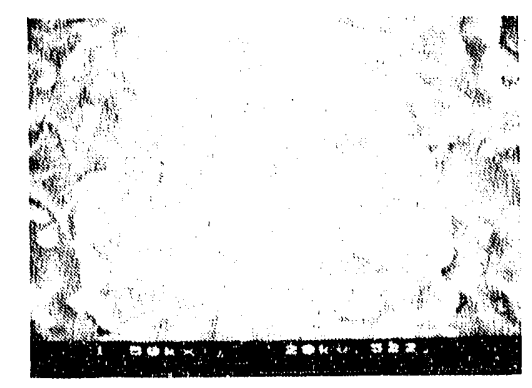

(c)

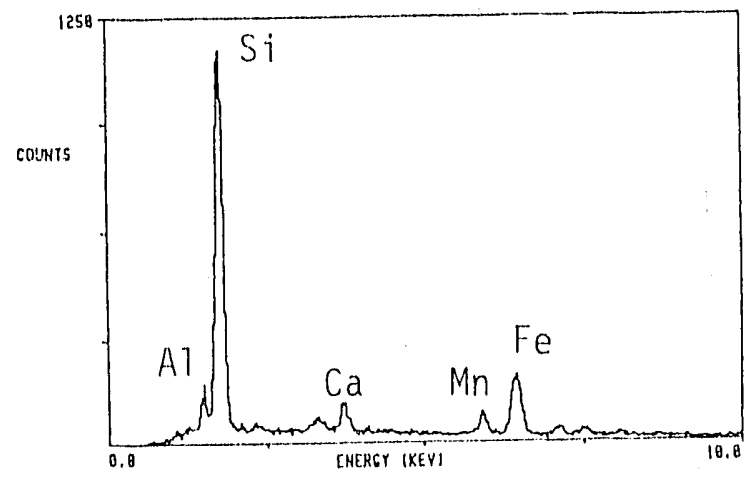

(e)

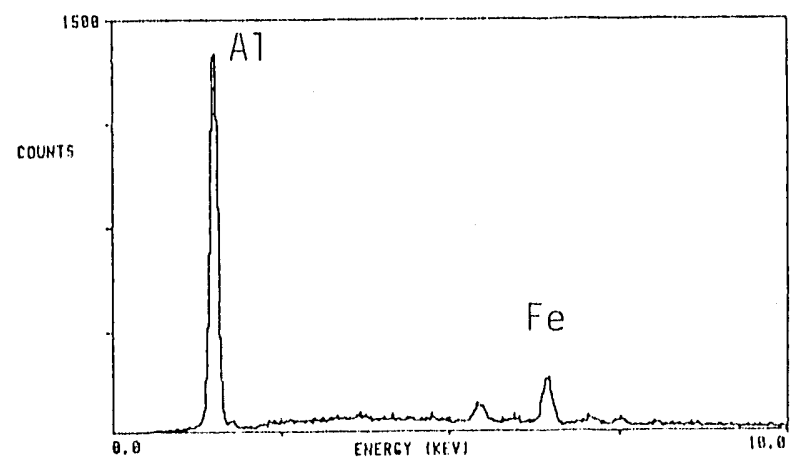

(b)

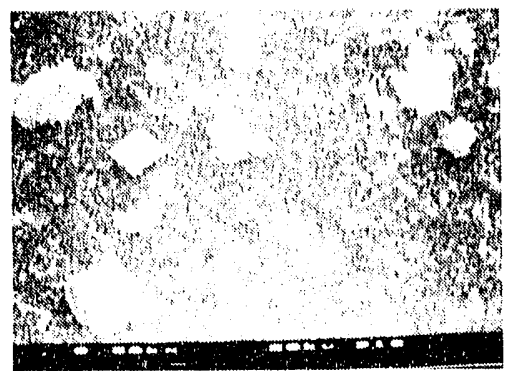

(d)

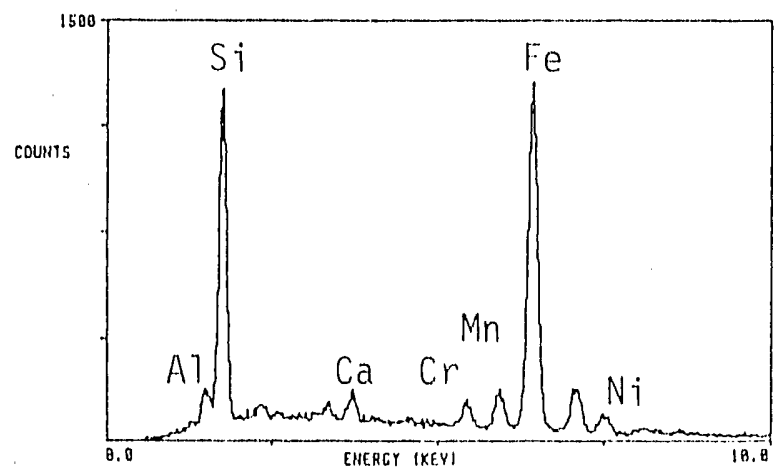

(f)

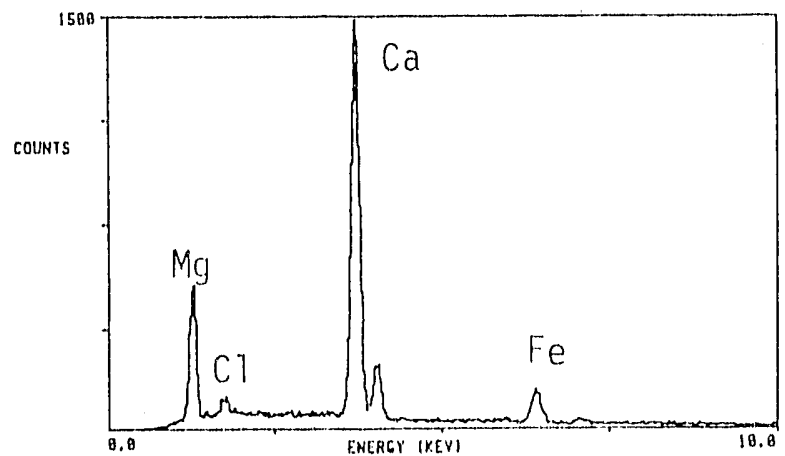

Fig. 34. SEM Micrographs and EDS Spectra from the Top of P-VIII-6. (a) $1500 \mathrm{X}$, (b) $300 \mathrm{X}$ (see text) 


\section{d. P-VIII-6, 52-Week Sample}

The glass and metal components were examined optically and by SEM/EDS. Two precipitates were also analyzed by XRD.

\section{(1) Glass}

The top portion of the glass has clearly marked contact and noncontact areas. The noncontact areds are lighter in color than the contact areas, being tan rather than gray. "This is due to heavier precipitate coverage in the noncontact areas. Some saw marks appear as light-colored, discontinuous streaks. Close optical inspection suggests the color difference is mostly due to the partial separation of the surface layer from the glass in the saw grooves. One region, encompassing approximately one-third of the top surface, has a rusty appearance and seems to have more precipitates on it.

The "as-cut" contours are preserved, although they are subdued (Fig. 34a). The surface has a poorly developed flaky texture at high magnification like that on P-VIII-4, indicating the presence of an altered layer (see Fig. 33a). A coarsening of this texture is locally observable, but this may be the result of precipitation. The layer composition is the same as for samples from other experiments; it is $\mathrm{Si}$ rich with some $\mathrm{Al}, \mathrm{Ca}, \mathrm{Fe}, \pm \mathrm{Mg} \pm \mathrm{Mn} \pm \mathrm{Ni}$, $\pm \mathrm{Na}$. Only minor cracking of the surface layer is apparent, although such features are present in both the contact and noncontact areas (Fig. 34a). Where cracking has occurred, small pieces of the adjacent layer have raised up from the glass.

There are a number of secondary phases present. The most abundant is a Si-rich material which occurs in numerous morphologies including: ribbons, round grains with flaky surfaces, string-shaped masses, and fine fromboidal masses (Figs. $34 \mathrm{~b}$ and $34 \mathrm{c} / \mathrm{EDS}$ ). This material has the same composition as the surface layer. The relative uniform Al-to-Si ratio suggests this is a crystalline shase and its composition is consistent with smectite. The $\mathrm{Fe}, \mathrm{Mn}$, and $\mathrm{Ni}$ coniact can be quite variable; sometimes $\mathrm{Ni}$ content can exceed that of Fe.

The next most abundant phase is Te oxide or hydroxide which is especially abundant in the rusty region. It occurs as irregular-shaped grains; however, sorne possess a good geometric form, like the diamond-shaped grain in the left center of Fig. 34b. Fe-rich material is also associated with many of the fine-grained precipitates that are present all over the surface. This may explain, in part, the apparent variability in $\mathrm{Fe}$ content of the Si-rich precipitates. Along with $\mathrm{Fe}$, a small amount of $\mathrm{Mn}$ is almost always present and $\mathrm{Cr}$ and $\mathrm{Ni}$ are locally important components (Fig. 34d/EDS).

A Ca- and S-bearing phase, most probably anhydrite or gypsum, is ubiquitous on the glass surfaces It occurs as very fire fromboidal gra.ns that grow on other phases and are often intimately intermingled with these phascs. For example, fromboids are growing on the Fe-rich grain in Fig. 34b. 
Several other phases are present in minor quantities which are worthy of note. A silica phase, presumably either quartz or opal, is present as small angular grains. An Al-rich phase occurs in several places. The absence of any other detectable elements, along with its flaky appearance, suggest it is gibbsite or some other Al-hydroxide (Fig. 34e/EDS). Another Ca-rich phase containing $\mathrm{Mg}$ and $\mathrm{Fe}$ is present which is probably a high-Mg calcite or possibly dolomite (Fig. 34f/EDS). In rare instances, $\mathrm{Cl}$ is detectable. These grains often have a complex composition suggesting the presence of numerous phases.

The surface layer and precipitates are well developed on the bottom glass surface. There is only a weak demarkation between the contact and noncontact areas. This is in contrast to the top surface where contactnoncontact areas are well delineated. Saw marks are clearly visible on the bottom surface, marked by light-colored streaks. As with the top layer, this color difference seems to result from buckling and separation of the surface layer from the glass.

The "as-cut" contours are mostly obscured and the surface has a flaky appearance that is much coarser than observed on the top surface (Fig. 35a). This suggests that much of the visible surface may have formed by precipitation, masking the original surface topography. The composition is typical of the altered layer and is probably smectite. An extensive network of cracks has developed across the surface (Fig. 35a). Most have the appearance of shrinkage cracks caused by dessication, presumably after termination of the experiment. However, the glass exposed within the cracks looks altered and has some fine precipitates on it. This suggests cracking must have begun during the experiment. The cracks would then become enlarged as the layer dried after termination of the experiment. Other cracks, where the surface layer has raised up, are associated with the saw marks (Fig. 35b). This represents the initiation of exfoliation of the surface layer.

The types of precipitated phases are essentially the same as described for the top surface with a couple of minor additions. A Ca-bearing phase without any $\mathrm{Mg}$ or $\mathrm{Fe}$ is present and is probably calcite. One analyzed grain contains only $\mathrm{Si}, \mathrm{Al}$, and $\mathrm{Na}$, with $\mathrm{Al}$ ex eeding the amount found in the surface layer (Figs. $35 \mathrm{c}$ and $35 \mathrm{~d} / \mathrm{EDS}$ ). It docs not have a distinctive morphology, but its composition suggests it is analcime.

\section{(2) Metal Components}

The top and bottom steel components generally have the same appearance. They have a dull rusty color where they were in contact with the glass during the experiment. Along the rims and the sides facing away from the glass, little reaction has occurred. There are some small irregular-shaped patches of corrosion on these surfaces. There are, however, small patches of thick precipitates that have developed in both the contact and noncontact areas on the side facing the glass. These are mostly intimate mixtures of Si-rich material, probably smectite clay, and Fe-oxide or hydroxide. The clumps can be stringy in form, similar to that observed on the glass. 
(a)

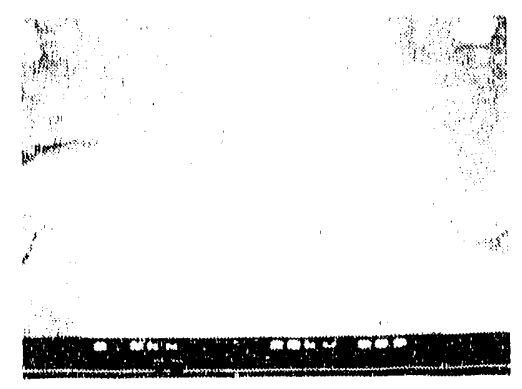

(c)

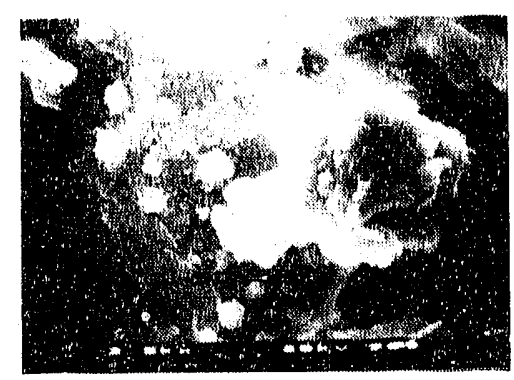

(b)

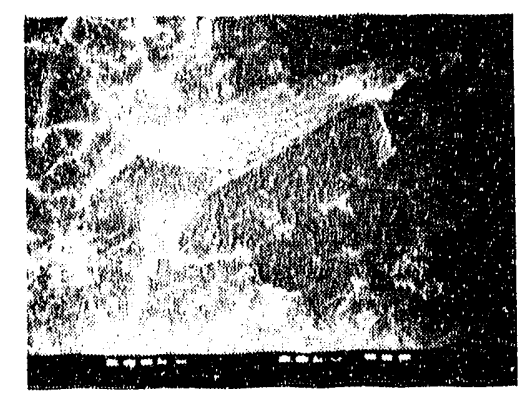

(d)

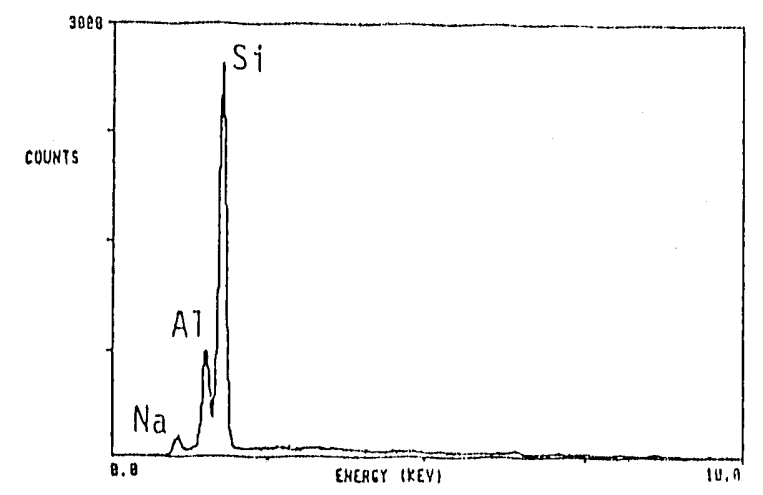

Fig. 35. SEM Micrographs of Surface Layer Features from the Bottom of P-VIII-6. (a) $2500 \mathrm{X}$; (b) $200 \mathrm{X}$; (c) a small grain on the surface that contains only $\mathrm{Si}, \mathrm{Al}$, and $\mathrm{Na}(3500 \mathrm{X})$; and (d) EDS spectrum from grain shown in (c)

On the bottom metal piece, there are numerous honey-colored precipitates. These are shaped like open cylinders and cones (Fig. 36a). Analysis of this material by XRD suggests that it is hematite. They occur on both sides of the metal but are most abundant along the edges on the side facing away from the glass. In general, there are more precipitates on the surfaces facing the glass than on the other side. Unlike the glass, there is no complete surface coating on the metal.

Virtually all the phases identified on the glass are also present on the metal components. The most common phases on the metal are the Si-rich clay, Fe-oxide or hydroxide, and calcium sulfate. These are often. intimately intergrown with each other. The Si-rich material has the same composition as that found on the glass except that it is generally very poor in $\mathrm{Ni}$. Fe-oxide or hydroxide occurs as the material covering the surface and as open cylinders and cones (Fig. 36a). Tiny dots of gypsum or anhydrite occur all over the metal surface. Chloride-rich grains are present, mostly associated with the welded regions. These grains may contain $\mathrm{Na}, \mathrm{K}$, and $\mathrm{Ca}$. XRD analysis confirms the occurrence of $\mathrm{NaCl}$. There is a Cr-rich substance present on both metal components that was not observed on the glass. While spectra from this 
(a)

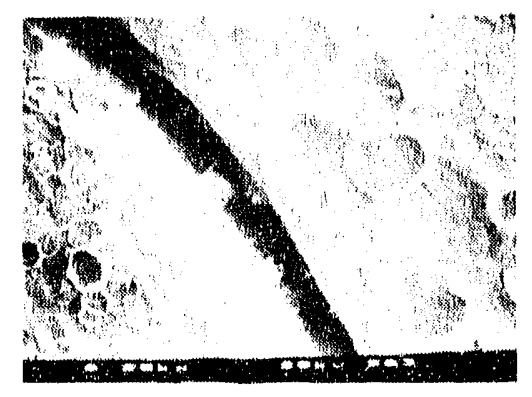

(b)

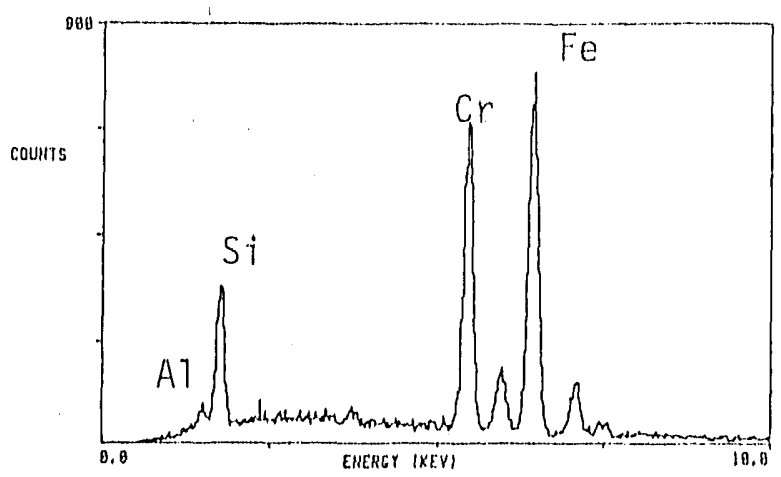

Fig. 36. SEM Micrograph (250X) and EDS Spectrum of Fe- and Cr-Rich Deposit on the Bottom Surface of the Metal Component on P-VIII-6

material resemble the metal and Fe-hydroxide, the $\mathrm{Cr}$ content is very high (Fig. 36b/EDS). This may be Fe-hydroxide that is for some reason locally very rich in $\mathrm{Cr}$. Considering that the source of the $\mathrm{Cr}$ is the metal, the absence of Cr-rich material on the glass suggests that $\mathrm{Cr}$ is not very mobile under the conditions of the experiments.

\section{e. P-VIII-7, 104-Week Sample} by SEM/EDS/WDS.

The glass and metal components were examined optically and

\section{(1) Glass}

The top glass has a general medium gray tone with a smooth, evenly colored region and a rough, mottled region. The roughness is from the saw blade during cutting of the glass cylinder. There is a distinction between the contact and noncontact areas but it is not very pronounced. Precipitates are sparsely scattered over the noncontact areas. A honey-colored mark and a concentration of precipitates are present in one small portion of the contact area, near the edge of the glass.

A well-developed altered layer is present over the entire surface. The "as-cut" contours arc not preserved and the layer has a "cardhouse" type morphology reminiscent of clay (this is consistent with its composition). Masking of the contours suggests at least a portion of the layer formed by precipitation, filling in depressions on the rough surface. The surface layer is cracked in many places and appears to be pulling away from the glass (Fig. 37a). Some of the cracks expose etched glass from below. The presence of precipitates bridging the cracks sugigests the cracks began to form during the experiments. Some shrinkage after termination of the experiment may have enlarged the cracks. The pulling away of the surface layer from the glass is more pronounced in the rough region. Here, it appears that the layer has variable thickness. 
(a)

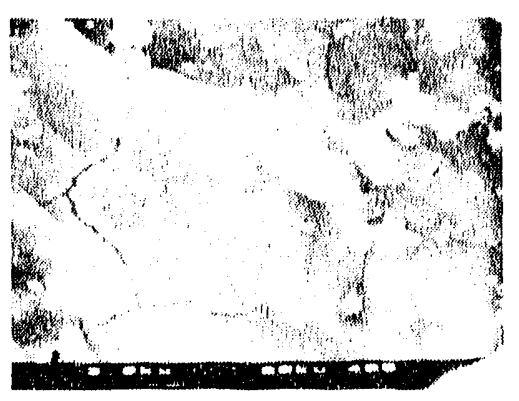

(c)

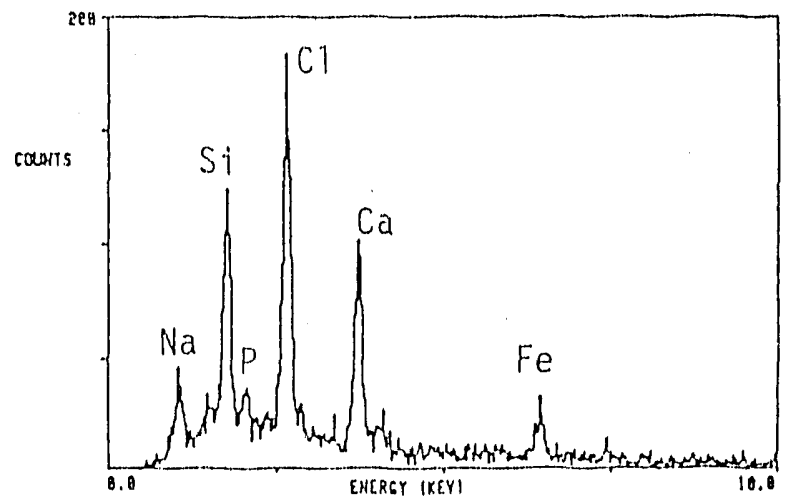

(e)

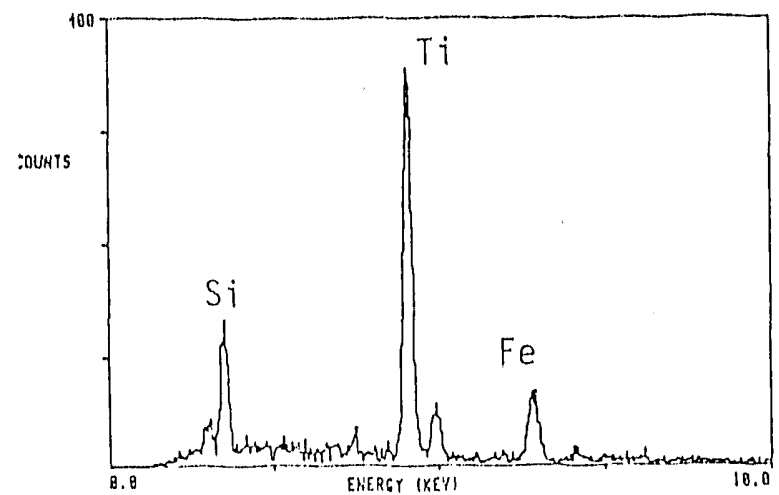

(g)

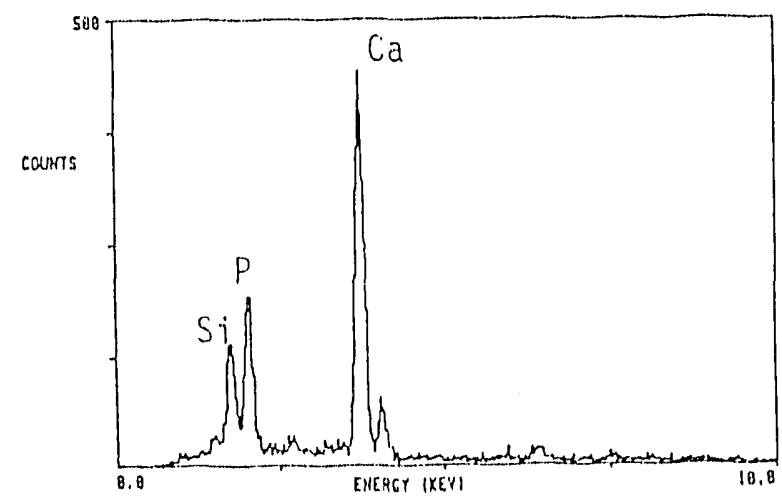

(b)

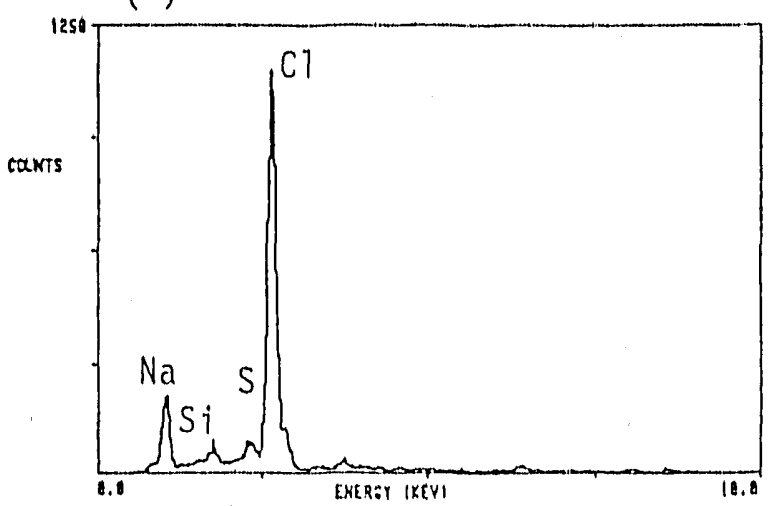

(d)

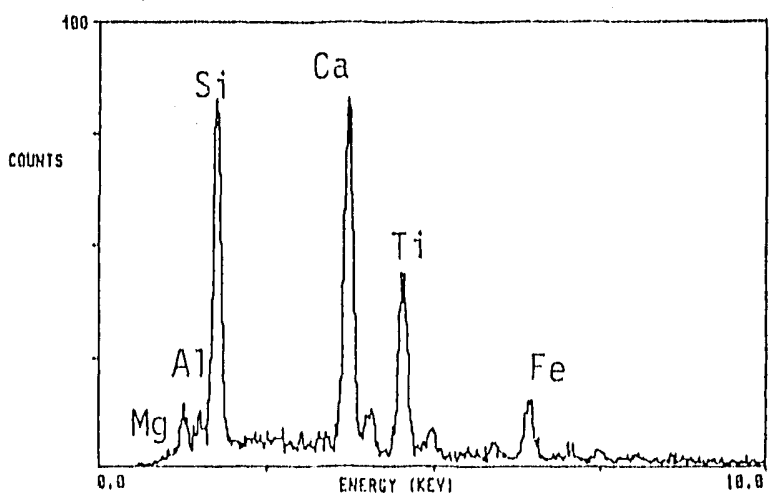

(f)

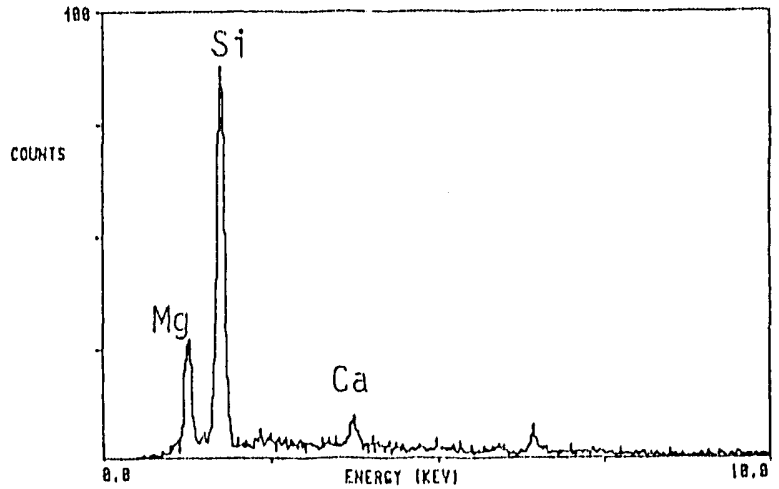

Fig. 37

SEM Micrograph and EDS Spectra of Reaction Products on the Top Glass of P-VIII-7. (a) $3000 \mathrm{X}$ (see text) 
The most abundant precipitated phase is Si-rich which also contains $\mathrm{Al}, \mathrm{Ca}, \mathrm{Fe}, \mathrm{Mn}, \pm \mathrm{Mg} \neq \mathrm{Ni}$, $\mathrm{Na}, \pm \mathrm{K}$, In proportions similar to the average surface layer. It occurs as ribbons, flaky grains, and fluffy textured masses of variable size (Fig. 37a). At high twagnification, the small fluffy masses have the same "cardhouse" type morphology as the top of the surface layer which suggests that the visible portion of this layer may also have formed by precipitation. The next most abundant phase is very Fe rich and is probably Fe-oxide or hydroxide. This material occurs as irregtalar-shaped grains and is almost always intergrown with Si-rich "clay". It is otherwise genesally quite pure with only a small amount of Mn present.

Other precipitated phases include Ca-rich grains, presumably calcite, which are fairly abundant Some Ca-bearing grains also contain $\mathrm{Mg}$ and $\mathrm{Fe}$, indicative of dolomite. Some grains are very Al-rich and are possibly gibbsite (or bayerite?, or nordstrandite?). Variable small Si and Te peaks on the spectra suggest this material is intermingled with Si-rich "clay". Tiny Cl- and S-rich grains occur on the surface layer and on many precipitates. Based upon numerous EDS arialyses, the phases present are likely to be $\mathrm{NaCl}$, $\mathrm{Na}_{2} \mathrm{SO}_{4}, \mathrm{CaSO}_{4}$, and possibly $\mathrm{CaCl}_{2}$ (Figs. 37b/EDS and 37c/EDS). Whether the sulfates are actually hydrated is impossible to determine by EDS. A number of grains contain significant Ti. When EDS spectra from several grains are compared, it is clear that they are a mixture of phases (Figs, 37d/EDS and $37 \mathrm{e} / \mathrm{EDS}$ ). For example, while the spectrum in Fig. $37 \mathrm{~d}$ has large $\mathrm{Si}$ and $\mathrm{Ca}$ peaks, that in Fig. $37 \mathrm{e}$ has a much smaller Si peak and virtually no $\mathrm{Ca}$. This suggests that the Ti-bearing phase does not contain either of these elements. A plausible interpretation is that these grains contain $\mathrm{TiO}_{2}$, anatase?, along with Si-rich "clay" and calcite.

Several other phases, while occurring rarely, are worthy of note. A couple elongate, layered grains are present which contain only $\mathrm{Si}$ and $\mathrm{Mg}$ (Figs. 37f/EDS). Their morphology and composition stggest they are serpentine. Ca-phosphate grains vresumably apatite, occur sparingly (Fig. $37 \mathrm{~g} /$ EDS). Silica, possibly quartz or opal occur very rarely.

The bottom surface has a medium gray color with smooth and rough cut regions. The noncontact areas are generally poorly defined, being only slightly darker gray than the adjacent contact areas. Under the SEM, the surface has a similar texture to that observed on the top surface. Small precipitated grains have the same "cardhouse" type texture and composition as the surface layer. An extensive network of cracks is present and, in places, pieces of the layer have exfoliated, exposing etched glass below (Fig. 38a). It is clear that exfoliation occurred during the experiment because of the presence of fine $\mathrm{NaCl}$ threads in some of the cracks and Si-rich precipitates on some of the freshly exposed surfaces (Figs. 38a and 38b). In these exfoliated regions there is a continuum of surface appearance from fresh etched glass, to glass with a few precipitates, to glass with a heavy cover of precipitates. This suggests that exfoliation occurred over a period of time up to the termination of the experiment. In one location, it is apparent that the surface layer is actually composed of two layers (Fig. 38b). Here, a flake of the upper portion of the layer has spalled off, exposing a lower layer which in turn is also in the process 
(a)

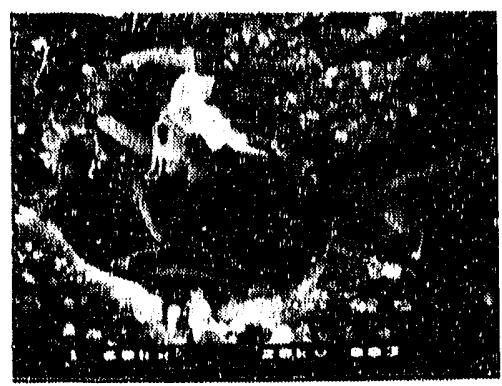

(b)

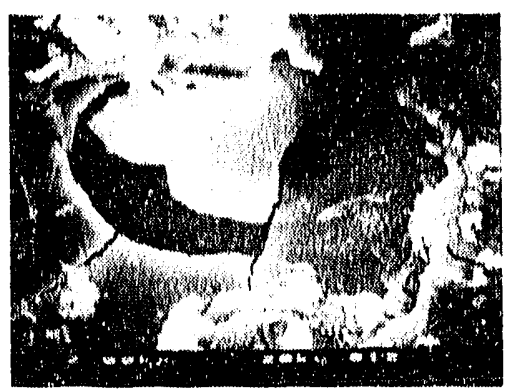

Fig. 38. SEM Micrographs of Surface Layer Features on the Bottom of P-VIII-7. (a) $1600 \mathrm{X}$, irregular-shaped grain in $\mathrm{Nar} / \mathrm{l}$; and (b) 2000X (see text)

of exfoliating. The glass below has many small dots on it either from precipitation or alteration. Based upon several EDS analyses, there are no significant compositional differences between the two layers. The lower layer is finer grained; however, it has the same texture as the upper layer when viewed at high magnification.

Like the other samples, the surface layer and associated Si-rich precipitates form the dominant alteration product on the bottom surface. The texture and composition is consistent with it being Fe-smectite. The next most abundant phase is $\mathrm{NaCl}$. It occurs as fine threads and blocky grains and may also be intimately associated with the Si-rich "clay". It often occurs with $\mathrm{Na}_{2} \mathrm{SO}_{4}$ and $\mathrm{CaSO}_{4}$ (whether these sulfates are hydrated is uncertain). These phases, along with $\mathrm{CaCO}_{3}$, calcite, are frequently intergrown with the Si-rich "clay" at a very fine scale. Fe-rich material is also present as irregular blobs on the surface which may contain minor $\mathrm{Mn}$ and $\mathrm{Ni}$. This is probably Fe-oxide or hydroxide, although the XRD results from P-VIII-6 suggest it is an oxide.

\section{(2) Metal Components}

There is an extensive deposit of precipitates on the metal components. Small patches of corrosion are associated with the welds. Most of the phases found on the glass are also present on the metal. There are two predominant phases: Si-rich "clay" and Fe-oxide or hydruxide. There is a thin Si-rich "clay" mat on the bottom component, but for the most part, the "clay" occurs in clumps with a fluffy texture. The clumps occur on both sides of the components indicating an origin by precipitation. The EDS spectra are often enriched in $\mathrm{Fe}$ (and not $\mathrm{Cr}$ ) suggesting that the clay is intergrown with Fe-oxide or hydroxide, as was observed on the glass. Fe-oxide or hydroxide occurs in irregular clumps and as tiny balls and open cylinders (see Fig. 36a from P-VIII-6). 
Ca-rich phases, presumably calcite and dolomite, are quite abundant. Some grains have a rhombohedral form which is characteristic of calcite. Many Si-rich "clay" clumps have detectable Ca and S suggestive of gypsum or anhydrite.

Very Al-rich grains are abundant on tile top component. These grains are generally only a few microns across with only Al in their EDS spectra, suggestive of Al-hydroxide (Fig, 39a/TDS), Ti-rich grains, which are possibly mixtures of clay and $\mathrm{TiO}_{2}$, are also present on the top metal piece. A rare Cr-Mn phase is associated with the metal grain boundaries and is probably the result of corrosion (Fig. $39 \mathrm{~b} / \mathrm{EDS}$ ).

\section{Solution Analyses}

Elemental releases from the continuous experiments are shown in Fig. 40, and the normalized releases of $\mathrm{B}, \mathrm{Li}$, and $\mathrm{U}$ are presented in Table 15. The raw data and the background subtracted cumulative releases are included in Appendix 'I for both the continuous and batch experiments. Continuous experiment P-VIII-2 was terminated after 170 weeks because the WPA would not remain in an upright position. Batch experiment P-VIII-8 is currently being treated as a replacement for P-VIII-2, but the data are not presented as such in Fig. 40,

There is good agreement in the trends and magnitudes of elemental release between the two continuous experiments, P-VIII-1 and P-VIII-2. Overall release is low and is comparable to the P-V experiments. The last sampling of P..VIII-2, at 170 weeks, showed a sharp change in all element releases (Fig. 40). The tipped WPA may, in some way, have caused this accelerated behavior. The release from P-VIII-8 is significantly greater than the other two continuous experiments. This is probably attributable to the period prior to the 37-week sampling when the bottom of the WPA was submerged. Comparison of the last two solutions, collected at 170 and 195 weeks, suggests a sharp reduction in the rate of release.

The relative magnitudes of release are $\mathrm{Li}>\mathrm{B} \geq \mathrm{U}$ (Table 15). There is a net negative release of $\mathrm{Ca}$ and $\mathrm{Mg}$ in all three experiments. This indicates that these elcments have been removed from the EJ-13 water and incorporated in secondary phases on the WPA. This is consistent with the occurrence of $\mathrm{CaSO}_{4}$ and calcite on the batch samples. Release of $\mathrm{Si}$ is negative in the P-VIII-1. and P-VIII-2 experiments. It is positive in P-VIII-8, however, the most recent sumpling at 195 weeks shows a minor net negative release. The negative Si release correlates with the extensive amount of precipitated clay on the glass and metal components in the batch experiments. Release of $\mathrm{Na}$ is crratic in P-VIII-1 and P-VIII-2 which is similar to that observed in the P-II and P-III experiments. Release of $\mathrm{Na}$ in P-VIII-8 is positive and mirrors that of $\mathrm{Li}, \mathrm{B}$, and $\mathrm{U}$. The erratic behavior of $\mathrm{Na}$ is attributable to periodic precipitation of $\mathrm{NaCl}$ or $\mathrm{Na}_{2} \mathrm{SO}_{4}$ followed by subsequent redissolution during later sampling intervals. These Na-bearing phases are commonly observed on the batch experiments. 
(11)

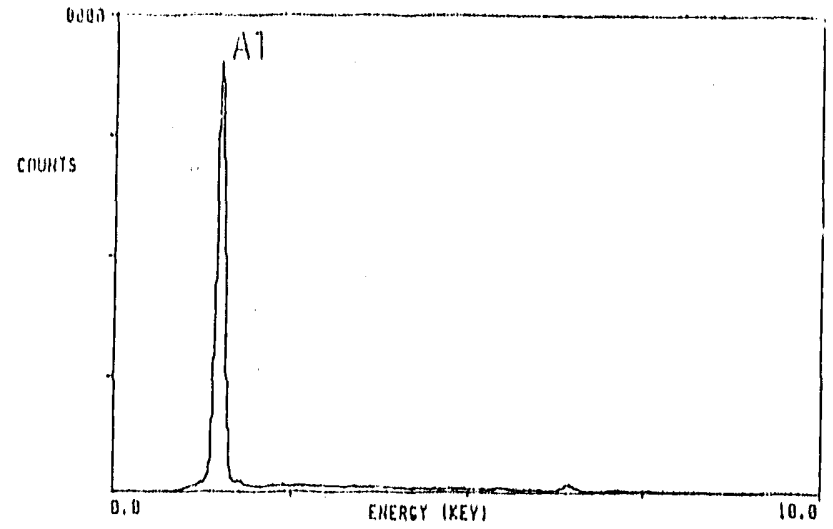

(b)

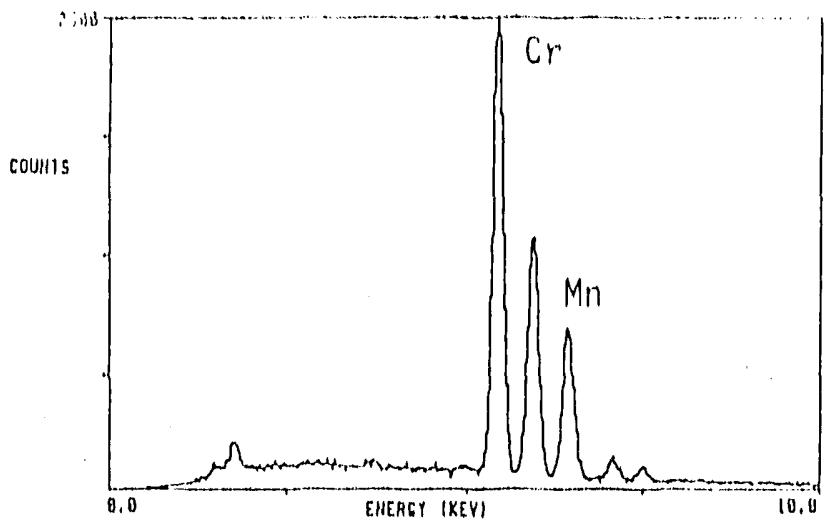

Fig. 39. EDS Spectra of Precipitates on the Top Metal Component of P-VIlI-7

Table 15. Normalized Elemental Release for the P.VIII Series

\begin{tabular}{|c|c|c|c|c|}
\hline \multirow[b]{2}{*}{ Test \# } & \multirow{2}{*}{$\begin{array}{l}\text { Period } \\
\text { (weeks) }\end{array}$} & \multicolumn{3}{|c|}{ Normalized Release $\left(\mathrm{g} / \mathrm{m}^{2}\right)$} \\
\hline & & $\mathrm{B}$ & $\mathrm{Li}$ & $\mathrm{U}$ \\
\hline P-VIII-3 & 13 & 0.1 & 0.4 & 0.10 \\
\hline P.VIII-4 & 26 & 0.2 & 0.9 & 0.10 \\
\hline P.VIII-5 & 39 & 0.2 & 0.4 & 0.09 \\
\hline P-VIII-6 & 52 & 1.2 & 2.1 & 1.24 \\
\hline P-VIII-7 & 104 & 1.5 & 2.6 & 1.54 \\
\hline P-VIII-8 & $\begin{array}{l}104^{*} \\
170 \\
195\end{array}$ & $\begin{array}{l}2.6 \\
5.1 \\
5.4\end{array}$ & $\begin{array}{l}4.8 \\
8.3 \\
8.8\end{array}$ & $\begin{array}{l}1.63 \\
3.17 \\
3.40\end{array}$ \\
\hline P-VIII-1 & $\begin{array}{r}52 \\
104 \\
143 \\
170 \\
195\end{array}$ & $\begin{array}{l}0.1 \\
0.2 \\
0.2 \\
0.2 \\
0.2\end{array}$ & $\begin{array}{l}1.0 \\
1.4 \\
1.6 \\
1.8 \\
2.0\end{array}$ & $\begin{array}{l}0.07 \\
0.11 \\
0.12 \\
0.12 \\
0.13\end{array}$ \\
\hline P-VIII-2 & $\begin{array}{r}52 \\
104 \\
143 \\
170\end{array}$ & $\begin{array}{l}0.2 \\
0.2 \\
0.2 \\
0.3\end{array}$ & $\begin{array}{l}0.6 \\
1.0 \\
1.2 \\
1.5\end{array}$ & $\begin{array}{l}0.05 \\
0.07 \\
0.18 \\
0.29\end{array}$ \\
\hline
\end{tabular}

"F-VIII-8 was treated as a batch experiment up to 104 weeks. 


\section{Earan}

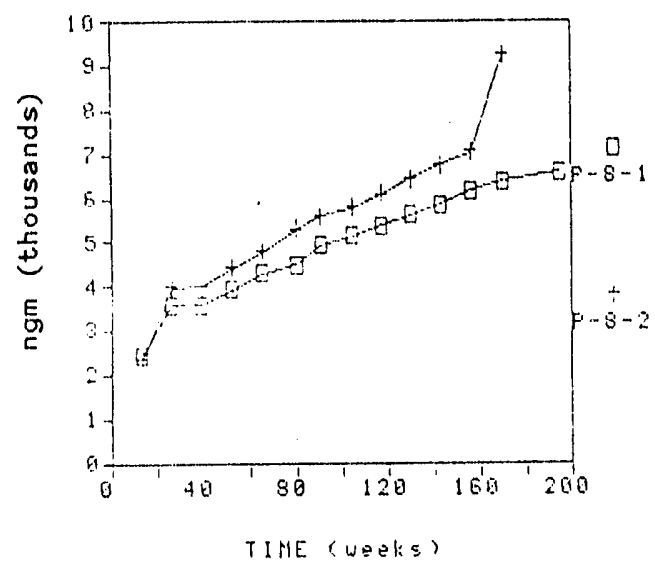

Ur. arium

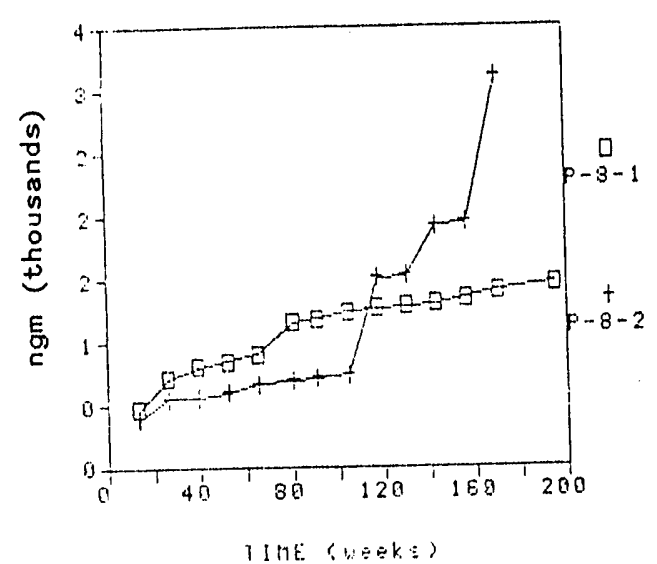

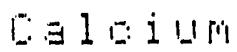

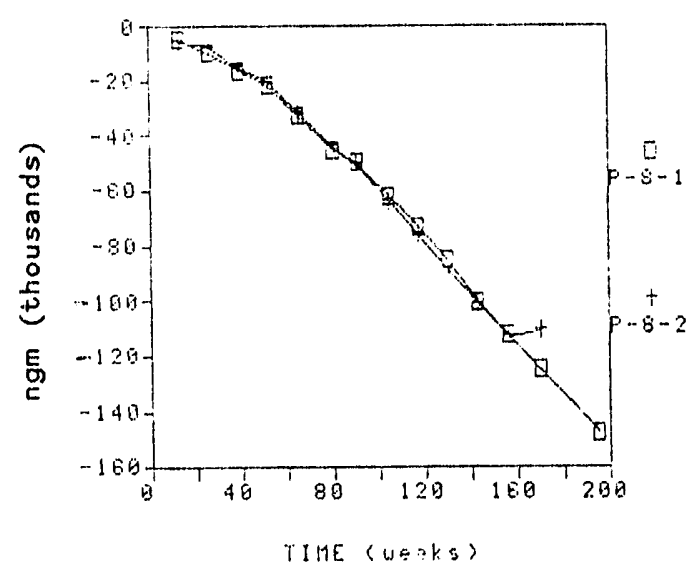

Lithis im
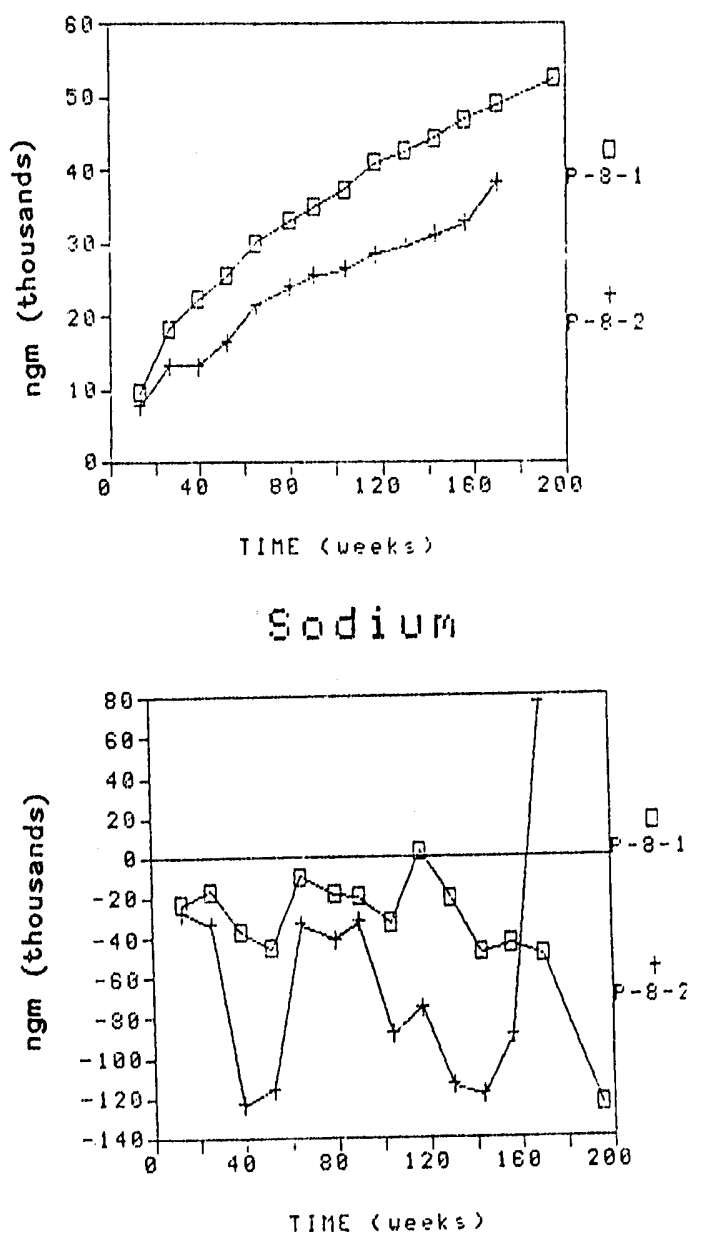

Siliogn

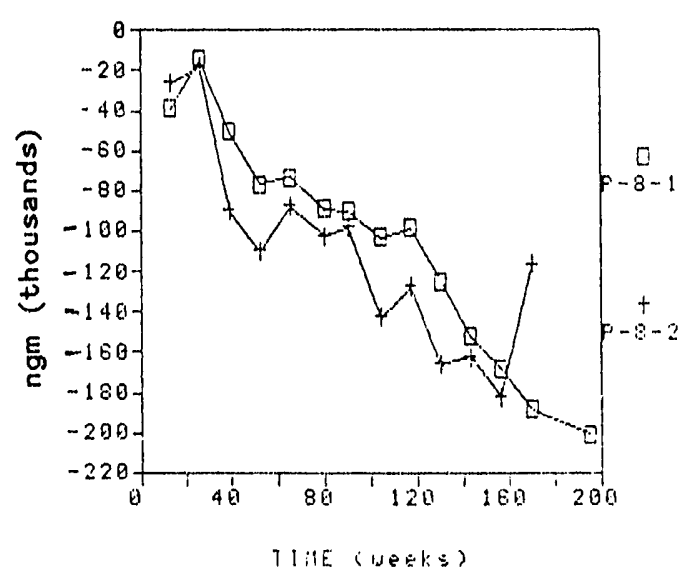

Fig. 40. Cumulative Release of Selected Elements from the P-VIII-1 and P.-VIII-2 Continous Experiments 


\section{Discussion}

There are several observations that can be made about the nature of reaction during the experiments. Despite the apparent difference in the conditions between the top and bottom surfaces (i.e., the top may have undergone wet/dry cycling, whereas the bottom remained wet at all times), the secondary phases are the same. The only difference is that the bottom appears to have undergone somewhat more reaction. The bottom has more precipitates and the surface layer may be a little thicker. The Si-rich "clay" is present as the reacted surface layer and as discrete grains on the glass and metal components. This indicates that the Si-rich material forms by both in situ transformation of hydrated glass and by precipitation. Its composition is consistent with $\mathrm{Fe}$-smectite. The flaky texture of the glass surface is the same as observed on the metal which suggests that much of what is visible on the glass developed by precipitation. Most of the precipitates are composed of a very fine scale mixture of Si-rich "clay," Fe-oxide or hydroxide, and gypsum or anhydrite. This suggests that coprecipitation has occurred which lends support to the interpretation that the visible surface formed by precipitation. There appears to be more Fe-oxide or hydroxide associated with the P-VIII experiments indicating that presensitizing the stainless steel has had an influence on the observed secondary phases. However, the amount of metal corrosion is slight.

The structure of the surface layer undergoes changes upon aging. A network of cracks forms and parts of the layer begin to pull away from the glass. As this process continues, pieces of the layer exfoliates and precipitates form on the freshly exposed glass surfaces. The surface layer also seems to have a complex internal structure of multiple layers. These may correspond to portions formed through glass transformation and precipitation.

\section{DISCUSSION AND CONCLUSIONS}

\section{A. Parametric Effects}

The series of five parametric experiments were designed to investigate the effect of various parameters on the rate of glass reaction. Overall element release is generally similar for the experiments suggesting that release is relatively insensitive to these parameters. However, there are differences in release and the observed extent of reaction which can, at least in part, be attributed to the varied parameters. The normalized releases of $\mathrm{Li}, \mathrm{B}$, and $\mathrm{U}$ are summarized in Fig. 41 for all the parametric experiments and the N2 standard Unsaturated Test using SRL 165U glass. ${ }^{6}$ Relative release for all the experiments except P-II is $\mathrm{Li}>\mathrm{B} \sim \mathrm{U}$ which suggests either nonstoichiometric dissolution of the glass or that $B$ and $U$ are accommodated in secondary phases. The SIMS profiles from the P-III experiments indicate that B is depleted on the surface and within the altered layer, favoring nonstoichiometric dissolution as the explanation for the observed release behavior (Figs. 10, 17, and 19). 
(a)

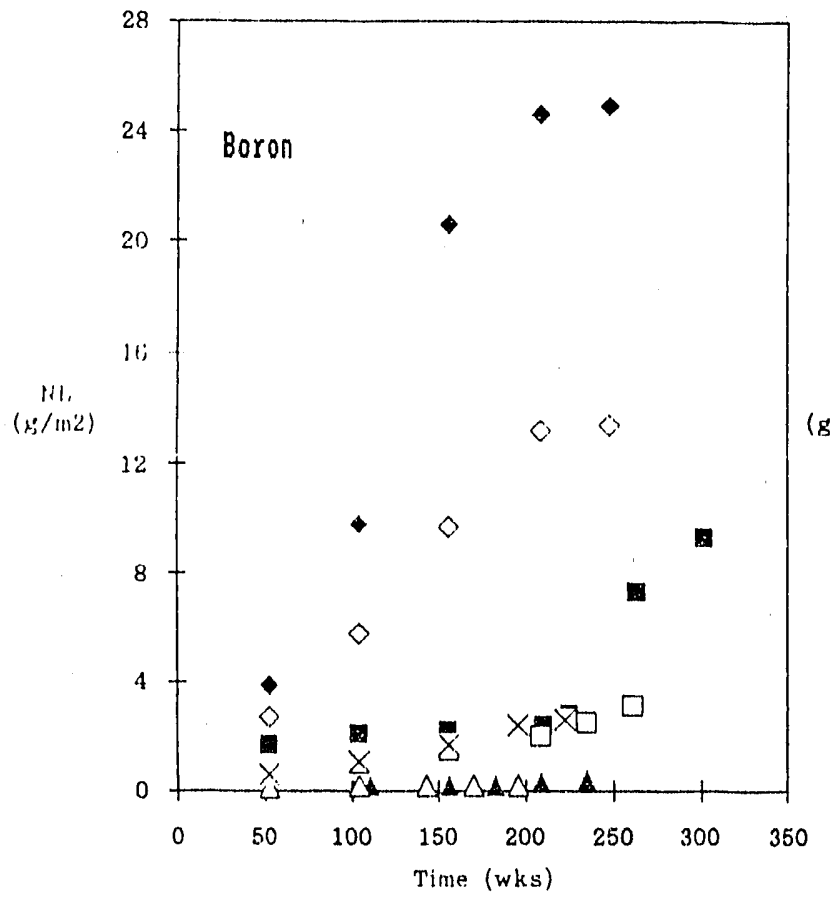

(c)

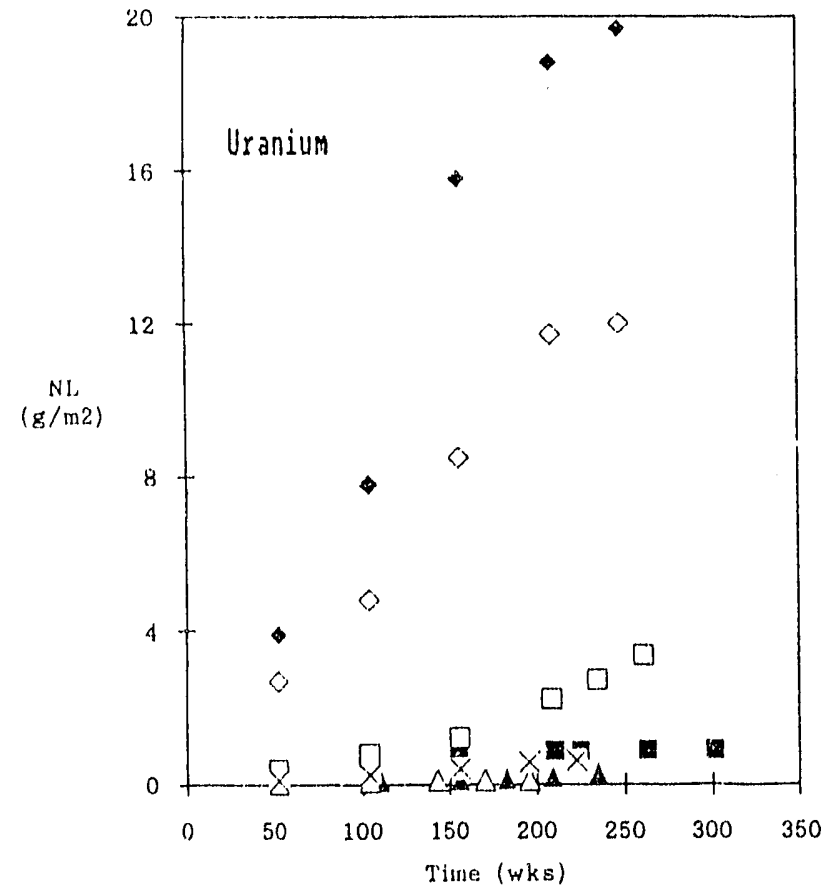

(b)

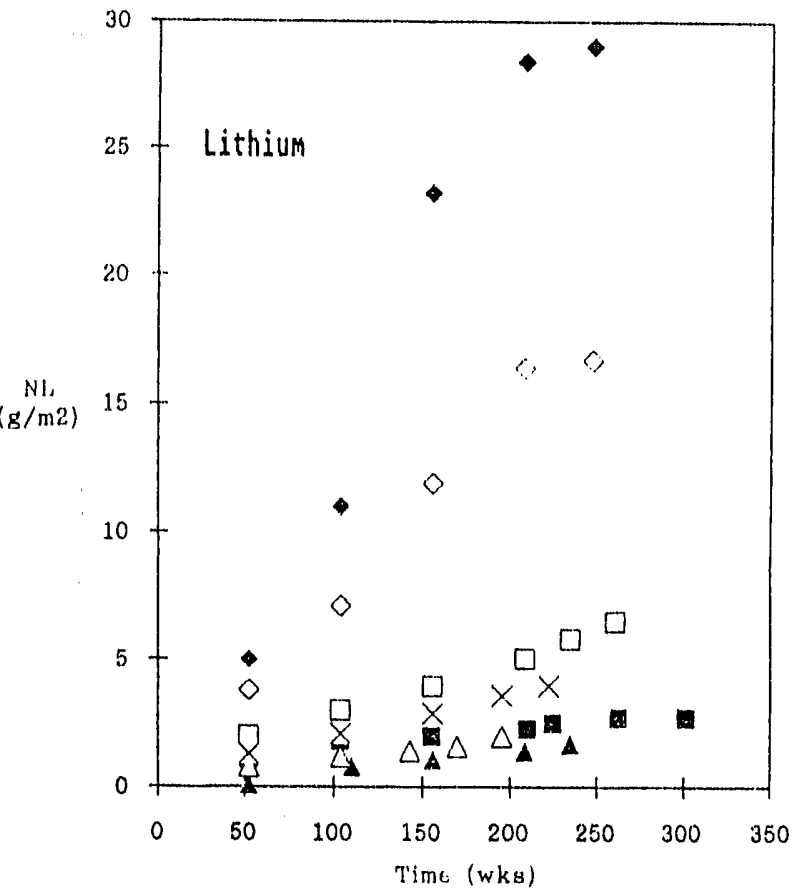

Fig. 41. Normalized Releases of $B, L i$, and $U$ for the Parametric and "Standardized" N2 Unsaturated Experiments 
The behavior of the experiment without the metal retainer (P-II) is similar to the N2 Test. The major difference between the P-II and the other experiments is the abundance of secondary phases that formed by evaporation (e.g., $\mathrm{NaCl}$ ) and that $\mathrm{B}$ release exceeds $\mathrm{Li}$ release. Without the metal component, the glass surface may be more prone to drying out between injections, however, a direct cause and effect is not possible, because of problems with water retention in the vessels during the experiments. These problems may also be the cause of the reversed element release.

The reduction of glass surface area (experiments P-III and P-IV) gives an apparent small increase in the normalized release of $\mathrm{Li}$ and $U$ relative to the N2 test (Fig. 41). This is an apparent increase because the geometric surface area was used in the normalization procedure, rather than an effective surface area. Visual observations and the results from SEM/EDS and SIMS examinations all indicate a variable extent of reacrion between the top, bottom, and side surfaces, with the sides showing the least reaction. Since the surface area was reduced by shortening the sides of the glass cylinder, the change in the effective surface area (i.e., that part of the surface where reaction takes place) should be minimal. Therefore, the normalized releases for the P-III and P-IV experiments are exaggerated by close to a factor of two relative to the other parametric experiments. This must be considered when comparing releases from different experiments. As the effective surface area is smaller than the geometric surface area, the reported normalized releases for all the parametric experiments, especially those with the "full size" glass, will be underestimates of the "true" release. This must also be accounted for when comparing with other types of experiments such as leach tests where geometric surface area is equal to the effective surface area.

The P-TV experiments have anomalously high element release. There are two modified parameters in these experiments: a reduction in suriace area and a reduction in the volume of water injected. Even if account is taken of the effective surface area (see above), the normalized releases are still significantly greater than any of the other experiments. The high release correlates with the extensive reaction observed on the surfaces by SEM. The reason for this anomalous behavior is uncertain. A reduction in injected water volume would seem to be an unlikely cause for a sharp increase in release. Conceivably, reaction could be enhanced by precipitation from a smaller fluid volume that would become rapidly saturated. However, the amount of precipitates on the P-IV samples is not noticeably greater than on samples from other experiments such as P-VIII. The observation that the WPAs in the P-IV experiments were always wet during sampling may provide a clue to the accelerated behavior, but, the reason why these experiments remained wettest is not known. In general, while the extent of reaction in these experiments was large, there was considerable variance in the batch and continuous test results.

Extension of the injection interval from $3-1 / 2$ to 14 days reduces the element release and apparent extent of glass reaction. Observation of dry surfaces during sampling suggest that water is virtually absent for prolonged periods between injections. Consequently, elemental release from the glass is limited to short periods directly following injection. 
The fifth parameter investigated is the effect of sensitizing the metal components. Assessment of this parameter is hampered by the poorly constrained degree of sensitization of the stainless steel. The stainless steel used in the P-VIII experiments has a lower $\mathrm{C}$ content $(0.016$ wt \%) than the steel used in the standard $\mathrm{N} 2$ tests $(0.022 \mathrm{wt} \%)$ which reduces the ability of the steel to become sensitized (Table 5). ${ }^{6,16}$ In the $\mathrm{N} 2$ tests, pervasive metal reaction was observed. ${ }^{6}$ However, in the P-VIII experiments, corrosion of the metal components is of a localized nature suggesting incomplete sensitization. Release is marginally greater for the experiments that exhibit metal reaction, but this is not definitive as these are also longer duration experiments. In addition, element release is much lower than in other experiments where unsensitized metal was used (compare P-VIII release and P-III, P-IV releases in Fig. 41). It is not clear that metal corrosion has any significant influence on glass reaction. At most it appears to be a second order effect. The metal components do act as sites for secondary phase precipitation and probably help to maintain water in contact with the glass by capillary action. These physical effects should act to enhance glass reaction.

\section{B. The Surface Layer and Secondary Phases}

The variation in the extent of reaction between individual parametric experiments provides the op $\mathrm{p}_{2}$ rtunity to investigate the evolution of the glass surface during reaction. The following discussion is limited because it is based only on SEM examination. Abrajano et al. ${ }^{11}$ have demonstrated that Analytical Electron Microscopy (AEM) is required to achieve the resolution necessary for thorough characterization of the alteration layer and its relation to the glass surface. Several samples from the parametric experiments are being prepared for AEM examination, and preliminary results are presented in the Addendum. To help track the phases tentatively identified on the reacted test components, Table 16 provides a listing of phases discussed in the text.

An altered layer develops on the glass surface, presumably resulting from hydration and leaching of the glass. Initially, there is very little structure to this layer at least up to $15,000 \mathrm{X}$ magnification. Over time there is a progressive coarsening of the layer texture creating a bumpy or flaky surface. This layer is Si-rich and contains $\mathrm{Fe}, \mathrm{Ca}, \pm \mathrm{Mg}, \pm \mathrm{Na}, \pm \mathrm{Mn}, \pm \mathrm{Ni}$. It is similar in composition to Fe-smectite and to an amorphous phase called hisingerite. Eggleton et al. indicate that Fe-smectite crystallizes from hisingerite upon aging. It is conceivable that this may also occur in the altered layer. The progressive coarsening of the layer with time supports this hypothesis.

Investigation of extensively reacted samples reveals a complex structure with two to four discrete components to the altered layer. The outermost layer usually has a "cardhouse" or coarse flaky texture and is often not continuous across the surface suggesting it formed by precipitation. Its composition is essentially the same as the other parts of the altered layer, although other phases such as $\mathrm{CaSO}_{4}$ and Fe-oxide or hydroxide are detectable in some EDS analyses. This intimate mixture of phases is consistent with the interpretation that the outermost layer formed by precipitation because the source for most of the $\mathrm{Ca}$ is the EJ-13 water. The lower portions of the altered layer have a variable texture as discussed above. The origin of these sublayers is not clear and awaits AEM examination. 
Table 16. Summary of Phases Tentatively Identified in the Parametric Tests

\begin{tabular}{|c|c|c|}
\hline Test \# & $\begin{array}{l}\text { Time of } \\
\text { Reaction }\end{array}$ & Tentative Phase \\
\hline \multirow[t]{2}{*}{ P-II } & 26 & $\begin{array}{l}\text { Si-rich layer (smectite) } \\
\text { Smooth layer (similar to glass composition) } \\
\text { Gypsum or anhydrite }\left(\mathrm{CaSO}_{4}\right) \\
\text { Calcite }\left(\mathrm{CaCO}_{3}\right)\end{array}$ \\
\hline & 52 & $\begin{array}{l}\text { Si-rich layer (smectite) } \\
\text { Calcite } \\
\text { Gypsum or anhydrite } \\
\mathrm{NaCl}\end{array}$ \\
\hline \multirow[t]{4}{*}{ P-III } & 13 & $\begin{array}{l}\text { Si-rich layer (smectite) } \\
\mathrm{NaCl} \\
\mathrm{Na}_{2} \mathrm{SO}_{4} \\
\mathrm{Na}_{2} \mathrm{CO}_{3}\end{array}$ \\
\hline & 26 & $\begin{array}{l}\text { Si-rich layer (Ca, smectite) } \\
\text { Gypsum or anhydrite } \\
\mathrm{U}, \mathrm{Si}, \mathrm{Ca} \text { grain (uranophane) } \\
\mathrm{Na}, \mathrm{Ca}, \mathrm{S}, \mathrm{Cl} \text { grains }\end{array}$ \\
\hline & 39 & $\begin{array}{l}\text { Si-rich layer } \\
\mathrm{Mn}, \mathrm{Cr}, \mathrm{Fe}, \mathrm{Si} \text { grains } \\
\mathrm{Fe}, \mathrm{Mn} \text { oxides/hydroxides } \\
\text { Gypsum or anhydrite } \\
\mathrm{TiO}_{2} \text { (anatase) }\end{array}$ \\
\hline & 52 & $\begin{array}{l}\text { Si-rich layer (smectite) } \\
\mathrm{NaCl} \\
\text { Gypsum or anhydrite } \\
\mathrm{CaCl}_{2} \\
\mathrm{Fe}, \mathrm{Mn} \text { oxide/hydroxide }\end{array}$ \\
\hline \multirow[t]{2}{*}{ P-IV } & 25.5 & $\begin{array}{l}\text { Si-rich layer (smectite) } \\
\text { Silica (opal/quartz) } \\
\text { Calcite } \\
\text { Cr, Fe, Mn oxide/hydroxide }\end{array}$ \\
\hline & 52 & $\begin{array}{l}\text { Si-rich layer (smectite) } \\
\text { Gypsum/anhydrite } \\
\text { Cr, Mn, Fe, Ni oxide/hydroxide }\end{array}$ \\
\hline
\end{tabular}

Cont'd 
Table 16 (Cont'd)

\begin{tabular}{|c|c|c|}
\hline Test \# & $\begin{array}{l}\text { Time of } \\
\text { Reaction }\end{array}$ & Tentative Phase \\
\hline \multirow[t]{2}{*}{$\mathrm{P}-\mathrm{V}$} & 26 & $\begin{array}{l}\text { Si-rich layer (smectite) } \\
\text { Gypsum/anhydrite } \\
\text { Fe, Cr, Mn oxide/hydroxide } \\
\text { Silica (opal/quartz) } \\
\text { Al-rich grains } \\
\text { KCl } \\
\text { Calcite } \\
\text { Ca-P grains (apatite) } \\
\text { Dolomite } \\
\text { Mixed Ti-rich grains }\end{array}$ \\
\hline & 52 & $\begin{array}{l}\text { Si-rich layer (smectite) } \\
\mathrm{Cr}, \mathrm{Mn}, \mathrm{Fe}, \mathrm{Ni} \text { oxide/hydroxide }\end{array}$ \\
\hline \multirow[t]{3}{*}{ P-VIII } & 26 & $\begin{array}{l}\text { Si-rich layer (smectite) } \\
\text { Fe-rich grains with Mn, Ni } \\
\text { Gypsum/anhydrite } \\
\text { Calcite } \\
\text { Si-Al-K grains (K-feldspar) }\end{array}$ \\
\hline & 52 & $\begin{array}{l}\text { Si-rich layer (smectite) } \\
\text { Fe, Mn, Cr, Ni oxide/hydroxide } \\
\text { Anhydrite/gypsum } \\
\text { Silica (quartz/opal) } \\
\text { Al-rich phase (gibbsite or Al-hydroxide) } \\
\text { High-Mg calcite (dolomite) } \\
\text { Calcite } \\
\text { Cl-rich phase } \\
\text { Na-Al-Si grain (analcime) } \\
\text { NaCl }\end{array}$ \\
\hline & 104 & $\begin{array}{l}\text { Si-rich layer (Fe-smectite) } \\
\mathrm{Fe} \text { oxide/hydroxide } \\
\text { Calcite, with } \mathrm{Mg} / \mathrm{Fe} \text { (dolomite) } \\
\text { Al-rich grain (gibbsite, bayerite, nordstrandite) } \\
\mathrm{Cl} \text { - and } \mathrm{S}-\mathrm{rich} \text { grains } \\
\mathrm{NaCl}, \mathrm{Na}_{2} \mathrm{SO}_{4}, \mathrm{CaSO}, \mathrm{CaCl}_{2} \\
\text { Ti-rich phase (anatase) } \\
\text { (Serpentine) } \\
\text { (Apatite) } \\
\text { Silica (quartz, opal) }\end{array}$ \\
\hline
\end{tabular}


The discontinuous nature of the precipitated layer along with its porous appearance of loosely intergrown grains indicate that the precipitates do not form a reliable barrier to fluid infiltration. While the precipitates will influence the local fluid chemistry, they do not physically impede fluid-glass interaction.

The surface layer undergoes other changes upon aging. A network of cracks form and parts of the layer begin to pull away from the glass. Cracking begins as a localized phenomenon even before the layer has fully developed across the surface. This process, sometimes referred to as crazing, has been observed during leaching of simple alkali-silicate glasses. ${ }^{17}$ The inception of cracking may be influenced by the surface topography. The cause of cracking may be tensional forces at the interface between the hydrated altered layer and the glass. A contributing factor may also be volume changes and tensional forces within the layer as it begins to crystallize upon aging. Once a network of cracks is established, pieces of the layer begin to exfoliate from the surface, exposing patches of glass from below. Eventually, the exposed glass becomes covered with precipitates. The ubiquitous occurrence of cracks indicates that the surface layer cannot retard glass-fluid interaction to any large degree. While the intact layer may (or may not) act as a diffusion barrier, the cracks provide free access to the glass.

There are a number of secondary phases that have precipitated on the surface of both the glass and the metal components. The most common is Si-rich "clay" which has the same composition as the altered layer. Fe-oxide or hydroxide (XRD results suggest it is an oxide) is common especially on samples where the metal components have corroded. Some samples have a $\mathrm{Cr}$ - and Mn-rich phase, presumably an oxide or hydroxide. While the source of the $\mathrm{Cr}$ is probably the metal, no localized metal corrosion is observable on the samples where this phase occurs.

There are two common Ca-bearing phases: calcite and $\mathrm{CaSO}_{4}$. They may occur together but generally only one is present. The net negative release of $\mathrm{Ca}$ in all the experiments indicates that $\mathrm{Ca}$ is removed from the EJ-13 water. Furthermore, the $\mathrm{Ca}$ depletion indicates that $\mathrm{CaSO}_{4}$ precipitated during the experiment rather than upon cooling during sampling. Being the stable phase at $90^{\circ} \mathrm{C}$, anhydrite must have precipitated. This demonstrates the influence of the EJ-13 water composition on the formation of secondary phases. Sodium-bearing phases are abundant on some samples but absent on others. Their occurrence is presumably linked to the availability of water. Phases tentatively identified include: $\mathrm{NaCl}, \mathrm{Na}_{2} \mathrm{SO}_{4}$, and $\mathrm{Na}_{2} \mathrm{CO}_{3}$.

A U-bearing phase was observed on the metal components of the P-III-6 batch experiment. The small clusters of acicular grains contain Si and $\mathrm{Ca}$ which is suggestive of uranophane. This is the only observed occurrence of an U-bearing phase in any of the parametric experiments, although U-bearing phases are observed in the N2 tests. ${ }^{6}$ 
In order to assess the relative effects of an unsaturated environment where water drips onto the waste form, it is informative to compare this study's results with other types of experiments. Two short-term leaching experiments have been performed at $90^{\circ} \mathrm{C}$ using the same SRL $165 \mathrm{U}$ glass. ${ }^{18,19}$ In these experiments, the glass was submerged in EJ-13 water and run both with and without an imposed $\gamma$-radiation field. The experiments of Ebert were performed at 0 and $1 \times 10^{-3} \mathrm{rad} / \mathrm{hr}$ up to 278 days and those of Abrajano had a $1 \times 10^{-4} \mathrm{rad} / \mathrm{hr}$ radiation field and a maximum duration of 182 days.

The normalized releases of $\mathrm{B}, \mathrm{Li}$, and $\mathrm{U}$ in the 278-day experiments of Ebert are presented in Table 17 along with the releases from selected batch and continuous experiments of similar duration. Element releases in the leaching experiments are only slightly greater than in the P-IV continuous and P-III batch experiments (by less than a factor of two). This difference is much less than

Table 17. Comparison of Normalized Release of B, Li, and $U$ between the Leaching Experiments of Ebert and the Parametric Experiments

\begin{tabular}{lcccc}
\hline & & \multicolumn{3}{c}{ Normalized Release $\left(\mathrm{g} / \mathrm{m}^{2}\right)$} \\
\cline { 3 - 5 } Test \# & $\begin{array}{c}\text { Tirne } \\
\text { (weeks) }\end{array}$ & $\mathrm{B}$ & $\mathrm{Li}$ & $\mathrm{U}$ \\
\hline G308 & 39.7 & 4.93 & 6.98 & 4.38 \\
G309a & 39.7 & 4.80 & 6.89 & 4.17 \\
G350b & 39.7 & 3.61 & 5.87 & 3.56 \\
G351 & 39.7 & 4.08 & 5.97 & 3.51 \\
& & & & \\
& Parametric & Experiments & & \\
P-II-1 & & & & \\
P-II-2 & 39 & 2.2 & 0.9 & 0.29 \\
P-II-6 & 39 & 1.0 & 1.1 & 0.24 \\
& 39 & 0.8 & 1.1 & 0.27 \\
P-III-1 & 39 & & & \\
P-III-2 & 39 & 0.5 & 1.8 & 0.46 \\
P-III-7 & 39 & 0.4 & 1.6 & 0.34 \\
P-III-8 & 39 & 3.1 & 4.2 & 2.11 \\
P-IV-1 & & 2.0 & 3.3 & 1.48 \\
P-IV-2 & 39 & & & \\
& 39 & 2.9 & 3.8 & 2.88 \\
P-V-1 & & 2.2 & 3.2 & 2.10 \\
P-V-2 & 39.5 & & & \\
& 39.5 & 0.1 & 0.0 & 0.00 \\
P-VIII-1 & 39 & & 0.5 & 0.06 \\
P-VIII-2 & 39 & 0.1 & 0.8 & 0.07 \\
P-VIII-5 & 39 & 0.1 & 0.5 & 0.05 \\
\hline & & 0.2 & 0.4 & 0.09 \\
\hline
\end{tabular}

${ }^{\mathrm{a}} 90^{\circ} \mathrm{C}$ leach test of Ebert with $1 \times 10^{-3} \mathrm{rad} / \mathrm{hr} \gamma$-radiation.

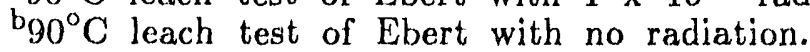


the order of magnitude range in release obtained for the set of parametric exper ments. Furthermore, the normalization procedure underestimates roiease only for the parametric experiments because the geometric and effective surface areas are equal in the leaching experiments (see above). This suggests that truc normalized releases, based upon the effective surface area, would be in even closer agreement between the parametric and leaching experiments.

The release trends of the leaching and parametric experiments do appear to differ. The rates of release in the leaching experiments become progressively reduced through 39 weeks. In contrast, the release rates remain relatively constant in the parametric experiments for at least 300 weeks. This differing behavior may be attributable to the dripping environment where fresh wates: is periodically added and where evaporation can occur.

Relative release for the leaching (complete liquid submersion) and parainetric (drip) experiments is $\mathrm{Li}>\mathrm{B} \sim \mathrm{U}$ (except for $\mathrm{P}-\mathrm{II}$ ) suggesting a similar mechanism of glass reaction for both types of experiments. In the leaching experiments $\mathrm{Na}$ and $\mathrm{Mg}$ exhibit large positive releases but $\mathrm{Ca}$ has only a very small release. In the parametric experiments $\mathrm{Na}$ release is often erratic and $\mathrm{Mg}$ and $\mathrm{Ca}$ have net negative releases. This contrasting behavior is most likely attributable to differences in the secondary phases that precipitate on the glass. Aside from an Fe-smectite-like surface layer, precipitation in the leach experiments is not very extensive. Some $\mathrm{Ca}$-rich precipitates such as calcite are reported by Ebert along with a U-silicate, an Al-rich phase, and rare $\mathrm{NaCl}$. In contrast, precipitates are generally much more abundant in the drip experiments. $\mathrm{Ca}$-rich precipitates such as calcite or anhydrite are common as is $\mathrm{NaCl}$. It appears that in the unsaturated environment of the parametric experiments precipitation is more extensive, w?.hich in idin influences the solution chemistry. The development of a clay-like surface layer is common to both types of experiments and the behavior of the elements most indicative of glass reaction ( $\mathrm{Li}, \mathrm{B}$, and $\mathrm{U}$ ) is the same.

\section{ACKNOWLEDGMENTS}

Work supported by the U.S. Department of Energy, Office of Civilian Radioactive Waste Management, Yucca Mountain Site Characterization Project, under subcontract to Lawrence Livermore National Laboratory, SANL 910-005. 


\section{REFERENCES}

1. J. K. Bates and T. J. Gerding, "NNWSI Phase II Materials Interaction Test Procedure and Preliminary Results," Argonne National Laboratory report ANL-84-81 (1984).

2. J. K. Bates and T. J. Gerding, "One-Year Results of the NNWSI Unsaturated Test Procedure: SRL 165 Glass Application," Argonne National Laboratory report ANL-85-41 (1986).

3. Site Characterization Plan, U.S. Department of Energy, Office of Civilian Radioactive Waste Management, DOE report DOE/RW-0199 (1988).

4. W. L. Bourcier, D. W. Peiffer, K. G. Knauss, K. D. McKeegan, and D. K. Smith, "A Kinetic Model for Borosilicate Glass Dissolution Based on the Dissolution Affinity of a Surface Alteration Layer," Mat. Res. Soc. Symp. Proc. 176, 209-216 (1990).

5. C. J. Bruton, "Geochemical Simulation of Dissolution of West Valley and DWPF Glasses in J-13 Water at $90^{\circ} \mathrm{C}$," Lawrence Livermore National Laboratory preprint UCRL-96703 (1987).

6. J. K. Bates and T. J. Gerding, "Application of the NNWSI Unsaturated Test Method to Actinide Doped SRL 165 Type Glass," Argonne National Laboratory report ANL-89/24 (1990).

7. G. T. Chandler, G. G. Wicks, and R. M. Wallace, "Effects of SA/V and Saturation on the Chemical Durability of SRP Waste Glass," Savannah River Laboratory report DP-MS-86-56 (1986).

8. "DWPF Waste Form Compliance Plan," U.S. DOE report DPST-86-746 (1988).

9. C. M. Jantzen and M. J. Plodinec, "Thermodynamic Model of Natural, Medieval, and Nuclear Waste Glass Durability," J. Non-Cryst. Sol. 67, 207-223 (1984).

10. W. A. Deer, R. A. Howie, and J. Zussman, An Introduction to the RockForming Minerals, Longman, London, $528 \mathrm{pp.} \mathrm{(1966).}$

11. W. L. Ebert, J. K. Bates, and W. L. Bourcier, "The Hydration of Borosilicate Waste Glass in Liquid Water and Steam at $200^{\circ} \mathrm{C}$," accepted for publication in Waste Management.

12. T. A. Abrajano, Jr., J. K. Bates, A. B. Woodland, J. P. Bradley, and W. L. Bourcier, "Secondary Phase Formation during Nuclear Waste-Glass Dissolution," Clay and Clay Min. 38, 537-548 (1990). 
13. J. K. Bates, T. J. Gerding, W. L. Ebert, J. J. Mazer, and B. M. Biwer, "NNWSI Waste Form Testing at Argonne National Laboratory, Semiannual Report, July-December 1987," Lawrence Livermore Nat: onal Laboratory report UCRL-21060-87-2 (1989)。 NNA.881115.0026

14. A. E. Nielsen, Kinetics of Precipitation, MacMillan Co., New York, pp. 72-85 and 108-119 (1964). NNA.910903.0118

15. W. Stumm and J. J. Morgan, Aquatic Chemistry, An Introduction Emphasizing Chemical Equilibria in Natural Waters, 2nd Edition, J. Wiley and Sons, New York, NY, 230-319 (1981). NNA.910903.0117

16. R. L. Cowan and C. S. Tedman, Jr., "Intergranular Corrosion of Fe-Ni-Cr Alloys," in Advances in Corrosion Science and Technology, Vol. 3, M. G. Fontana and R. W. Staehle, eds., Plenum Press, New York, 292-400 (1973). NNA.890921.0111

17. B. C. Bunker, G. W. Arnold, E. K. Geauchamp, and D. E. Day, "Mechanisms for Alkali Leaching in Mixed Na-K Silicate Glasses," J. Non-Cryst. Sol. 58, 295-322 (1983). NNA.910215.0015

18. T. A. Abrajano, Jr., J. K. Bates, T. J. Gerding, and W. L. Ebert, "The Reaction of Glass during Gamma Irraciation in a Saturated Tuff Environment, Part 3: Long-Term Experiments at 1 x $10^{4}$ Rad/Hour." Argonne National Laboratory report ANL-88-14 (1988). HQX.880721.0013

19. W. L. Ebert, J. K. Bates, and T. J. Gerding, "The Reaction of Glass during Gamma Irradiation in a Saturated Tuff Environment, Part 4: SRL 165, ATM-1c, and ATM-8 Glasses at $1 \mathrm{E} 3 \mathrm{R} / \mathrm{h}$ and $0 \mathrm{R} / \mathrm{h}$," Argonne National Laboratory report ANL-90/13 (1990). NNA.900509.0197

20. J. P. Bradley and J. K. Bates, "Leached Nuclear Waste Glasses: Ultramicrotomy and Electron Microscopic Characterization," Proc. of the 12th Mtg. of the Microbeam Analysis Soc. (1990). NNA.910903.0119 


\section{ADDENDUM}

While the SEM provides important information about the nature of glass reaction, it lacks the requisite resolution to understand the detail of alteration layer development. Analytical electron microscopy (AEM) may provide the key to unravelling this process. For example, the AEM study by Abrajano et al. of leached SRL 131 glass reveals a reaction layer with a complex structure, composed of six distinct sublayers and a mixture of amorphous material and crystalline phases. ${ }^{12}$ At present two samples from the parametric experiments have been prepared. The following a ver $r$ brief description of these samples. A thorough AEM investigation will be the subject of a future topical report.

A section through the reacted layer from the bottom glass surface of P-VIII-7 (104 weeks) is presented in Fir, 42. As there is no accompanying glass in this sample, this must be viewed as only a partial section through the upper part of the layer. This part has a complex structure of repeated bands only partially attached to one another. Each band has a fine-grained Fe-rich element with an epitaxial growth of smectite on either side. The structure of the individual bands is reminiscent of that observed for the same glass after 280 days in static MCC- 1 leach tests. ${ }^{20}$ The origin of the multiple bands is uncertair: at this time.

A sample from the side of P-III-10 (52 weeks) was taken from near the top surface where prolonged water contact had occurred during the experiment. There is a layer of coarse, loosely packed smectite grains which lies above the glass surface (Fig. 43). No Fe-rich band is observed here. The smectite may have formed by precipitation on the glass. However, etching has caused retreat of the glass surface, resulting in a gap between the smectite layer and the glass.

Much more work needs to be done; however, it is clear that the AEM is an extremely useful tool for investigating the mechanisms of glass alteration. This work is underway. It is comforting that some of the interpretations based on SEM observations are confirmed by the preliminary AEM results. 


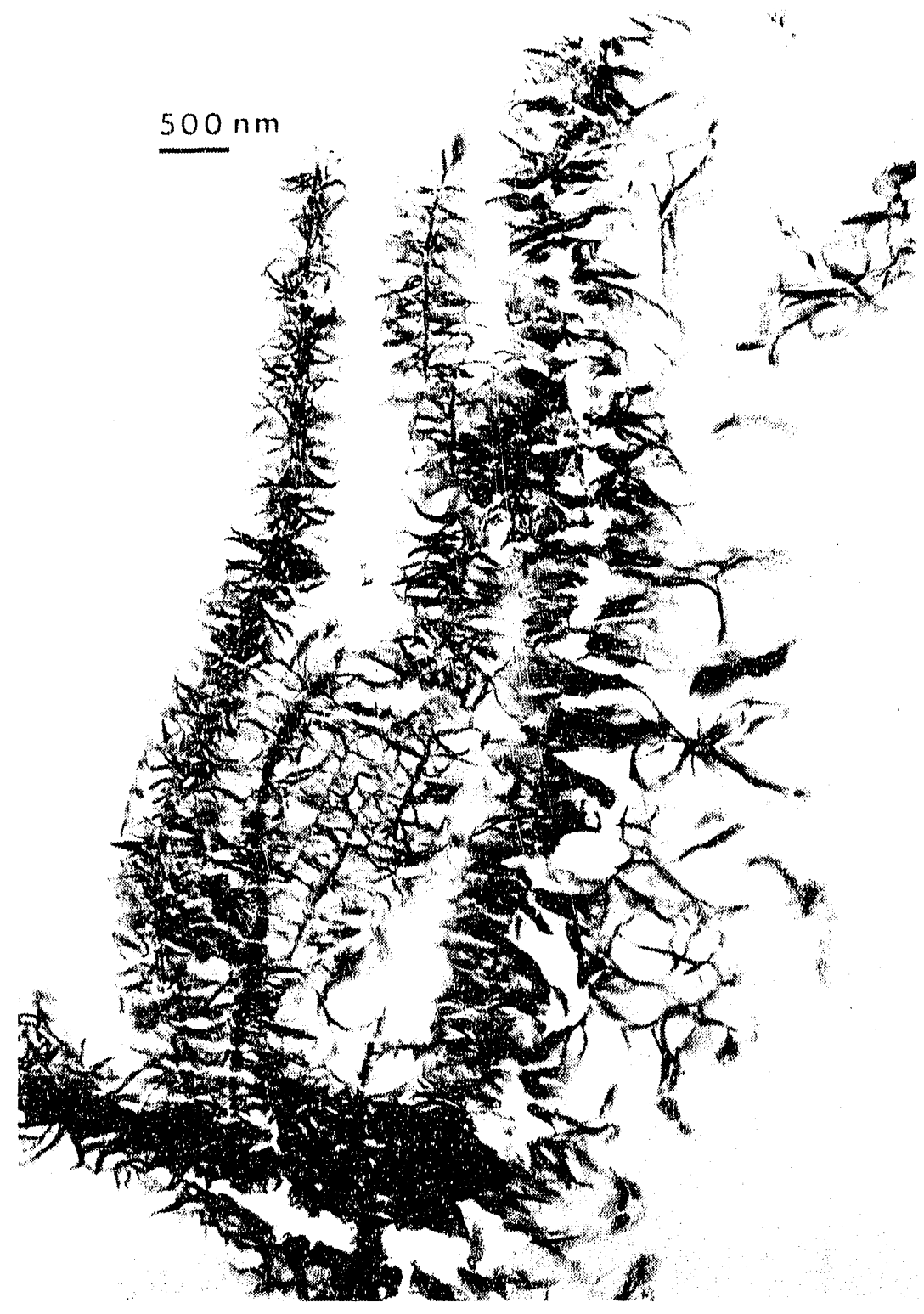

Fig. 42. TEM Micrograph of the Layer from the Bottom of P-VIII-7. The scale is $7 \mathrm{~mm}=500 \mathrm{~nm}$ 


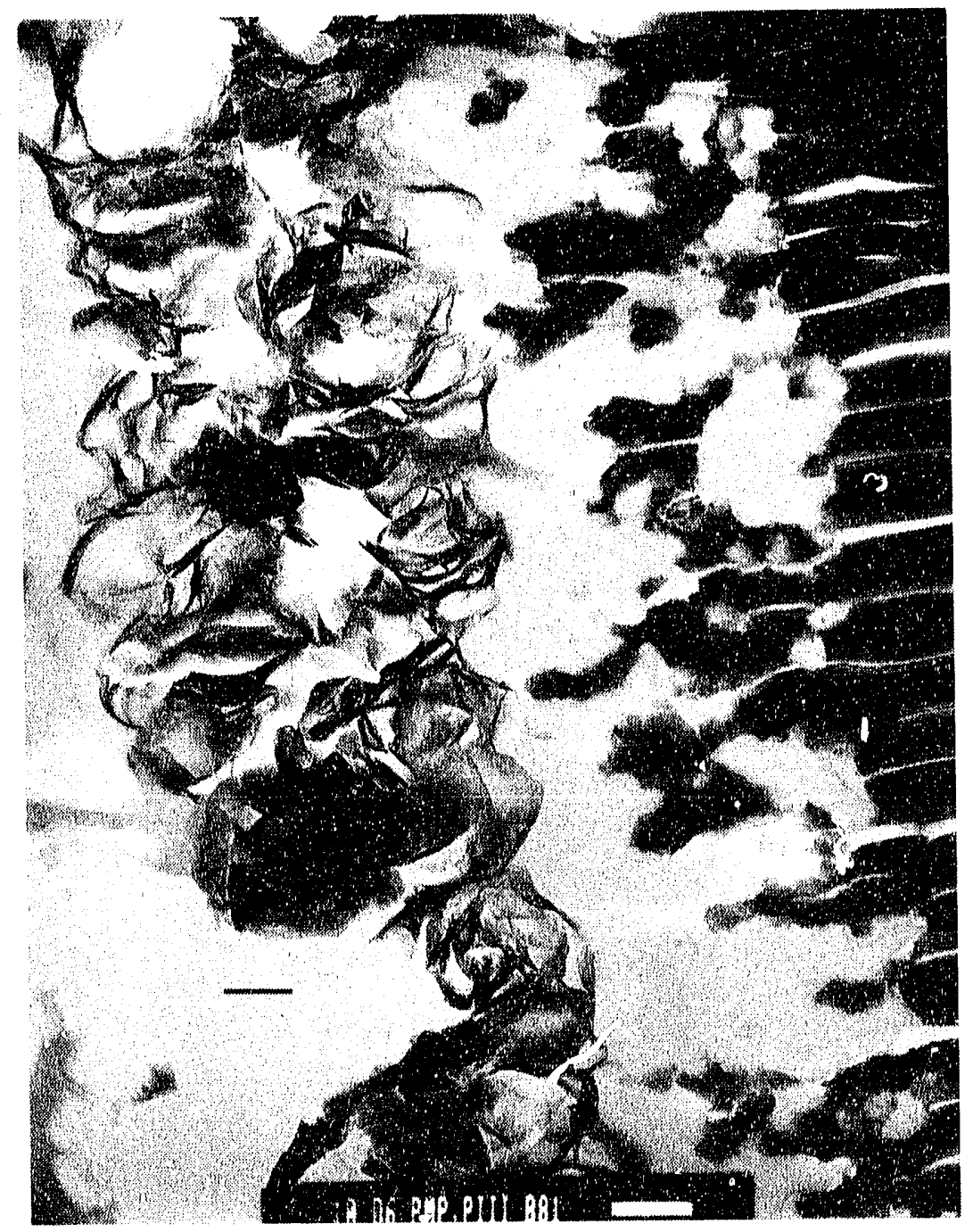

Fig. 43. TEM Micrograph of the Side of P-III-10. The scale is $9 \mathrm{~mm}=200 \mathrm{~nm}$ 


\section{APPENDIX I}

Raw data for the analyses of solutions from the parametric unsaturated experiments (continuous mode) are presented. The data presented include the test number, sample interval (in weeks; both the interval and cumulative time periods are given), sample identifier ( $\mathrm{TF} \#$ ), the solution volume in $\mathrm{mL}$ submitted for analysis (the original solution volume is diluted with acidified DIW prior to analysis), and the volume of test solution added during the test period (water is injected throughout the test period and a specified volume of water is added to the bottom of the test vessel at the beginning of each test period. The water added at the beginning of the test period is DIW for the P-II experiments and EJ-13 for the other experiments. The volume given in the $\mathrm{H}_{2} \mathrm{O}$ Added column is only the volume of EJ-13 or J-13 water and the value is used in the background subtraction process).

The composition of groundwater (ppm) added during the test is given in the first row(s) under the heading of elements. For each sampling period, generally three rows of data are presented. The first row is the total mass of each element in the diluted solution submitted for analysis, the second row is the total mass of each element in solution that can be attributed to the glass (the value is obtained by subtracting from the tota! elemental mass the mass attributed to groundwater added to the test. 'The value will be negative if elements are precipitated from solution). The third row is the cumulative mass of each element attributed to the glass. 
要

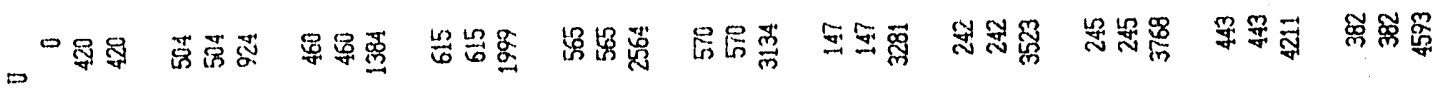

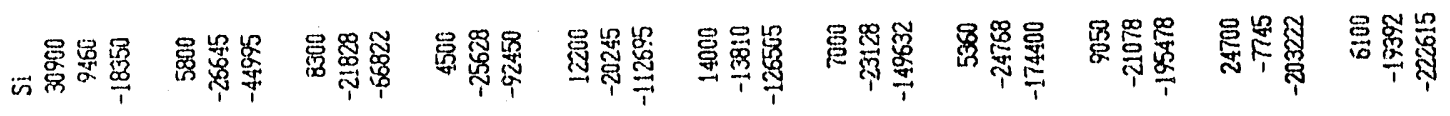

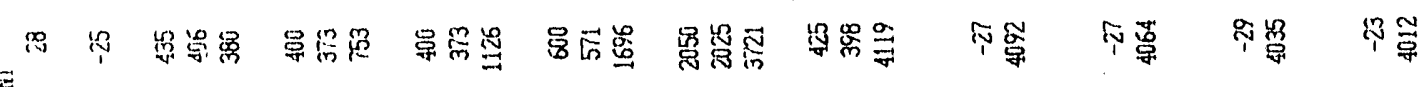

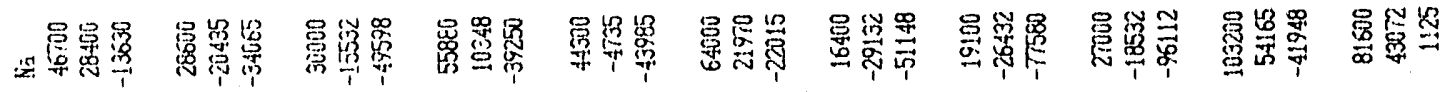

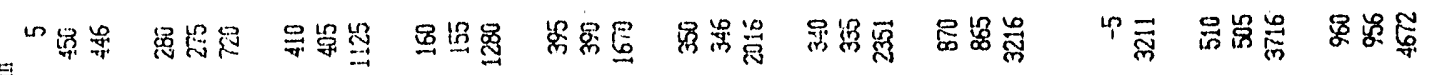

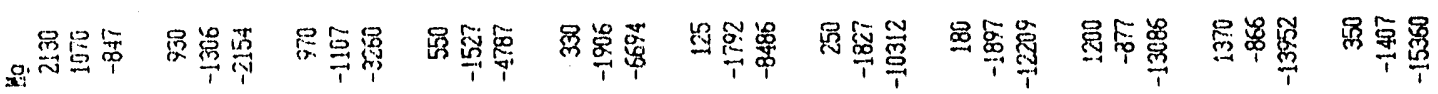

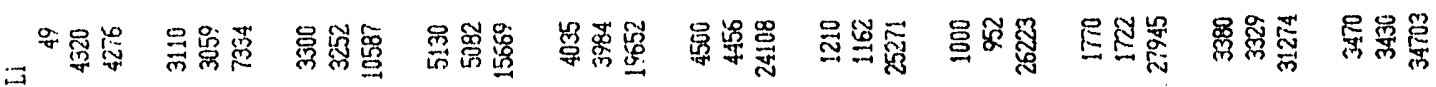

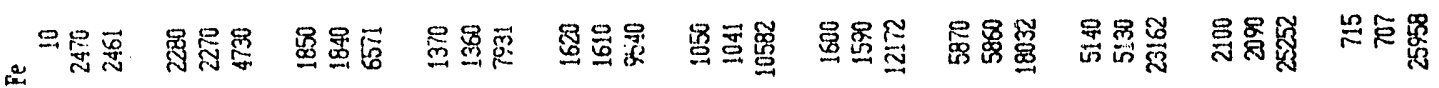

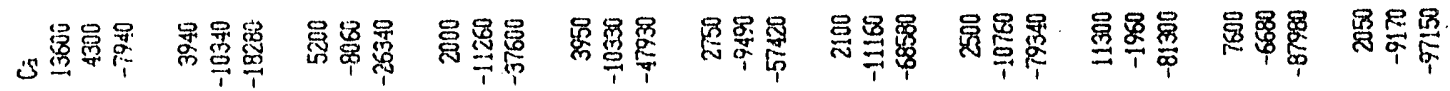

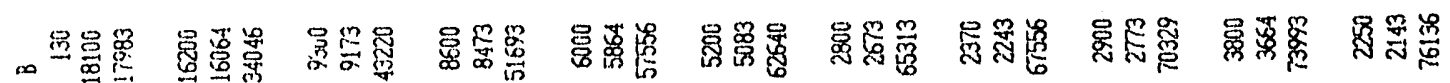

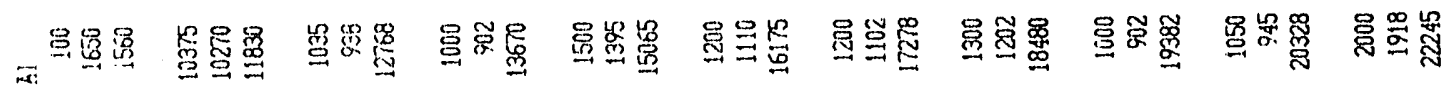

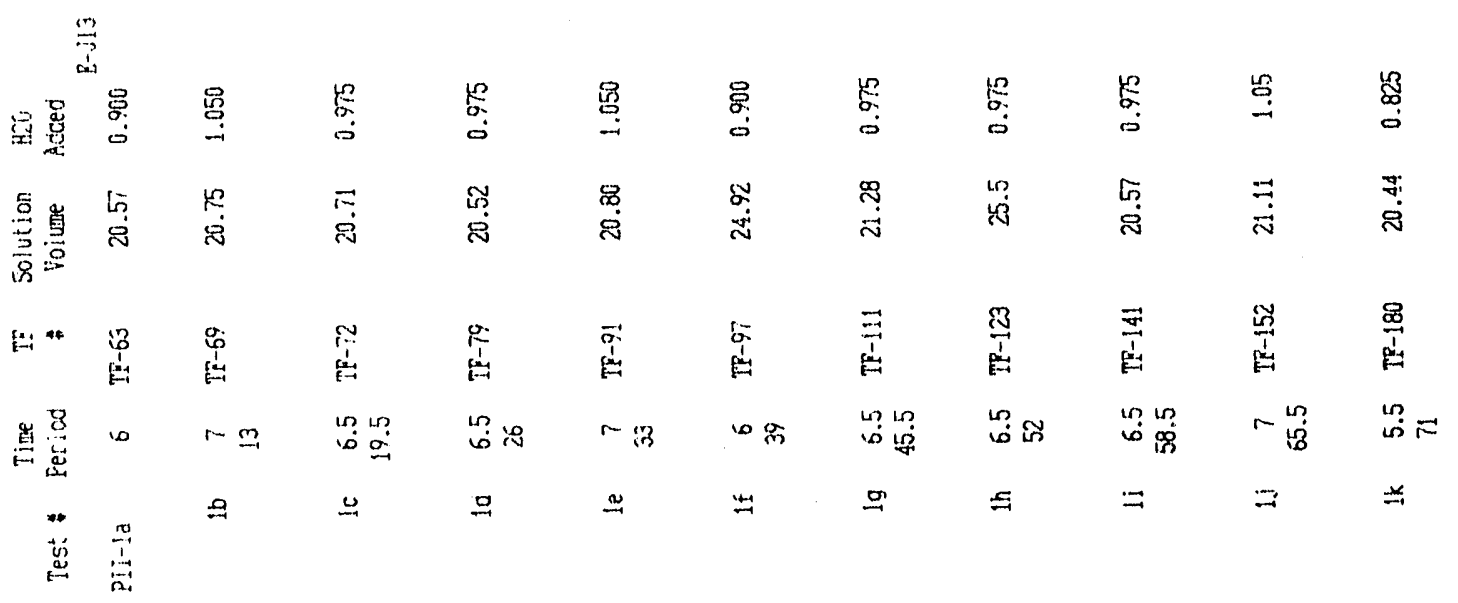




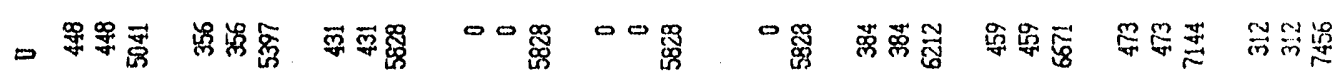

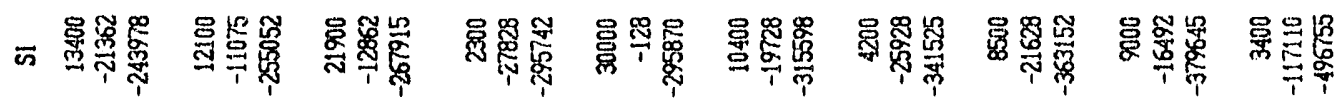

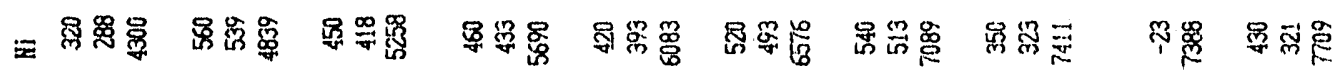

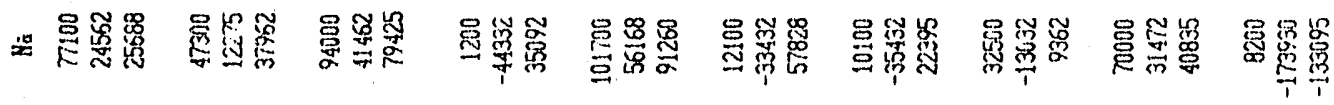

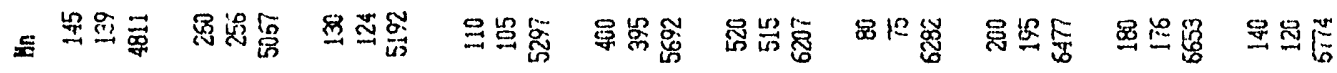

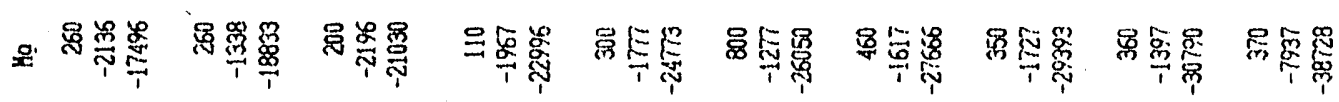

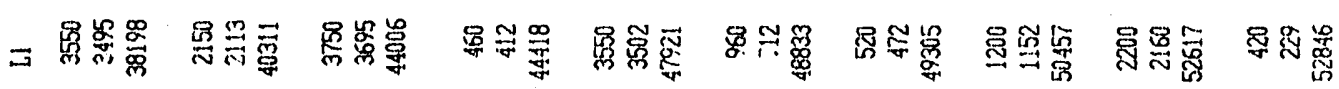

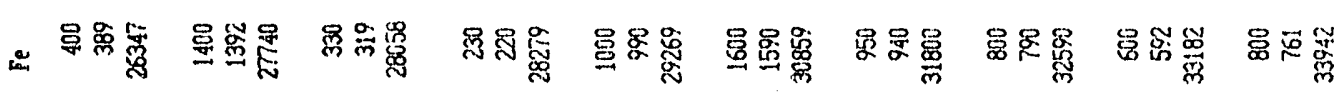

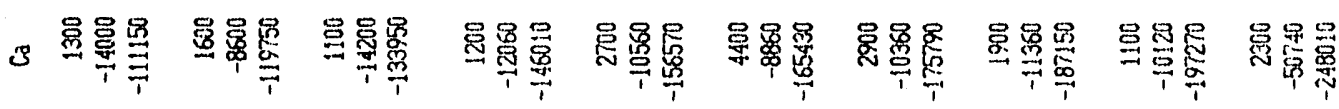

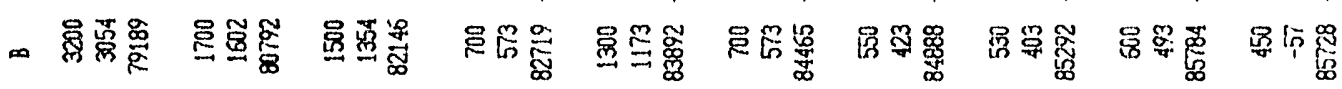

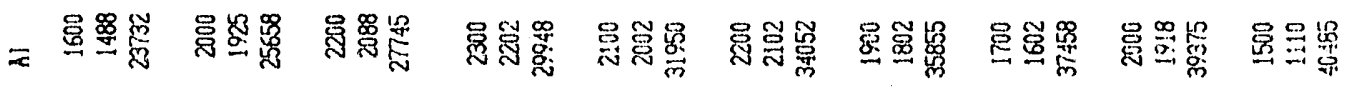

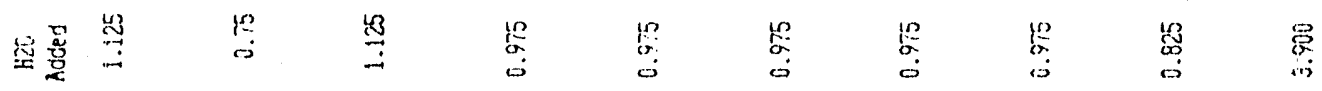
尊息兽

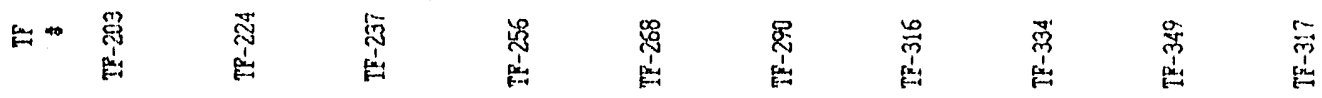

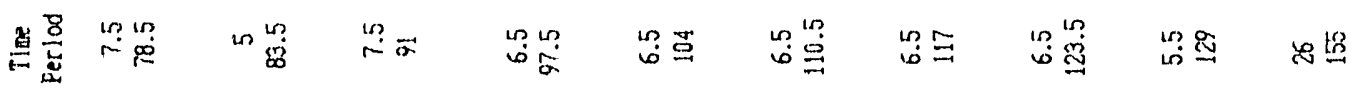

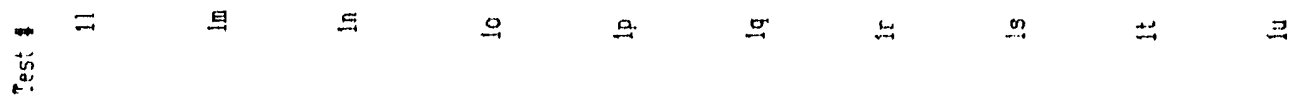




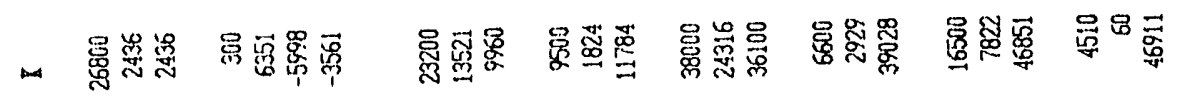

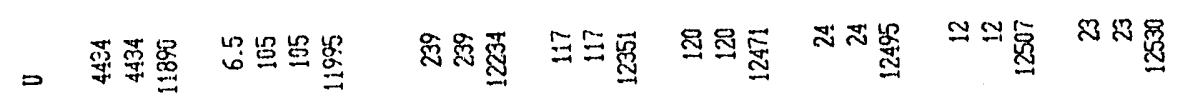

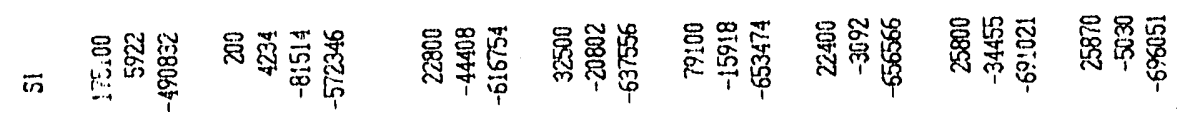

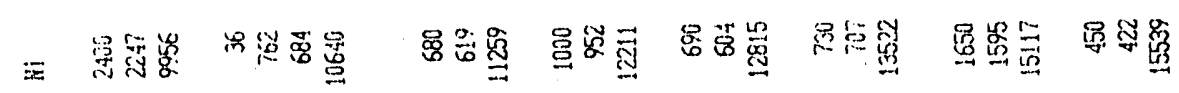

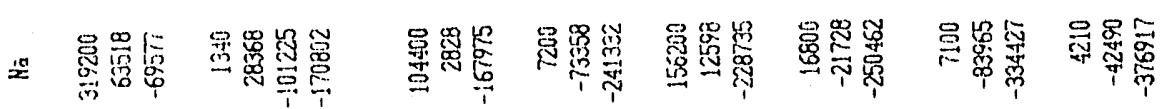

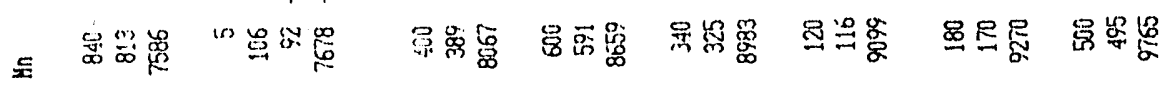

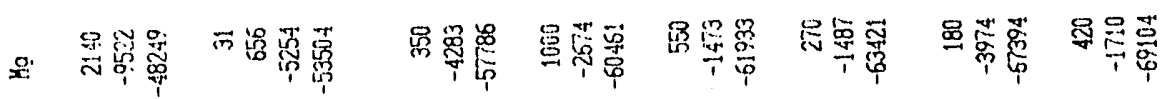

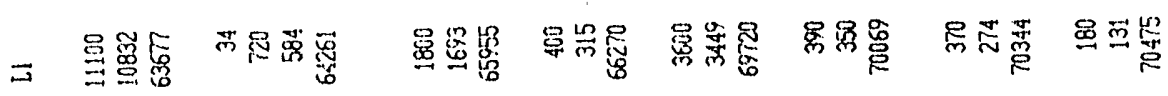

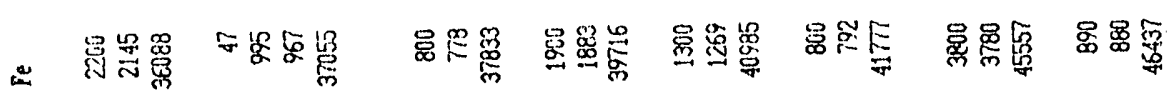

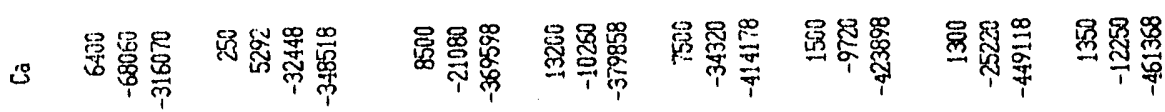

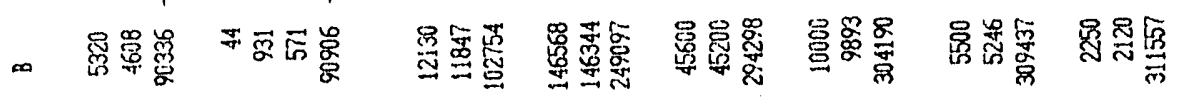

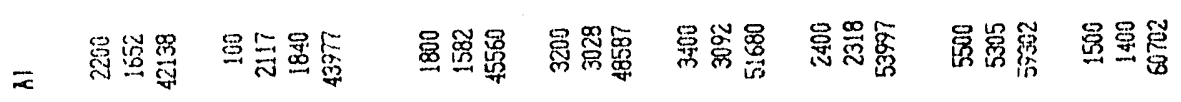

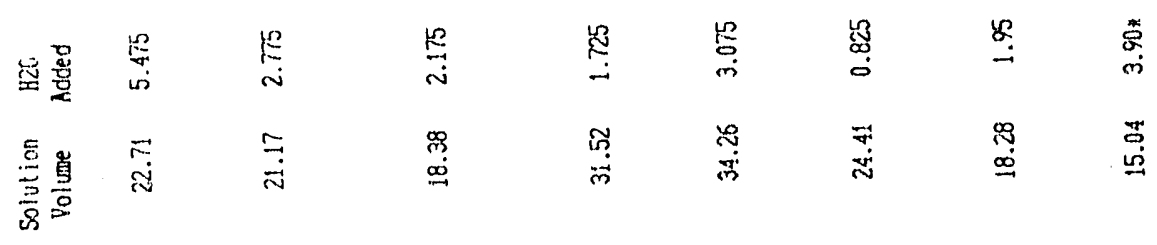

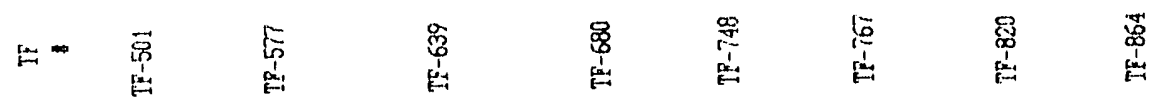

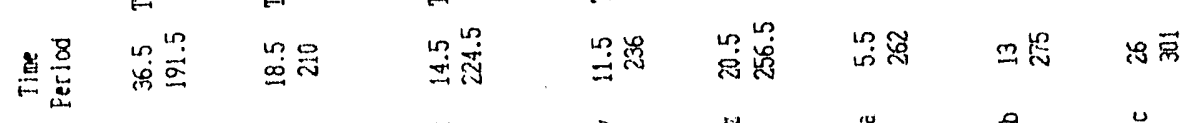

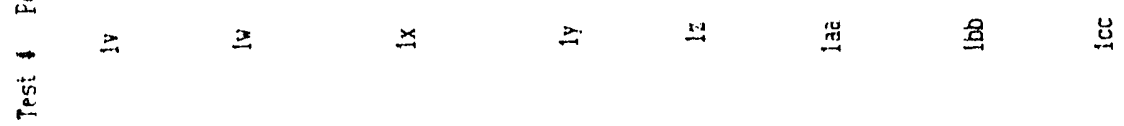




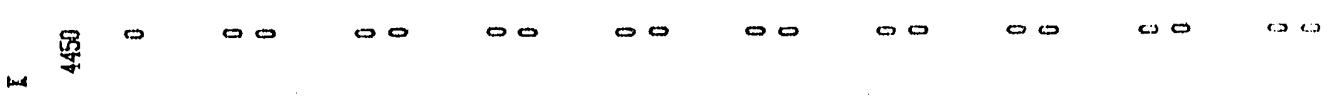

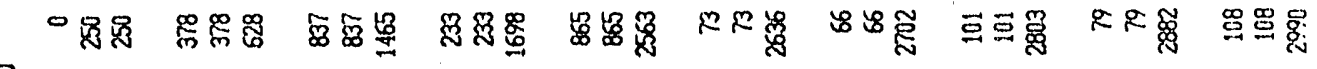

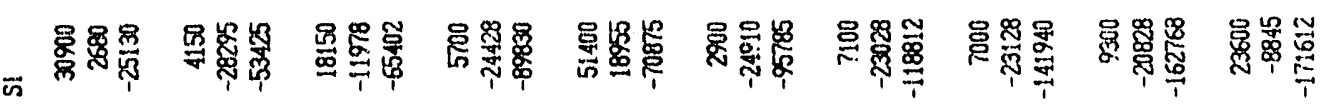

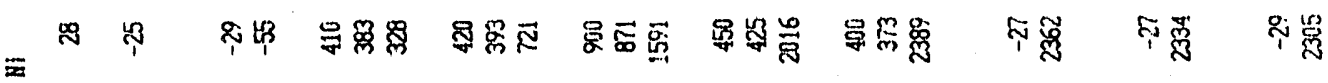

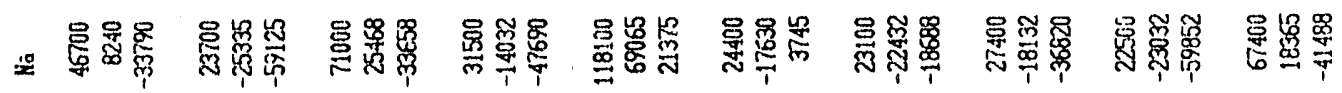

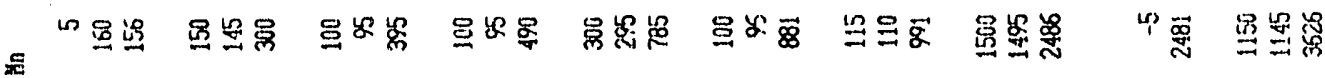

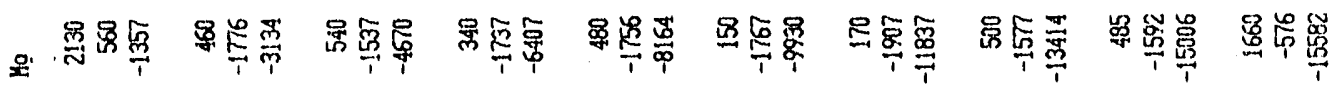

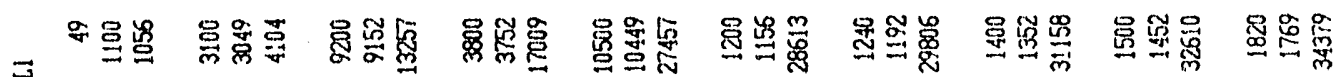

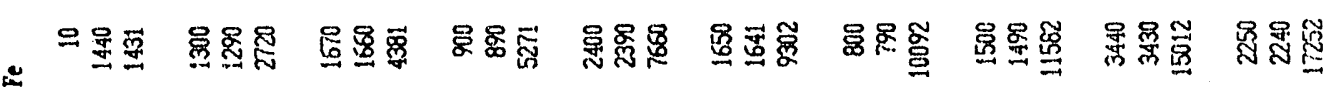

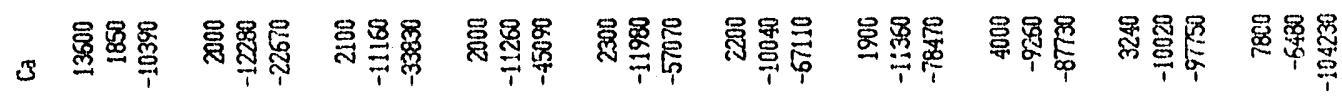

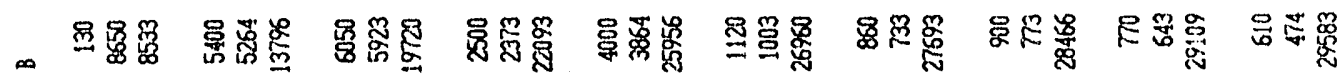

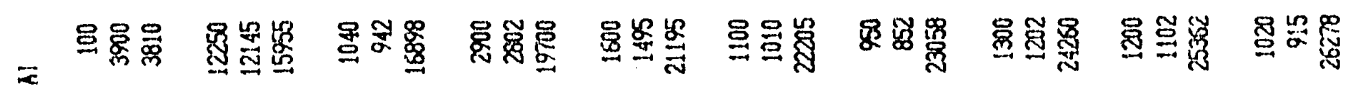

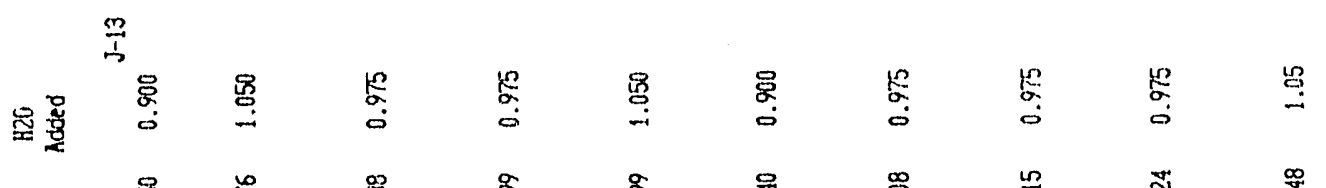

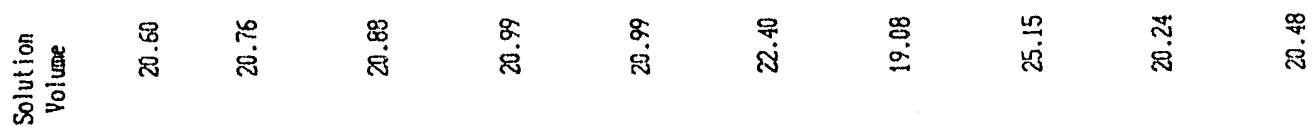

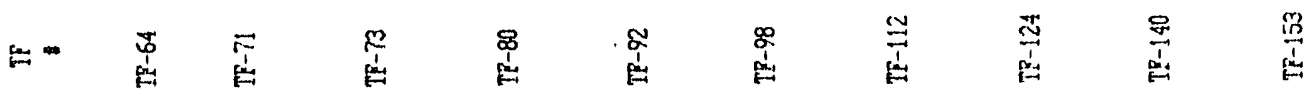

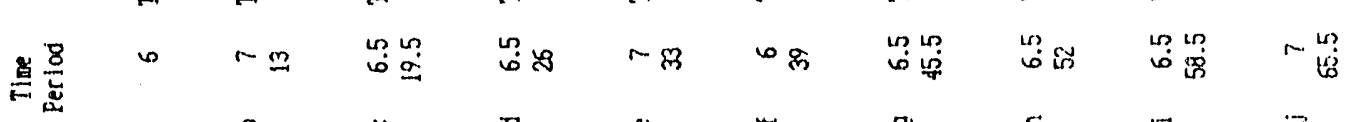

$\stackrel{\square}{\stackrel{9}{\leftrightarrows}}$ 


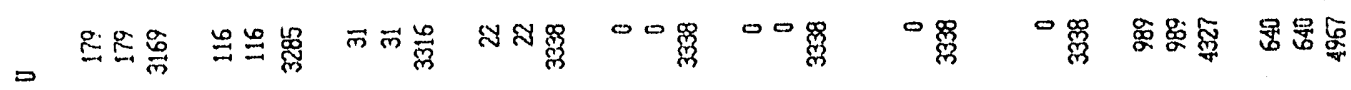

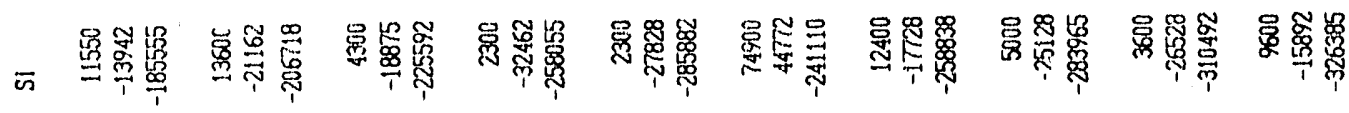

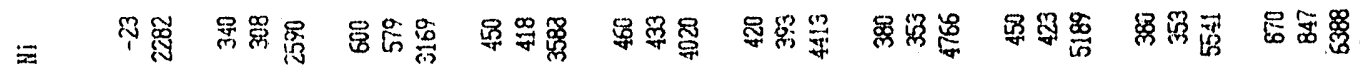

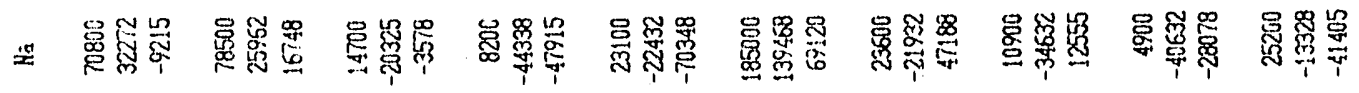

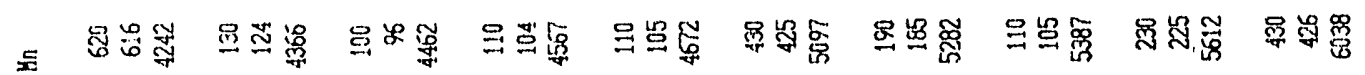

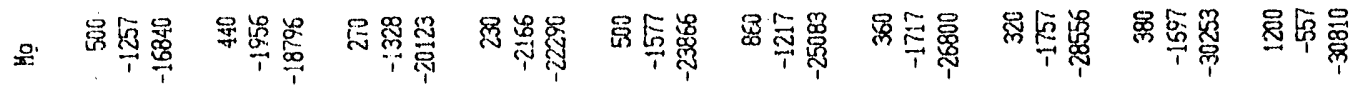

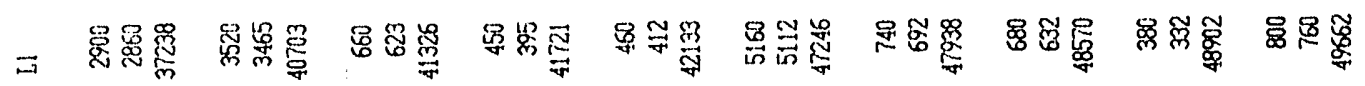

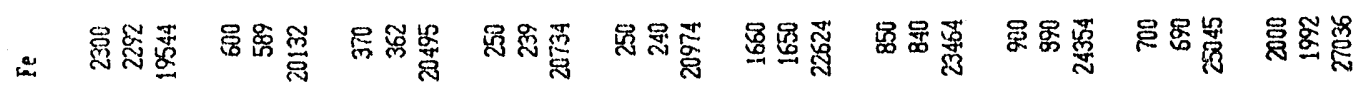

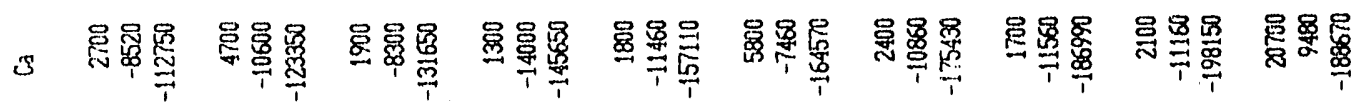

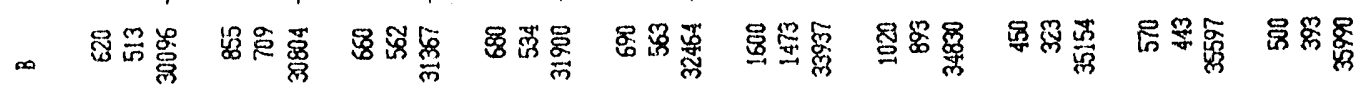

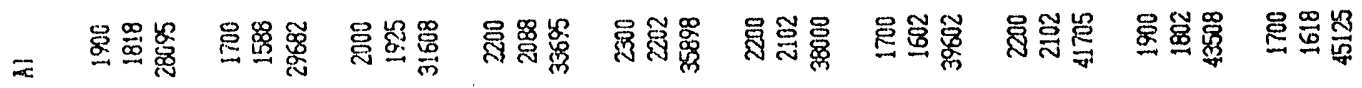

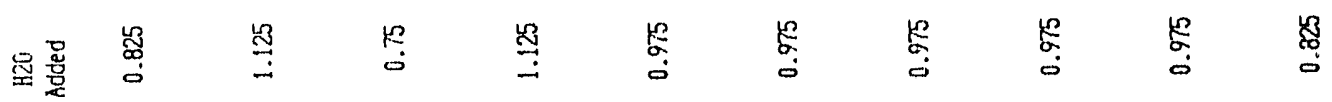
总䙷

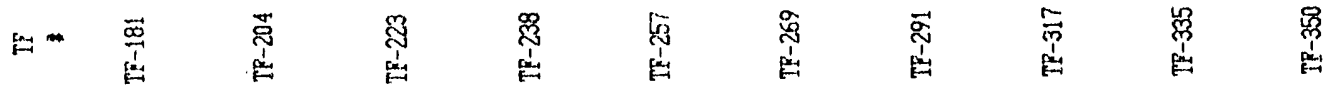

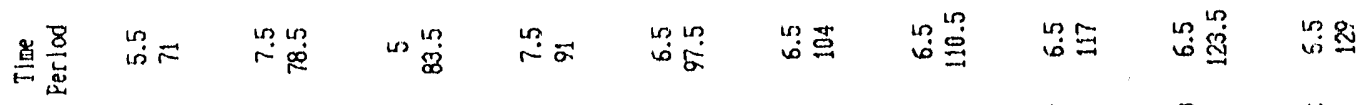

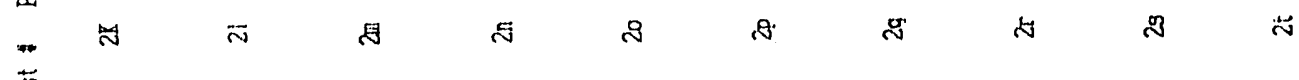




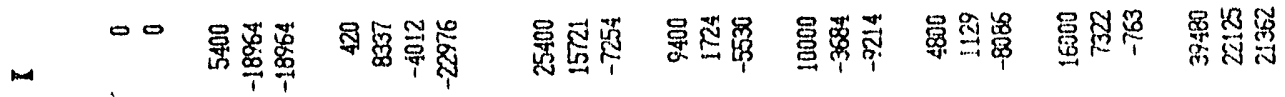

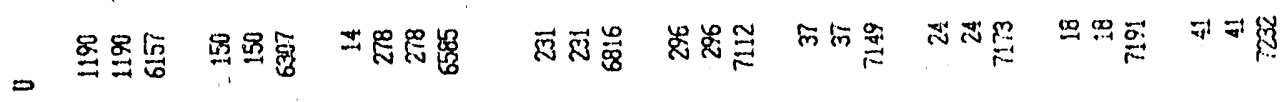

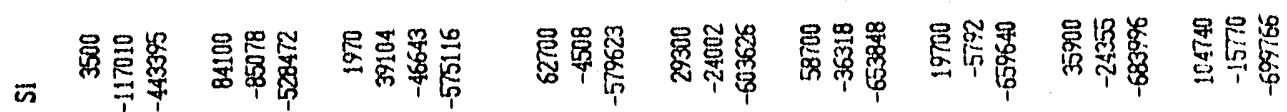

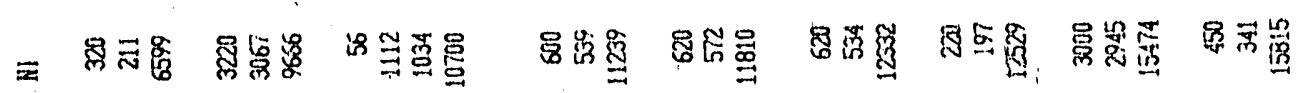

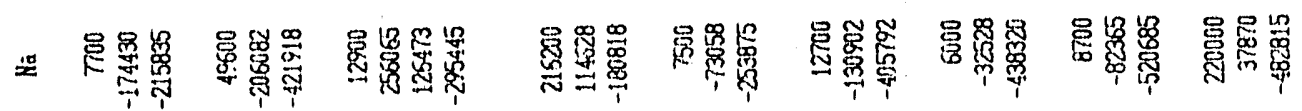

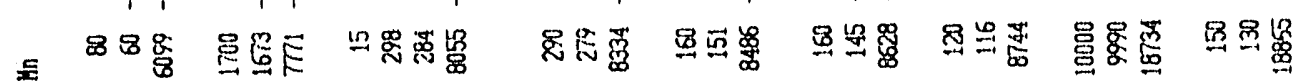

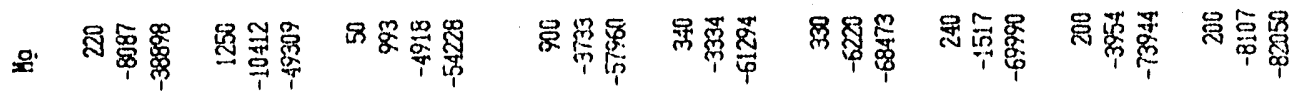

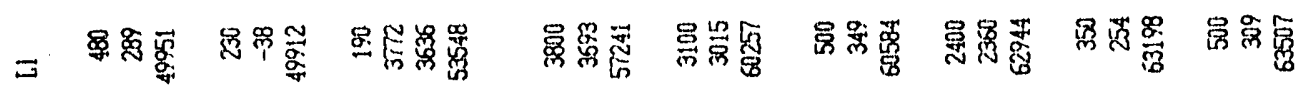

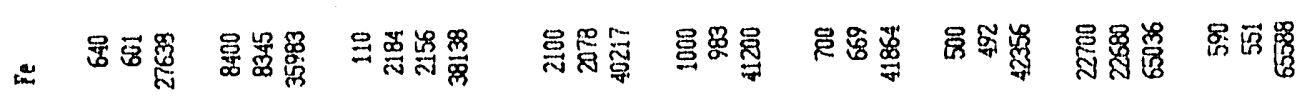

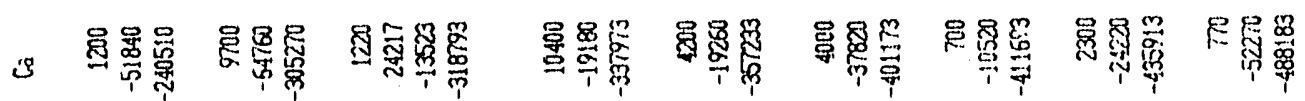

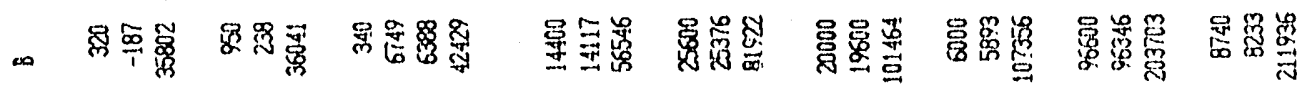

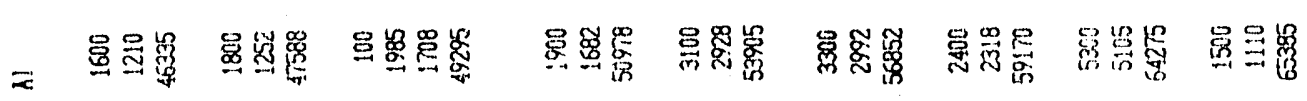

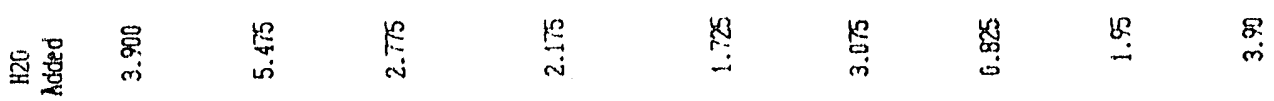

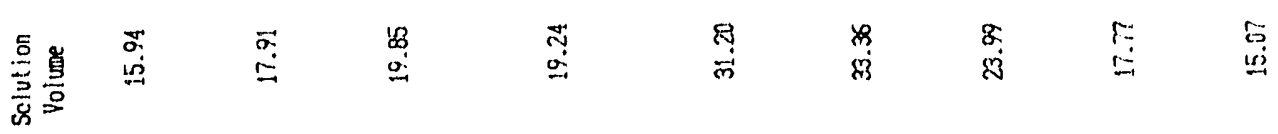

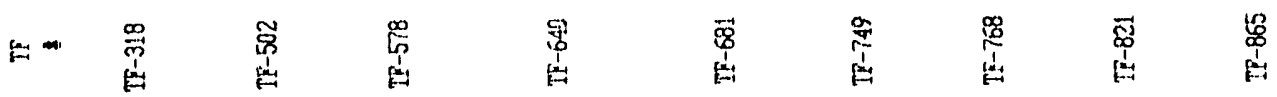

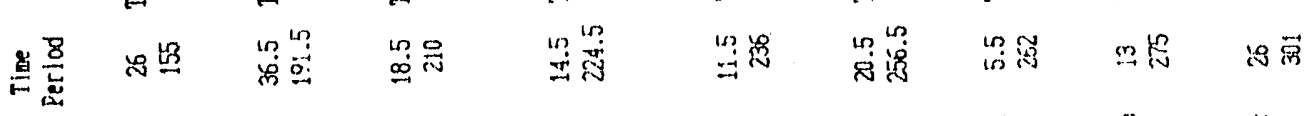

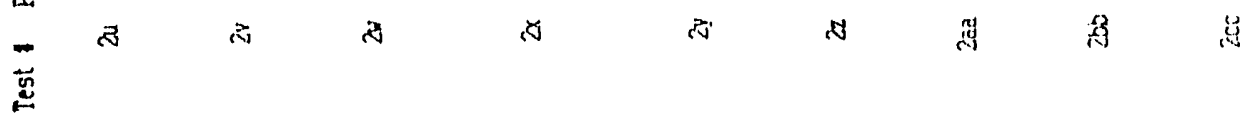




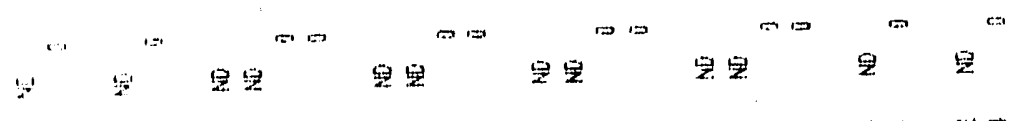

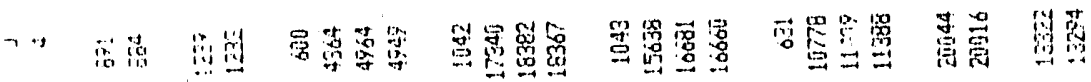

的雚

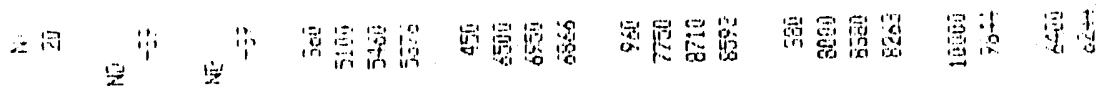

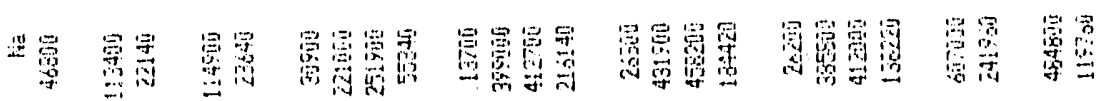

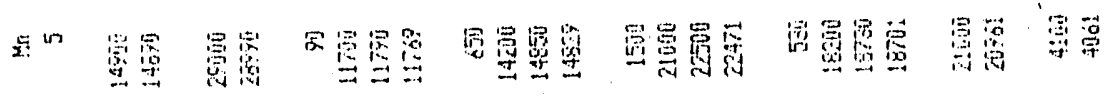

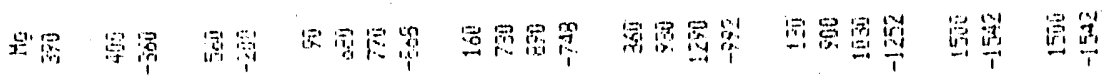

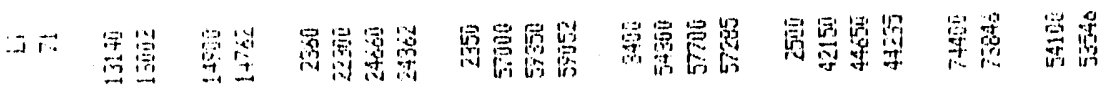

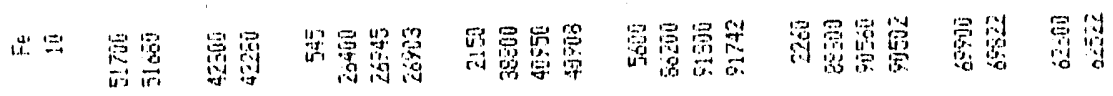

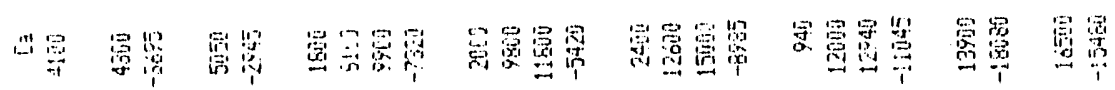

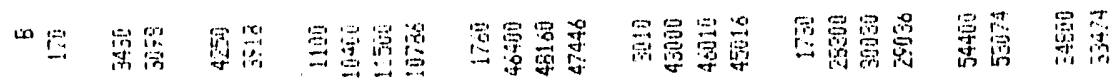

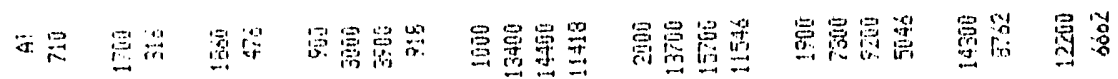

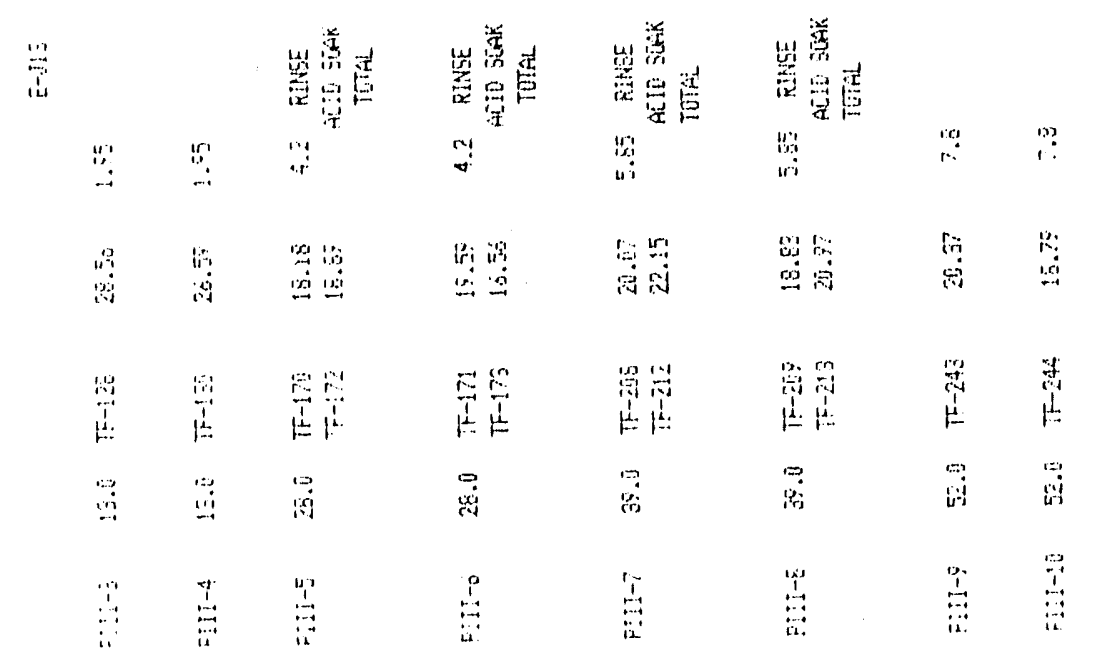




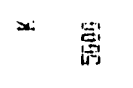

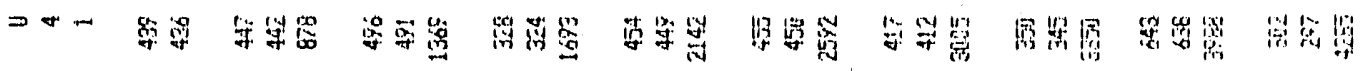

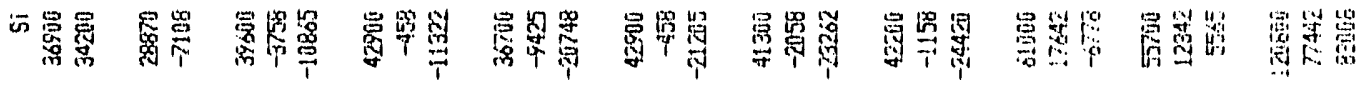

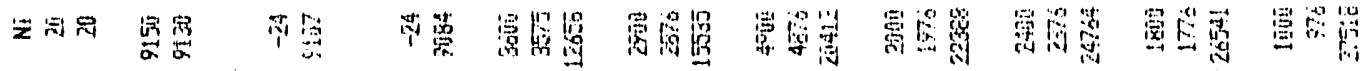

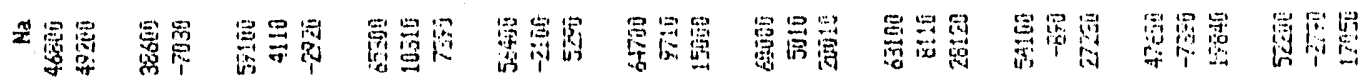

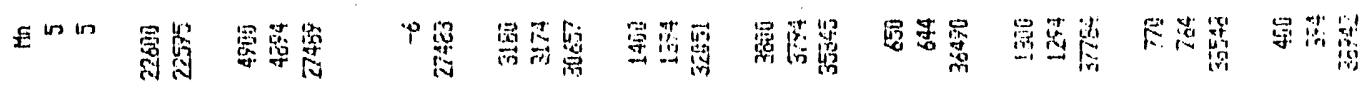

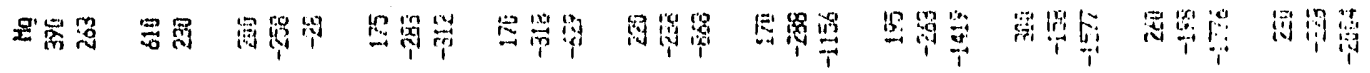

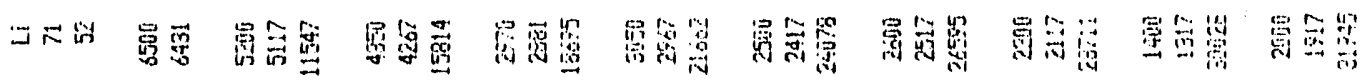

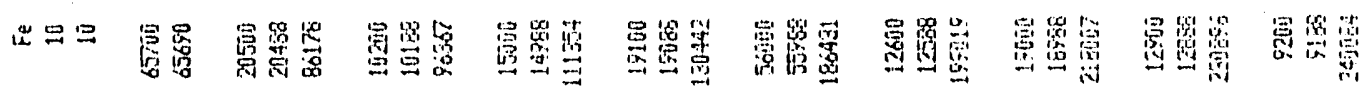

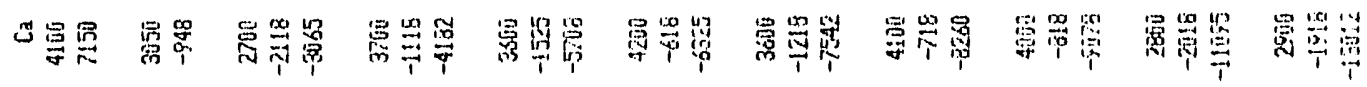

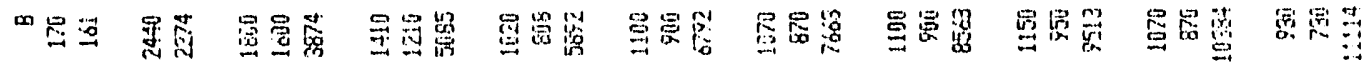
王是是

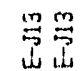

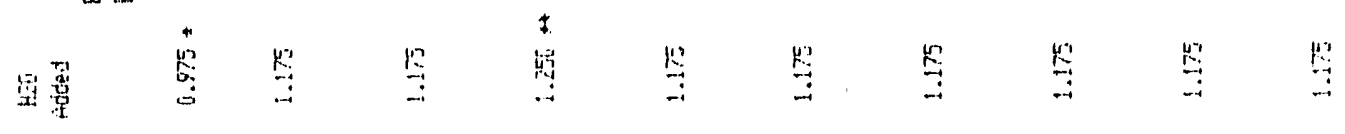

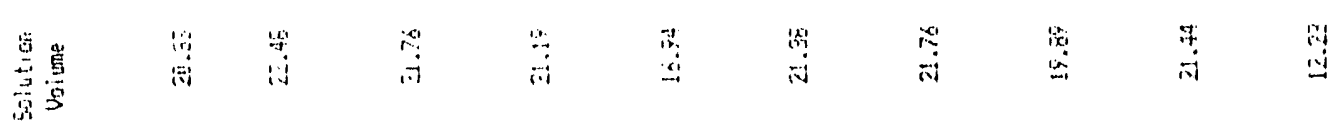

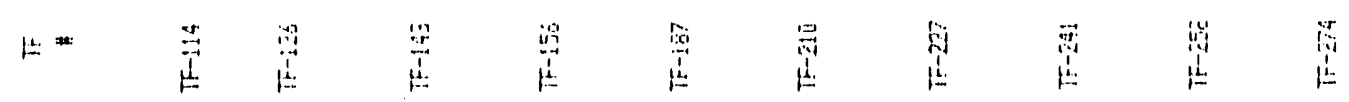

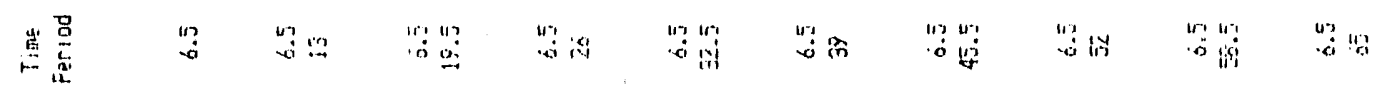

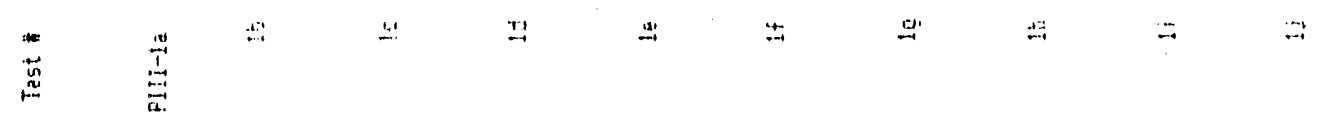




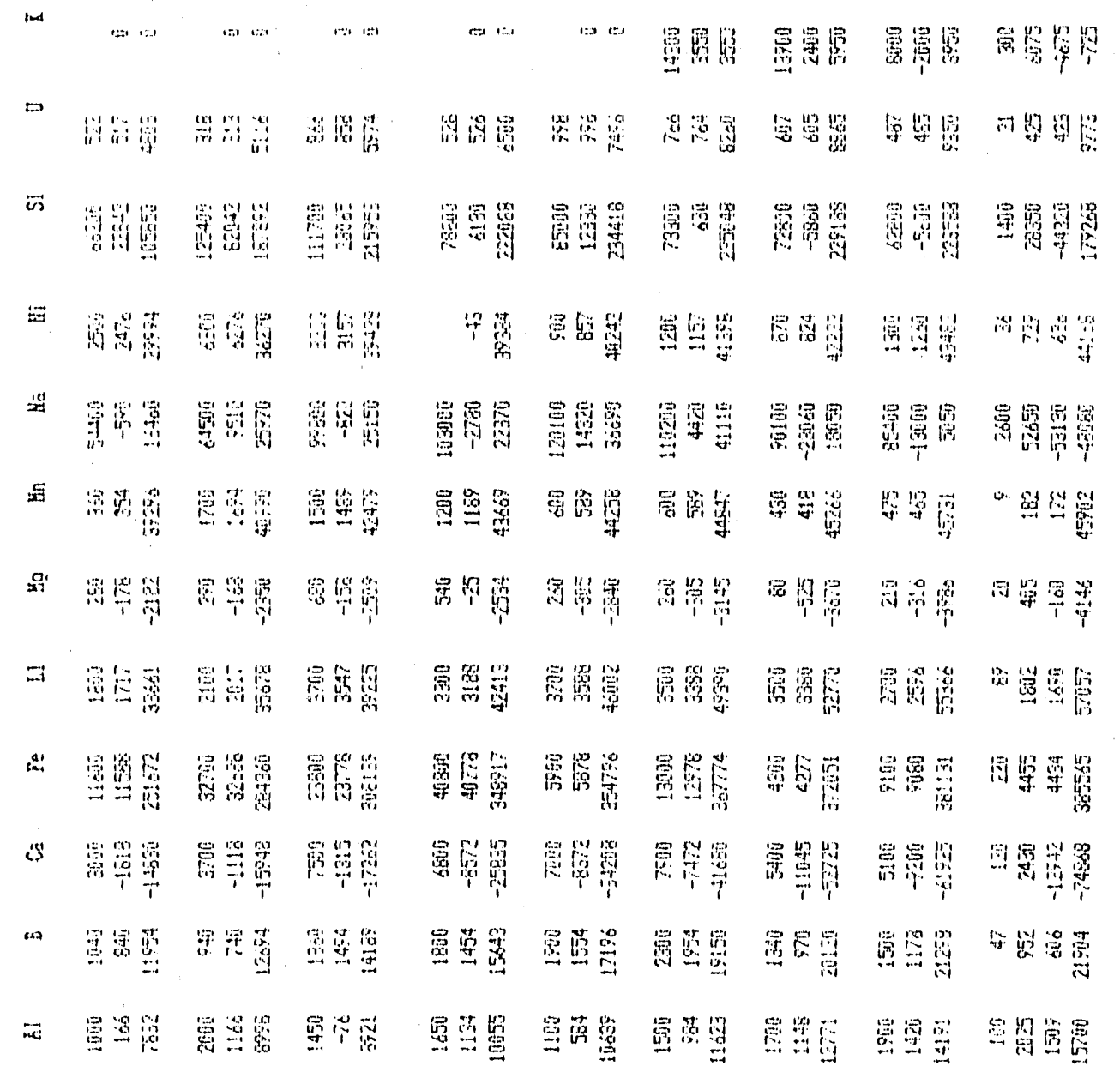

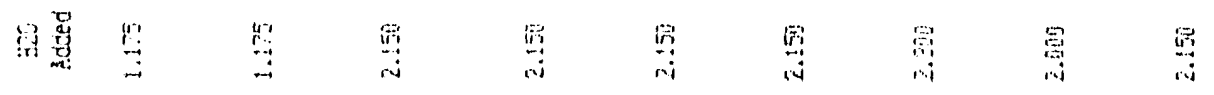

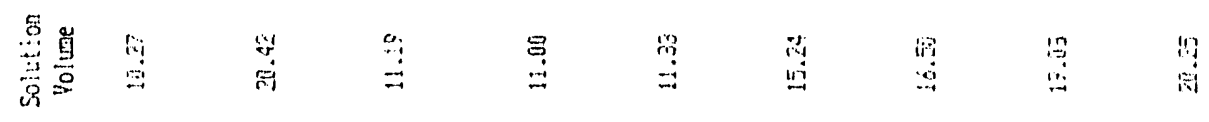

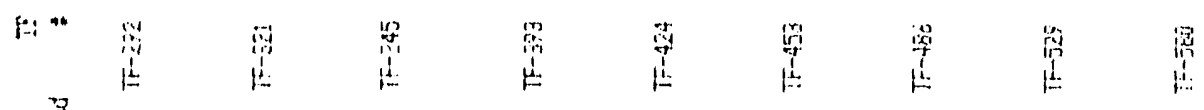

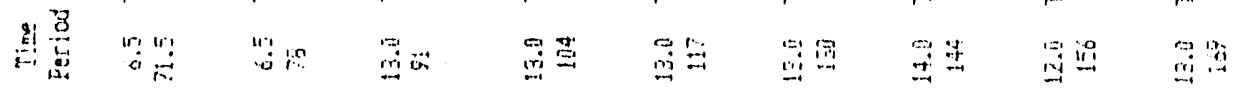

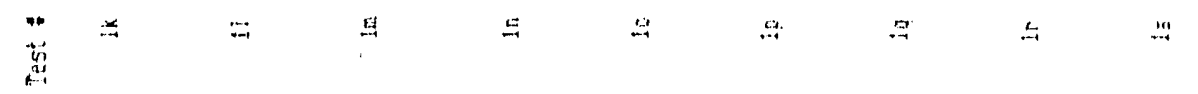


in.

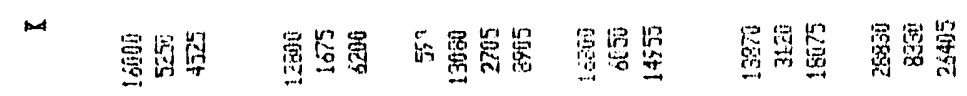

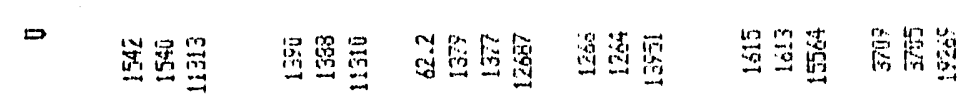

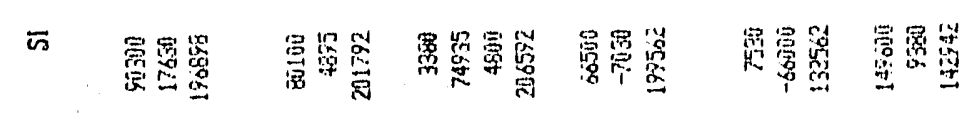

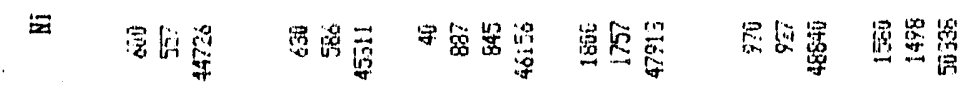

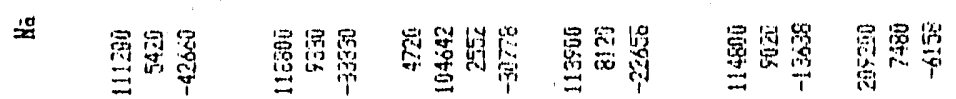

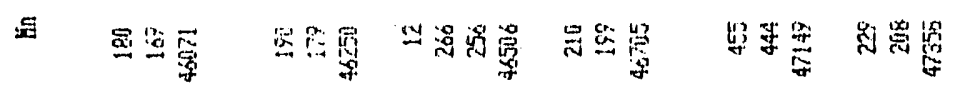

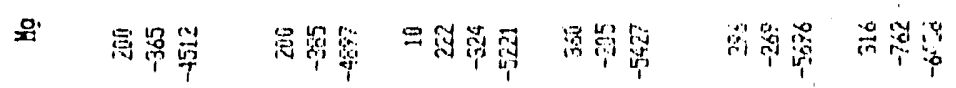

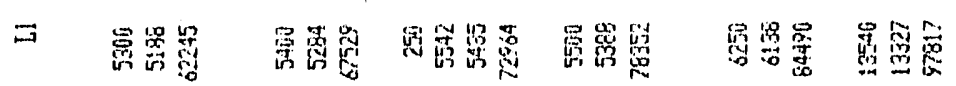

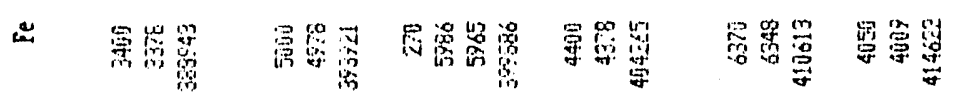

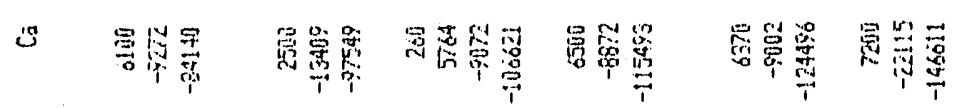

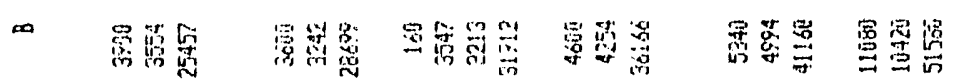

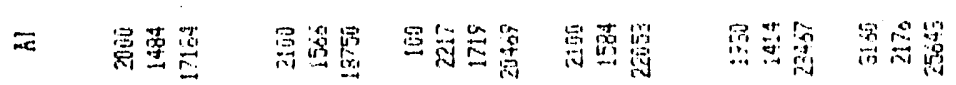

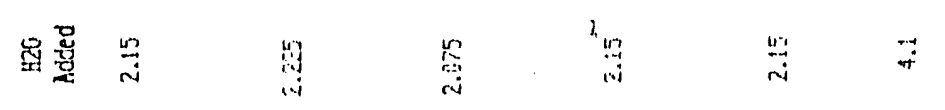

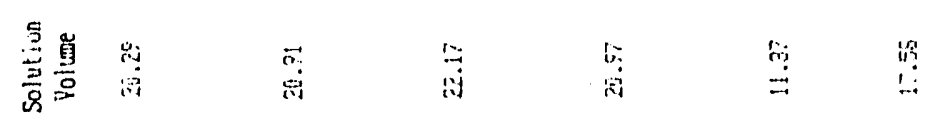

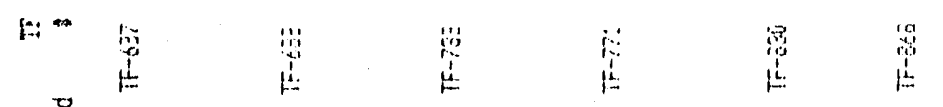

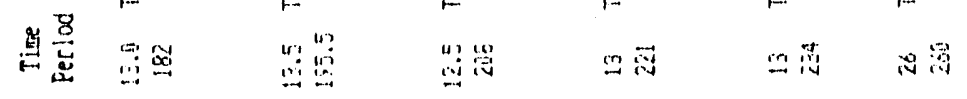

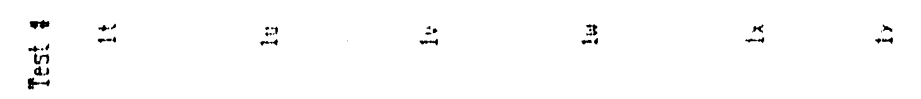


- 番

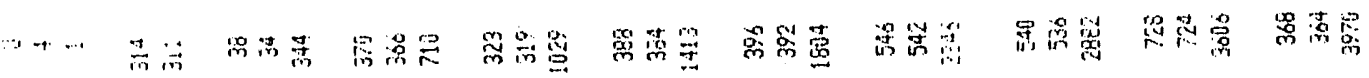

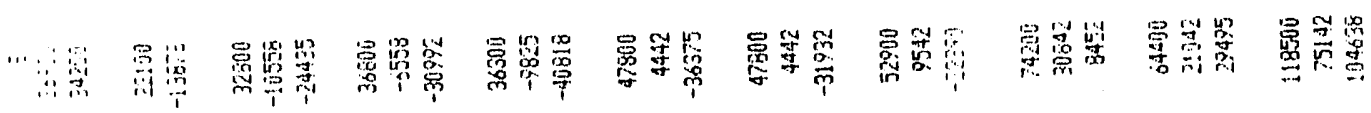

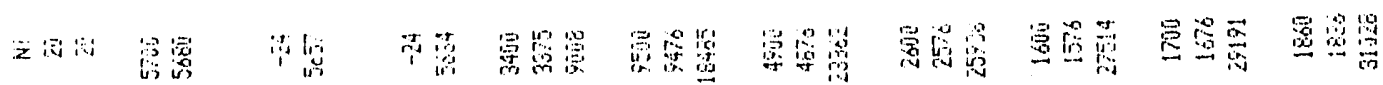

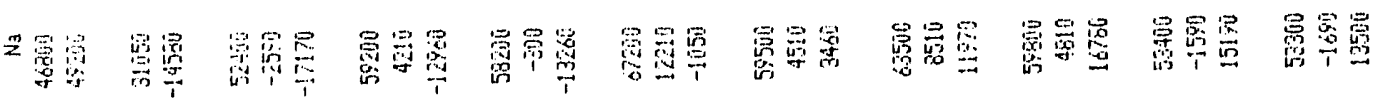

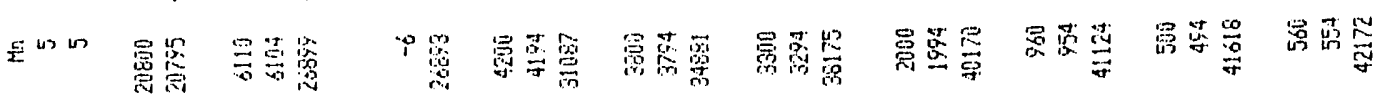

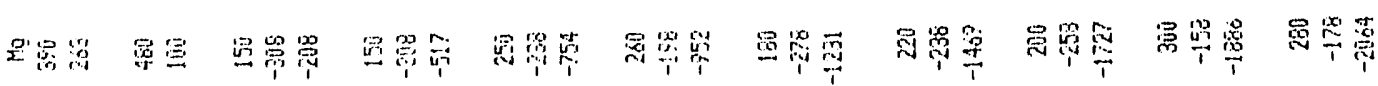

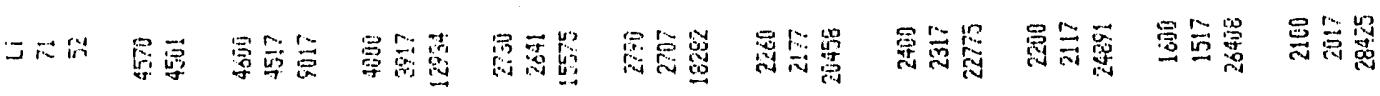

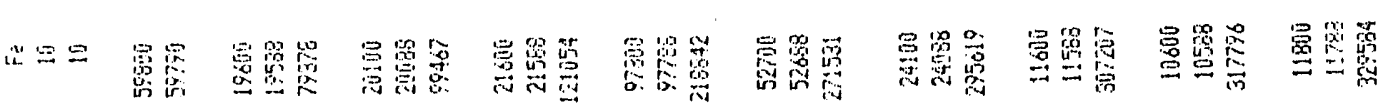

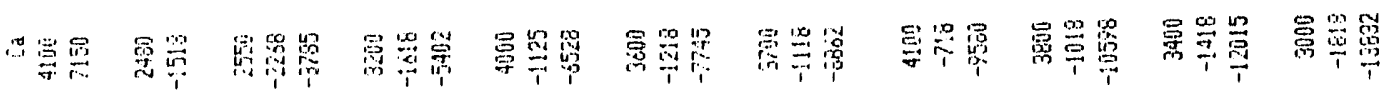

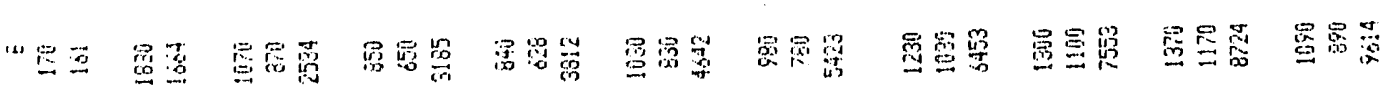

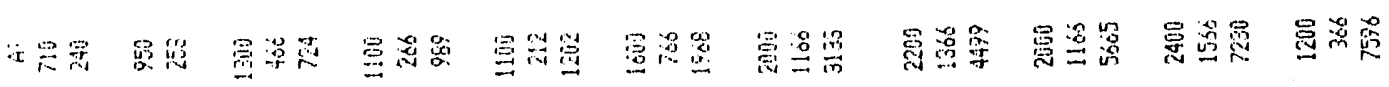
$\stackrel{m}{\stackrel{m}{m}}$

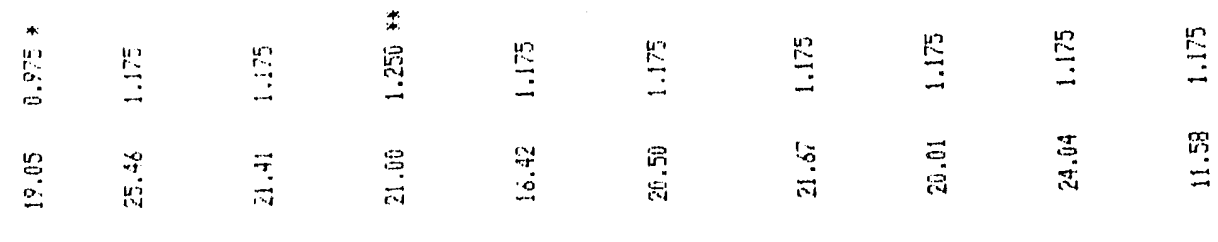

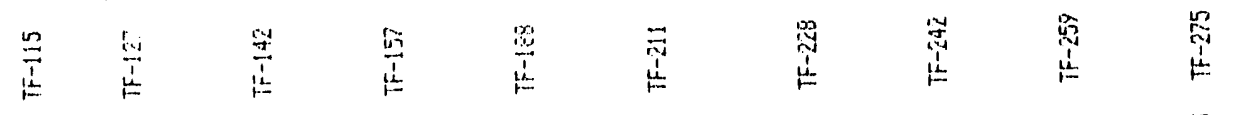

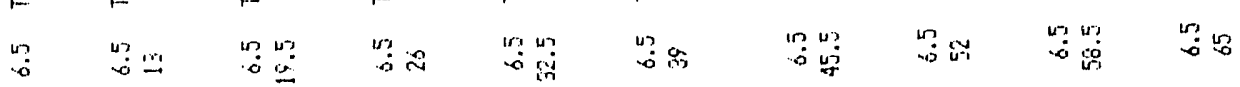

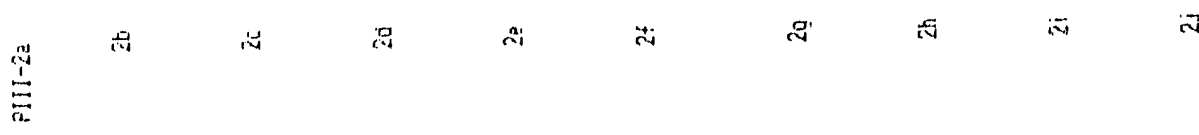




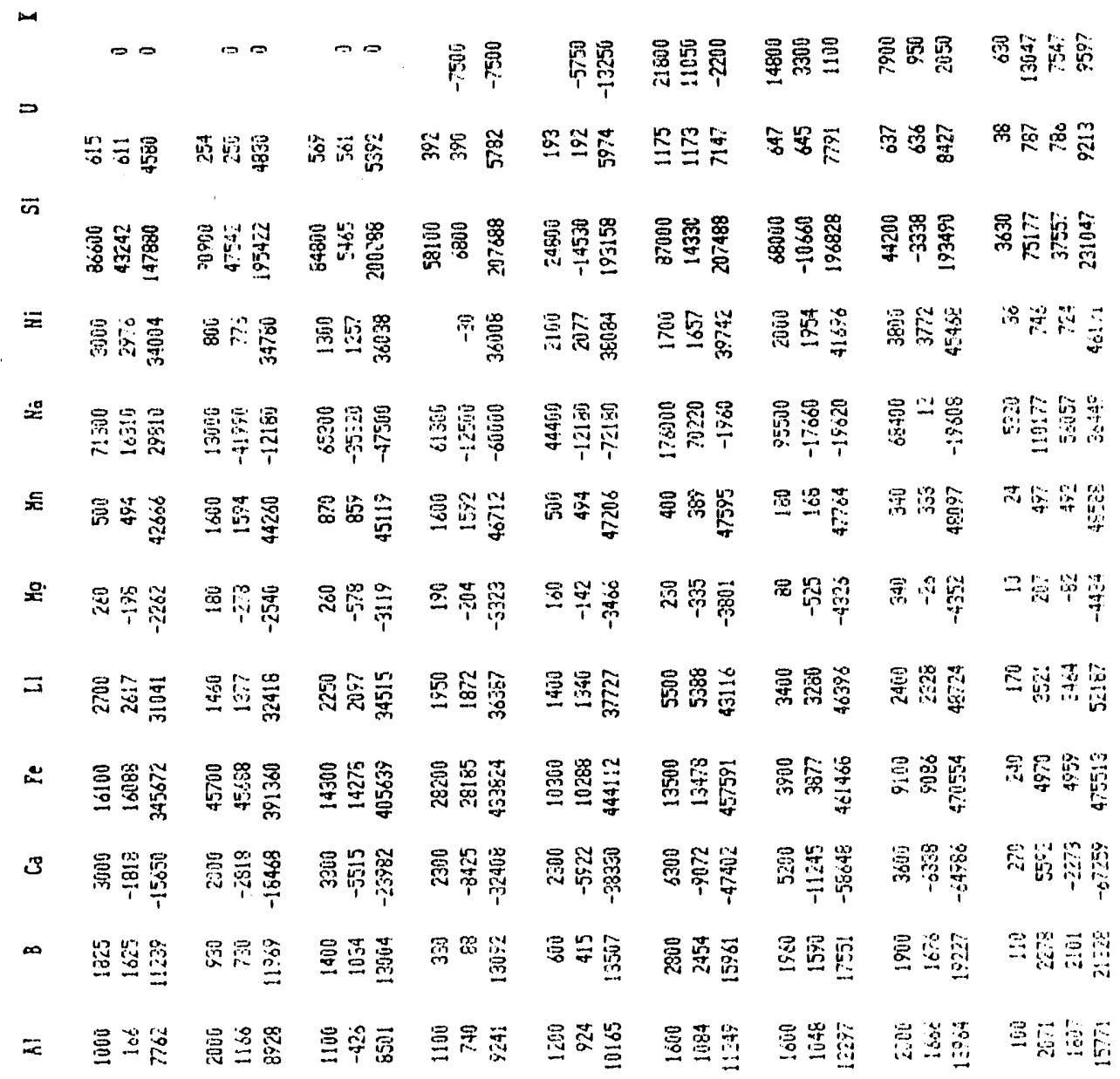

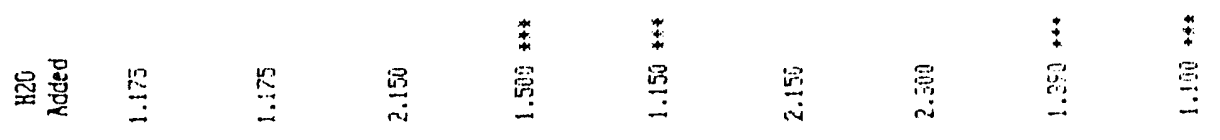

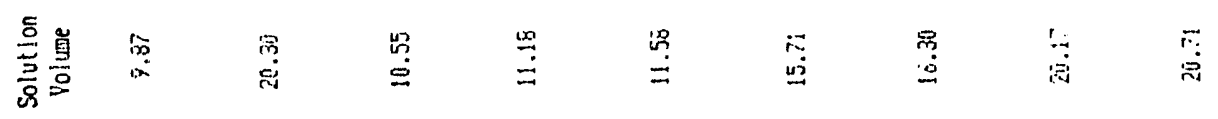

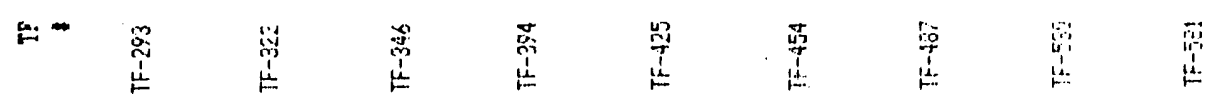

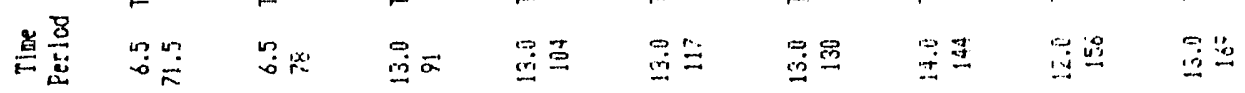

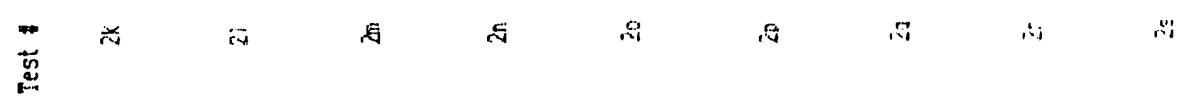




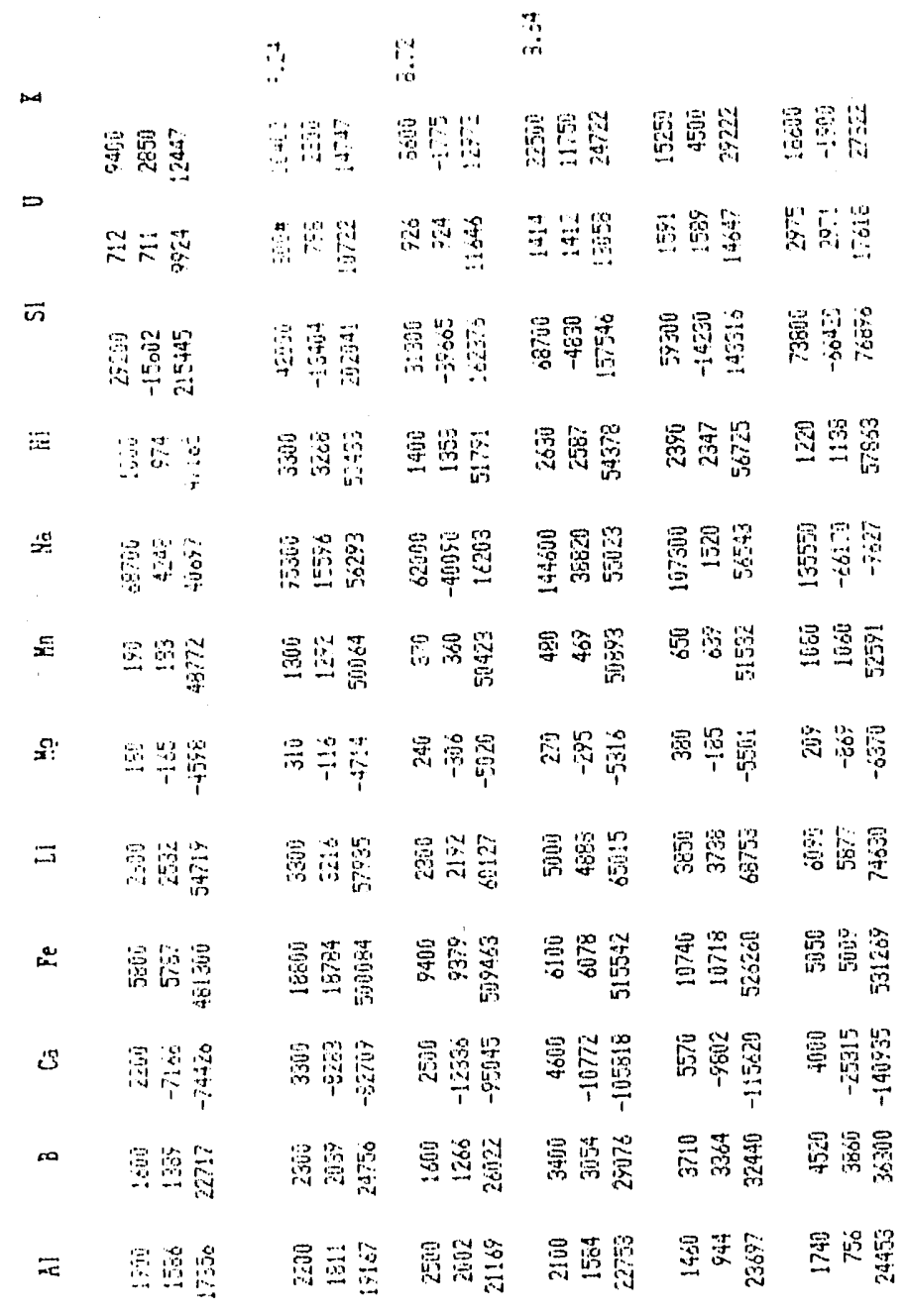

\begin{tabular}{|c|c|c|c|c|}
\hline \begin{tabular}{ll}
$\vdots$ \\
\hdashline
\end{tabular} & 渵 & 謌 & 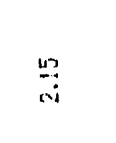 & $\stackrel{m}{a ? d}$ \\
\hline 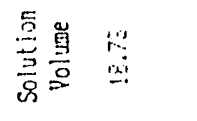 & $\because$ & 言 & $\vec{a}$ & 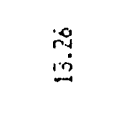 \\
\hline 蕉 & 篔 & 营 & E & 踓 \\
\hline 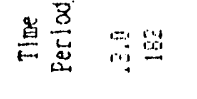 & 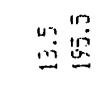 & 唯羂 & a茳 & 嗦 \\
\hline 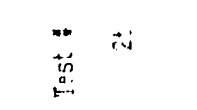 & $a$ & is & $\sqrt[3]{3}$ & $\approx$ \\
\hline
\end{tabular}


× 嚊

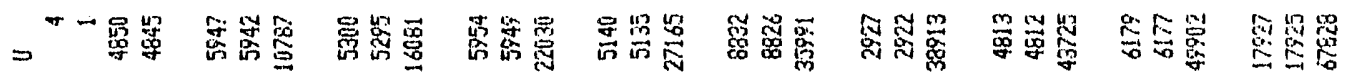

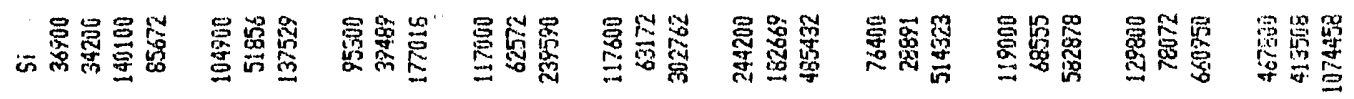
之

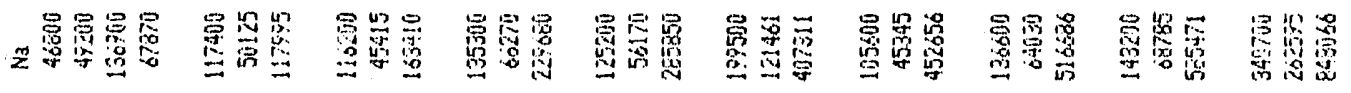

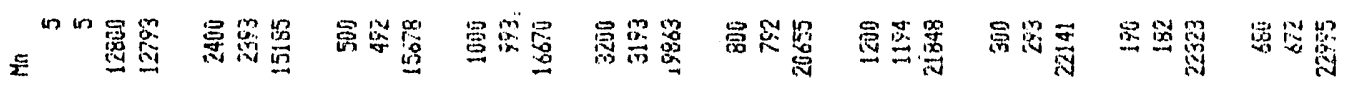

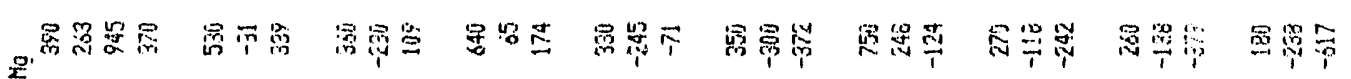

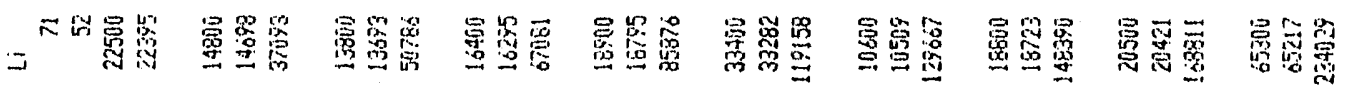

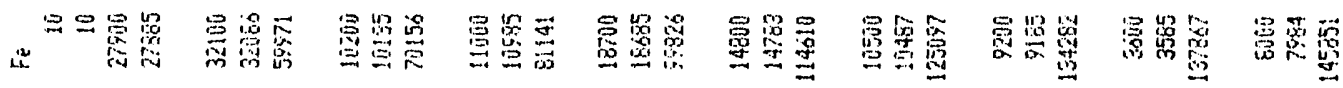

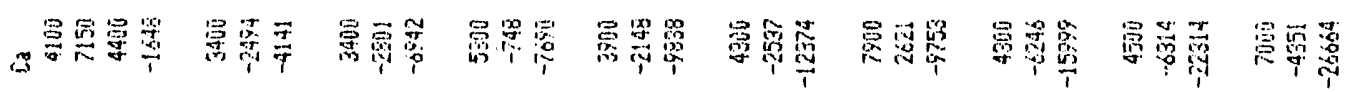

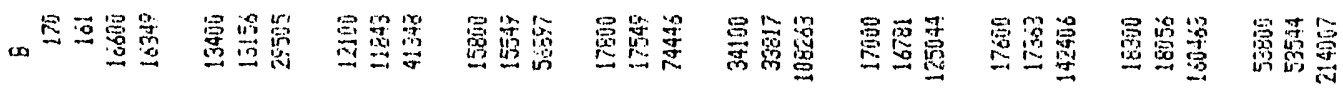

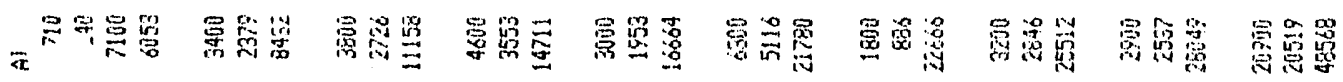

$$
\begin{aligned}
& \stackrel{3}{3}
\end{aligned}
$$

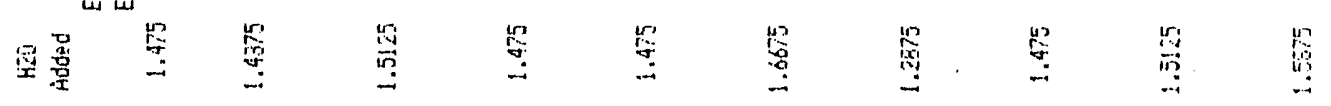

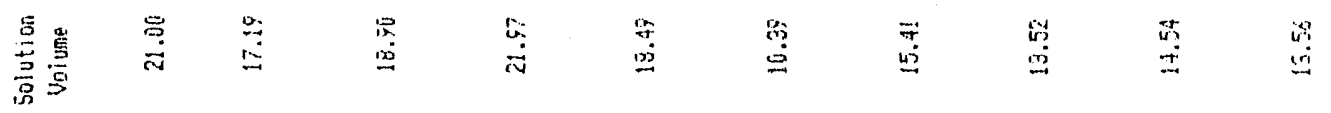

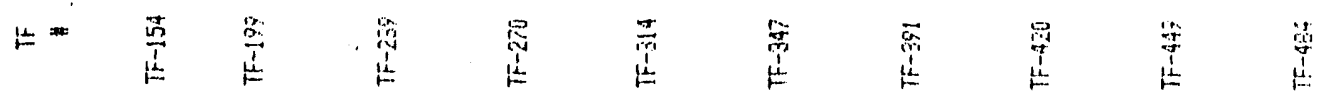

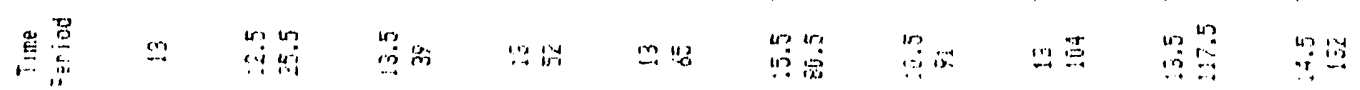

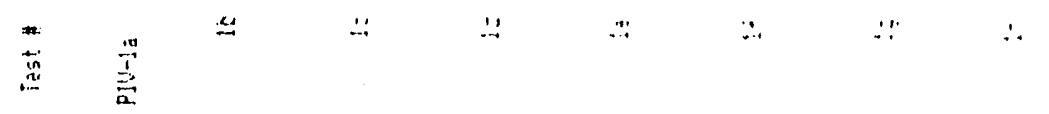




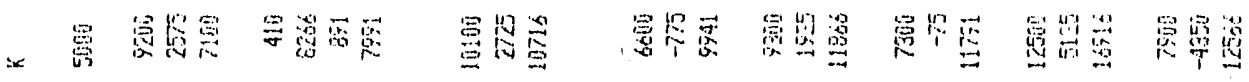

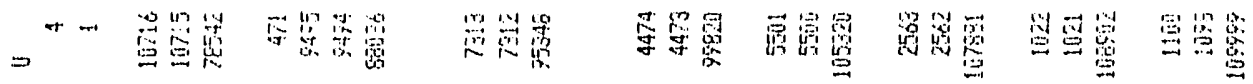

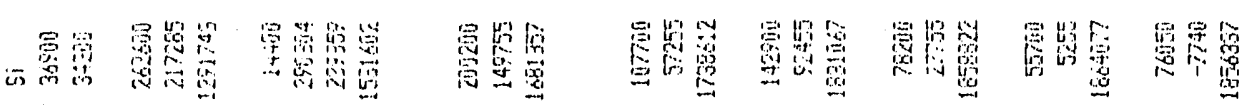

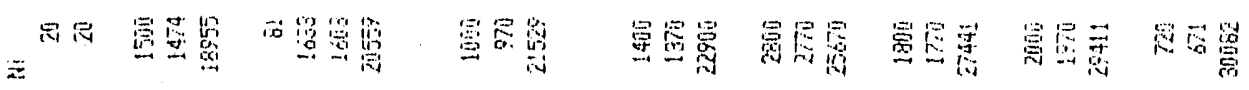

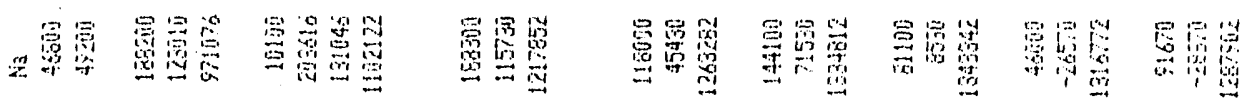

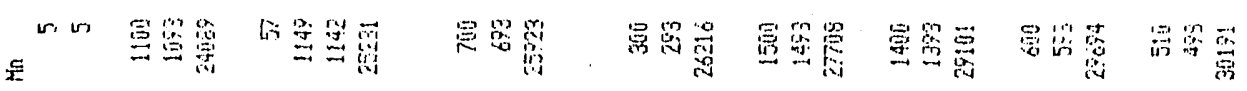

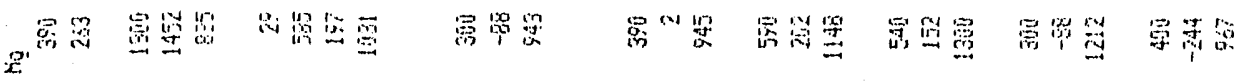

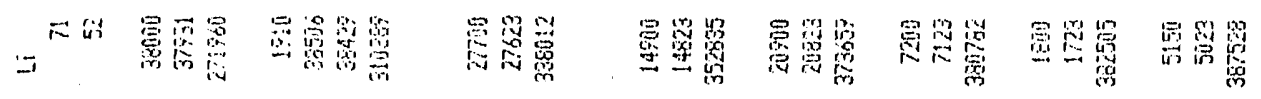

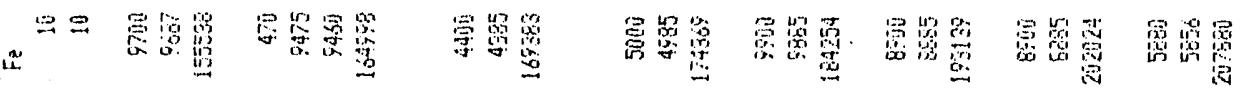

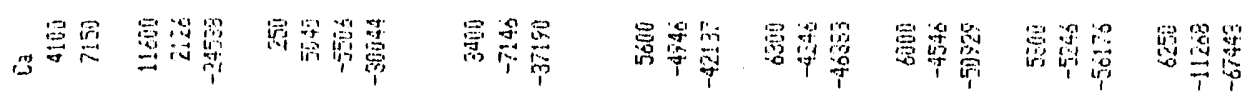

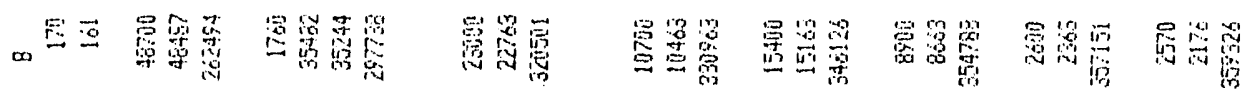

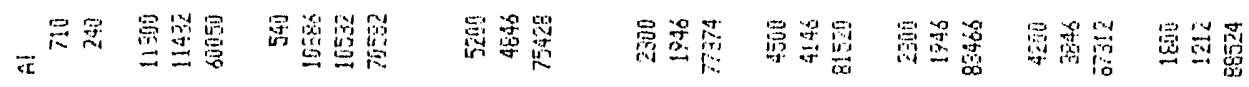

\begin{tabular}{|c|c|c|c|c|c|c|c|}
\hline 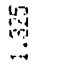 & 等 & 管 & $\underset{\mathrm{S}}{\mathrm{g}}$ & $\stackrel{\text { 哭 }}{2}$ & 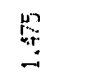 & 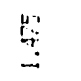 & 崩 \\
\hline tr & 吾 & 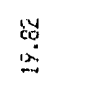 & 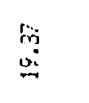 & 艿 & \begin{tabular}{l}
$a$ \\
\hdashline
\end{tabular} & $\begin{array}{l}\because \\
\because \\
a 1\end{array}$ & 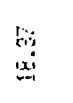 \\
\hline $\begin{array}{l}9 \\
\text { in } \\
i=2\end{array}$ & 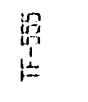 & 㟋 & 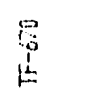 & 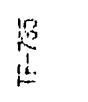 & $\underset{1}{12}$ & 语 & $\begin{array}{l}W_{0} \\
:\end{array}$ \\
\hline$=\underline{9}$ & 此证 & 吗哭 & 呮害 & 吅墨 & 的營 & $2 \pi$ & 次感 \\
\hline$\simeq$ & $=$ & 兵 & $\underline{E}$ & ㅁ & 뭉 & 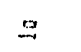 & $\therefore$ \\
\hline
\end{tabular}




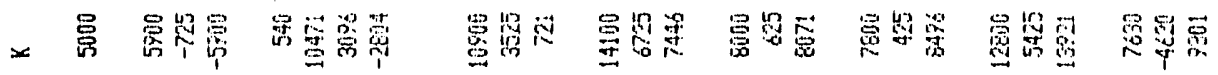

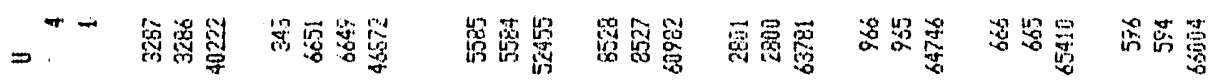

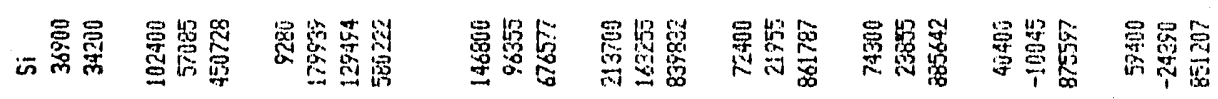

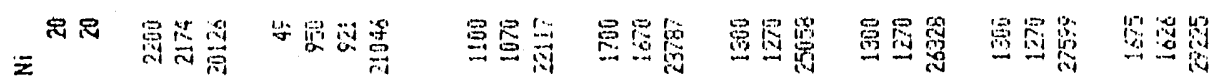

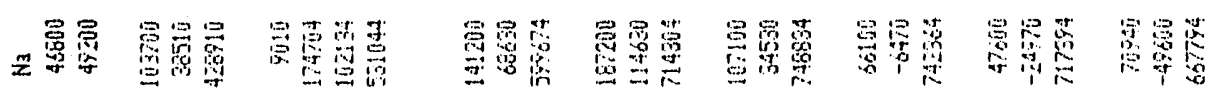

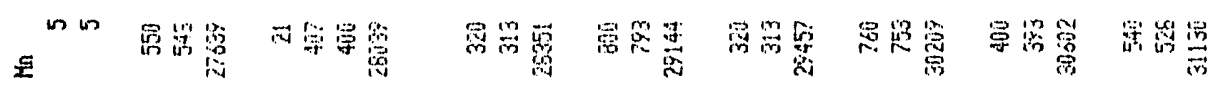

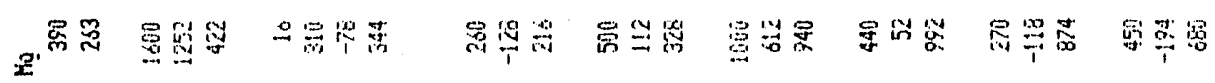

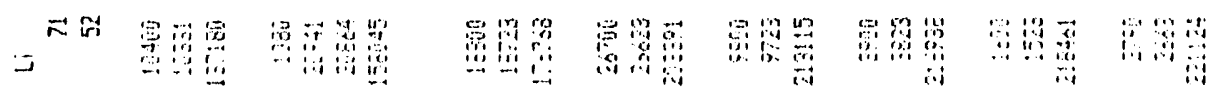

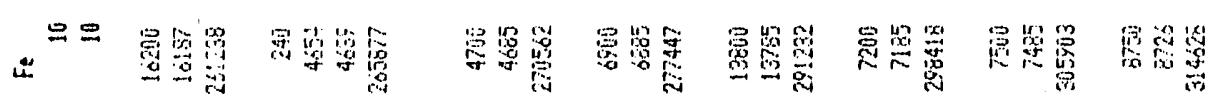

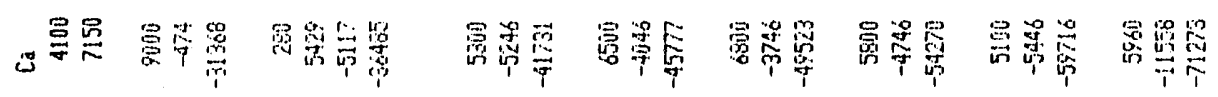

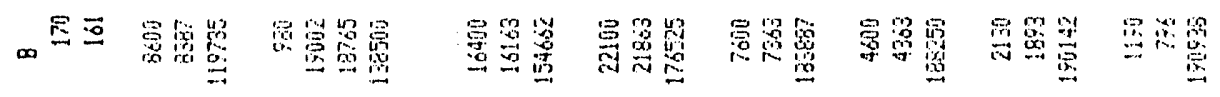

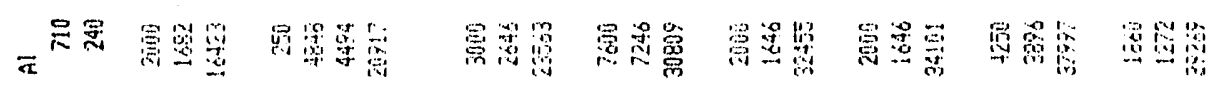

\section{無嵒}

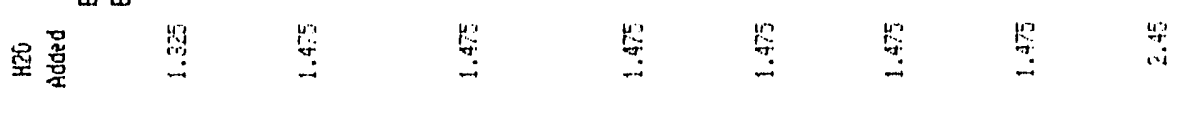

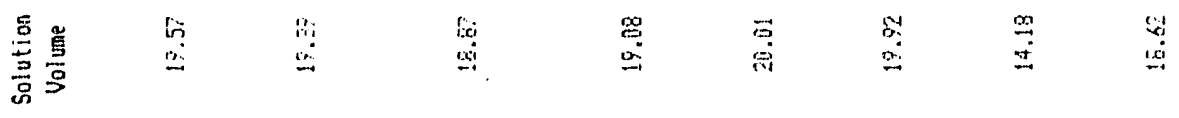

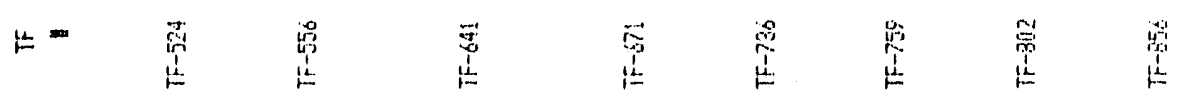

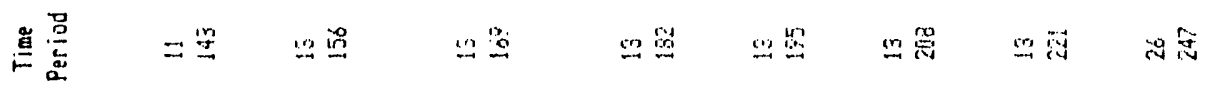

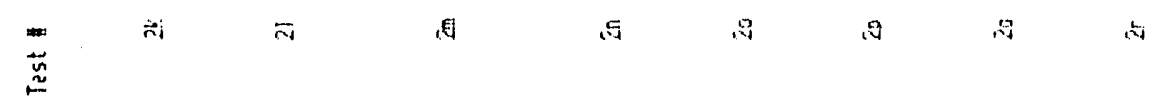




\begin{tabular}{|c|c|c|c|c|c|c|c|c|c|c|}
\hline 总 & $\Rightarrow$ & 00 & $\Leftrightarrow 0$ & $\infty$ & 0 & $\infty 0$ & $\infty$ & 高紫 & 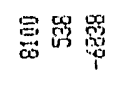 & 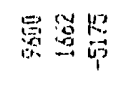 \\
\hline$={ }^{\top}$ & 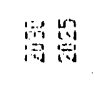 & 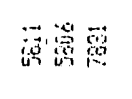 & 恕然总 & 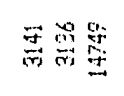 & 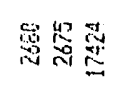 & 总罦点 & 跑总 & 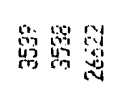 & 星舜总 & 哭品 \\
\hline 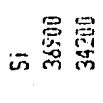 & 翠 & 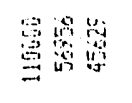 & 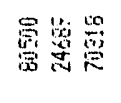 & 量悹 & 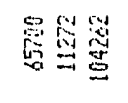 & 急䓌萿 & 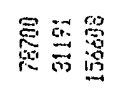 & 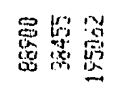 & 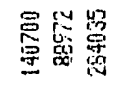 & 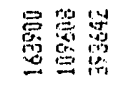 \\
\hline$\sum \approx$ & 唃 & 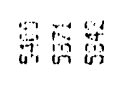 & 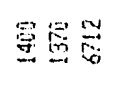 & 甞䍐染 & 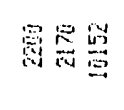 & 题急嵒 & 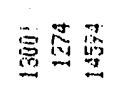 & 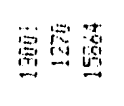 & 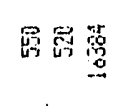 & 总䖵 \\
\hline 量暴 & 总昆 & 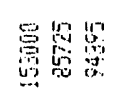 & 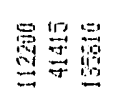 & 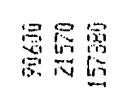 & 篦琶器 & 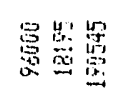 & 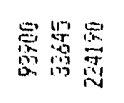 & 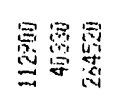 & 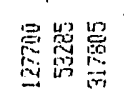 & 焉 \\
\hline un & 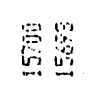 & 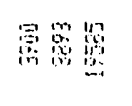 & 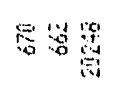 & 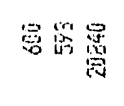 & 象恕 & 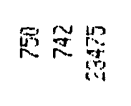 & 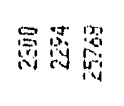 & 沙密密 & 畓期嵒 & \\
\hline & 9 & 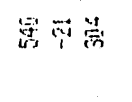 & 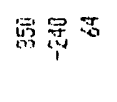 & 品哭装蒜 & 있 & 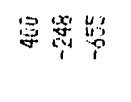 & 浔忿浮 & 舁器品 & 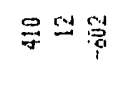 & \\
\hline$=\approx$ in & 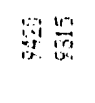 & 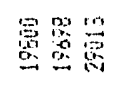 & 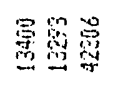 & 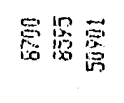 & 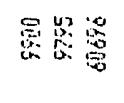 & 黑鹗哭 & 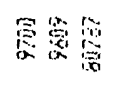 & 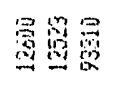 & 塌哥哭 & \\
\hline $9=$ & 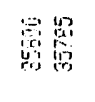 & 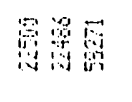 & 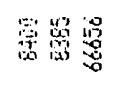 & 寻恕䨖 & 惠哭潈 & 嵒嵒害 & 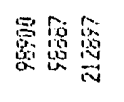 & 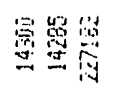 & 泏哭嵒 & \\
\hline 总总 & 政 & 寻要豆 & 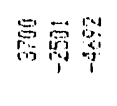 & 总等导 & 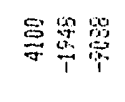 & 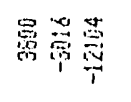 & 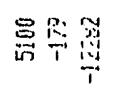 & 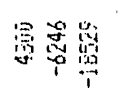 & 总志塄 & 量 \\
\hline$\Xi \Xi$ & 害管 & 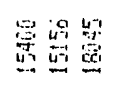 & 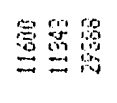 & 急兴管 & 总怼题 & 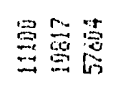 & 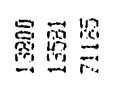 & 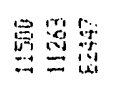 & 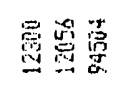 & 查 \\
\hline 焉是 & 怘 & 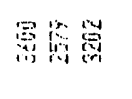 & 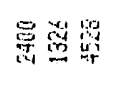 & 密恕嵒 & 表恕管 & 貟要 & 萗息㩊 & 器㴔㗊 & 急哭熙 & \\
\hline
\end{tabular}

$\stackrel{9}{3}$

是菜

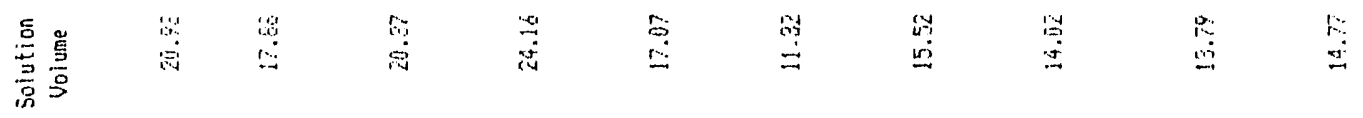

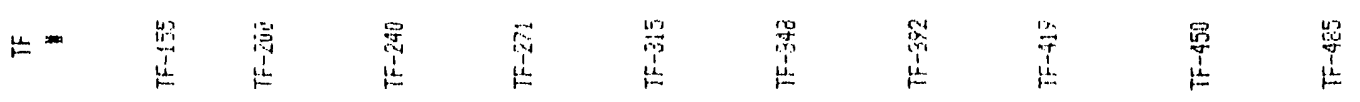

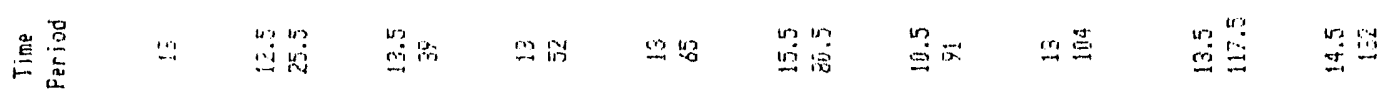

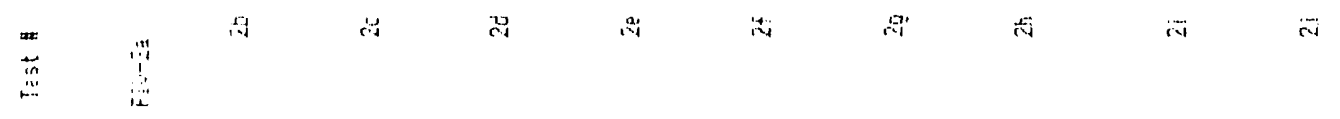




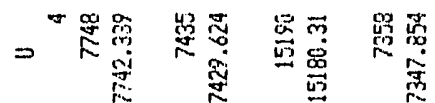

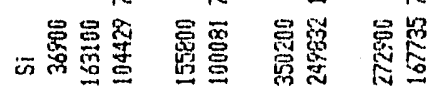

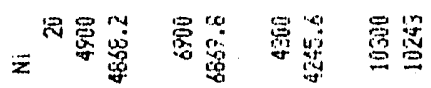

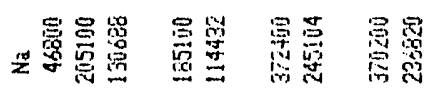

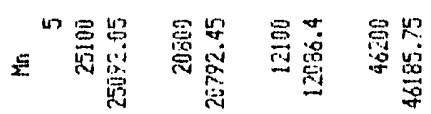

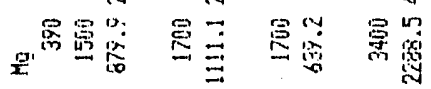

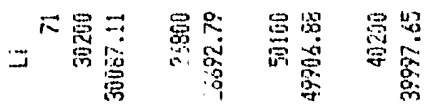

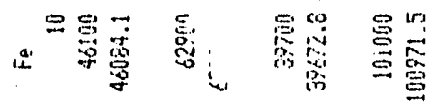

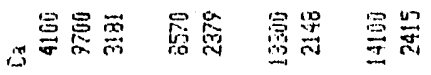

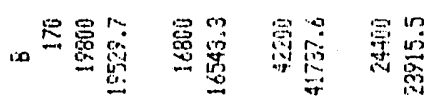

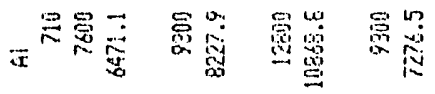

$\stackrel{m}{3}$

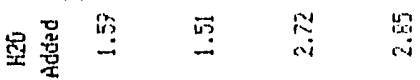

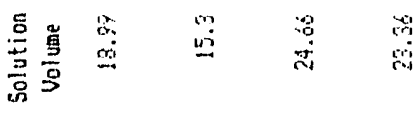

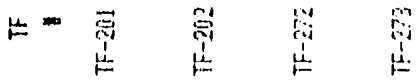

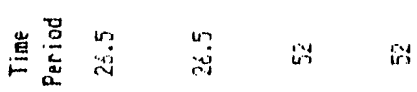

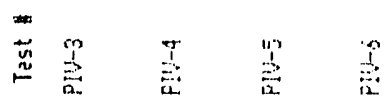




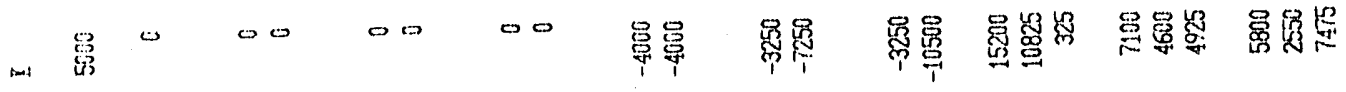

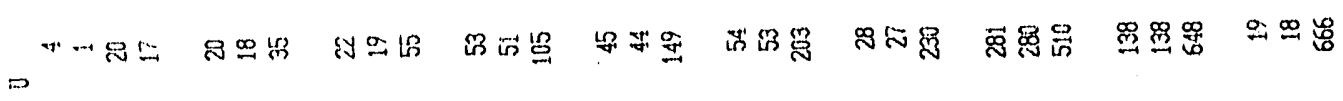

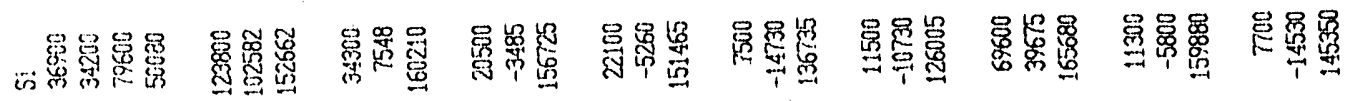

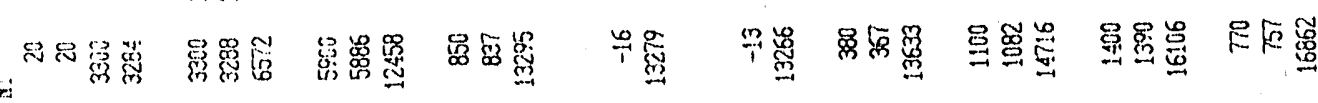

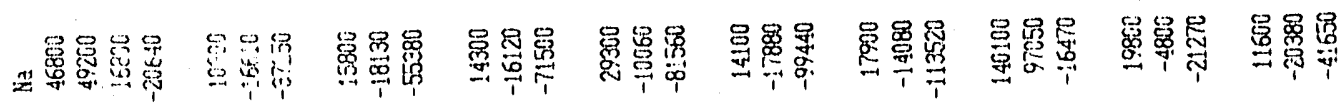

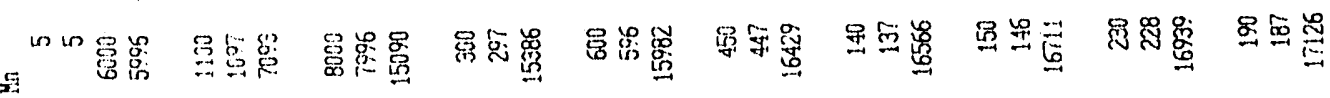

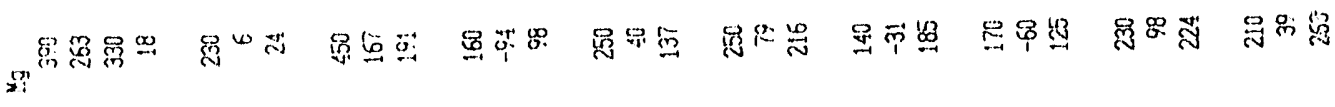

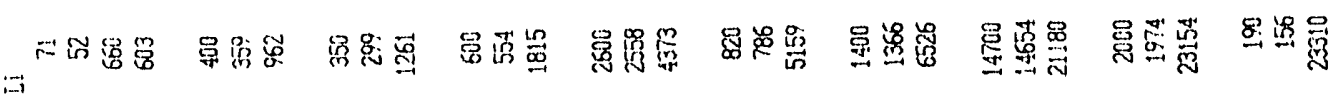

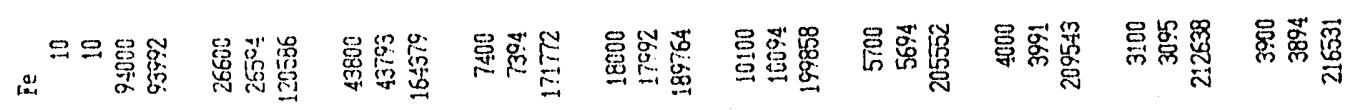

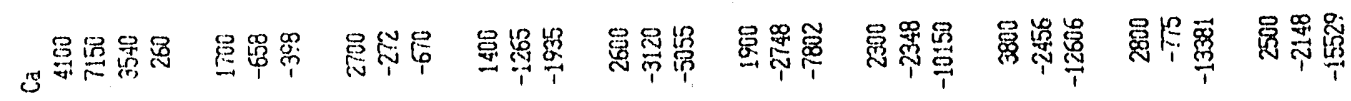

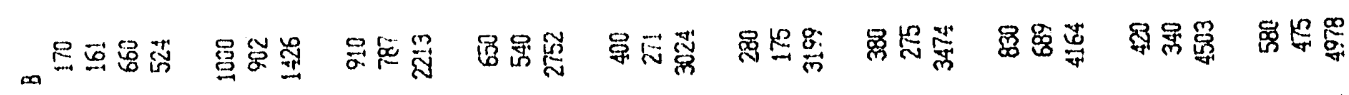

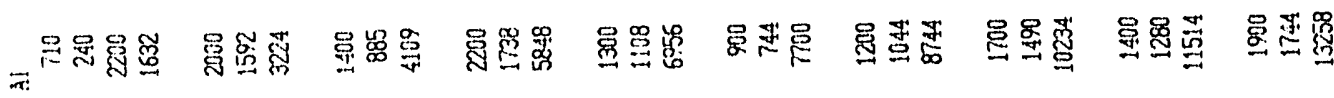

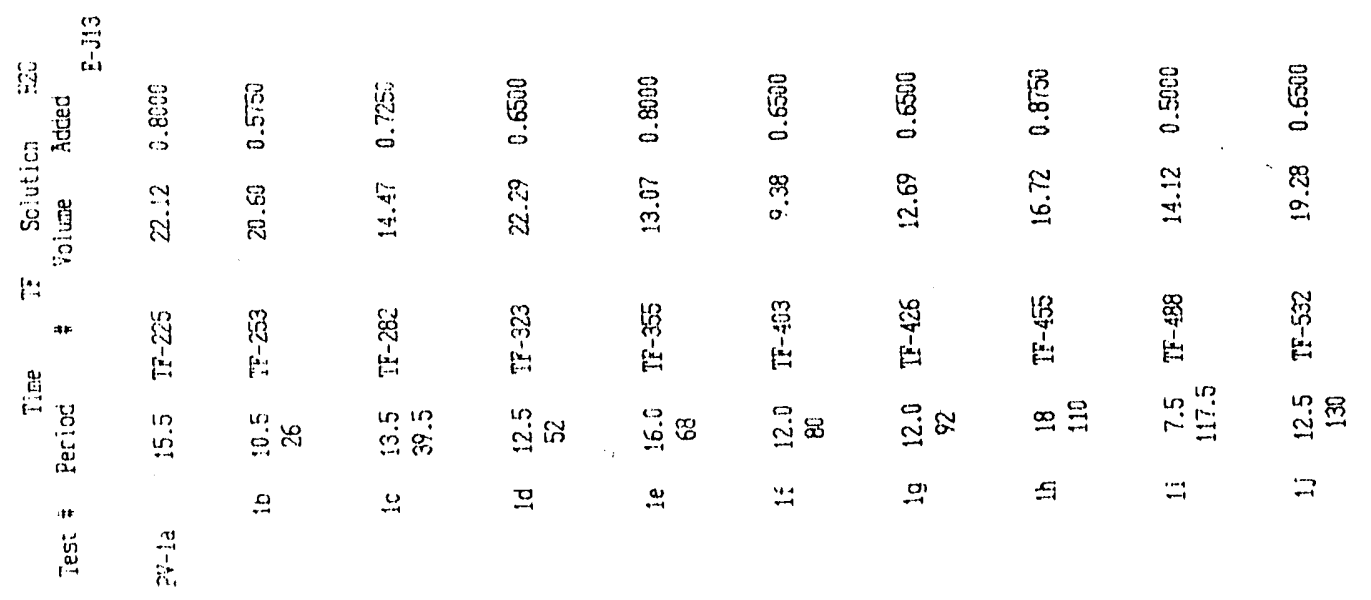




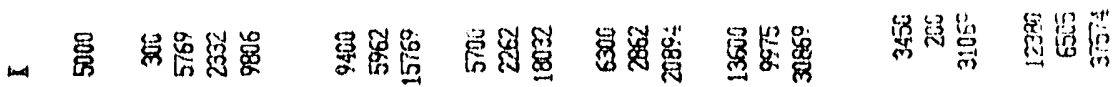

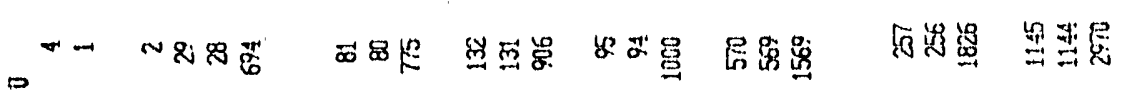
万量骨

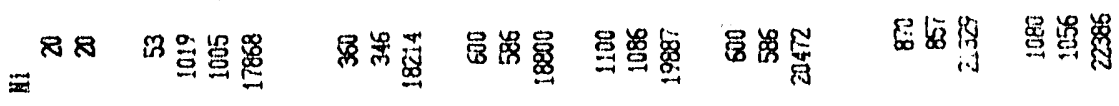

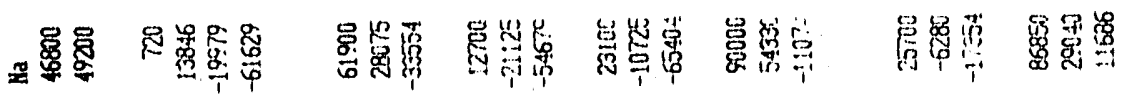
“留

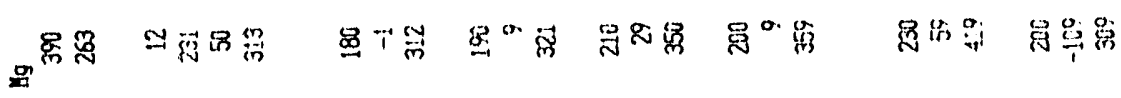

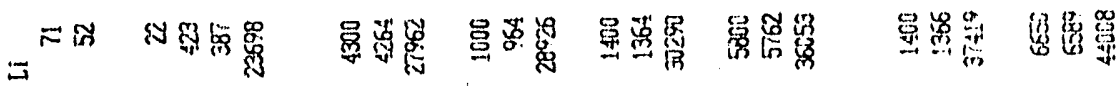

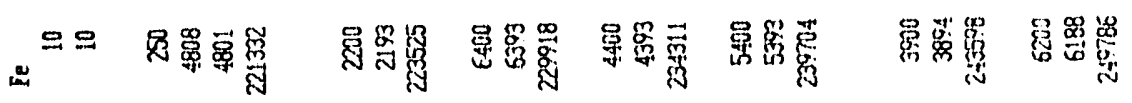

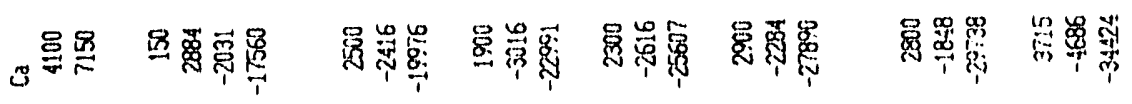

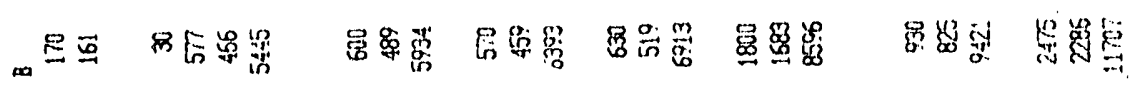

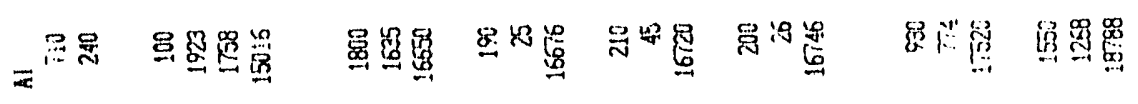

\begin{tabular}{|c|c|c|c|c|c|}
\hline 楞 & 器 & 总 & 兽 & 萿 & 畹 \\
\hline 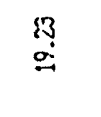 & $\stackrel{g}{\stackrel{g}{g}}$ & 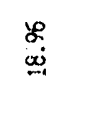 & 寄 & 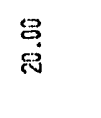 & "5 \\
\hline 资 & 薥 & 莡 & 稊 & 蛋 & 罩 \\
\hline$\frac{9 g}{2}$ & 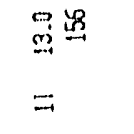 & 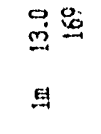 & $\underline{\underline{x}}$ & 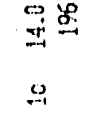 & ئ \\
\hline
\end{tabular}




\begin{tabular}{|c|c|c|c|c|c|c|c|}
\hline 必费口 & 0 & $\Leftrightarrow 0$ & $\theta$ & $\circ$ & $\Leftrightarrow$ & 繁 & 桑霓 \\
\hline , & 江出 & 溻崩点 & 管菑 & 总器 & 管得 & 营鼠 & 等 \\
\hline 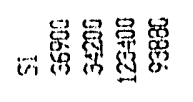 & 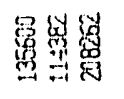 & 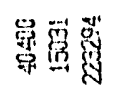 & 鹪总 & 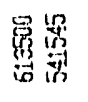 & 泪照 & 舁䍙 & \\
\hline 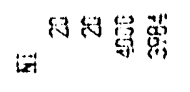 & 幽罚是 & 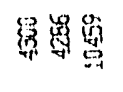 & 象煘 & 霄薄 & 叠总 & 鼠澡 & \\
\hline 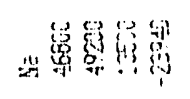 & 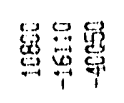 & 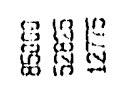 & 雷点 & 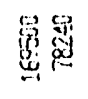 & 墨擂 & 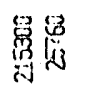 & \\
\hline "w) & 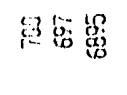 & 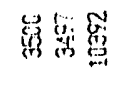 & 是㟟 & 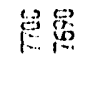 & 䝿泡 & 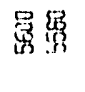 & \\
\hline 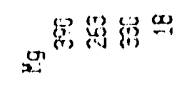 & 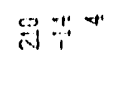 & 丞照识 & 8: 방 & 量 & 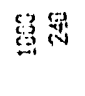 & 然昭 & \\
\hline 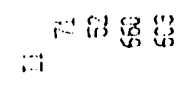 & 象靬总 & 总浔漶 & 粱梁 & 急菤 & 兒落 & 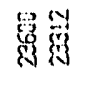 & \\
\hline 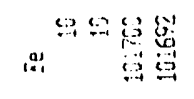 & 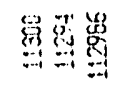 & 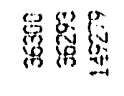 & 露舁 & 昫莡 & 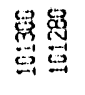 & 急㸃 & \\
\hline 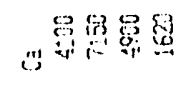 & 果早苔 & 忽总浔 & 罳賻 & 总总 & 蛋号 & 箈总 & \\
\hline 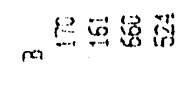 & 炰总䍖 & 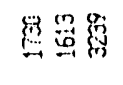 & 舀朵 & 总罯 & 舁悉 & 题营 & \\
\hline 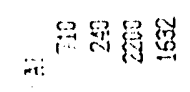 & 总总菏 & 总染兽 & 罚总 & 墨幕 & 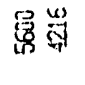 & 寔总 & \\
\hline
\end{tabular}

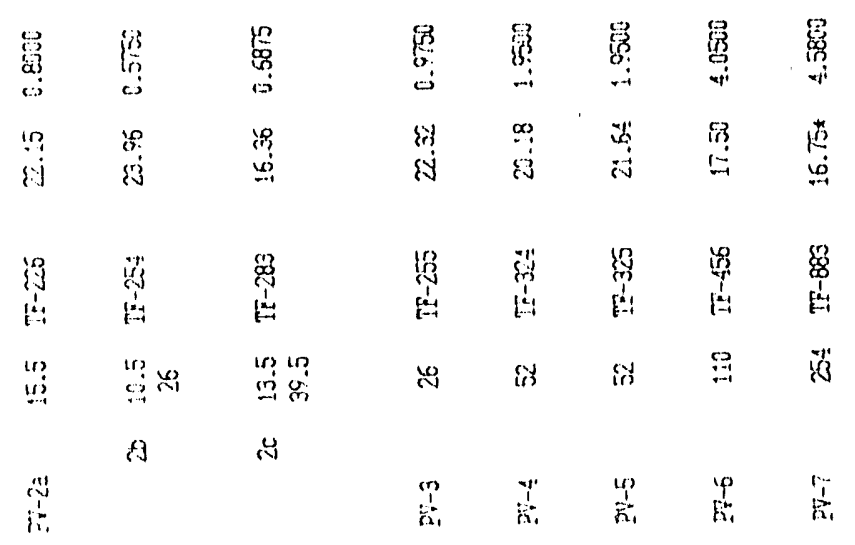




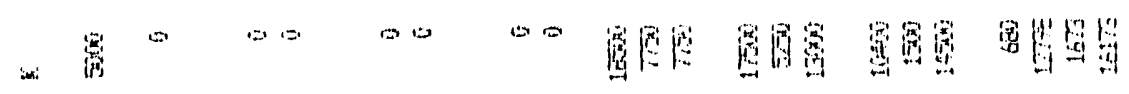

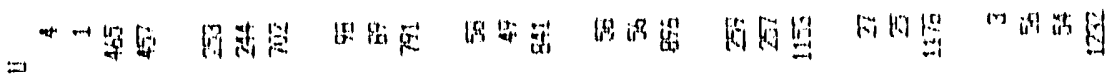

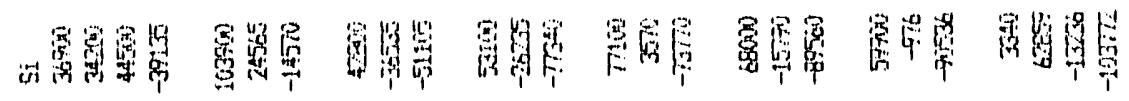

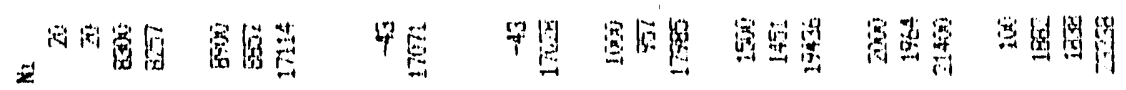

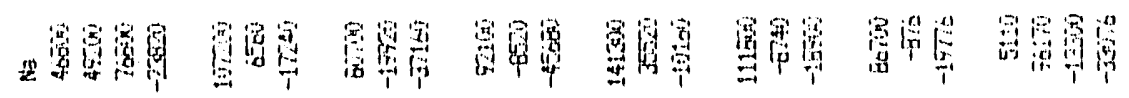

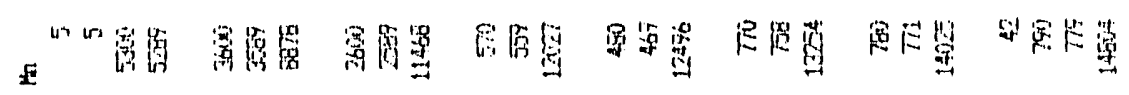

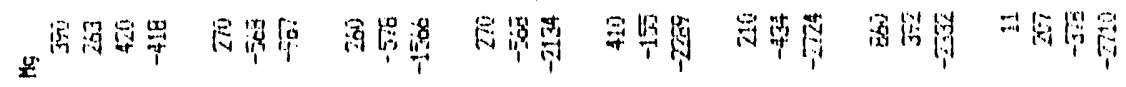

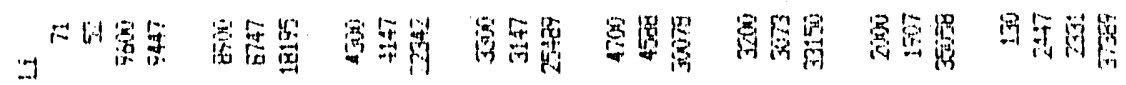

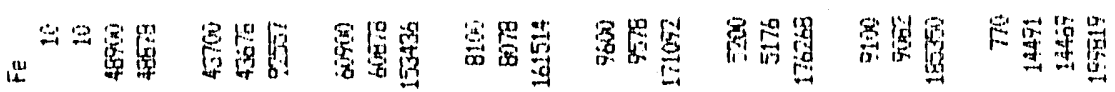

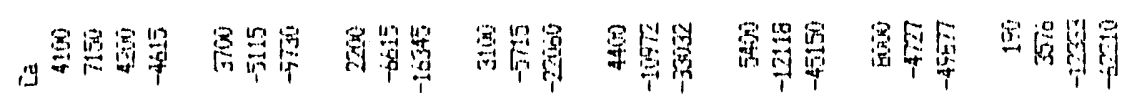

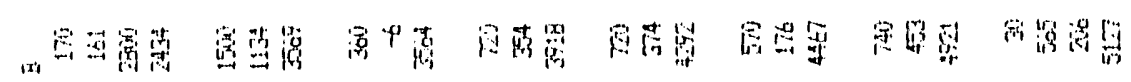

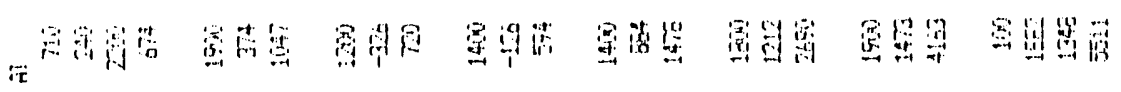

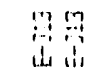

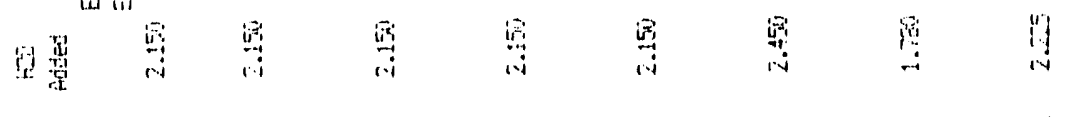

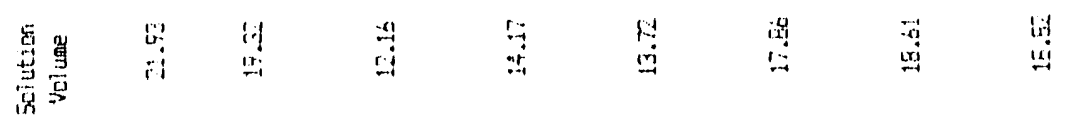

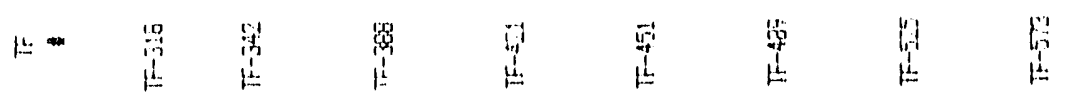

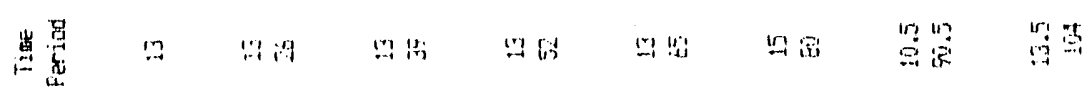

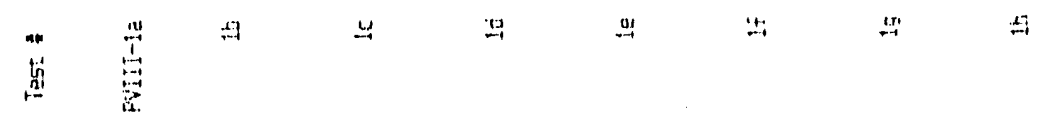




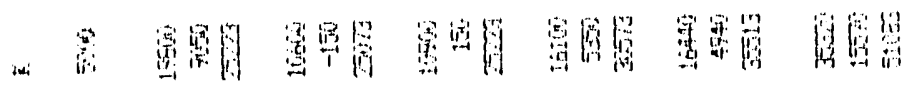

$\Rightarrow$ …

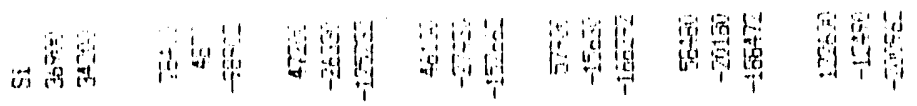

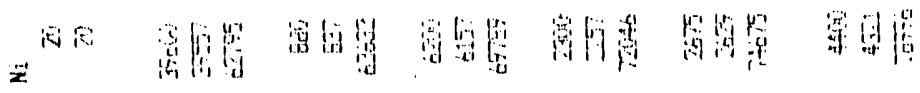

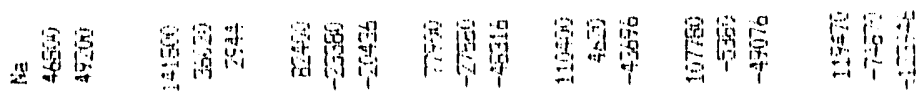

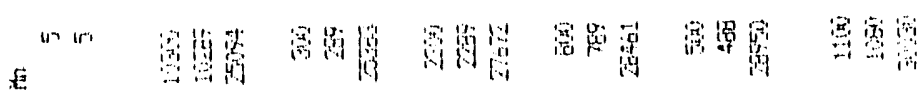

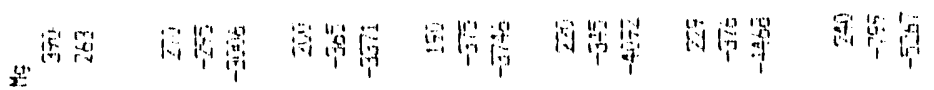

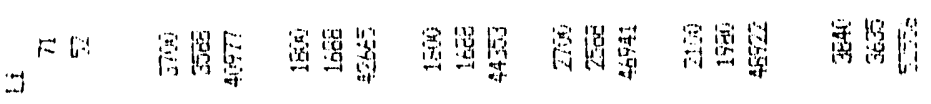

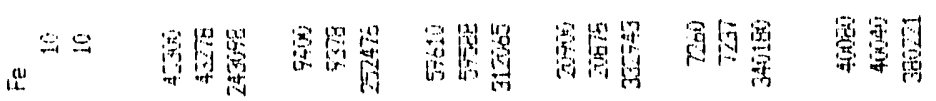

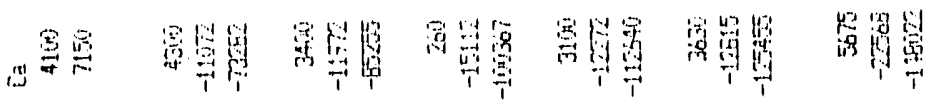

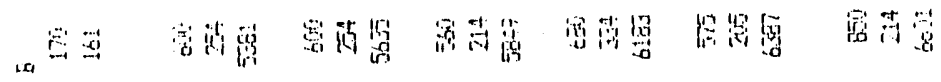

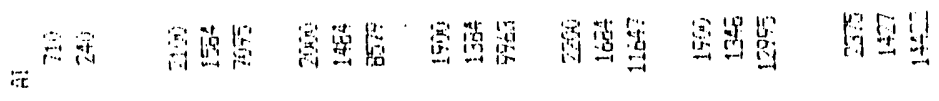

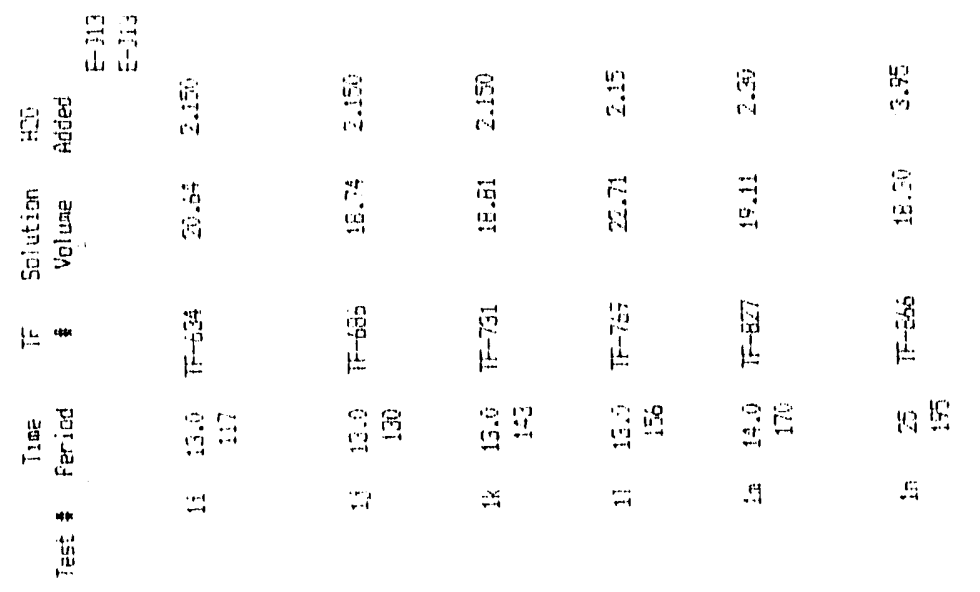




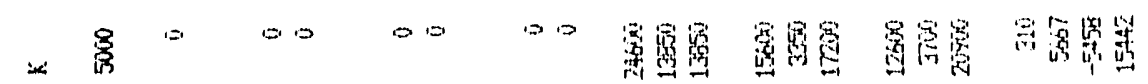

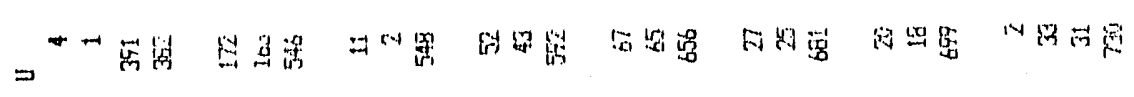

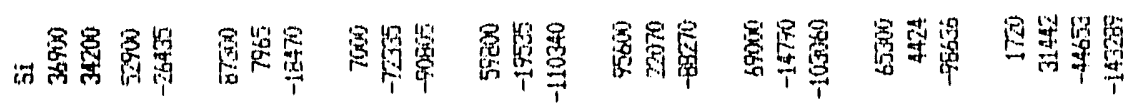

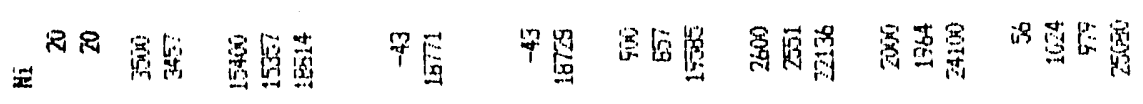

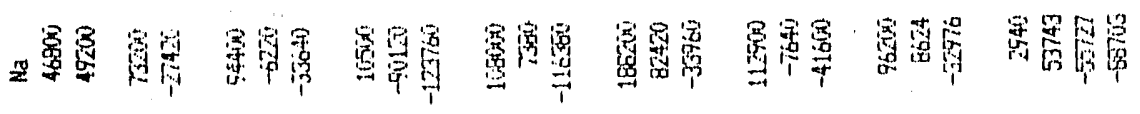

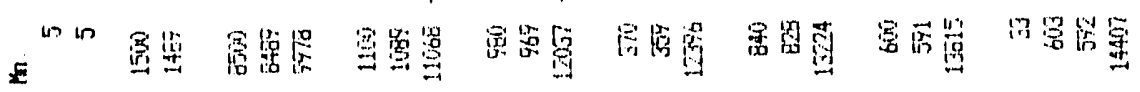

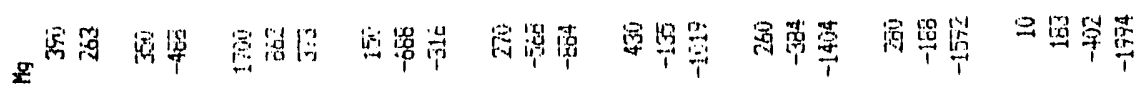

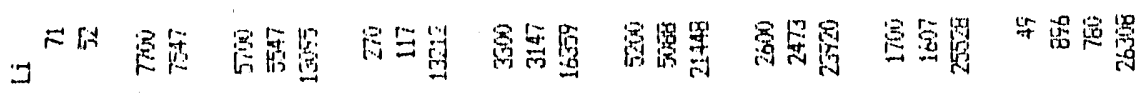

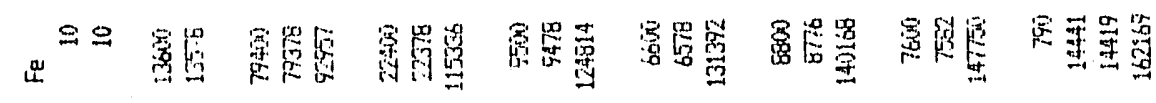

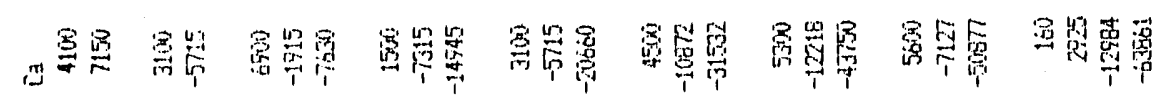

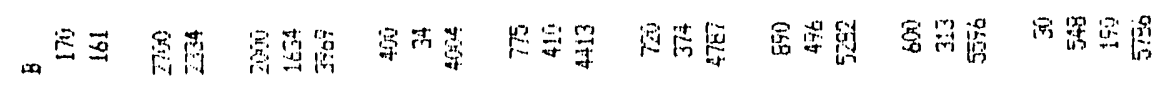

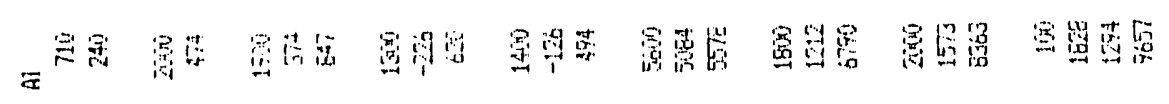

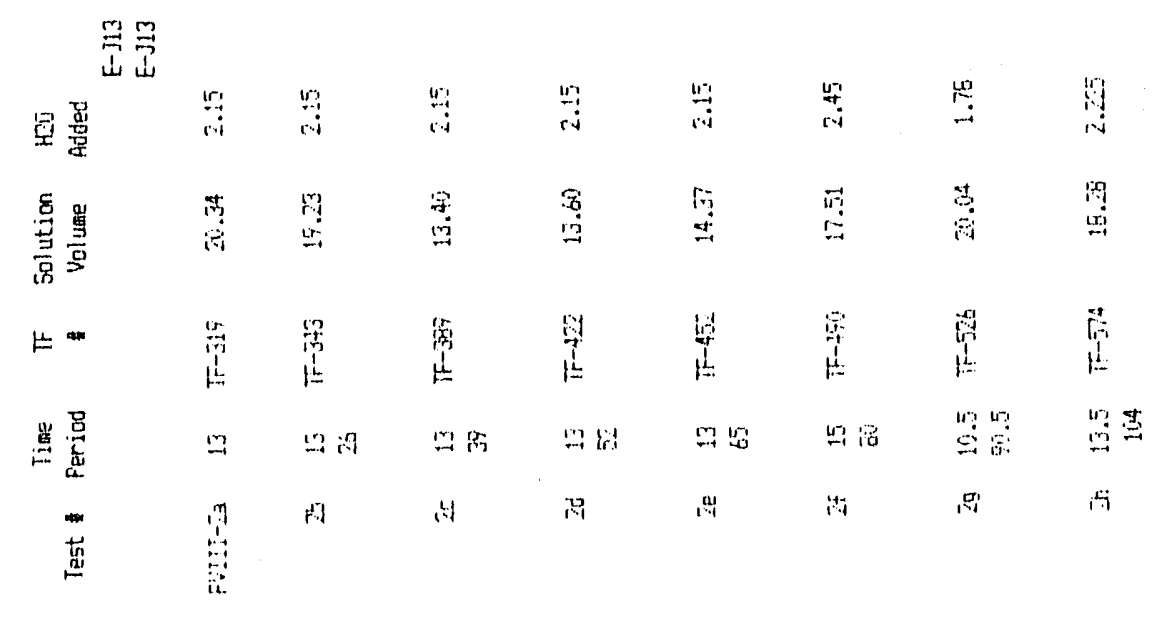




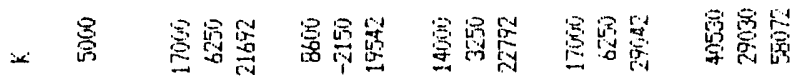

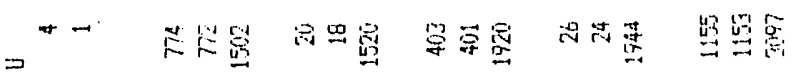

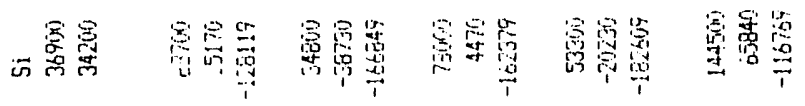

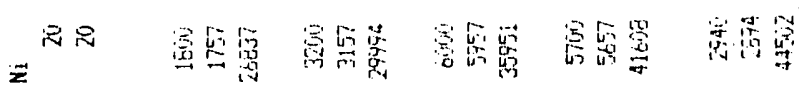

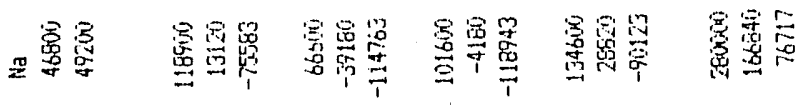

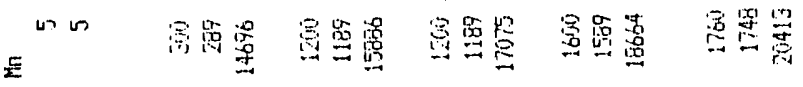

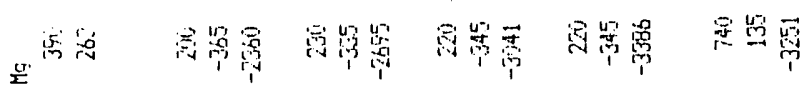

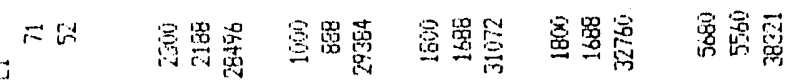

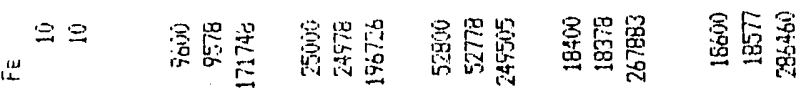

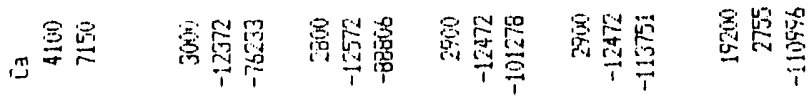

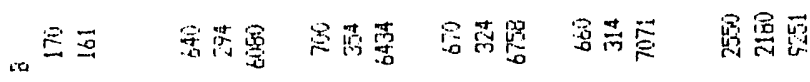

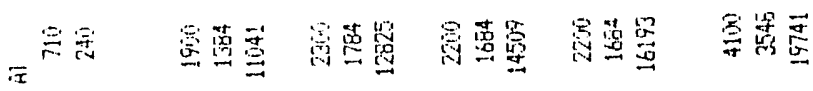

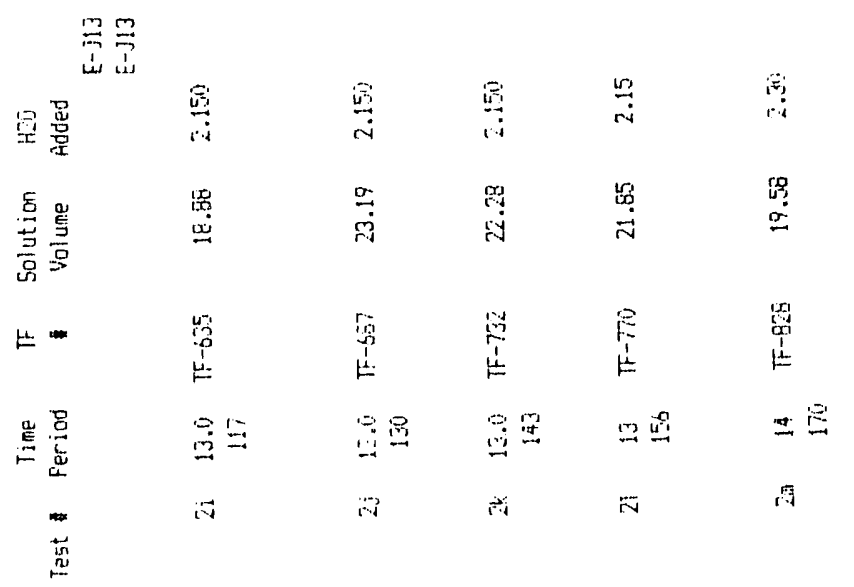




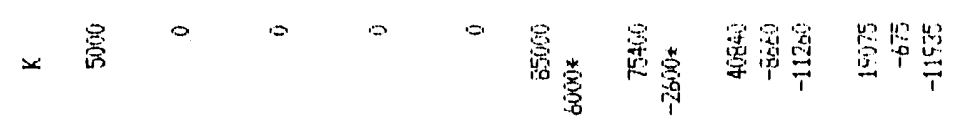

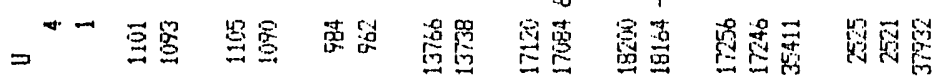

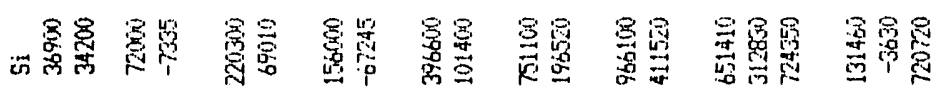

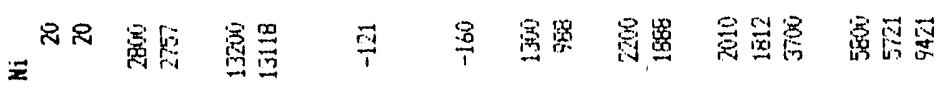

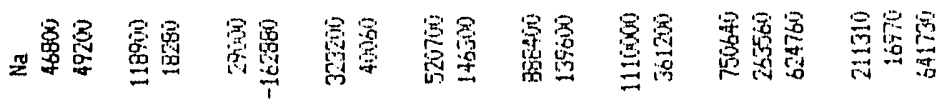

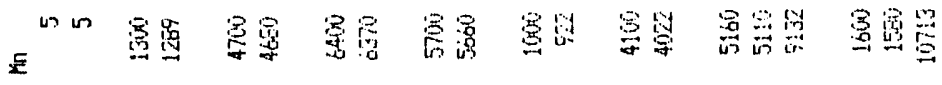

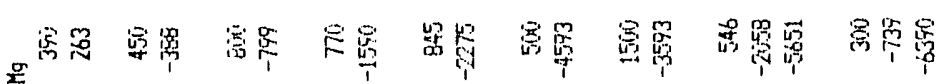

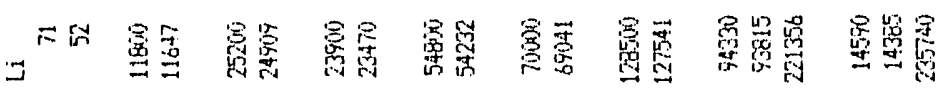

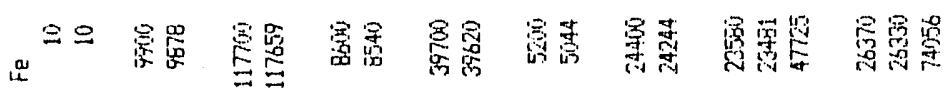

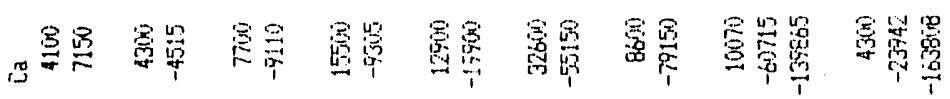

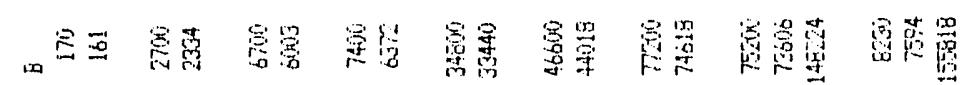

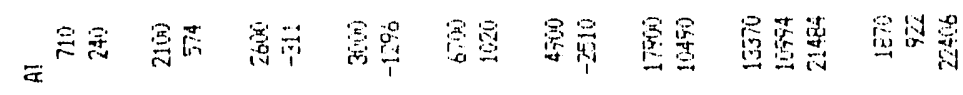

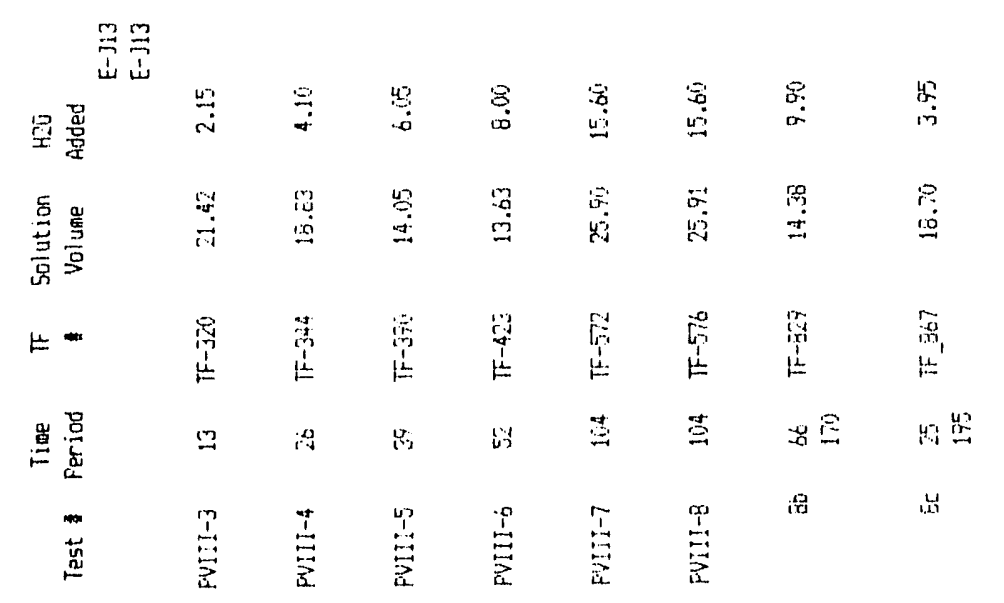


Distribution for ANL-91/36

Intcrnal:
A. Anderson
J. K. Balles (25)
J. E. Batlles
J. C. Cunnane
T. J. Gerding
J. E. Harmon

J. E. Helt

M. J. Steindler

ANL Patent Dept.

ANL Contract File

TIS Files (3)

\section{Exicrnal:}

DOE-OSTI (2)

ANL Library

Manager, Chicago Operations Office, DOE

A. Bindokas, DOE-CH

J. Haugen, DOE-CH

Chemical Technology Division Review Committee Members:

S. Baron, Brookhaven National Laboratory, Upton, NY

N. Jarrett, Nocl Jarrelt Associates, Lower Burrell, PA

L. Newman, Brookhaven National Laboratory, Upton, NY

J. Stringer, Electric Power Research Institute, Palo Alto, CA

J. B. Wagner, Arizona State University, Tempe, AZ

R. G. Wymer, Oak Ridge Nutional Laboratory, Oak Ridge, TN

E. B. Yeager, Case Western Reserve University, Cleveland, OH

C. R. Allen, Nuclear Waste Technical Review Board, Pasadena, CA

J. Allison, USDOE, Environmental Restoration \& Waste Management, Germantown, MD

E. Anderson, Mountain West Research-Southwest, Inc., Phoenix, AZ

D. H. Appel, U.S. Geological Survey, Denver, CO

Associate Director, USDOE, Storage and Transportation, OCRWM, Washington, DC

Associate Director, USDOE, Contract Business Management, OCRWM, Washington, DC

Aa. Barkatt, Catholic University of America, Vitreous State Laboratory, Washington, DC

J. W. Bartlet, USDOE, Civilian Radioactive Waste Manage., Washington, DC

S. Bates, Idaho Falls, ID

D. A. Beck, U.S. Geological Survey, Las Vegas, NV

C. G. Bell, Jr., University of Nevada, Las Vegas, NV

A. Berusch, USDOE, Civilian Radioactive Waste Manage., Washington, DC

N. E. Bibler, Westinghouse Savannah River Co., Aiken, SC

E. P. Binnall, Lawrence Berkelcy Laboratory, Berkeley, CA

M. Blanchard, DOE Field Office, Nevada, Las Vegas, NV

T. E. Blejwas, Sandia National Laboratory, Albuquerque, NM (5)

J. Blink, Lawrence Livermore National Laboratory, Las Vegas, NV

W. Bourcier, Lawrence Livermore National Laboratory, Livermore, CA

I. C. Bresce, USDOE, Civilian Radioactive Waste Manage., Washington, DC

S. J. Brocoum, USDOE, Civilian Radioactive Waste Managc., Washington, DC

R. L. Bullock, Raytheon Services Nevada, Las Vegas, NV

M. H. Campbell, Westinghouse Hanford Co., Richland, WA

D. Campbell, U.S. Bureau of Reclamation, Denver, CO 
I. E. Cantlon, Nuclear Waste Technical Revicw Board, East Lansing, MI

M. W. Carter, Nuclear Waste Technical Review Board, Allanta, CiA

K. W. Causseaux, U. S. Geological Survey, Denver, CO

Center for Nuclear Waste Regulatory Analyses, San Antonio, TX

K. A. Chacey, USDOE, Waste Management, Germantown, MD

Chicf, DOE Field Office, Nevada, U.S. Geological Survey, Las Vegas, NV

P. Childress, Lynchburg, VA

P. Cloke, Science Applications International Corp., Las Vegas, NV

M. O. Cloninger, Yucca Mountain Project Office, Las Vegas, NV

B. W. Colston, Raytheon Services Nevada, Las Vegas, NV

Community Planning and Development, North Las Vegas, NV

C. F. Costa, U. S. Environmental Protection Agency, Las Vegas, NV

D. U. Deere, Nuclear Waste Technical Revicw Board, Arlington, VA

Department of Comprehensive Planning, Clark County, Las Vegas, NV

Director of Community Planning, Boulder City, NV

J. F. Divine, U. S. Geological Survey, Reston, VA

M. J. Dorsey, Reynolds Electric \& Engineering Co., Inc., Las Vegas, NV (2)

R. S. Dyer, Yucca Mountailı Project Office, Las Vegas, NV

Economic Development Department, Las Vegas, NV

D. R. Elle, USDOE, DOE Ficld Office, Nevada, Las Vegas, NV

R. C. Ewing, University of New Mexico, Albuquerque, NM

E. Ezra, EG\&G Energy Mcasurements, Inc., Las Vegas, NV

R. Fish, TRW Environmental Safety Systems, Las Vegas, NV

P. K. Fitzsimmons, USDOE, DOE Field Office, Nevada, Las Vegas, NV

A. L. Flint, U.S. Geological Survey, Mercury, NV

J. Fordham, Water Resources Center, Desert Research Institute, Reno, NV

J. Foremaster, City of Caliente, Caliente, NV (5)

D. Foust, TRW Environmental Safety Systems, Las Vegas, NV

D. L. Fraser, Reynolds Electrical \& Engineering Co., Inc., Las Vegas, NV

C. P. Gertz, USDOE, Civilian Radioactive Waste Manage., Washington, DC

C. P. Gertz, USDOE, DOE Field Office, Nevada, Las Vegas, NV (5)

P. A. Glancy, U.S. Geological Survey, Carson City, NV

V. M. Glanzman, U. S. Geological Survey, Denver, CO

S. E. Gomberg, USDOE, Civilian Radioactive Waste Manage, Washington, DC

J. Hale, USDOE, Civilian Radioactive Waste Manage., Washington, DC

D. Harrison-Giesler, Yucca Mountain Project Olfice, Las Vegas, NV

C. K. Hastings, Pacific Northwest Laboratories, Richland, WA

T. Hay, Office of the Governor, State of Nevada, Carson City, NV

L. R. Hayes, U. S. Geological Survey, Denver, CO (6)

D. Hedges, Roy F. Weston, Inc., Las Vegas, NV

E. J. Helley, U.S. Geological Survey, Menlo Park, CA

R. J. Herbst, Los Alamos National Laboratory, Los Alamos, NM (4)

C. Interrante, U. S. Nuclear Regulatory Commission, Washington, DC

T. H. Isaacs, USDOE, Civilian Radioactive Waste Manage., Washington, DC

R. E. Jackson, Roy F. Weston, Inc., Washington, DC

C. Jantzen, Westinghouse Savannah River Co., Aiken, $\mathbf{s}^{\prime}$,

L. J. Jardine, Lawrence Livermore National Laboratory, Livermore, CA

C. H. Johnson, Nuclear Waste Project Office, State of Nevada, Carson City, NV

H. N. Kalia, Los Alamos National Laboratory, Las Vegas, NV

W. S. Ketola, USDOE, West Valley Project Office, West Valley, NY 
B. G. Kitchen, E. I. DuPont, Savannah River Laboratory, Aiken, SC

D. A. Knecht, Westinghouse Idaho Nuclear Co., Idaho Falls, ID

W. L. Kuln, Battelle Pacific Northwest Laboratory, Richland, WA

D. Langmuir, Nuclear Waste Technical Review Board, Golden, CO

W. Lee, Universily of California, Berkeley, CA

H. Leider, Lawrence Livermore National Laboratory, Livermore, CA

Lincoln County Commission, Pioche, NV

R. R. Loux, Jr., Nuclear Waste Project Office, State of Nevada, Carson City, NV (3)

R. E. Lowder, MAC Technical Services, Las Vegas, NV

R. W. Lynch, Sandia National Laboratories, Albuquerque, NM

H. Manaktala, Southwest Research Institute, San Antonio, TX

S. Marschman, Pacific Northwest Laboratory, Richland, WA

J. Matuszek, State of New York, Department of Health, Albany, NY

G. B. Mellinger, Battelle Pacific Northwest Laboratory, Richland, WA

M. Mifllin, Watter Resources Center, Desert Research Institute, Las Vegas, NV

R. Morissette, Science Applications International Corp., Las Vegas, NV

P. K. Nair, Center for Nuclear Waste Reg. Analyses, Southwest Research Institute, San Antonio, TX

J. L. Nelson, Westinghouse Hanford Co., Richland, WA

J. H. Nelson, Science Applications International Corp., Las Vegas, NV

D. Warner North, Nuclear Waste Technical Review Board, Decision Focus, Inc., Los Altos, CA

NRC Document Control Desk, U. S. Nuclear Regulatory Commission, Washington, DC

W. O'Connell, Lawrence Livermore National Laboratory, Livermore, CA

ONWI Library, Battellc Columbus Laboratory, Columbus, $\mathrm{OH}$

R. Palmer, West Valley Nuclear Services, West Valley, NY

G. J. Parker, USDOE, Civilian Radioactive Waste Manage., Washington, DC

W. D. Pcarson, Savannah River Laboratory, Aiken, SC

I. Pegg, Catholic University of America, Vitreous State Laboratory, Washington, DC

F. G. Peters, USDOE, Civilian Radioactive Waste Manage., Washington, DC

T. H. Pigford, University of California, Berkeley, CA

Planning Department, Nye County, Tonopah, NV

M. J. Plodinec, E. I. DuPont, Savannah River Laboratory, Aiken, SC

P. T. Prestholt, NRC Site Representative, Las Vegas, NV

D. L. Price, Nuclear Waste Technical Review Board, Blacksburg, VA

R. F. Pritchett, Reynolds Electrical \& Engineering Co., Inc., Las Vegas, NV

Project Directorate, U. S. Nuclear Regulatory Commission, Washington, DC

R. B. Raup, Jr., U.S. Geological Survey, Denver, CO

J. Roberts, USDOE, Civilian Radioactive Waste Manage., Washington, DC

S. Rousso, USDOE, Civilian Radioactive Waste Manage., Washington, DC

C. G. Russomanno, USDOE, Civilian Radioactive Waste Manage., Washington, DC

SAIC-T\&MSS Library, Science Applications International Corp., Las Vegas, NV (2)

J. D. Sallzman, USDOE, Civilian Radioactive Waste Manage., Washington, DC

J. H. Sass, U.S. Geological Survey, Flagstaff, AZ

P. S. Schaus, Westinghouse Hanford Co, Richland, WA

V. R. Schncider, U.S. Geological Survey, Reston, VA

Senior Project Manager for Yucca Mountain, U.S. Nuclcar Regulatory Commission, Washington, DC

D. E. Shelor, USDOE, Civilian Radioactive Waste Manage., Washington, DC

D. Stahl, B\&W Fuel Co., Las Vegas, NV

R. Stout, Litwrence Livermore National Laboratory, Livermore, CA

D. Strachan, Battelle Pacific Northwest Laboratories, Richland, WA

A. T. 'Tamura, USDOE, Office of Scientific \& Technical Information, Oak Ridge, TN 
Technical Information Center, Roy F. Weston, Inc., Washington, DC

Technical Information Officer, USDOE, DOE Field Office, $\wedge$ 'ada, Las Vegas, NV (10)

M. Len-Brink Buchholtz, Lawrence Livermore National Laboratory, Livermore, CA

M. Tomozawa, Rensselacr Polytechnic Instilute, Troy, NY

R. Van Konynenburg, Lawrence Livermore National Laboratory, Livermore, CA

E. D. Verink, Nuclear Waste Technical Review Board, Gainesville, FL

R. V. Watkins, U.S. Geological Survey, Denver, CO

C. L. West, USDOE, DOE Field Office, Nevada, Las Vegas, NV

S. S. C. Wu, U.S. Geological Survey, Flagstaff, AZ

D. Zesiger, U.S. Geological Survey, Las Vegas, NV

Commission of the European Communities, Brussels, BELGIUM

C. Davison, Atomic Energy Canada Ltd., Manitoba, CANADA

K. Dormuth, Atomic Energy Canada Ltd., Manitoba, CANADA

L. Johnson, Atomic Energy Canada Ltd., Manitoba, CANADA

R. Odoj, Institut for Chemische Technologie, Julich, WEST GERMANY

F. P. Sergent, Atomic Energy of Canada, Lid., Manitoba, CANADA

G. Simmons, Atomic Energy Canada Ltd., Manitoba, CANADA

E. Vernaz, Centre d'Etudes Nucleares de la Valle du Rhone, FRANCE

L. Werme, Svensk Karnbranslehantering AB, Stockholm, SWEDEN 
The following number is for Office of Civilian Radioactive Waste Management Records Management purposes only and should not be used when ordering this document:

Accession Number: NNA.911206.0022 

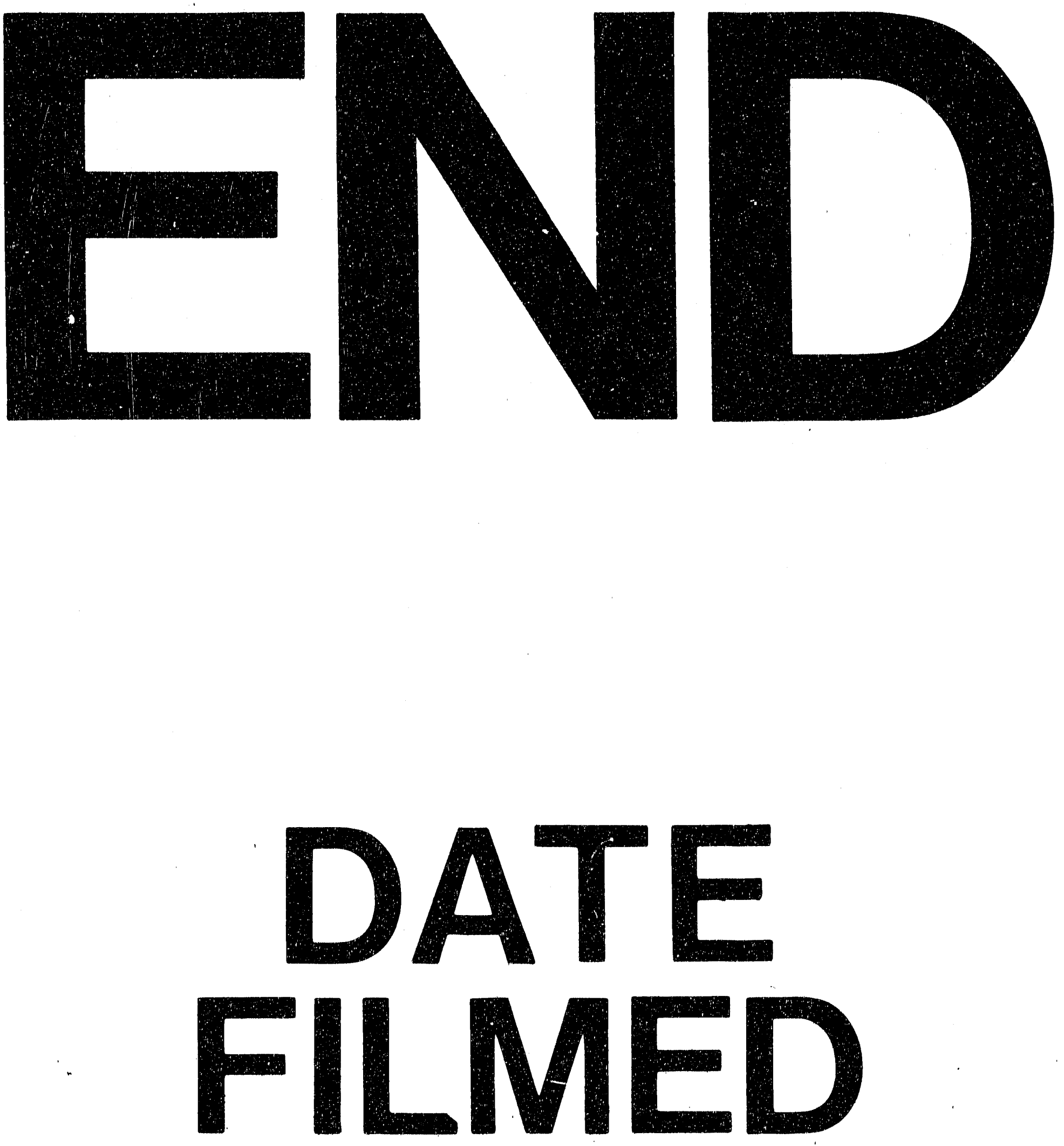

$-3$

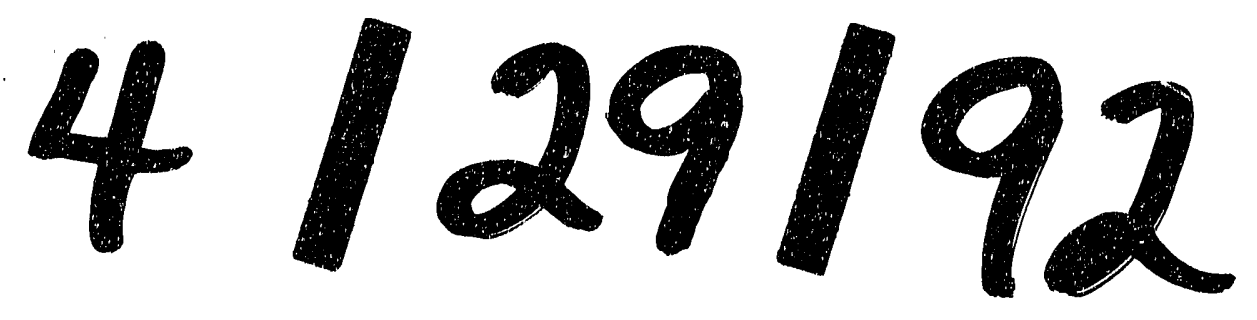


